Andrews University

Digital Commons @ Andrews University

2019

\title{
Archaeological Backgrounds of the Sanctuary: A Search for Egyptian Cultural Influence in the Construction of the Hebrew Tent-Sanctuary
}

Leslie Scott Baker Jr

Andrews University, Isbakerjr@andrews.edu

Follow this and additional works at: https://digitalcommons.andrews.edu/dissertations

Part of the Biblical Studies Commons

\section{Recommended Citation}

Baker, Leslie Scott Jr, "Archaeological Backgrounds of the Sanctuary: A Search for Egyptian Cultural Influence in the Construction of the Hebrew Tent-Sanctuary" (2019). Dissertations. 1680.

https://digitalcommons.andrews.edu/dissertations/1680

https://dx.doi.org/10.32597/dissertations/1680

This Dissertation is brought to you for free and open access by the Graduate Research at Digital Commons @ Andrews University. It has been accepted for inclusion in Dissertations by an authorized administrator of Digital Commons@ Andrews University. For more information, please contact repository@andrews.edu. 


\begin{abstract}
ARCHAEOLOGICAL BACKGROUNDS OF THE SANCTUARY: A SEARCH FOR EGYPTIAN CULTURAL INFLUENCE IN THE CONSTRUCTION OF THE HEBREW

TENT-SANCTUARY
\end{abstract}

by

Leslie Scott Baker, Jr.

Adviser: Randall W. Younker 


\title{
ABSTRACT OF GRADUATE STUDENT RESEARCH
}

\author{
Dissertation \\ Andrews University \\ Seventh-day Adventist Theological Seminary
}

\section{Title: ARCHAEOLOGICAL BACKGROUNDS OF THE SANCTUARY: A SEARCH FOR EGYPTIAN CULTURAL INFLUENCE IN THE CONSTRUCTION OF THE HEBREW TENT-SANCTUARY}

Name of researcher: Leslie Scott Baker, Jr.

Name and degree of faculty adviser: Randall W. Younker, Ph.D.

Date completed: April 2019

\section{Problem}

Although the documented description of the construction of the tent-sanctuary appears to give it an Egyptian context in terms of the materials used and the culture of the artisans, in three distinct spheres (sacred, royal-domestic, and military), very little work has been done in comparing the descriptions in the text with the recovered archaeological fabric from Egypt and no study has, as yet, taken the next step of quantifying that comparison through a potentially-repeatable statistical analysis in an effort to determine, in an unbiased manner, the nature of the relationship. 


\section{Method}

Design and frequency data of the appearing materials were collected from the Hebrew text regarding the Hebrew tent-sanctuary’s courtyard perimeter barrier, its tabernacle (the central structure itself), and the furnishings within the courtyard and tabernacle. These data were analyzed to provide data sets that could be used for purposes of comparison.

Data were next collected from mobile structures and their courtyard perimeter barriers. This was taken from sacred, royal-domestic, and military spheres of New Kingdom Egypt. Frequency data of appearing materials data were also collected from mobile structures, their courtyard perimeters, and any known furnishings. Design data from the furnishings in KV62 (Kings Valley tomb number 62, i.e., the tomb of Tutankhamun) were analyzed and compared with similar data from furnishings in other New Kingdom period-contexts as well as contexts before it to determine cultural preference tendencies in New Kingdom Egypt. These data were analyzed to provide data sets that could be used for purposes of comparison.

Finally, data from the Hebrew text were finally compared with data from the Egyptian archaeological record to determine if cultural influence could be identified in each of the elements under study.

\section{Results}

Cultural influence can clearly be identified in some of the elements of the tentsanctuary. 


\section{Conclusion}

Although the archaeological record is recognized to be incomplete, enough data is available to determine confidently that the description of the construction of the Hebrew tent-sanctuary fits well with the context of New Kingdom Egypt. While not every element of the tent-sanctuary appears to have had Egyptian cultural influence in design, significantly all materials were only available in one period of Egyptian history - the New Kingdom. This study has the potential to inform other studies (typological, symbolic, phenomenological, or interpretive) regarding the tent-sanctuary. Also, because of the relatively clear connection, some of the descriptions of the tent-sanctuary can inform studies on certain elements of New Kingdom Egypt, particularly those associated with the mobile military camp. 
Andrews University

Seventh-day Adventist Theological Seminary

ARCHAEOLOGICAL BACKGROUNDS OF THE SANCTUARY:

A SEARCH FOR EGYPTIAN CULTURAL INFLUENCE

IN THE CONSTRUCTION OF THE HEBREW

TENT-SANCTUARY

\author{
A Dissertation \\ Presented in Partial Fulfillment \\ of the Requirements for the Degree \\ Doctor of Philosophy
}

by

Leslie Scott Baker, Jr.

April 2019 
(C) Copyright by Leslie Scott Baker, Jr. 2019

All Rights Reserved 


\title{
ARCHAEOLOGICAL BACKGROUNDS OF THE SANCTUARY: A SEARCH FOR EGYPTIAN CULTURAL INFLUENCE IN THE CONSTRUCTION OF THE HEBREW TENT-SANCTUARY
}

\author{
A dissertation \\ presented in partial fulfillment \\ of the requirements for the degree \\ Doctor of Philosophy
}

by

Leslie Scott Baker, Jr.

\section{APPROVAL BY THE COMMITTEE:}

Faculty Adviser, Randall W. Younker Professor of Archaeology and History of Antiquity

Roy E. Gane

Professor of Hebrew Bible \& Ancient Near Eastern Languages

Paul J. Ray, Jr. Associate Professor of Old Testament and Biblical Archaeology

Paul Z. Gregor

Professor of Old Testament and Biblical Archaeology

Efraín Velázquez

President Inter-American Adventist

Theological Seminary
Director of Biblical and Ancient Near Eastern Archaeology Program Randall W. Younker

Dean, SDA Theological Seminary Jiří Moskala 
to my wife and daughters

for your belief in me 


\section{TABLE OF CONTENTS}

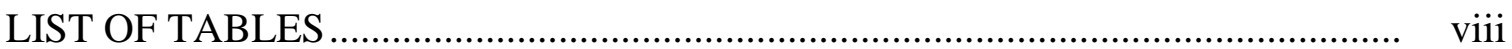

LIST OF ABBREVIATIONS ....................................................................... xii

Chapter

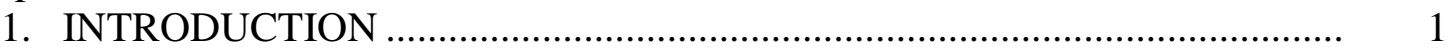

Introduction to Subject under Study ………………………...................... 2

Background to Problem ...................................................................... 3

Statement of Problem........................................................................

Research Question ................................................................................. 6

Research Design/Methodology .................................................................. 6

Definition of Terms/Literature Review .................................................... 9

Tangible and Intangible Cultural Heritage .......................................... $\quad 10$

Egyptian Culture in the Pharaonic Era................................................ 12

Biblical Archaeology Methodology.................................................... 13

The Hebrew Tent-Sanctuary ................................................................ 16

Construction of the Hebrew Tent-Sanctuary ………………................ 17

Significance of the Study ..................................................................... 24

Outline of the Study ............................................................................... 26

2. CHRONOLOGICAL AND GEOGRAPHICAL PLACEMENT ..................... 28

Chronological Placement .................................................................. 28

Geographical Placement .............................................................. 31

Raamses, the City........................................................................... 32

Rameses, the Land …………....................................................... 36

Pithom, the City ……………………………………………....... 39

Conclusion and Direction of Study........................................................... 42

3. DESIGN ELEMENTS OF THE HEBREW TENT-SANCTUARY ................. 43

Design of the Courtyard and Tabernacle ..................................................... 43

Courtyard Textual Record and Analysis of Data ................................. 44

Courtyard Perimeter ..................................................................... 45

Courtyard Gate........................................................................... 48

Courtyard Statistical Analysis.......................................................... 49

Tabernacle Textual Record and Analysis of Data ............................... 51 
Tabernacle Frame........................................................................ 51

Tabernacle Screen ....................................................................... 5

Tabernacle Linen Cloth Layer ....................................................... 58

Tabernacle Goat Hair Layer.............................................................. 60

Tabernacle Skins Layer................................................................ 61

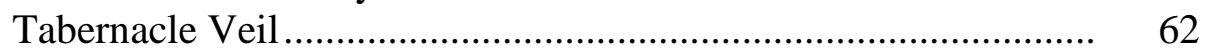

Tabernacle Statistical Analysis .......................................................... 64

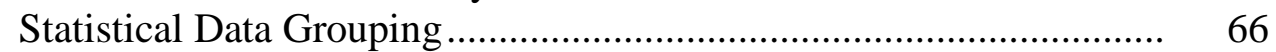

Design of the Furnishings ....................................................................... $\quad 70$

Furnishings Textual Record and Analysis of Data .............................. $\quad 70$

Bronze Altar ......................................................................... 71

Laver ............................................................................. 73

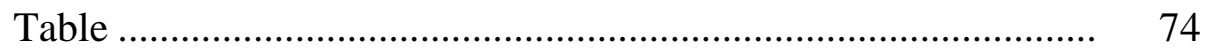

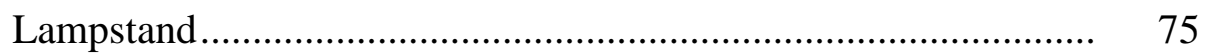

Gold Altar ................................................................................ 77

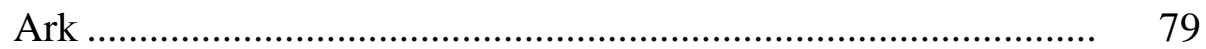

Furnishings Statistical Analysis ....................................................... 81

Statistical Data Grouping ................................................................. 81

Summary of Design Data and Direction of Study ..................................... 85

4. MATERIAL ELEMENTS OF THE HEBREW TENT-SANCTUARY ........... 88

Materials of the Tabernacle and Furnishings............................................. 88

Textual Record and Analysis of Data ............................................... 89

Acacia Wood - Tabernacle and Furnishings ................................. 90

Linen Cloth Layer - Tabernacle ..................................................... 92

Blue, Purple, and Scarlet Thread - Tabernacle............................... 93

Goats Hair Layer - Tabernacle .................................................... 94

Skins Layers - Tabernacle ............................................................... 95

Bronze - Tabernacle and Furnishings............................................. 98

Silver - Tabernacle .................................................................... 99

Gold - Tabernacle and Furnishings ............................................... 100

Statistical Analysis....................................................................... 101

Statistical Data Grouping ................................................................... 102

Summary of Materials Data and Direction of Study ................................. 104

5. DESIGN ELEMENTS IN THE ARCHAEOLOGICAL RECORD.................. 106

Design of Egyptian Courtyard and Central Structure ............................... 107

Courtyard Archaeological Record ................................................... 108

Sacred Sphere.......................................................................... 109

Royal-Domestic Sphere .............................................................. 109

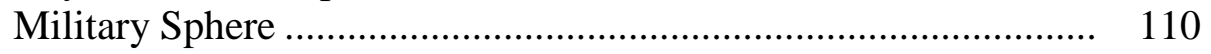

Courtyard Statistical Analysis........................................................... 112

Central Structures in the Archaeological Record................................. 113

Sacred Sphere............................................................................ 114 


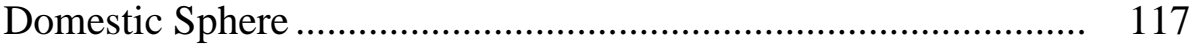

Military Sphere ...................................................................... 119

Central Structure Statistical Analysis ................................................ 120

Statistical Data Grouping ................................................................. 121

Courtyard and Structure Design Comparison and Discussion.............. 123

Design of Egyptian Furniture................................................................. 123

KV62 Archaeological Record......................................................... 125

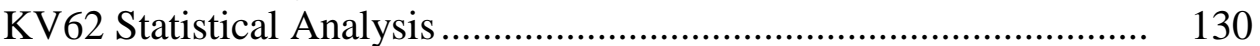

KV62 Statistical Data Grouping ........................................................ 133

Control Group Archaeological Record .............................................. 138

Control Group - New Kingdom (not KV62) Statistical Analysis ....... 142

Control Group - New Kingdom (not KV62) Statistical Data

Grouping .................................................................................. 143

Control Group - pre-New Kingdom Statistical Analysis .................... 158

Control Group - pre-New Kingdom Statistical Data Grouping .......... 158

Furniture Design Comparison and Discussion ................................... 169

Summary of Design Data and Direction of Study ..................................... 172

6. MATERIAL ELEMENTS IN THE ARCHAEOLOGICAL RECORD ............ 176

Materials of Sacred, Royal-Domestic, and Military Spheres ..................... 177

Archaeological Record and Analysis of Data..................................... 178

Acacia Wood............................................................................. 178

Woven Linen....................................................................... 182

Blue, Purple, and Scarlet Thread ................................................ 183

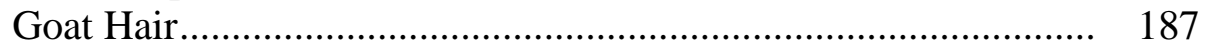

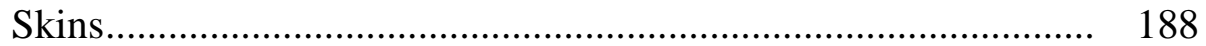

Bronze .......................................................................... 191

Silver ............................................................................... 196

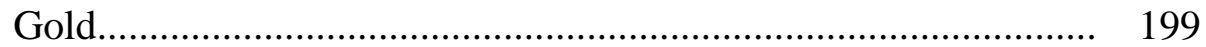

Review of Data ....................................................................... 202

Statistical Analysis and Data Grouping ............................................. 204

Summary of Materials and Direction of Study ....................................... 206

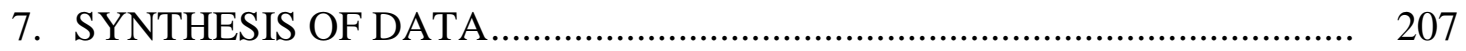

Synthesis of Data for Design Elements .................................................. 208

Courtyard Statistical Comparison ....................................................... 208

Central Structure Statistical Comparison.............................................. 212

Furniture Statistical Comparison ...................................................... 214

Design Data Comparison ................................................................ 227

Synthesis of Data for Material Elements ……………….......................... 228

Acacia Wood Statistical Comparison ................................................. 229

Woven Linen Cloth Statistical Comparison ........................................ 230

Blue, Purple, and Scarlet Thread Statistical Comparison .................... 230

Woven Goats Hair Statistical Comparison .......................................... 231 
Skins Statistical Comparison ...................................................... 232

Bronze Statistical Comparison........................................................ 233

Silver Statistical Comparison......................................................... 234

Gold Statistical Comparison ....................................................... 234

Material Data Comparison .......................................................... 235

Summary of Synthesis of Data ........................................................ 235

8. DISCUSSION, IMPLICATIONS, AND RECOMMENDATIONS ............... 236

Discussion ........................................................................... 237

Implications.......................................................................... 248

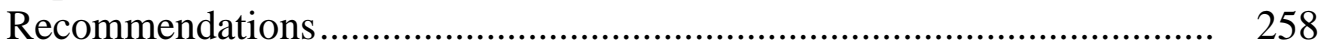

Appendix

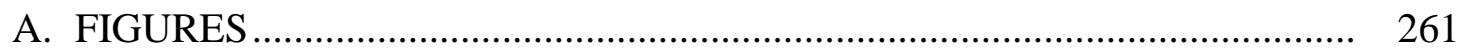

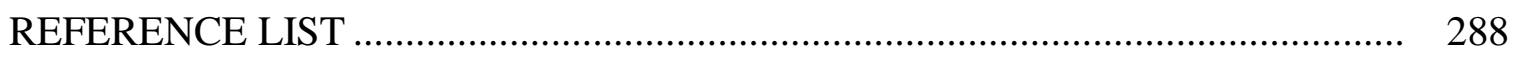

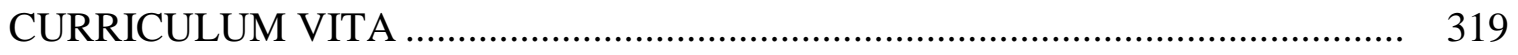




\section{LIST OF TABLES}

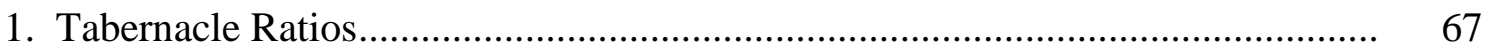

2. A Stem-and-leaf Plot of the Length of the Woven Strips .................................... 67

3. A Stem-and-leaf Plot of the Width of the Woven Strips ..................................... 68

4. Frequency of Repetition in Features A ....................................................... 69

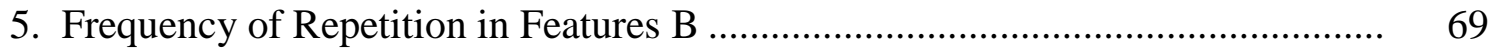

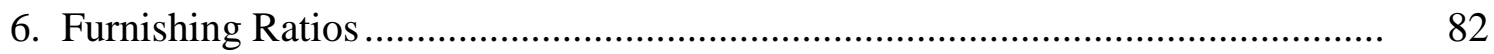

7. A Stem-and-leaf Plot of the Length of the Volume.......................................... 83

8. A Stem-and-leaf Plot of the Width of the Volume ........................................ 83

9. A Stem-and-leaf Plot of the Height of the Volume ......................................... 83

10. Frequency of Repetition in Features A ....................................................... 84

11. Frequency of Repetition in Features B ......................................................... 84

12. Frequency of Repetition in Materials ........................................................ 103

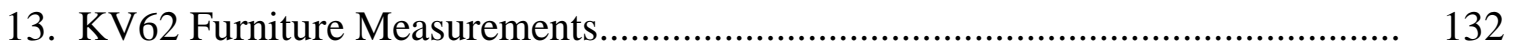

14. A Stem-and-Leaf Plot of the Length of the Bedframes (KV62)......................... 133

15. A Stem-and-Leaf Plot of the Width of the Bedframes (KV62) .......................... 133

16. A Stem-and-Leaf Plot of the Height of the Bedframes (KV62) ......................... 134

17. A Stem-and-Leaf Plot of the Length of the Boxes (KV62) ............................... 134

18. A Stem-and-Leaf Plot of the Width of the Boxes (KV62) ................................ 135

19. A Stem-and-Leaf Plot of the Height of the Boxes (KV62) .............................. 135 
20. A Stem-and-Leaf Plot of the Width of the Chairs (KV62) .................................. 136

21. A Stem-and-Leaf Plot of the Height of the Chairs (KV62) …............................. 136

22. A Stem-and-Leaf Plot of the Width of the Stools (KV62) .................................. 137

23. A Stem-and-Leaf Plot of the Height of the Stools (KV62) ................................. 137

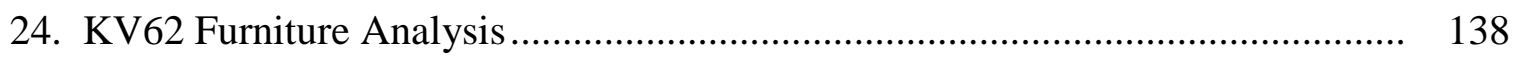

25. New Kingdom (N.K.) Furniture Measurements .................................................... 144

26. A Stem-and-Leaf Plot of the Length of the Bedframes (N.K.)........................... 146

27. A Stem-and-Leaf Plot of the Width of the Bedframes (N.K.) ………………...... 147

28. A Stem-and-Leaf Plot of the Height of the Bedframes (N.K.) …….................... 147

29. A Stem-and-Leaf Plot of the Length of the Boxes (N.K.) .................................... 148

30. A Stem-and-Leaf Plot of the Width of the Boxes (N.K.) ……............................. 148

31. A Stem-and-Leaf Plot of the Height of the Boxes (N.K.) .................................... 149

32. A Stem-and-Leaf Plot of the Length of the Chairs (N.K.).................................... 149

33. A Stem-and-Leaf Plot of the Width of the Chairs (N.K.) .................................... 150

34. A Stem-and-Leaf Plot of the Height of the Chairs (N.K.) .................................... 150

35. A Stem-and-Leaf Plot of the Length of the Chests (N.K.) .................................. 151

36. A Stem-and-Leaf Plot of the Width of the Chests (N.K.)................................... 151

37. A Stem-and-Leaf Plot of the Height of the Chests (N.K.).................................... 152

38. A Stem-and-Leaf Plot of the Length of the Stools (N.K.) .................................... 153

39. A Stem-and-Leaf Plot of the Width of the Stools (N.K.) …………..................... 154

40. A Stem-and-Leaf Plot of the Height of the Stools (N.K.) ……………………..... 155

41. A Stem-and-Leaf Plot of the Length of the Tables (N.K.) ………...................... 156

42. A Stem-and-Leaf Plot of the Width of the Tables (N.K.)................................... 156 
43. A Stem-and-Leaf Plot of the Height of the Tables (N.K.)............................... 157

44. New Kingdom Furniture Analysis A ....................................................... 157

45. New Kingdom Furniture Analysis B ...................................................... 158

46. Pre-New Kingdom (P-N.K.) Furniture Measurements .................................... 159

47. A Stem-and-Leaf Plot of the Length of the Bedframes (P-N.K.) ...................... 160

48. A Stem-and-Leaf Plot of the Width of the Bedframes (P-N.K.) ....................... 161

49. A Stem-and-Leaf Plot of the Height of the Bedframes (P-N.K.)........................ 161

50. A Stem-and-Leaf Plot of the Length of the Boxes (P-N.K.) ............................ 162

51. A Stem-and-Leaf Plot of the Width of the Boxes (P-N.K.) .............................. 163

52. A Stem-and-Leaf Plot of the Height of the Boxes (P-N.K.) ............................. 164

53. A Stem-and-Leaf Plot of the Length of the Stools (P-N.K.) ….......................... 164

54. A Stem-and-Leaf Plot of the Width of the Stools (P-N.K.) ............................... 165

55. A Stem-and-Leaf Plot of the Height of the Stools (P-N.K.) ............................. 165

56. A Stem-and-Leaf Plot of the Length of the Tables (P-N.K.) ............................ 166

57. A Stem-and-Leaf Plot of the Width of the Tables (P-N.K.) .............................. 166

58. A Stem-and-Leaf Plot of the Height of the Tables (P-N.K.) ............................. 167

59. Pre-New Kingdom Furniture Analysis A .................................................. 168

60. Pre-New Kingdom Furniture Analysis B...................................................... 168

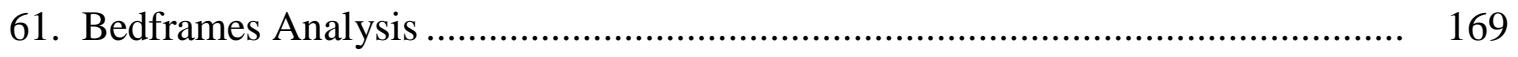

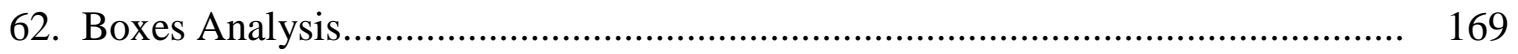

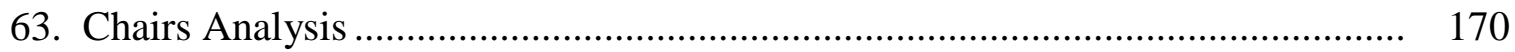

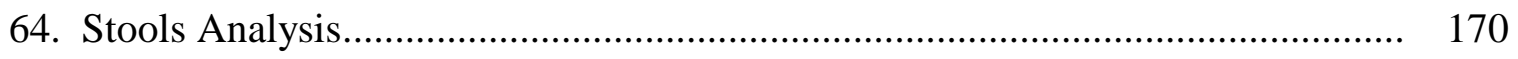

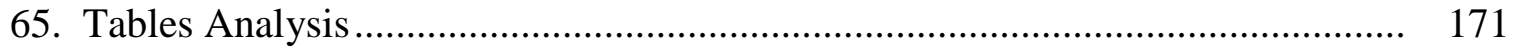


66. Specialty Wood and Their Uses..................................................................... 179

67. Native Egypt Wood and Their Uses .................................................................. 181

68. Egyptian Terms for Copper in Erman Grapow’s Egyptian Dictionary ................ 192

69. Egyptian Terms for Gold in Erman Grapow’s Egyptian Dictionary .................... 198

70. Frequency of Materials in New Kingdom Egypt............................................ 205

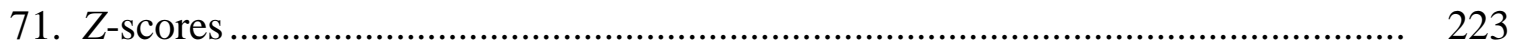

72. Tabernacle Table Conversion to Known Egyptian Cubits ..................................... 225

73. Z-scores for Tabernacle’s Table...................................................................... 226 


\section{LIST OF ABBREVIATIONS}

\begin{tabular}{ll} 
BDB & Brown-Driver-Briggs \\
BT & Babylonian Talmud \\
D & Deuteronomist \\
E & Elohoist \\
EES & Egyptian Exploration Society \\
J & Yawist \\
JB & Jerusalem Bible \\
KJV & King James Version \\
LXX & Septuagint \\
n/a & Not applicable \\
NASB & New American Standard Bible \\
NEB & New English Bible \\
NIV & New International Version \\
NJB & New Jerusalem Bible \\
N.K. & New Kingdom \\
NKJV & New King James Version \\
NJPS & New Jewish Publication Society \\
NRSV & New Revised Standard Version \\
P & Priestly \\
\hline
\end{tabular}


P-N.K. $\quad$ Pre-New Kingdom

REB Revised English Bible

RSV Revised Standard Version 


\section{CHAPTER 1}

\section{INTRODUCTION}

"Even with topics repeatedly discussed new perspectives can be gained, which open a better understanding of the events."

(Goedicke 1985: vii)

Transparency is vital. Archaeological excavation is an exploratory science and not an experimental science in that the often-destructive methods of recovery are not repeatable. On the other hand, the analysis of what has been recovered, in most cases, is. But to be repeatable, the analysis must be clear so that errors in bias, calculation, and method can be subject to peer review.

The accident of survival must be recognized as an unavoidably skewing element to any quantitative analysis of the archaeological fabric (be it material culture, dirt layers, debris, landscape, or any other element of study) that is used to visualize any ancient civilization. Much of what has survived — the natural deterioration of archaeological environments over time, concerted efforts to loot, the devastating results of war, and the erosion caused by the activities of human life (much of which happens directly above, in, or around archaeological materials) — has not been recovered by archaeological efforts so that what is studied is only a fraction of what exists. What fraction still remains to be discovered is unknown. Thus, what survives is a fraction of what has ever existed. What 
has been recovered is a fraction of what exists potentially waiting to be discovered. What has been studied is a fraction of what has been recovered. And what has been published is a fraction of what has been studied. Because these fractions are unknowable, statistical analysis is bias.

With this limitation in mind it would be foolish to dogmatically state any result as an accurate representation of the past. However, this knowledge should not stand as a detriment to efforts to understand the small fragments gifted to us through professional and sometimes quite a bit less than professional efforts. Limitations are not roadblocks to knowledge. They simply stand as solemn reminders to the scholar to be responsible in the academic treatment of the subject under study and to be humble in the results.

This chapter will present the subject under study, the motivation for study, the method of study, and a brief justification for the study so that peer review on this study can be efficient.

\section{Introduction to Subject under Study}

Architectural remains of the ancient past are easiest to study if the studied structure was relatively permanent in nature, being of stone, plaster, mudbrick, or, in rare cases of survival, wood. Organic building materials have a much shorter shelf-life, so to speak, than inorganic, making mobile structures, constructed almost entirely of organic material, nearly, if not completely, invisible in archaeological recovery efforts. Such mobile structures include, but are not limited to, military camps, nomadic tent dwellings, and other such structures intended for temporary and focused use. Often all that remains are verbal descriptions or iconographic representations and these generally are preserved in religious or political spaces such as tombs, temples, palaces, or in documents that were 
intended for purposes other than their rigorous and accurate presentation.

Yet, these structures remain vital parts of ancient life and, as such, deserve attention from the academic world. One such structure, described in great detail and which was the centerpiece of an emerging world religion was the Hebrew tent-sanctuary.

\section{Background to Problem}

The construction of the Hebrew tent-sanctuary is described in Exod 25:1—40:38 within the overall context of Exod 1:1—Num 10:10. It would stand as a central object in the Hebrew life until a temple-sanctuary was constructed in 1 Kin 6:1—8:66. The tentsanctuary, as opposed to the permanent temple-sanctuary, was constructed for mobility and as such was a semi-permanent structure.

The construction of the mobile tent-sanctuary is described as having taken place in just a little more than six months. The Hebrews had left Egypt on the $14^{\text {th }}$ day of the first month the morning after Passover (Exod 12:6; 30-32), which was still considered the same day since nighttime preceded daytime in their reckoning (Gen 1:5, 8, 13, 19, 23, 31; Lev 23:32; Ps 55:17). They arrived in the Mount (hereafter Mt.) Sinai area on the same day of the third month after leaving Egypt (Exod 19:1). They left the Mt. Sinai area about eleven months later, leaving on the twentieth day of the second month the next year (Num 10:11-13). The Hebrews had heard the Ten Commandments recited by God on the third day after making camp (Exod 19:11). Moses had next led the people in worship of God (Exod 24:1-8), and he, Aaron, Aaron's two eldest sons, and seventy unnamed elders of Israel had gone to meet God in some way (Exod 24:9-11). Moses and Joshua had finally been called up to the mountain for one week (Exod 24:12-17). Moses went to talk with God about the tent-sanctuary for the next forty days (Exod 24:18—32:29) making 
the Golden Calf event at least fifty days after arriving at Mt. Sinai. Moses then communicated with God (Exod 32:30 —34:3) and Moses spent forty more days with God (Exod 34:4-28) before returning to the people (Exod 34:29-35). Thereafter work began on the tent-sanctuary (Exod 35:1—40:38) over the next roughly six months. On the first day of the first month of the second year (Exod 40:17), one and a half months before leaving the Mt. Sinai area (Num 10:11-13), it was set up.

The tent-sanctuary consisted of two elements: the tabernacle and the furnishings (Exod 25:9). It is described as having been set up in the center of the Hebrew camp so that the meeting area and entrance was toward the east. The tabernacle and furnishings were enclosed by a hanging of curtains that formed a rectangular courtyard. The tabernacle was located in this courtyard toward the western side. Everything inside that hanging of curtains that defined the courtyard was considered part of the sacred sphere or sanctuary (Exod 25:8, called "tent-sanctuary" in this study to set it apart from later “temple-sanctuaries”) that allowed God to dwell among His people (Exod 25:8), making it also a type of royal domestic sphere (since He was not only their God, but their King; 1 Sam 12:12). Immediately encamped around the tent-sanctuary was the tribe of Levi, which had been set apart as a tribe assigned for duty in the sacred sphere (Num 3:40-51) based on their loyalty to God at the Golden Calf event (Exod 32:25-29). Moses, Aaron, and their families were to camp before the gathering area in front of the entrance of the tent-sanctuary on the east side (Num 3:38). The three tribes of Judah, Issachar, and Zebulun encamped farther east of them "according to their armies" (Num 2:3-9), an unusual phrase to be associated with recently former slaves (cf Exod 12:17, 41, 51). Levites from the family of Kohath were to encamp on the south side (Num 3:29) with the 
three tribes of Reuben, Simeon, and Gad farther south of them encamped "according to their armies” (Num 2:10-16). Levites from the family of Gershon were to encamp on the west side (Num 3:23) with the three tribes of Ephraim, Manasseh, and Benjamin farther west of them encamped "according to their armies" (Num 2:18-24). Levites from the family of Merari were to encamp on the north side (Num 3:35) with the three tribes of Dan, Asher, and Naphtali farther north of them encamped "according to their armies" (Num 2:25-31). In this way, the tent-sanctuary was at the center of a military camp giving it a military context.

The Hebrew tent-sanctuary is described as having been constructed over a period just a little more than six months, all less than a year after leaving Egypt, putting this event in a potential Egyptian context for cultural influence both in materials used and in the design culture of the artisans. It is described as having been constructed in terms of sacred, royal-domestic, and military spheres. Finally, it was clearly intended to be a mobile structure constructed of mostly organic materials of which no archaeological remains have been recovered. There are a few iconographic representations of later iterations of some of the furniture, such as on the triumphal Arch of Titus, that show items from the $2^{\text {nd }}$ Temple Period.

\section{Statement of Problem}

Although the documented description of the construction of the tent-sanctuary appears to give it an Egyptian context in terms of the materials used and the culture of artisans, in three distinct spheres (sacred, royal-domestic, and military), very little work has been done in comparing the descriptions in the text with the recovered archaeological fabric from Egypt and no study has, as yet, taken the next step of quantifying that 
comparison through a potentially-repeatable statistical analysis in an effort to determine, in as unbiased a manner as is possible, considering the available data, the nature of the relationship.

\section{Research Question}

Can the extent of the relationship of the description of the construction of the Hebrew tent-sanctuary with the recovered archaeological fabric of ancient Egypt be determined through statistical analysis? To answer this it will be important to compare the description of both the physical materials (the tangible cultural heritage) and the design culture of the artisans (the intangible cultural heritage) in the Hebrew textual record with the Egyptian archaeological record from sacred, royal-domestic, and military spheres as represented through the published results of recovery efforts (that include excavation, survey, antiquities market, etc.) as they exist today.

\section{Research Design/Methodology}

"It is impossible to fail to notice that many aspects of archaeological information are numerical and that archaeological analysis has an unavoidably quantitative component” (Drennan 1996: v). This being the case, it is possible to apply statistical analysis to the problem at hand. Doing so in a valid manner can be challenging, however, and requires exact statements of what is being compared to ensure precision.

The first step needs to necessarily be one that delineates the scope of the study both temporally and spatially. This should be followed, in step two, by an identification of what is to be studied, which, in this case, will be the materials used in the construction and the designs employed as described in the text. Next, it is desirable "to sample 
because we can find out more about a population from a sample than by studying the entire population,” (Drennan 1996: 81) even if it were possible (if the archaeological record was complete - which it is not), because there is less data to sift through. As a result, the third step will be the collection of data from the Egyptian record (population) as will be delineated in Chapter 2 (sample) for each of the elements of the study. The sample will be determined by the accident of survival, which, by nature, was random and outside of this study's ability to manipulate but not delineate. Step four will be to compose a set of numbers called a "batch" because they are different examples of the same thing (Drennan 1996: 3) organized (in step five) either by category (material culture) or measurement (immaterial culture). This will be followed (in step six) by a statistical analysis of each varying objective as is appropriate and then (in step seven) by a discussion of the results.

The Egyptian batches that are categorized by material type will record frequency through tabulation. This data will be represented in a table that should present a clear picture of what sort of materials are more frequent than others. Objects suspected to be from Egypt (such as those used in the construction of the Hebrew tent-sanctuary) can then be compared with the results to determine if the objects are represented in the archaeological record and to what extent (according to the accident of survival and efforts of recovery as they exist today, making the evaluation of "extent” unintentionally subjective).

The Egyptian batches that describe dimensions will be organized by measurement. These will be placed into simple stem-and-leaf plots (in Chapters 3 and 5) from which further analysis for any items that are comparable between the tent-sanctuary 
and Egyptian can be determined. The stem-and-leaf plots are a quick way to isolate numbers for comparison by revealing patterns. This will be done in Chapter 7 by using the trimmed mean through which can then determine the most likely characteristic that can be considered "Egyptian,” (using the standard rule of thumb that any number lying 1.5 midspreads outside either quartile of a batch is an outlier, Drennan 1996: 41). From this the trimmed standard deviation can be calculated (Drennan 1996: 33-34).

Standardized scores (or z scores) can then be calculated by subtracting the trimmed mean from every number in the batch and then dividing that by the trimmed standard deviation. In this way, the centrality or peripheralness of each number (its unusualness) can be determined (Drennan 1996: 51). Although all examples used are clearly Egyptian, characteristics can be mathematically delineated so that objects that are suspected to be Egyptian (such as those that compose the Hebrew tent-sanctuary) can be checked against this to determine if they are clearly a known ancient Egyptian style (within the first standard deviation, called midspread), within the range of the known ancient Egyptian style (within all remaining standard deviations, called adjacent values and outliers), or outside known ancient Egyptian styles altogether (beyond all standard deviations, called far outliers). By making these design elements quantifiable, it will be possible to assess cultural influence with these three categories (midspread - within expected cultural norms; adjacent values - slightly outside expected cultural norms; outliers - on the edge of expected cultural norms; and far outliers - outside expected cultural norms).

It is the hope that when the results of the analyses between both batch sets are compared with the description of the Hebrew tent-sanctuary that cultural influence can be either identified clearly or clearly not identifiable. 


\section{Definition of Terms/Literature Review}

It is vital, before beginning a study such as this, to understand what has taken place already along similar lines of inquiry. To give this study firm footing from which to launch, to ensure that work is not being repeated (unless it is necessary to do so), and to recognize appropriately those who have made contributions that this study will take for granted, a modified literature review is necessary, touching on research done in the five areas where this study will interact. This is recognizably weighted toward this study and should not be considered a comprehensive discussion of any of the following five topics.

In the five sections that follow, only those areas that affect this study will be discussed. The first will address what has happened and is happening in the area of cultural heritage (tangible and intangible) as it affects this study. Building on this, the next section will briefly review what is understood about ancient Egyptian culture in order to more narrowly focus this study in that direction. Ancient Egyptian culture is chosen for this study primarily because the biblical text sets the construction of the tentsanctuary in that context and thus it is that ancient culture's influence that will be tested as determined in Chapter 2. As a result, the next section to be discussed will be Biblical Archaeology as it relates to this study. The Hebrew tent-sanctuary has been studied and analyzed in great detail (much of which, has nothing to do with its construction). The next section will focus on the cultural influences and what has been done on this topic in published literature. The final section will briefly discuss the construction of the tentsanctuary (as opposed to a study on types, theology, or symbols). Further reviews, as they are appropriate, will appear in each chapter surrounding each topic as is appropriate. 


\section{Tangible and Intangible Cultural Heritage}

Perhaps because Europeans live in and around heritage in a way that Americans generally do not, defining heritage has been more of a focus. To protect heritage, one must first define heritage. The material culture that composes tangible cultural heritage is fairly easy to recognize and define. Material culture has long been recognized as an integral part of what should be recovered in archaeological efforts (which include excavation, survey, remote sensing, etc.). Certain destructive non-archaeological activities (looting, demolition, urban expansion, etc.) have led to governing heritage organizations such as International Council on Monuments and Sites and The United Nations Educational, Scientific, and Cultural Organization being forced through necessity to define heritage so laws could be made both at state and international levels to protect culture heritage in the form of "monuments, groups of buildings, and sites” (Ahmad 2006: 294-95), so that both the movable and immovable aspects are represented. In this process it became apparent that not just tangible but also intangible cultural heritage should be protected. These organizations have looked to anthropology and archaeology to help them understand the concepts behind these terms. In return, these disciplines have benefited from the exercise of having to explain the difference to people not trained in these areas of study. This has led, and is leading, to more clarity of thought in this area.

Recently, the difference between tangible and intangible cultural heritage is thought to be that tangible is the physical object, while intangible is "the knowledge and skills to create” that object (Kurin 2004: 70). In this way tangible cultural heritage is both what exists physically today and also the material culture that archaeologists recover from the past. Likewise, intangible cultural heritage is the immaterial culture that "exists 
only because a heavily material base supports it and makes it possible,” (Moles and Jacobus 1988: 25). Many find that the separation of tangible from intangible is "quite artificial and [often] makes little sense,” since the two are often inextricably linked (Kurin 2004:70). So (for example), while the material culture would be the tangible ship, the immaterial (or intangible) is "the know-how related to a particular type of shipbuilding,” (Blake 2000: 66). The intangible is measured by what remains of the tangible.

The immaterial (or intangible) culture has been hard to define (Blake 2000: 65; Kurin 2004: 70). Some use it to talk in modern culture of virtual reality (Moles and Jacobus 1988). Others speak of the absence that becomes materialized so that the immaterial can be traced (Meyer 2012). Neither of these definitions are useful for this study. A good example to illustrate the need to define, discover, identify, analyze, and record intangible cultural heritage is the pronunciation of the name of the God of the Hebrews. The tangible cultural heritage is the actual name written on papyrus, parchment, stone, and the like. The intangible cultural heritage is the pronunciation. Because pronouncing the name was intentionally avoided for centuries, it has been lost. Without the intentional effort to identify other aspect of the intangible cultural heritage of the Hebrews, these too might be lost forever.

While the archaeological, anthropological, and heritage communities continue to have discussions about the actual meaning of "immaterial culture," and how it is separated from the "material culture," in this study these terms will be used in a mechanical way for the sake of clarity. They will refer to both the design elements that are the identity of a culture (the intangible) as well as the physical materials (the tangible) used to make cultural objects. 


\section{Egyptian Culture in the Pharaonic Era}

Identifying ancient Egyptian culture is a bit problematic since at any particular point in history, Egyptians living upriver (south) in the Nile River Valley had a different living environment than those living downriver (north) in the marshlands of the Nile Delta Region. Even speech seems to have reflected this separation (Allen 2013: 4). When the element of time, foreign influence through trade and rule both by Egypt and on Egypt, and the lack of unified leadership at various points in history are added to the mix trying to identify something as uniquely "Egyptian” becomes a complex task. However, even with all of these factors, life in and around the Nile River resulted in distinctive styles of art and architecture, both of which display "a remarkable continuity over the enormous span of time," whether the style is "using two- or three-dimensional representations and irrespective of medium - wood, metal, stone, or glazed material,” (Morkot 2005: 213) that can be quickly recognize as "Egyptian.”

To further compound the problem of narrowing culture, exhaustive studies on any single ancient near eastern culture do not exist (Hundley 2011: 120). In Egyptian culture, studies exist for some elements but not all. For example, there is a lack of focus on ritual action (Ritner 1993; Sauneron 1966), with most research in that area going into the relationship between magic and medicine (Hundley 2011: 120). It is thought that both “royal and religious functions of art” were the reason the official "Egyptian” style was first created and also was what “dictated its continuity” (Morkot 2005: 214), however, without an exhaustive study (if it were possible) this hypothesis cannot be known with certainty.

This continuity does not mean that there were no subtle changes. One such 
change, for example, was the proportions used to depict figures in iconography. As has been demonstrated in Tutankhamun's burial chamber (Robins 1984, 2007), the north wall was “decorated independently of, and at an earlier date than,” the south, east, and west walls (Reeves 2015: 9). The official Egyptian grid system of the $18^{\text {th }}$ dynasty (approx. $16^{\text {th }}$ to $14^{\text {th }}$ centuries B.C.) used an 18-square proportion system which was used on the south, east, and west walls of his burial chamber, while the Amarna style used a 20square proportion system (used on the north wall of Tutankhamun's burial chamber). During the Saite dynasty (664-525 B.C.) a 21-square proportion system was used (Morkot 2005: 214), further adjusting the official style, but allowing for a dating method by modern researchers.

Thus, while it is not possible to determine an "Egyptian" style that would account for all periods and locations, if the temporal and spatial elements can be delineated, perhaps a style can be identified that can be useful for this study so that "Egyptian culture” will refer to that delineation (Chapter 2).

\section{Biblical Archaeology Methodology}

The results of any scientific endeavor must be interpreted. To do this the results of archaeological efforts (data) relies heavily on other disciplines (anthropology, metallurgy, zoology, etc.). Biblical archaeology compares archaeological data with biblical studies.

The Egyptian Exploration Society (EES) stated in its charter announcement, published in leading newspapers, that Egyptian archaeology was being done to illustrate the Old Testament as it had to do with Egypt and the Egyptians (EES 1882; James 1982: 9; Moorey 1991: 6). This obviously was a biased approach to archaeology that has long since been adjusted. However, biblical studies still do benefit from the work done in 
archaeological studies as long as faith and science are allowed to remain separate (Younker 2000). In fact, G. E. Wright felt that these efforts (both epigraphic and nonepigraphic) needed to develop independently of each other in order to avoid bias (Wright 1983).

William Dever recognized the interrelationship and potential necessity of a comparison between archaeology and biblical studies. While most of his career was spent attacking biblical archaeology, it was his contention that the biblical text and the archaeological "text" had to be read after one had mastered the "vocabulary, grammar, and syntax" of both, or else they both would remain "mute" (Dever 2002: 82). Thus, it is necessary for a scholar to have both an expertise in working with the biblical text and also with the archaeological data in order to properly compare them, which Dever felt gave each of them a voice.

LaBianca seems to have agreed. He felt that archaeology provides the details for anthropologists and historians (LaBianca 2007: 8). If archaeology provides those details, then it must be assumed that it can do the same for those looking at the historical backgrounds in the biblical text. Biblical studies need to consider the phenomenological elements to the experiences related in the text as part of this historical context. Phenomenology, as a result, was considered by Levine (1993: 196) to be an important method to connect the text with archaeology.

The final element in studying the biblical text is to ask the question, "Is it possible?” (Finkelstein and Silberman 2001: 58). Finkelstein does not consider any portion of the Hebrew Scriptures before the Omride dynasty as containing any historical reality. And while he may not have meant the question to be taken in this way, it is the 
right question. Too often the question, “Is it true?” or “Did it happen?” is asked.

However, archaeology is poorly suited to answer either of those questions since they both require interpretation. For example, a blade found in a battlefield where a battle has been written about in historical accounts does not prove that the particular battle written about actually happened. It does, however, demonstrate that it could have happened. The best archaeology can do for Biblical studies is to answer if it is possible.

The Andrews way of conducting biblical archaeology involves six key principles as defined by Randall Younker, the director of the Institute of Archaeology (Cline 2007: 187). First, honesty is the best policy. This includes not only reporting what is found but not minimizing how the results might adversely affect cherished theory. Second, be accurate. It is unprofessional to claim results that are not supported by the data. Third, be timely. Responsible archaeological method includes publishing results of excavations as soon as possible for the benefit of all. Fourth, work with others. No one works in isolation. Often those on the outside of one's circle can see data from a useful perspective and so interacting with mainstream scholarship is vital to the advancement of knowledge and the discipline. Fifth, diversity provides new perspectives. Diversity both in people and specialties further help approach data from new and potentially useful perspectives. And sixth, the Hebrew Scriptures are data that should be treated as any other ancient document. In doing this, scholars must not place the burden of proof upon archaeology to "prove" the Bible. Archaeology is not particularly equipped to do this. Other studies (Velazquez 2008: 31-69) address the history of Biblical Archaeology more clearly and provide backgrounds to archaeology theory as it is related to that discipline, most of which is not directly relevant to this study. 
Archaeology is useful to biblical studies if both disciplines are developed independently of each other so that data of each can be compared before interpretations take place. When combined in this way these two disciplines will be termed "Biblical Archaeology” in this study.

\section{The Hebrew Tent-Sanctuary}

Scholars call the structure that is described as having been built near Mt. Sinai by many names: sanctuary, tabernacle, tent of meeting, among others. Sometimes the word "earthly" is applied to it (i.e., Papaioannou and Giantzaklidis 2017) to distinguish it from an original of some sort in "heaven". Nearly always, the study compares structures (i.e., temples) constructed at a later date than the one described in the book of Exodus. Often the study has more to do with the doctrine developed by the Seventh-day Adventist denomination (i.e. Holbrook 1989a, 1989b) or study of the rituals associated with it (i.e. Gane 1992, 1999, 2005) than with the actual construction.

Elias Brasil de Souza (2005) conducted a significant study on the motif of the Heavenly Sanctuary/Temple in the Hebrew scriptures in which he also reviewed other work in this area (Gray 1908; Metzger 1970; Davidson 1981; Andreasen 1981; Shea 1982; Hartenstein 2001), work concerned with extrabiblical apocalyptic literature (Hamerton-Kelly 1970; McNicol 1974, 1987), work concerned with a background for the New Jerusalem in the New Testament (Lee 2001; Sharkey 1986; Valentine 1987), work dealing with the Dead Sea Scrolls (Newsom 1985; Shea 1992), work concerned with Rabbinic literature (Aptowitzer 1931; Ego 1989), work with early Christian materials (Bietenhard 1951; Briggs 1999), as well as providing a good general literature review on 
the topic (Kim 2002: 27-44). Little of that material deals with the construction of the tent-sanctuary at Sinai.

In Exod 25:8-9, the first instructions concerning the construction of the Israelite sanctuary, God specifically called what is to be built a "sanctuary" (v. 8) and then described it as including both a "tabernacle” and "furnishings" (v. 9). This study will take the position that everything considered part of the holy ground (courtyard boundary inward) is the "sanctuary" or sacred sphere since all structural elements (excluding priestly garments, which are not a part of this study) are included in the description of both the instructions (Exod 25:1-31:18) and construction (Exod 35:1—40:38) of the tent-sanctuary. The word "sanctuary" will be considered to be a distinct term in this study from both the tabernacle and the furnishings although both are elements that make up the sanctuary. The term "tabernacle," will refer to the framed tent with paneling inside the sacred sphere. The term "furnishings" will refer to all objects in the tabernacle and outside the tabernacle in the courtyard inside the sacred sphere. To further distinguish it from later temple-sanctuaries (Solomon - 1 Kin 5:1—8:66; Zerubbabel - Ezra 3:1—6:22; Zech 4:9; and Herod - John 2:19-20), this entire sanctuary, which was the only one in the Hebrew Scriptures to be constructed with a tent, will be called in this study, "tentsanctuary.”

\section{Construction of the Hebrew Tent-Sanctuary}

Acknowledging the various early translations of the Hebrew text (such as the Septuagint, Vulgate, and other attempts to represent the text in another language) and the recounting of the text by Josephus, the first real efforts to interpret the construction of the Hebrew tent-sanctuary appears to be the extra-mishnaic treatise on the work of the 
tabernacle (Venice 1602, Hamburg 1782, and Zürich 1892, the last of which was a work by Heinrich Flesch for his doctoral degree). However, in regard to the Pentateuchal text, they are "unsatisfactory" (Epstein 1911: 581-82) and "the ancient rabbis were by no means a unit on the subject” (Epstein 1911: 585), presumably meaning that they were not united.

T. O. Paine (1885), was probably the first scholar to publish a study on the construction of the Hebrew tent-sanctuary from the Pentateuchal text having studied it for nearly forty years and, as a result, his research is quoted in many later works. There were a few other scholars who went before him (Bähr 1837 and Knobel 1857), but these worked mostly from tradition (and not the text) and thus offer little that can help in the study of the Pentateuchal text (Epstein 1911: 585-87). Not allowing for cultural influence, and clearly biased by his personal experience, Paine's idea of the tentsanctuary has been described as representing “a structure exactly like a little New England barn, having a roof of sharp pitch supported by a frame” (Wright 1899: 195). In fact, it seems to have been the prevailing wisdom of the day to consider the tentsanctuary to have been a special building that was not touched by cultural influence being an entirely unique revelation from God (Wright 1899: 196).

Frank M. Cross, Jr. (1947) is often cited as his work was the first effort to explore an archaeological perspective of the tent-sanctuary. In a very real way, his study ended the era of speculation regarding the tent-sanctuary's construction. About this time scholars switched to a study of typology and theology. In fact, in his opening remarks he noted that most scholars had given up studying the tent-sanctuary in any meaningful way by the time of his publication (Cross 1947: 45). He credited an acceptance of 
Wellhausen's theory as the main reason for this (Cross 1947: 46). Cross saw the best parallel of the tent-sanctuary's construction to have been the Arab tents of his day (1947: 59). He appealed to Ugaritic tablets to support this theory (1947: 62). He maintains a distinction between ohel mo'edh ("tent of meeting") as being part of JE and mishkan ("tabernacle"), which he claimed is "the typical Priestly designation of the tentsanctuary” (Cross 1947: 65). There is very little actual archaeology in his study in spite of the title and his reputation. He later changed his position in favor of David's tent being the prototype of P's tent-sanctuary (Cross 2000).

Strong (1952) produced one of the earliest comprehensive studies on each of the elements of the tent-sanctuary, using the textual record in Exodus, Josephus, rabbinical literature, and, to some degree, Egyptian temples and religious articles (Strong 1952: 3). He also provides a literature review of antiquarian efforts in this area (Strong 1952: 4-8), to which he concludes that most, if not all, were severely hampered by a lack of data, and relied on tradition and modern convention to which very little of value is gained. His arguments are logical and detailed and admirably represent the extent of scholarship without much information from cultural contexts. In this line, he agreed with Cross that imagination was the main drive behind earlier studies.

Carol L. Meyers (1976) looked for ancient near eastern archaeological parallels for the lampstand in her dissertation and shows, by her study, the rich backgrounds that can be discovered through observation. However, she fails to measure anything statistically, which leaves the reader to pick and choose which observation fits their understanding best. This effort shows the richness of the tent-sanctuary for further studies of each element, which have yet to be done. 
Hurowitz (1985) compared the account of the construction of the tent-sanctuary with the account of the construction of Solomon's temple-sanctuary in 1 Kings and accounts from Mesopotamia (the account Gudea of Lagash, Tiglath-pileser I, the Sippar cylinder of Nabonidus, the Ugaritic account of the building of the temple of Baal, and the bilingual "B" inscription of Samsuiluna of Babylon; the last of which he found to be the closest parallel) all in an effort to refute Wellhausen's theory. He built his study on a “form-critical” textual study by Levine (1965: 311).

Hendrix (1989) did a study on the specific contexts in the text for the terms for tabernacle (mishkan) and tent of meeting ('ohel mo'edh), finding that they are parallel terms for the same structure. He discovered that mishkan was used in the text when discussing the physical aspects of the tent-sanctuary and that 'ohel mo'edh was used when discussing the function of the tent-sanctuary (Hendrix 1989: 107-08). Since the present study is only concerned with the physical nature of the structure and not the function, Hendrix's study informs this research only as it relates to the nature of the tentsanctuary apart from its function. Further, in this study all non-furnishing items are referred to as "tabernacle," which is a reflection of the use of the terms "tabernacle" and “furnishings” in Exod. 25:8-9.

Kitchen (1993), leaning heavily on the work of Cross (1947), considered the tentsanctuary (and particularly the tabernacle) to be a bronze-age artefact heavily influenced by Egypt. He did not see anything particularly "sophisticated or elaborate” in its design, and pointed to its "collapsible, portable" nature (Kitchen 1993: 119). He pointed to the bed canopy of Queen Hetepheres (see discussion of this in Chapter 5) as potentially informing Bible readers of the exact nature of the construction of the tabernacle 
(observationally; Kitchen 1993: 119-20). He also pointed to the nested shrines of the New Kingdom, the gilding technique over wood, the "tricoloured linen curtains [sic]" complete with repeated design elements, Tutankhamun's pall (on a frame), the shrine of Amenhotep I, the sail of Sahure (of the $5^{\text {th }}$ dynasty, conventionally date to approximately the $25^{\text {th }}$ to $24^{\text {th }}$ centuries B.C.), the palladium of Min, the great tent cloth of Ramesses III, and the use of leather for coverings (all discussed in Chapter 5; Kitchen 1993: 120-21). He also pointed out the possible parallel of the tent-sanctuary with Ramesses II's military camp at Qadesh, which he pointed out is a much closer observational parallel than anything in Mesopotamia (also discussed in Chapter 5; Kitchen 1993: 121-23; see also Kitchen 2000). Kitchen's contribution is primarily observational. He conducted no statistical analysis.

Homan (2002) has probably the most complete observational study of the construction of the tent-sanctuary's possible connection to the ancient near east (with a focus on the tent aspect). This built on some earlier work he had done (Homan 2000). However, in spite of all of the observational parallels (particularly with Egypt) he provides in this large study, he still clung to the conclusion that the texts were written late, in an urban setting (Homan 2002: 191). He also did not provide a statistical analysis of any of the data.

Hoffmeier (2005) touched on the topic, summarizing the highlights of most who had written on the topic but did not provide a comprehensive study (he left a number of elements out). His was mostly an argument that the tent-sanctuary was possible in an ancient near eastern context (particularly Egypt). He did not provide a statistical analysis of any of the data. 
One of the reasons for so much discussion and speculation about the construction of the tent-sanctuary seems to be a fundamental disagreement as to potential cultural influences. There is a line of thought that suspects that the lack of unified insight in regard to the construction of the tent-sanctuary is because the subject is decidedly on a non-human matter (Meyers 1976: 1) and thus, because it is a building for the Divine, it is beyond human comprehension. There are currently three main positions regarding a potential cultural influence in constructing the Hebrew tent-sanctuary. The first position is seemingly the default assumption that there is no culture influence. This position holds that the text does not present the tent-sanctuary as having an earthly cultural influence but intends the reader to believe that it is entirely of heavenly origin, which, in practical terms, means that God endowed the artisans who were tasked with its construction with skill that they did not previously have so that the tent-sanctuary was an entirely unique phenomenon (see Nixon 1984: 136). This seems to be a position held by biblical scholars (both conservative and liberal) who do not associate their studies with the ancient world but work only with the text.

The second position is that the tent-sanctuary had Mesopotamian or Levantine cultural influence (Cross 1947; Haran 1962; Rabe 1966; Hurowitz 1985; Zevit 1992). Since the majority of those scholars who hold this position consider the text to be of late composition, most do not consider the tent-sanctuary to have actually existed and thus read into the text a cultural influence based on where they believed the author(s) of the text to have been when they composed it. There are a few scholars who hold this position who consider that the Hebrews retained some sense of cultural identity from the Levant (via Jacob) or Mesopotamia (via Abraham) during their stay in Egypt (or that they never 
were in Egypt) and the artisans tasked with its construction used local culture. Some scholars consider the design to be "too cumbersome and elaborate [to be realistic] in the nomadic setting” and point to “Arab tent-shrines” (Rabe 1966: 132) as examples of what it may have looked like, thus suggesting that the biblical text is not accurate.

The third position is that the tent-sanctuary had Egyptian cultural influence (Kitchen 1960; Meyers 1982; Kitchen 1993, 2000; Homan 2000, 2002; Kitchen 2003; Hoffmeier 2005). This is the position of those who see a cultural shift in the Hebrews from when they entered Egypt as shepherds living in nomadic tents to when they left Egypt as builders living in houses. This position considers the artisans to have been trained in Egypt in Egyptian style of artwork/architecture and that this was employed in the construction of the tent-sanctuary (i.e., Strong 1952: 3-4). Some in the group still leave open the possibility of a late authorship, which others in this group steadfastly reject. It is this third position that will be directly tested in this study.

For a recent study on the connection between the tent-sanctuary rituals and ancient near eastern cultures, see Hundley 2011. Also, there is an abundance of studies on Egyptian religion and religious practice (Assmann 2001, 2002; Bell 1992, 1997; Blackman and Fairman 1946; Borghouts 1978, 2000; Černý 1952; David 1981; Frandsen 2000, 2004; Frankfort 1948; Hoffmeier 1985; Hornung 1983; Lichtheim 1976; Lorton 1999; Meeks 1975, 1999; Mercer 1949; Quirke 1992; Ritner 1993, 2002a, 2002b, 2002c; Robbins 2005; Roth 2006; Sauneron 1966, 2000; Spalinger 1998; Thompson 2002; Tobin 2002a, 2002b, 2002c; Wilkinson 2000; Willems 2004). But even within that field of study, there has been very little work in quantifying the construction of the sacred spheres in which these practices took place (Wilkinson 2000). It seems that before conclusions 
could take place in regard to religious practices, the structures they took place in should be understood, however, this has not yet happened in scholarship.

\section{Significance of the Study}

For the better part of two centuries, scholars who have dealt with the topic of the construction of the Hebrew tent-sanctuary have done so acknowledging the work of Julius Wellhausen. The documentary hypothesis, which considers the Pentateuch to be of late composition (various theories placing the redacting of source documents just before, during, or after the Babylonian captivity), has dominated theory and textual studies. This does not mean that the documentary hypothesis is universally accepted. Some historicalgrammatical scholars reject it outright. Dwayne Garrett, for example, states, “A discussion of the origin or sources of Exodus should not remain trapped in the nineteenth century, continuing to talk about J, E, D, and P as though those terms actually mean something real and historical. That path is a dead end” (Garrett 2014: 19). He takes this position because the source-critical position "is not based on any ancient Near Eastern analogies but is from start to finish an analysis based on extrinsic and peculiar criteria” (Garrett 2014: 17); criteria that is not held in consensus by anyone who supports it. Garrett reviews the various theories by leading source-critical scholars on Exodus that led him to this conclusion (Garrett 2014: 15-19). That said, it is import to understand how the documentary hypothesis has affected sanctuary studies and so a brief review is necessary.

In 1833, Karl Graf heard his professor, Eduard Reuss state that the prophets of the Old Testament do not mention the Priestly (P) law. This has been challenged since then by Friedman (1987: 167-71). However, this idea set Graf on a study to see how often the 
Elohoist (E), Yawist (J), and Deuteronomist (D) sources mentioned the tabernacle and found that in his calculations, E only mentioned it three times while J or D never mention it (Friedman 1987: 162-63), which is an incredible example of circular reasoning since $\mathrm{P}$ is supposed to reflect all the content around the services of the tent-sanctuary, and thus it is unlikely that any mention of the tent-sanctuary would be accredited to any source other than P. Nevertheless, Julius Wellhausen built on these ideas and concluded that since, in his studies, $\mathrm{P}$ assumed rather than commanded centralization (which has also been challenged, see Friedman 1987: 172) and the description of the construction of the tentsanctuary was either impractical or impossible, "the truth is, that the tabernacle is the copy, not the prototype, of the temple of Jerusalem” (Wellhausen 1957: 37). This study resulted in Wellhausen’s declaration that P “alone wrote after 539 B.C.” when Cyrus released the Jewish captives in Babylon out of a "desire to establish a centralized cult in Jerusalem” (Homan 2000: 24). Bernhard Pelzl $(1975,1976)$ supported this theory by proposing that the tent-sanctuary replaced "the temple during the Babylonian captivity" (Hoffmeier 2005: 194). The tent-sanctuary "was the primary evidence of the priestly source’s fraudulence” (Homan 2000: 24), although some scholars are still inclined to search for "an actual historical tent-sanctuary behind the elaborated Priestly narratives" (Rabe 1966: 132). While Wellhausen's understanding of the primacy of the account of the directions for construction and the account of the construction itself in Exodus has been challenged (Hurowitz 1985: 30), the idea that Mesopotamian or some Levantine culture, rather than that of Egypt, is the extra-biblical type to which the tent-sanctuary should be compared, often goes unchallenged as the standard paradigm for study of this structure (Rabe 1966; Hurowitz 1985; Brinkman 1992). 
It is not appropriate in this archaeological study to address the issue of the historical reality of the Hebrew tent-sanctuary or to argue for or against the Documentary Hypothesis. This does not mean that this study would not be of use to a study on the historical reality of the tent-sanctuary. Such a study would have to evaluate the claims of the text, which is what this current study will do.

Further, the description of the construction of the tent-sanctuary is presented in a theological document (the Hebrew Bible) allowing for a theological system of understanding to be developed (see Holbrook 1989a, 1989b). This study will not delve deep into theological treatments but will provide useful material for future studies.

\section{Outline of the Study}

Since descriptions in the textual record (Hebrew Scriptures) are to be compared with the archaeological record (from ancient Egypt), both of which are extensive, certain limitations must be set. These limitations, both in terms of chronology and geography, will be established in Chapter 2. This does not mean that material outside the temporal and spatial limits will not be used, but rather that any material used outside these limits will need to be justified and then used with caveats.

Since the Hebrew tent-sanctuary is the subject under study, it is appropriate to begin with analysis of it. This will take place over two chapters. Chapter 3 will deal with the immaterial culture, particularly in respect to design elements. Chapter 4 will deal with the material culture (the physical materials used). The tent-sanctuary consisted of both the tabernacle and the furnishings and so both of these chapters will separate analysis along those lines.

Egypt is presented in the Hebrew Scriptures as the cultural context of the 
construction of the tent-sanctuary. As such, the next two chapters will analyze material (both intangible - Chapter 5; and tangible - Chapter 6) from that culture as limited by Chapter 2. Since the tent-sanctuary is described as being associated with three distinct spheres, Egyptian immaterial and material culture will be examined in those (sacred, royal-domestic, and military) spheres.

Chapter 7 will include a synthesis that will compare statistical analyses of data related to the design results of Chapter 3 and the design results of Chapter 5. A synthesis of data will also compare the materials results of Chapter 4 with the materials results of Chapter 6.

These results will need to be discussed. This will take place in Chapter 8. The results of this study will have implications on various aspects of the biblical text in relation to the construction of the tent sanctuary. Finally, the study will present recommendations for future study. 


\section{CHAPTER 2}

\section{CHRONOLOGICAL AND GEOGRAPHICAL PLACEMENT}

Science works within time and space.

(Brinkman 1992: 11-19)

Countless books (scholarly and otherwise), plays, and movies about the Exodus event have been produced through the years. Most of them seem to assume the when and where of this event. This is not untrue of those in scholarship as well. In the late $19^{\text {th }}$ century and early $20^{\text {th }}$ century many scholars sought to locate this event in time and space often based on assumptions. Recognizing that it is very likely that the Egyptians did not recognize the categories of time and space the same way we do (Leclant 1969: 218-19), these categories are still helpful as they allow a more clear dissection of the ancient past and are currently how we think in science.

The purpose of this chapter is to briefly review the options, to reflect on the archaeological evidence, and then to place a limit on the research that will follow these temporal and spatial boundaries.

\section{Chronological Placement}

The temporal element in research provides a delineation that limits research to a specific period making the data collected manageable. There is a lack, however, of 
scholarly consensus for the intended date of the Exodus event (see Dyer 1983; Geraty 2013). Scholars still can't agree if the event was intended to have taken place in the early $18^{\text {th }}$ dynasty, approx. $16^{\text {th }}$ to $14^{\text {th }}$ centuries B.C. (Shea 1982: 233; Kitchen 2003: 203; Young 2003) or early $19^{\text {th }}$ dynasty, approx. $14^{\text {th }}$ to $12^{\text {th }}$ centuries B.C. (Arnold and Beyer 1999: 108). Perhaps for this reason another option has been presented, suggesting that Akhenaten was the historical reality for the "myth" that was Moses (Assmann 2014). This option does not pretend to suggest that any of the details in the textual account occurred in any way. While Akhenaten's so-called monotheistic revolution needs to be addressed (and is; see Hoffmeier 2015) Assmann's theory is not developed based on a foundation that treats the text as literal and so, as a result, does not offer much for this study.

The two major options for the Exodus event are during either Thutmose III's or Amenhotep II's reign in the early $18^{\text {th }}$ dynasty (Josephus 1.26; Garstang and Garstang 1948; Kenyon 1951: 117; Unger 1954: 145-46, 149-50; Yadin 1959: 8-9; Kitchen 1966: 62; Merrill 1966: 108; Pritchard 1969: 486-88; 26; Davis 1971: 27, 31; Waltke 1972: 401; Archer Jr. 1974: 225-26, 229-30; Kitchen 1977: 88; Ahlström 1991; Hasel 1994; Van der Veen 2001; Petrovich 2006, 2013) or during the reign of Ramesses II in the early $19^{\text {th }}$ dynasty (Glueck 1940: 125-47; Kenyon 1951: 121-22; Yadin 1959: 3-4; Pfeiffer 1963 : 52-4; Schwantes 1965: 158; Kitchen 1966: 57-59, 61-2; Francisco 1977: 12; Aling 1979: 98; Oswalt 1979: 1:677; Kitchen and Mitchel 1980: 1:275; Thompson 1982: 60-2). Another option proposed by Hans Goedicke (Shanks 1981) is that it happened during the reign of Hatshepsut, but this theory has received some push-back (Oren 1981; Schiller 1983). 
The reason there is even a debate is that the Biblical account does not indicate in which year the Exodus event took place in absolute dating but rather does so with relative dating (1 Kings 6:1), which allows for various interpretations. The first scholarly attempt to work out an absolute chronological system for the Bible took place in 1650-54 by Irish archbishop James Ussher, published as Annales Veteris et Novi Testamenti (Ussher 1722; Thiele 1951: 228; Finegan 1964: 191; Jones 2004: 6). Around the end of the nineteenth century many others also tried to do this (ex. Bliss 1887; Goodenow 1896; Beecher 1907; Auchincloss 1908; Anstey 1913; Mauro 1922). By 1951, Edwin Thiele had enough data to make a breakthrough and a relative chronological system was established that fit with known historical events, allowing for an absolute system that places the Exodus event sometime between 1450 and 1445 B.C., although some scholars have argued that 1 Kings 6:1 was not meant to be understood literally, allowing for a thirteenth century B.C. date.

Egyptian chronology itself is extremely complex (Åström 1987; Casperson 1988; Åström 1989; Kitchen 1991; Ray 1997; Hornung, Krauss, and Warburton 2006) and many scholars have worked to try to find a solution that would reconcile its many problems (Kuniholm et al. 1996; Haas et al. 1987; Dever 1991; Shaw 2000; Bietak 2002; Greenberg 2004; Levy and Higham 2005; Bruins, Van der Plicht, and MacGillivray 2009). It should be noted that all of the proposed options for the Exodus event place it within the context of New Kingdom Egyptian culture. All of the dates for the kings in the New Kingdom are agreed upon by scholars within \pm 50 years.

Rather than debating which of the above options is more likely to be correct, all that is needed for this study is to have a fairly broad chronological setting from which to examine culture. Regardless of which date, that appears to be the New Kingdom. 


\section{Geographical Placement}

The biblical text is clear that Egypt was the country from which the Exodus occurred. The Hebrew word for Egypt (Heb. mișěrāyîm) is used more than 70 times in the book of Exodus and no hint is even given for any other location. There is little debate that the story was meant to have happened there. Even those studies (Oblath 2004; Wellhausen 1957) that suggest that perhaps this event was an invention by a later author do not argue that the Hebrew text does not place the Exodus event in an Egyptian context. As a result, this study will proceed generally from that position and will examine the culture from Egypt in relation to the construction of the tent-sanctuary.

When the Hebrews were pressed into slavery (Exod. 1:11) they were forced to build two supply cities. However long it was between this event and the Exodus event, they appear to have been still building these cities because they were still producing mudbricks when Moses appeared before Pharaoh for the first time after returning to Egypt (Exod. 5:6-19). It seems then, that these two cities might be key to locating the launching point of the Exodus event, as those who were engaged in their construction had to live in some proximity to these cities.

The account of the Exodus proceeds with a list of toponyms (Exod. 12:37; 13:20; 14:2, 9; 15:22-23, 27; 16:1; 17:1; 19:1-2; cf. Num. 33:3-15ff.). Lists of toponyms were popular in Egypt from the Middle Kingdom onward "with the longest surviving example coming from the walls of temples in the New Kingdom” (O’Conner and Quirke 2003: 6). In fact, one such list comes from Thutmose III's trips into Nubia and Punt (O’Conner and Quirke 2003: 8). The fact that most of these toponyms are not equated with known sites is normal as "most ancient Egyptian...sites remain partially explored, undiscovered, or 
destroyed or are not equated with ancient toponyms” (Parcak 2008: 61).

The Hebrews were from Mesopotamia via the Levant. The Egyptians (in Africa) considered all peoples from that area to be ' $3 m w$, which is translated by modern scholars as "Asiatic" since the Levant is in Asia. Asiatics did have a presence in Egypt from the Middle Kingdom through the early New Kingdom in the eastern delta (Hoffmeier 1996: 62-68). The EES has conducted extensive surveys of the delta, the reports of which have been published in various places and a bibliography of these reports posted online (EES 2017). The reports show that during the Middle Kingdom and into the early New Kingdom, the western side of the delta had little occupation. Apparently only Sais and Buto had any important activity (cult centers) during this period, most likely due to political considerations (Bietak 2017: 53) since most trade (and the majority of the threats) was happening with the Levant and Mesopotamia. This situation, of course, changed during the reign of Ramesses III, in the late New Kingdom (20 ${ }^{\text {th }}$ dynasty, approx. $12^{\text {th }}$ to $11^{\text {th }}$ centuries B.C.) with the entrance of the Sea Peoples in Egypt (Nibbi 1975). That the eastern delta is where most of the population lived is measured by the wealth of cities that were built in the early New Kingdom in that region. Thus, it is in the eastern delta that we should expect to find the two supply cities if they existed.

\section{Raamses, the City}

Mentioned only in Exod. 1:11, Raamses (Heb. ra'aměsēs) was one of two supply cities built by the Hebrews for the Egyptians, seemingly immediately after they were pressed into slavery. A similar name "Rameses" appears four times in the Hebrew Scriptures (Gen. 47:11; Exod. 12:37; Num. 33:3-5; Heb. ra ěmĕsēs) as the land from which the Hebrews lived and began the Exodus. The assumption that these two toponyms 
both refer to the city that the Hebrews built may have caused confusion in locating the launching point for the Exodus event. However, that they do not refer to the same location is clear in the text where one is the name of a city (Exod. 1:11) and the other the name of a land (Gen. 47:11). The spelling of the two names are similar but not identical, with the vowel pointing, indicating that the Masorites understood that they were pronounced slightly differently. Thus, it is first important to review what is known about the possible location of the city of Raamses that the Hebrews were building and then briefly review what is known about the possible location of the land of Rameses where the Hebrews were living.

In the early $18^{\text {th }}$ Dynasty (approx. $16^{\text {th }}$ to $14^{\text {th }}$ centuries B.C.), there were two military supply cities built in the eastern delta that serviced the two main routes in and out of Egypt in relation to the Levant (Holladay Jr. 1982: 1; Redmount 1989: 1): one was located at Tal ed-Dab’a (currently under excavation by Manfried Beitak), in the northeastern delta (the former capital of the Hyksos when it had been called Hwt-Wart or “Avaris;” Snape 2014: 202) and the other at Tal er-Retabah (currently under excavation by Slawomir Rzepka and Jozef Hudec) in the Wadi Tumilat, which was a frontier fortress (Redmount 1989: 212, 306) called “Pi-Tum” (see Pithom below).

The northern capital during this time appears to have been at Tal ed-Dab’a. But excavation has shown that before the large 13-acre palace was built (during the reigns of Hatshepsut and Thutmose III) at Tal ed-Dab’a (Bietak 2005a, 2005b, 2007: 13-43;

Bietak et al. 2001; Bietak and Forstner-Müller 2003, 2005; Snape 2014: 203), “significant storage facilities and military camps" (Beitak 2017: 60) were built here. As such, during the time of the Exodus (most likely either in Thutmose III's or Amenhotep 
II's reign) the northern capital was at Tal ed-Dab'a and it was a supply city for the purpose of military planning to attack the Levant either by ship or by land along the coast (Spalinger 2005: 52-58; 112). In fact, it appears from the war reports that Thutmose III's policy of using the sea to both transport soldiers and to supply the army on campaign was new (Spalinger 2005: 58). However, his son, Amenhotep II, was the last king to live at this site, which was then abandoned until the last king of the $18^{\text {th }}$ Dynasty, at which time Horemheb, built significant fortifications built here (Bietak 2017: 60-61). By then, or perhaps because of that (Bietak 2017: 61), the sea port at Tal ed-Dab’a (that had been able to hold a hundred ships) was unusable as a major port, having silted up.

Seti I, two kings after Horemheb, returned to this area (where his family was actually from; Snape 2014: 203). Unable to use Tal ed-Dab’a for the purpose it had been used before, Seti I began construction of a city for similar use about $2 \mathrm{~km}$ downstream (thus closer to the Mediterranean) at modern Qantir (Hamza 1930: 64; Boreux 1932: 410; Hayes 1937: 5-7, 17, 29-30; Habachi 1974, 2001: 51-53, 69, 107, 123-26, 130-32, 14143, 186, 210, 229-30, 254). His son, Ramesses II (“the Great”) continued building that city. He or his father named it Pi-Ramesses-Mery-Amun-Aa-Nehtu (pi-r'mss sw mry imn '3 nhtw meaning “The House of Ramesses, Beloved of Amun, Great of Victories;” Snape 2014: 202). According to the Papyrus Anastasi II and archaeological efforts, it is know that the eastern part of the city was residential with gardens, the western part had a large temple to Amun-Ra-Harakhty-Atum, and the southern part contained the palace and a barracks for the elite chariot corps (Snape 2014: 204-05). Later, during the late $20^{\text {th }}$ Dynasty (approx. $12^{\text {th }}$ to $11^{\text {th }}$ centuries B.C.), Qantir had silted up and a new city with a 
harbor was built even farther downstream at Tanis or San el-Hagar (Snape 2014: 204; Bietak 2017: 63).

The great city of Perunefer was the military supply city and northern capital of Thutmose III and Amenhotep II according to a papyrus in the British Museum (BM10056), which dates to the 51 $1^{\text {st }}$ year (Bietak 2017: 65) of Thutmose III (who ruled for about 54 years). This was also where Amenhotep II spent much of his life as crown prince and also as king (Glanville 1931: 121, 1932: 30, 36). However, the name "Perunefer" has not been discovered through archaeological efforts to date at any site. As a result, there has been a sizable debate through the years (Badawi 1948: 34-36, 55-63, 137-39; Glanville 1931: 109, 1932; Helck 1939: 49-50, 1971: 160, 166, 356-57, 447-48, 454-56, 460, 471, 473, 501; Jeffreys and Smith 1988: 61; Edel 1977: 155; Kamish 1985, 1986; Der Manuelian 1987: 159; Säve-Söderbergh 1946: 37-39; Stadelmann 1967: 3235; Zivie 1988: 107; Forstner-Müller 2014; Spiegelberg 1927; Daressy 1928; Habachi 1974, 2001: 9, 106-07, 121; Collombert and Coulon 2000: 217; Pumpenmeier 1998: 8993; Röhrig 1990: 126-27; Bietak 2005a, 2005b, 2009a, 2009b, 2010a: 165-69, 2010b: 19-21, 2017; Dorner 1999: plan 1; Forstner-Müller 2009; Forstner-Müller et al. 2007, 2010; Tronchère et al. 2008; Tronchère 2010) suggesting two locations. Many felt that Perunefer should be associated with Memphis (an ancient capital that was called Mennefer). On the other hand, more recently, because of the excavations and the development of better and more trustworthy techniques at Tal ed-Dab'a, it has become clear that Tal ed-Dab'a and not Memphis was in fact, the city of Perunefer (Bietak 2017: 57). The name only appears in ancient texts during the reign of Thutmose III and Amenhotep II and then disappears until it is again mentioned in the early $19^{\text {th }}$ Dynasty 
about the time that Seti I began building in the area. It is for the reason of this debate that some modern historians have claimed that Amenhotep II grew up in Memphis (Pritchard 1969: 246), while others say he grew up in Tal ed-Dab’a (Glanville 1931: 121, 1932: 30, 36; Bietak 2017: 65). Now it is known for certain that it was the latter.

It is thought that the name of the city at Tal ed-Dab'a was changed from Avaris around the time the Hyksos were pushed out. What it was called between then and when Thutmose III renamed it Perunefer, no one knows. However, that this was one of the supply cities that the Hebrews were forced to build seems quite likely. And if the Exodus event took place during the New Kingdom (either during the early $18^{\text {th }}$ Dynasty or $19^{\text {th }}$ Dynasty), this would have been the city where Moses and Aaron met with Pharaoh (either Thutmose III, Amenhotep II, or Ramesses II) to demand that the Hebrews be set free.

Many have suggested that the city of Ramesses II was the Raamses of Exod. 1:11. Others have suggested that it was a later gloss that reflects the name of the site as it was remembered by its last occupant. A third option is that "Raamses" was the name given to the city at Tal ed-Dab'a between when it was called "Avaris" and "Perunefer," which was the logical reason that Seti I give his new city, not far away, a similar name (PiRamesses). This would not necessarily mean that there was a cultural memory for why the city at Tal ed-Dab’a was called "Raamses."

\section{Rameses, the Land}

Genesis 47:1-6, 11, make it clear that the land that Jacob settled in with his family was called by two names “Goshen” (vv. 1, 4, 6, 27) and "Rameses” (v. 11). It is this very land where the Hebrews continued to live even up through the plagues (Gen. 
50:8; Exod. 8:22; 9:26) and the very land they left from during the Exodus event (Exod. 12:37; Num. 33:3, 5).

Some scholars believe that Goshen is the Asiatic name that reflects a familiar location in the southern Levant (Hoffmeier 1996: 121), which seems to be reflected elsewhere in the Hebrew Scriptures (Joshua 10:41; 11:16; 15:51; all of which are clearly not in Egypt). This makes "Rameses" (an obvious Egyptian name meaning, "born/conceived of Ra”) likely the Egyptian name for this same land. It is used in the Biblical text (indicated by spelling) only when the Hebrews settle and when they depart from Egypt. This seems to suggest that "Goshen” was the name that was more familiar to the audience for which Genesis and Exodus were composed. Used in this way, "Rameses" appears to be an example of the idiolect of the author (Coulthard 2004) and is one piece of forensic linguistics (meaning the search for linguistic clues that point to an author's idiolect; as used by Coulthard 2004) that suggests these two books (Genesis and Exodus) were written by the same author.

The land of Goshen/Rameses was not in the same location where Joseph lived and from which he administered the country, but it was close enough to take a chariot to go to it and it was uphill/upstream (Gen. 45:10; 46:28). It was a land where flocks and herds pastured, likely away from the Egyptian population (Gen. 46:34; 47:4, 27; Exod. 8:22; 9:26). It was a land that was a logical entry into Egypt from the southern Levant but not the most obvious route (Gen. 46:29; 47:1).

"There are only two easy land routes into Egypt from Syria-Palestine [the Levant]” (Holladay Jr. 1982: 1). The shortest route was north along the coast of the Mediterranean that slowly drops in elevation to the northeastern delta region and was 
used by the Egyptian military and caravans alike connecting Gaza with Tal ed-Dab’a (via Tal el-Farama [Pelusium], Tal Defenneh [Daphnia], and Qantir [Pi-Ramesses] Gardiner 1920; Holladay Jr. 1982: 1). A longer route connected the Negev with the Wadi Tumilat via the northern Sinai wastes. It is for this reason that the two supply cities were built in the early New Kingdom where they were. The Wadi Tumilat is uphill/upstream from Tal ed-Dab’a, the known northern capital at least from the $2^{\text {nd }}$ Intermediate Period.

There is a "tripartite topography" in the Wadi Tumilat that "appears to have had a significant influence on human occupation in the area: the three regions exhibit different historical settlement and use patterns,” (Redmount 1989: 27). During the Second Intermediate Period, Asiatic nomadic pastoralists moved into the central zone of the Wadi Tumilat, which appears to have been primarily used just for "pasturage or game hunting” (Redmount 1989: 35; see also Peet 1923: 79, 82). The central zone was an area that had sporadic lakes (Redmount 1989: 56) and the Papyrus Anastasi IV speaks of a fortress that allowed desert people to pass by to water their flocks at the "pools of Pithom [Pi-Tum],” (Peet 1923: 82) which, depending on the location of Pithom (see below), does suggest that the pasture land was in the central or western zones. However, the central zone was ideal for pastoring flocks (Redmount 1989: 56). Further, “[it] is conceivable that this clustering [of pottery sherds in the central zone] reflects a social or political grouping of some sort, perhaps a petty dynasty or a clan or both, that laid claim to territory in the Wadi Tumilat,” (Redmount 1989: 228) during the $2^{\text {nd }}$ Intermediate Period. It is entirely probable that these Asiatics either left with the Hyksos at the end of the $2^{\text {nd }}$ Intermediate Period or were moved to the western zone where Naville believed they lived as the Hebrews (Naville 1887: 20, 1903: 27) after they were put into bondage. 
It is for these reasons primarily that the Wadi Tumilat and/or land just to the west of it, is today (and has been) considered to be the logical location for the land of Goshen/Rameses (Naville 1903; Noth 1960: 112; Wright 1962: 61; May 1962: 58-59; Aharoni 1967: 179). The Wadi Tumilat was also the route out of Egypt for those who tried to escape for various reasons as reflected in Egyptian literature (Pritchard 1969: 1822; 259; 414-19; 444-46; Van Seters 1966: 18, 92). However, because of military restrictions, the only archaeological work (excavation or survey) done before 1977 (Holladay Jr. 1982: 5; Holladay excavated Tal al-Maskhuta from 1977-85) in the Wadi Tumilat was based on the work of Eduard Naville $(1887,1903)$ and William Matthew Flinders Petrie (1906:1, 28-34). Because of this, most of what was written about the Wadi Tumilat was speculative before 1976 (Holladay Jr. 1982: 4).

\section{Pithom, the City}

The Papyrus Anastasi IV quoted a frontier official that mentioned Pi-Tum, which linguistically is associated with Pithom (Bimson 1981: 40): "We have finished causing the Bedawi tribes of Edom to pass the fortress of Merenptah belonging to Theku towards the pools of Pithom [Pi-Tum] (of) Merenptah belonging to Theku, in order to feed themselves and to feed their flocks,” (Peet 1923: 82), and since Theku was believed to be in the Wadi Tumilat (at Tal al-Maskhuta), Peet recognized that the Wadi Tumilat was where Pithom was located (Peet 1923: 79). Naville believed from his work in the area that Goshen was in the western Wadi Tumilat or even a bit further north (Naville 1887: 20, 1903: 27).

Naville found bricks made without straw at Tal al-Maskhuta and thought they were from the time of the Exodus even though the text clearly says that the bricks were 
made with straw, but that they had to find the straw for themselves (Exod. 5:6-19). Naville thought that Tal al-Maskhuta was Pithom because he found the name "Pi-Tum" at the site, and explained that "tum" was in reference to a nome (Naville 1903: 5-6). Petrie thought Tal er-Retabeh was Raamses (Holladay Jr. 1982: 3) and his wife Hilda believed it was the capital of Goshen (Drower 2004: 178). It is now known that bricks were only made without straw in two periods of Pharaonic history: the Amarna period (and only at Akhetaten [Tal Amarna] where gravel was used instead of straw; Kemp 2012: 69) and in the Persian period (Morgenstein and Redmount 1998). However, Naville's identification is suspect since he only dug a few trial shafts (Drower 2004: 178).

It is now known that Tal al-Maskhuta was not occupied during the New Kingdom. Material culture from the late New Kingdom and Third Intermediate Period most likely were brought to that location at a later date (Snape 2014: 213). Archaeological evidence from the earliest efforts there show that the region of Theku $(\underline{T} k w)$ is at Tal al-Maskhuta. As a result this should probably to be associated with Succoth (Exod. 12:37; Holladay Jr. 1982: 3), which in the $2^{\text {nd }}$ Intermediate Period was only marginally settled by Asiatics associated with the Hyksos ethnically and chronologically (according to pottery sherds found their; Redmount 1989: 145, 177). Tal al-Maskhuta was abandoned in the early New Kingdom except for an Asiatic cemetery (Redmount 1989: 228, 231; Snape 2014: 213) and not occupied again until the Late Period (Holladay Jr. 1982; Redmount 1989: 148; Snape 2014: 213). Succoth, the first stop in the Exodus (Exod. 12: 37-38; Num. 33: 5-6) was therefore most likely east of the land of Goshen/Rameses since Egypt is generally west of the "promised land.” This fits with the Exodus event's list of toponyms 
since Moses collected Joseph’s mummy at Succoth before departing for Etham (Gen. 50:25-26; Exod. 13:19-20). Succoth was a region associated with booths, possibly related to shepherding (Gen. 33:17), but is also the name of a location in the Levant on the eastern side of the Jordan river (Gen. 33:17; Josh. 13:27; Judg. 8:5-16; 1 Kin. 7:46; 2 Chron. 4:17; Ps. 60:6; 108:7) indicating that it also might be a name from the southern Levant borrowed and used by the Asiatics living around Tal al-Maskhuta. Excavations at Tal al-Maskhuta demonstrate that it has a founding phase around 609 B.C. (much too late for an Exodus event; Holladay Jr. 1982: 19-20).

In fact, Tal er-Retabeh was the only occupied site in the Wadi Tumilat in the early New Kingdom (Goedicke 1987a: 93; Redmount 1989: 124; 176; Hoffmeier 1996: 120) and as such marked the eastern end of "Egypt” (Goedicke 1987b; Redmount 1989: 217) making it a frontier fortress (Snape 2014: 214) and supply city for the military. Because Tal er-Retabah was built in the early New Kingdom (during the early $18^{\text {th }}$ Dynasty Redmount 1989: 124; 176; 212; 306; Snape 2014: 214), there has been a move in scholarship to shift the identification of Pithom to Tal er-Retabah (Gardiner 1924; Lambdin 1962; Bietak 1975). Gardiner (1924) was the first to suggest this shift (Bimson 1981: 40) and argued that Tal al-Maskhuta should be identified at Theku of the Papyrus Anastasi IV (Bimson 1981: 41). Bimson said that most scholars by the early 1980's agreed with Gardner (Bimson 1981: 43) although there are some today who still suggest that Tal al-Maskhuta was Pithom (cf. Smoláriková 2008: 31; Snape 2014: 213).

Tal er-Retabah had a temple to Atum (Redmount 1989: 311; cf. Holladay Jr. 1982: 4), which is a better explanation for the name Pi-Tum ("house/domain of Atum") than that of Naville (Naville 1903: 5-6). It was surrounded by an enclosure wall $400 \mathrm{~m}$ 
by 200 m, with a massive western gateway (Snape 2014: 214). It was expanded during Ramesses II’s and III’s reigns (Snape 2014: 214).

\section{Conclusion and Direction of Study}

Most of the scholars who believe that the Exodus event was meant to have happened during the reign of Ramesses II point to Qantir as the location of the city of Raamses. Most of those who believe that the Exodus event was meant to have occurred during the reign of either Thutmose III or Amenhotep II point upriver about $2 \mathrm{~km}$ to Tal ed-Dab'a as the location of Raamses. Most now consider Tal er-Retabah to be the location of Pithom regardless of $18^{\text {th }}$ or $19^{\text {th }}$ Dynasty-dating, with the Land of Goshen/Rameses existing somewhere between them and Succoth located at Tal alMaskhuta.

Thus, in general, the culture to be evaluated in this study must come from Egypt during the New Kingdom. More narrowly, the culture most likely comes from the eastern delta region during either the early $18^{\text {th }}$ Dynasty or early $19^{\text {th }}$ Dynasty. Thus, the culture to be studied must come from a time no later than the New Kingdom and probably not later than the early $19^{\text {th }}$ Dynasty. Since this was a period of unification and Egyptian culture was somewhat standardized throughout the country by this point, evidence can come from any part of Egypt during this time period, but an eye should be focused on the eastern delta and the military supply cities built there. 


\title{
CHAPTER 3
}

\section{DESIGN ELEMENTS OF THE HEBREW TENT-SANCTUARY}

\author{
“[Modern renderings of the tent-sanctuary's] construction \\ [come] partly from the author's imagination \\ and largely from his...surroundings.”
}

(Wright 1899: 195)

The purpose of this chapter is to collect design data from the Hebrew Scriptures and organize them into usable sets that can be compared with the results of the statistical analysis conducted on the Egyptian design data sets of Chapter 5. This comparison will take place in Chapter 7.

The data collected in this chapter will only be concerned with the design elements of the Hebrew tent-sanctuary. For clarity, these data will be divided into two parts as delineated in Exod 25:9. The first will consider all design elements of the tent-sanctuary’s central structure, which was the tabernacle structure itself, and courtyard's perimeter barrier that surrounded it. The second will consider all design elements of the furnishings within the courtyard and the tabernacle.

\section{Design of the Courtyard and Tabernacle}

As stated in Chapter 1, in order to assess a cultural influence (intended or unintended) the design elements must be quantifiable. The first step (as laid out in 
Chapter 1) will be to examine the textual record for data regarding the design elements. This will include brief summations of scholarly opinion as examples of work that has been done in the past. These examples are not comprehensive but rather are representative and will not inform the data set except to show gaps in usable data in the text. These gaps will be addressed, as much as is possible, in Chapter 7. The second step will be to analyze these data. This will be done separately for the courtyard and tabernacle. The third step will be to organize them into usable data sets.

The purpose of this exercise is to identify, as precisely as is possible, what cultural design preferences are present in the design of the tent-sanctuary. The end goal is to produce statistics that can be compared with similar design elements in the archaeological record of Egypt in the New Kingdom. If some of these design preferences are comparable then it should be possible to suggest cultural influence. If cultural influence is present in some but not all elements, the reason will need to be ascertained. If none of the design preferences are comparable then it should be possible to suggest that the tent-sanctuary was unique in all aspects.

\section{Courtyard Textual Record and Analysis of Data}

The courtyard was to be defined by a perimeter of hangings held in place by pillars. The text is not clear on all aspects of this construction. Each element will be described as it is presented in the Hebrew text. This will be followed by a brief review of a few scholarly attempts to interpret the practical logistics of this description. An analysis of the data will then be presented. Analysis of materials used will be considered in Chapter 4. 


\section{Courtyard Perimeter}

The perimeter barrier was set up to be a physical barrier between the space inside and the armies camped outside (Num 2:1-34). The Levites were camped between the armies and the courtyard (Num 3:21-39). The hangings (Heb. māsāk) for the perimeter of the courtyard (Heb. hâș̣err) were to be five cubits high (Exod 27:18; 38:18) and made of fine woven linen so that the south side was one hundred cubits long (Exod 27:9; 38:9), the west side fifty cubits long (Exod 27:12; 38:12), and the north side one hundred cubits long (Exod 27:11; 38:11). The hangings on the east side were to be fifteen cubits on each side of the gate (Exod 27:14-15; 38:14-15) with the total length of the east side being fifty cubits (Exod 27:13; 38:13). These hangings were held up by silver hooks and silver bands on pillars, with the capitals overlaid with silver set on bronze sockets (Exod 38:17), twenty to the south, ten to the west, twenty to the north (Exod 27:10-12; 38:10-12), and three pillars, with their sockets on each side of the gate on the east side (Exod 27:14-15; 38:14-15; for more on the courtyard gate, see below). The text does not indicate if the hangings were fastened on the inside of the perimeter, the outside, or alternating in and out. The pegs (Heb. yâtêe $\underline{d}$ ) used all around the court (presumably to hold the rope needed to keep the hangings upright, although the text does not make this clear) were to be made of bronze (Exod 27:19; 38:20).

Strong surmised that the pillars described here were most likely round acaciawood columns (rather than squared pillars since this is how they are found in nature). Because round is a stronger architectural shape than square, he concluded that this must have been the shape (Appendix A, Figure 1) and estimated that at least about a fourth of a cubit in diameter, equally top to bottom, would be required for strength (Strong 1952: 
13). Zehr (1981: 33) did not agree but does not give a reason for his representation of them as squared pillars (Appendix A, Figure 2). Kiene (1984: 41) also imagined that the pillars were squared (Appendix A, Figure 3).

Strong imagined that the sockets were plates of metal that formed a foot base that was laid flat on the ground with a hole in them for the tenon to pass through, which would keep the pillar from rotating in the socket (Strong 1952: 13-14).

Strong also felt that the pillars were held upright by ropes, both inside and outside of the courtyard, connected to metal pegs (supposedly pegs with a head to keep the rope from slipping) that had been driven into the ground (Strong 1952: 14).

Both Strong and Zehr decided that the hangings must have rested on rods (which measured just under five cubits in length, acting like curtain rods) that kept the pillars equal distance apart and that the corners were where the entire line was braced (Strong 1952: 14; Zehr 1981: 32). Rods are not mentioned in the text but Strong equated them with the bands (Strong 1952: 15).

Strong imagined that the capitals were simply rounded plates of metal to protect the top of the poles as a cap (Strong 1952: 15). He also surmised that the hooks on the pillars were shaped like the Hebrew waw (१) presumably because the Hebrew word for hook is $w \bar{a} w$ (Strong 1952: 15).

Strong envisioned that the hangings were sheets of woven linen so that they formed a continual barrier wall "hung on the outside" of the poles but must have contained eyelets for the hooks so as to not tear them (Strong 1952: 15-16). Zehr speculated that the weaving must have been loose to allow the wind to pass between the threads (Zehr 1981: 32). The practical problem of wind has influenced the interpretation 
of the shape and nature of the entire structure of the tent-sanctuary (Epstein 1911: 574), and is an element that is not discussed in the text.

Cultural preference among design elements is not immediately obvious through units of measurement. Ratios often allow for repeated design preference to be identified. All units of measure in the record of the construction of the tent-sanctuary are in cubits. These can easily be converted to ratios that can then be compared with other ratios within the tent-sanctuary and then later (in Chapter 7) with ratios from the Egyptian context where applicable. This will be the practice for all elements of this study.

The courtyard perimeter barrier had a length of 100 cubits x five cubits high and a width of 50 cubits $x$ five cubits high providing a ratio of 2:1 (100:50), where two is the length and one is the width. This also provides a ratio of 20:1 (100:5), where 20 represents length and one is the height, a ratio of 10:1 (50:5), where the width is 10 and the height is one, and a ratio of 20:10:1 (100:50:5), where 20 is length, 10 is the width, and one is the height. Further, there were 20 pillars along the length (20 pillars spanning 100 cubits) and 10 pillars along the width (10 pillars spanning 50 cubits) producing ratios 5:1 (100:20) for the length and 5:1 (50:10) for the width. This strongly suggests that the pillars were spaced every five cubits so that the hanging between pillars would have the ratio of 1:1 (five cubits long by five cubits high), resulting in hangings of visible squares (visible inside or outside depending on how they were hung in respect to the pillars), 20 squares along the length and 10 squares along the width, a ratio of 2:1 (20:10).

Along the eastern width of 50 cubits, 20 of these cubits were taken up for the gate (see courtyard gate below). This is a 3:2 ratio $(30: 20 ; 30+20=50)$, with three as the 30 cubits not part of the gate (15 cubits on each side of the gate) and two as the 20 cubits (of 
the total 50 cubits for the entire width) as the gate. Thus, a 15:20:15 (or 3:4:3) ratio is produced for the eastern width. With three pillars on either side of the gate, a ratio of 5:1 (15:3) is produced, again suggesting that the hangings were visible squares (five cubits long by five cubits high), but it is unclear if these squares were visible inside, outside, or both, alternating (in which case the visible hangings would appear as squared rectangles).

The presence of sockets to hold up the pillars and the use of hooks, capitals, and bands on the pillars to hang the hangings do not provide detail as to how this was done, or the shape, size, or logistics. As a result, a simple measure of their presence is all that can be used statically.

\section{Courtyard Gate}

The gate (Heb. $\check{s} a$ 'ar) of the courtyard (east side) was to be a screen (Heb. $m \bar{a} s \bar{a} k$ ), twenty cubits long, made of woven linen (blue, purple, and scarlet thread), five cubits high, and hung on four pillars (Heb. 'ammûd) set on four bronze sockets (Heb. 'eden), with silver hooks (Heb. wāw), capitals (Heb. rō’š), and bands (Heb. hăǎšqu) (Exod 27:16-17; 38:18-19).

Strong imagined that the hangings that formed the screen for the gate were woven like the hangings of the perimeter except with superimposed embroidery so that the horizontal threads were white linen, while the vertical threads were alternating blue, purple, and red (Strong 1952: 16). As one piece and according to the way they were hung, Strong surmised that the only way entry would be allowed was to roll the gateway up to pass beneath it (Strong 1952: 16-17). What design was used for the embroidery is unknown, although Strong speculates intricate designs of shapes rather than images (Strong 1952: 16 note). Kiene agreed and created a design (not reflecting anything in the 
text) to represent this (Appendix A, Figure 4).

A 20 cubit by five cubit screen, hung on four pillars allows for a variety of possibilities unless it can be determined that the four pillars were evenly spaced.

However, as described, a ratio of 4:1 can be determined for the screen where four is the length and one is the height (see Appendix A, Figure 5). Further, there were four pillars along the length of the screen (four pillars spanning 20 cubits) producing a ratio of 5:1 $(20: 4)$

The presence of sockets to hold up the pillars and the use of hooks, capitals, and bands on the pillars to hang the screen do not provide detail as to how this was done, its shape, size, or logistics. As a result, a simple measure of their presence is all that can be used statistically. The presence of blue, purple, and scarlet thread is noted.

\section{Courtyard Statistical Analysis}

Regardless of the actual length of the cubit, certain design patterns can be determined through the use of ratios, which could be useful for comparison with the Egyptian design elements. Also, a careful analysis of the ratios leads to tentative conclusions regarding the spacing of the pillars.

The text states that there were 20 pillars on both the north and south sides and there were 10 pillars on the west side. On the east side, there were three pillars on either side of gate and four pillars for the gate, which equals 10 pillars on the east side $(3+4+3=10)$ matching the 10 pillars on the west. Since a length of cloth can only be hung as a wall between two or more pillars (meaning one pillar can only hang a cloth like a flag, because it takes at least two to stretch it out so that it provides a barrier), for that length of cloth to be five cubits each time (as the ratios suggest), 11 pillars would need to 
exist on the west and east sides (two of them shared corners with the north and south sides) and 21 pillars would be needed on the north and south sides (with two of them being shared corners on the east and west). Yet these are not the numbers provided in the text. This results in three possibilities that are reasonable.

The first possibility is that one corner pillar on each side was provided in the total for that side so that each side provided one of the four corner pillars (see Appendix A, Figure 6). The second possibility is that the north and south pillars were spaced wider than the east and west pillars so that the long sides provided all four corner pillars. Finally, the third possibility is that the east and west pillars were spaced wider than the north and south pillars so that the short sides provided all four corner pillars. Statistical analysis may suggest which of these is more likely.

In statistics, repeated ratios are strong evidence of pattern. The ratio of pillars to cubit as provided in the text was 5:1, meaning five cubits for every one pillar. This appears on all four sides (even the more complicated eastern side). This provided for a five cubit by five cubit section of cloth between pillars on all four sides, which is another pattern. Both of these strongly suggest that the correct understanding of the spacing of the pillars was that each side provided one corner pillar (the first possibility). This also strongly suggests, statistically speaking, that the spacing was uniform. The ratio of 2:1 for the length and width of the perimeter also matches the proposed ratio (2:1) for the visible hanging squares (between pillars), further supporting this evenly spaced theory. Squares would have been the visible shape if the pillars were all on the inside or all on the outside of the perimeter. Squared rectangles (meaning the longer side of the rectangle is equal to twice the length of the short side) would have been the visible shape if the pillars were 
alternated inside and outside. The ratio 5:1 still is applicable regardless of the visible shape.

The use of sockets and pegs to hold up the pillars was true for all four sides (including the courtyard gate itself). The use of hooks to hold up the hangings was also true for all four sides. Capitals and bands were also present on the pillars.

The text does not describe how the hangings allowed wind to pass through, how the hangings avoided tearing on the hooks, how the pillars were connected to the pegs, or the shape of any of these items. The presence of blue, purple, and scarlet thread is noted but the design is uncertain, as was the function of the gate screen. Some of these will be addressed in Chapter 7.

Tabernacle Textual Record and Analysis of Data

The tabernacle was to be constructed with a frame of acacia boards overlaid by two layers of curtains and that overlaid by two layers of skins. The text is not clear on all aspects of this construction. Each element will be described as it is presented in the Hebrew text. This will be followed by a brief review of a few scholarly attempts to interpret the practical logistics of this description. An analysis of the data will then be presented. Analysis of materials used will be considered in Chapter 4 so will not be done here.

\section{Tabernacle Frame}

The frame of the tabernacle was to consist of boards (Heb. qereš) standing upright at ten cubits in height and one and one-half cubit in width held together by two tenon joints (Heb. $y \bar{a} d$ ), each (Exod 26:15-17; 36:20-22) overlaid with gold (Exod 26:29; 
36:34). The text does not indicate how the gold overlay was attached to the wood. There were twenty boards on the south side (Exod 26:18; 36:23), six boards and two corner boards on the west side (Exod 26:22-25; 36:27-30), and twenty boards on the north side (Exod 26:20; 36:25). These boards were set on silver sockets, two to a board, so that forty were on the south side (Exod 26:19; 36:24), sixteen on the west side (Exod 26:25; 36:30), and forty on the north side (Exod 26:21; 36:26). The corner boards were to be coupled by a ring (Heb. tabba' $a t$ ) at the top and bottom (Exod 26:24; 36:29). All of the boards were further held in place by five bars (Heb. berrîah) on each side, with the middle bar passing through the boards end to end (Exod 26:27-28; 36:32-33). The practical logistics of this design are not described. Aside from the boards being overlaid with gold, the bars and the rings were made entirely of gold (Exod 26:29; 36:34).

Josephus stated that the tabernacle was 30 cubits long and 12 cubits wide (Josephus 3: §115). Some editors have tried to correct this down to 10 cubits because he also stated that the "height should be equal to its breadth” (Josephus 3: §116) but he did not give the height. He did say that the boards were 1.5 cubits wide and four fingers thick (Josephus 3: §116), something the text did not say. He says that the west wall had six boards that were fitted together so accurately that the "joints were invisible," which together made nine cubits (Josephus 3: §118-19). It is at this point that he is inconsistent with his earlier statement. He next says that the two corner boards were cut "out of one cubit,” which must be where the 10-cubit idea comes in spite of his earlier statement (Josephus 3: §119). Josephus also says that Moses separated the inside of the tabernacle into three parts (Josephus 4: §122), by which he almost surely means into thirds. He says that the "most secret end" had a depth of 10 cubits (Josephus 4: §122) and the rest of the 
space was 20 cubits (Josephus 4: §123).

The main disagreement regarding the frame of the Tabernacle concerns the total width intended in the Hebrew text. The text says that each board was one and a half cubits wide (Exod 26:15-17; 36:20-22). It goes on to say that 20 boards were on both the north and the south but only six and two corner boards on the west. General scholarly consensus (Comfort and Elwell 2001: 1235) is that the six boards were one and half cubits wide but that the two corner boards had a different width that is not stated in the text and must be deduced by the scholar. Friedman (1980), for example, discusses the possibility of overlapping the boards (Appendix A, Figure 9) in order to shorten the tabernacle to give it the needed ratio Wellhausen postulated (Alexander 2017: 556-65). Wellhausen proposed that the tabernacle was exactly half of the size of Solomon's temple (on Wellhausen's theory, see Chapter 1). It should be noted that the text does not suggest the possibility that the boards were overlapped. Homan also refuted Wellhausen's ratio theory (Homan 2000) upon which this notion was based. However, this theory persists in general tabernacle scholarship today.

Hoffmeier (2005: 198) declared that the text did not reveal the actual dimensions of the tabernacle. This is, of course, true if by this Hoffmeier meant that it did not give final summation for the western side. Generally, it is maintained by scholars that the tabernacle was only 10 cubits wide, which Hoffmeier, for example, says has "always been assumed” (Hoffmeier 2005: 198, 200). Friedman wanted to make the tabernacle only six to eight cubits wide by 10 cubits tall and only 20 cubits long so that it could have fit inside the Most Holy Place of Solomon’s Temple (Friedman 1980: 245), a position, his student Homan strongly supported (Hoffmeier 2005: 200). While Hoffmeier didn’t 
agree with this notion, he did recognize a similar "idea of transferring the holiness of one sanctuary to another" in Egypt (Hoffmeier 2005: 203).

It is appealing for structural reasons to consider doubling the corner, however, there is nothing in the text that demands such an understanding. Even if the corner was not doubled, there would still have been an overlap (one way; Appendix A, Figure 10; or the other; Appendix A, Figure 11) of the thickness of the board on the west end. But since the text does not indicate the thickness of the boards there is no way, beyond speculation, to know how much this was or in which way there was an overlap (lengthwise or widthwise). If, as is assumed, the six boards were one and a half cubits wide and the two corner boards were not, this would provide only nine of the cubits needed to get to the desired 10 cubit-width. The two corner boards could then only account for a half cubit each.

Although an older study, Strong examined every detail of the text exhaustively. He correctly pointed out a practical consideration that is often overlooked. The boards had to have some thickness and this would add to either the length or the width of the frame. Strong believes that the Hebrew word for boards (Heb. qereš) provided a potential solution. He felt that the Hebrew word indicates that these were unworked planks that were rough and simply cut logs, not flat boards (Strong 1952: 21 note). He also felt that this design would have provided strength for the weight of the coverings, avoided gaps in the corners (Appendix A, Figures 7 and 8), and explained the odd verbiage in the text. The result was that Strong concluded that each board was $1 / 6^{\text {th }}$ of a cubit thick (Strong 1952: 22), although the text does not state this.

Based on this belief, Strong imagined that the sockets were bases or feet for the 
boards that were a $1 / 2$ cubit square and $1 / 6^{\text {th }}$ of a cubit thick based on the cubic inches of silver available and their weight, evenly divided into the specified number of sockets (Strong 1952: 23-24), the size also allowing for a uniform placement of all sockets (Appendix A, Figure 12). Zehr believed that this would have created an almost continuous silver platform below the boards based on a breakdown of the amount of silver collected (Zehr 1981: 60). Kiene agreed with Zehr and worked out a model to reflect this (Appendix A, Figure 13).

Strong imagined that the middle bar was really "three series of bars" that ran through the rings that were stapled to the boards (Appendix A, Figure 7), with only the middle of the three running the entire length and all about $1 / 4$ of a cubit thick (Strong 1952: 25). This dimension is entirely fabricated and one that Epstein earlier rejected as entirely “unworkable,” since it didn’t fit with the description of the text (Epstein 1911: 575-76). Also unhelpful is his belief that the wood structure was held up by ropes and stakes (Strong 1952: 25-26) of which the text says nothing. That the bars were used for ease in construction, to keep the boards together, seems the obvious intent (Appendix A, Figure 14). That the middle bar passed inside the boards is one way of understanding the text (Appendix A, Figures 15 and 16).

Strong supported the peaked-roof frame design in words but not illustrations, pointing out that modern Bedouins (Appendix A, Figure 17) peak their tent roofs (Strong 1952: 26-32), to which he added that there must have been more tent-poles than the text mentions for this purpose (Strong 1952: 32).

It is the silver sockets that may provide some insight into how the boards on the western side should be understood. The Hebrew text says that there were two sockets for 
each board (Exod 26:19, 21, 25) and this included those on the west side. I believe the confusion rests on how the text has been separated into modern verse numbers. Exodus 26:22 simply says that there should be six boards for the west side. The very next sentence (Exod 26:23) states that there should be two corner boards. This easily can explain why so many scholars could overlook what is said two verses later. Exodus 26:25 says that there were eight boards (the reader is left to assume that this means the six western boards mentioned in verse 22 plus the two corner boards of verse 23). Under each of these eight boards should rest two sockets for each board, which the author of the text totals for the reader as 16 sockets (Exod 26:25).

A ratio then can be established for the sockets of 5:2 (40:16), where five represents the length and two is the width for the number of sockets because there were 40 sockets on the long sides and 16 sockets on the narrow (or width) side of the tabernacle. This also provides a ratio that can be used in analyzing the boards. Thus, the ratio for the tabernacle (length to width, see Appendix A, Figure 3) itself is 5:2 (20:8), where 20 boards represent the length and eight represent the number for the narrow (width side). Without knowing the exact dimensions of the sockets, all that can be established from the text is the ratio of 2:1 (two sockets for each board). The boards have a ratio of 20:3 (10:1.5), where 20 is the height and three is the width (see Appendix A, Figure 18). The boards are each described as being 1.5 cubits wide and it is clear from the sockets that eight boards spanned the width. Thus, one way to understand this would be to give a total of 12 cubits for the narrow side of the tabernacle. The same formula yields a total of 30 cubits for each length (north and south; 20 boards each). Thus, statistically speaking, the tabernacle frame of 30 cubits (length) by 12 cubits (width) by 10 cubits 
(height) had a ratio of 15:6:5 (30:12:10; slightly over a 3:1:1 ratio). This will be the dimensions used in this study. Any other width (six, eight, or the most commonly believed 10 cubits), must be produced using other means of interpretation. The presence of tenon joints, sockets, rings, and bars without dimensional data restricts statistical analysis to just measuring their presence.

\section{Tabernacle Screen}

A screen (Heb. $m \bar{a} s \bar{a} k$ ) of woven linen (Heb. šëš), using blue, purple, and scarlet thread, was to be a barrier on the east side at the entrance to the tabernacle (Exod 26:36; 36:37). It was to be hung on five gold hooks, one each on an acacia-wood pillar (five total) itself overlaid with gold and set up on a bronze socket (five in total) (Exod 26:37; 36:38). How the gold was attached to the pillars is not described in the text.

Josephus says that the screen was in every way just like the veil in "magnitude and texture and color” (Josephus 4: §127). He also says that it hung by rings attached to the corner of every pillar so that it hung "top downwards half the depth of the pillars, the other half affording an entrance for the priests, who crept under it” (Josephus 4: §127). He then makes a strange statement about another veil of linen that was placed over it but that could be drawn aside to protect it in the event of snow (Josephus 4: §128-29) and that this was a design that was retained as a custom in the temple-sanctuary later (Josephus 4: §129). This veil of linen is not to be confused with the linen covering which he discusses next. This veil of linen is an element he introduced that is not mentioned in the text.

On the basis of the materials and description, Strong believes that the entrance screen for the tabernacle was of similar design to that of the screen (Heb. $m \bar{a} s \bar{a} k$ ) at the 
entrance gate (Heb. $\check{s} a{ }^{\prime} a r$ ) to the courtyard (Strong 1952: 33). Zehr likens the pillars to those found in the Levant and Egypt (Zehr 1981: 66). Kiene (1984: 86) provided an example of possible designs (Appendix A, Figure 19).

The width of the tabernacle on the east end was certainly equal to the width on the west end (if the courtyard perimeter design is an indication). If this is correct then the width would have been 12 cubits. Thus, the ratio of pillars to cubit would have been 12:5, so that 12 is the cubits and five is the pillars. There is no data for the dimensions of the screen itself. It is presumed that it must have at least spanned the width of the east end, but the height is unknown. The presence of sockets to hold up the pillars and the use of hooks on which to hang the screen do not provide detail as to how this was done, or its shape, size, or logistics, and so a simple mention of their presence is all that can be measured statically. The presence of blue, purple, and scarlet thread is also noted.

\section{Tabernacle Linen Cloth Layer}

Over the wooden frame there was to be a woven layer composed of ten linen cloth curtains, each of woven linen (blue, purple, and scarlet thread) and decorated with artistic designs of cherubim (Heb. kěrûb) (Exod 26:1; 36:8). The dimension of each linen cloth (Heb. yề ' $\hat{a}$ ) was to be twenty-eight cubits by four cubits (Exod 26:2; 36:9). The linen curtains were to be coupled together along the long ends in two groups of five (see below) (Exod 26:3; 36:10). The two sets were to be joinable by a series of fifty loops (Heb. lûla' 'â) and fifty gold clasps (Heb. qeres) (Exod 26:4-6; 36:11-13).

Josephus claimed that the ten curtains were joined together so neatly that it appeared to be only one curtain (Josephus 4: §130). This curtain, he stated, came within a cubit of the ground, hanging down the sides (Josephus 4: §130). 
Strong interpreted this layer as being interior hangings (Appendix A, Figure 20) and worked out some construction ideas to explain how this might have worked (Strong 1952: 33-40). Another idea is that the linen cloth layer was the tabernacle, while the hair layer was the Tent, which has led some scholars to suggest two different shapes with the hair layer being peaked; this later idea is rejected by Zehr (1981: 70). Neither of these ideas are supported by the direct language of the text.

Since the curtains can only be attached along the long ends of the individual strips to cover the tabernacle, the ten curtains must have had a final dimension (when coupled together) of 28 cubits by 40 cubits. Since the 28 -cubit side would not cover the 30 cubits of length of the tabernacle frame (see above) the 28-cubit long side must have actually served as the width when covering the tabernacle and the 4-cubit short side must have served the length when covering the tabernacle. In this way, individually, the curtains each had a ratio of 1:7 (4:28), where one is the length, and seven is the width (which seems counter initiative at first, yet is born out in the design). Coupled by fives (see Appendix A, Figure 21 for only one of the two groupings of five strips), each coupling had a ratio of 5:7 (20:28), where five is the length, and seven is the width. The linen cloth layer had a ratio (when the two sets of five strips were coupled) of 10:7 (40:28), where 10 is the length, and seven is the width. In this way, it can easily be seen that in describing the curtain in this way (individual curtain, coupled curtains, and entire curtain layer) in the text, it had a ratio of 1:5:10.

Fifty loop/clasp combinations for every width (long side of a single strip, which was 28 cubits) has a ratio of 25:14, because every 14 cubits, 25 loop/clasp combinations were fastened. Without dimensions for their exact size or shape, the loops and clasps can 
only be measured statistically by the frequency of their presence. The presence of linen is also noted and will be discussed further in Chapter 4. The presence of the design element of cherubim woven into the fabric is also noted but without more description, their exact shape and depiction is unknown, although it is possible that this design was connected artistically to the cherubim on the Mercy Seat (see ark below). The presence of blue, purple, and scarlet thread is noted. How the curtain was connected (if at all) to the frame or how it was secured from slipping is also not described in the text. That it was not visible from anywhere except inside the tabernacle is evident from the lack of a ceiling for the frame and the covering of other layers above it (see below).

\section{Tabernacle Goat Hair Layer}

Over the linen curtains were to be eleven curtains made of goats' hair (Heb. 'ẽz) (Exod 26:7; 36:14). Each goat-hair curtain was to be thirty cubits by four cubits (Exod 26:8; 36:15). The goat-hair curtains were to be coupled together in two groups, one of five curtains and the other of six curtains, with the sixth curtain doubled over to serve as the forefront of the tent (Exod 26:9; 36:16). The two sets were to be joinable by a series of fifty loops and fifty bronze clasps (Exod 26:10-11; 36:17-18) so that the extra piece (half of a curtain) was to hang over in the back and the extra two cubits in length was to hang one cubit over on each side, so that the linen curtain combination was completely covered (Exod 26:12-13).

Josephus claimed that the hair curtain "extended loosely down to the ground" (Josephus 4: §131). Modern Bedouin still make tents from weaving goat’s hair in a way that seems similar to what is described here, by fastening strips together, and Strong goes 
to great lengths to work out how this might have been done for the tent-sanctuary (Strong 1952: 27-32).

Since the curtains can only be attached along the long ends for this to in any way cover the tabernacle, the eleven curtains must have had a final dimension (when coupled together, and the last 4-cubit length doubled back) of 30 cubits by 42 cubits (rather than 44 cubits because of the doubling of the last strip). Since the hair layer was to extend past the linen layer by one cubit on all sides, the 30-cubit long end must have been the width and the 4-cubit short end of each curtain strip must have been the length. Thus, each goat hair strip was four cubits by 30 with a ratio of 2:15 (4:30), where two is the length and 15 is the width. The coupling of five had a ratio of 2:3 (20:30) and the coupling of six (see Appendix A, Figure 22 for only one of the two groupings - the one with the extra strip) had a ratio of 11:15 (22:30). In this way, the goat hair layer had a ratio (when all eleven sections were coupled) of 7:5 (42:30), where seven is the length, and five is the width.

Fifty loop/clasp combinations for every width yields a ratio of 5:3 (50:30), so that every three cubits, five loop/clasp combinations were fastened. With dimensions not given, the loops and clasps can only be measured by their presence. The presence of goat hair layer is also noted and will be discussed further in Chapter 4. Also noted is the design element of a one-cubit extension of a covering layer over the inner layer. How the curtain was connected (if it was at all) to the linen layer or how it was secured from slipping is also not described in the text.

\section{Tabernacle Skins Layers}

Above the goat-hair curtain combination were two layers of skins; the first a layer 
of skins (Heb. 'ayil 'ôr) dyed red and the second, another layer of skins (Heb. tahaš 'ôr) above that (Exod 26:14; 36:19).

Josephus stated that the skins were added as protection from the heat and rain (Josephus 4: §132). He claimed that these layers also reached down to the ground and further claimed that, very curiously, "great was the surprise of those who viewed these curtains at a distance, for they seemed not at all to differ from the color of the sky” (Josephus 4: §132), a statement that needs some interpretation, for it is not at all clear how this could be possible. Strong thought that the outer layer of skins was fastened to the wood frame (Strong 1952: 26). This seems difficult to understand since the frame was covered by both the linen cloth and goat hair layers.

No dimensions were supplied for either of the skin layers except that the first was to be above the hair layer and a second skin layer covered the first skin layer. Thus, their presence is all that can be noted statistically. Both will be discussed further in Chapter 4. How they were secured from slipping or how they were fastened (if at all) to the layers below each is not described in the text.

\section{Tabernacle Veil}

A veil (Heb. porōket) of woven linen (blue, purple, and scarlet thread) and decorated with artistic designs of cherubim (Exod 26:31; 36:35) was to be used as a divider between the Holy Place (Heb. qōdeš) and the Most Holy Place (Heb. qōdeš haqŏdāšîm) (Exod 26:33). It was to be hung on four gold hooks, one each on an acaciawood pillar with a total of four, each overlaid with gold and set up on a silver socket (four in total) (Exod 26:32; 36:36). How the gold was attached to the wood pillars is not described in the text. 
Josephus stated that the veil was "ten cubits every way," that was "spread over the pillars” (Josephus 4: §125) which is a curious statement that requires interpretation. Strong felt that the veil was similar in design to the tabernacle screen in that it was a single sheet hung in a straight line across the room as a divider between the two spaces. He reached this conclusion since the way it was to be suspended resembles both the screen and gate hangings (Strong 1952: 51-53), both of which appear to be hung in a straight line across a space. Zehr believed that the four poles used in connection with the veil were unevenly spaced, so that the gap between the two in the center were the widest (Zehr 1981: 69) although the text does not indicate the spacing. The assumption that it was a hanging curtain appears to be traced back to a tradition in the rabbinic period but the Greek word used in the LXX (katapetasma) and statements in the Talmud (b. Sukk. 76) seem to agree with the way it is described in other parts of the Hebrew text (Exod 40:3, 21; Num. 4:5; cf. Ps 27:5) that have led other scholars to see the veil as a pavilion or canopy inside of the Tabernacle (Friedman 1992: 295). Kitchen (2000) has suggested that the four pillars were set up as four corners so the veil was a canopy around and over the ark, making this space the Most Holy Place.

Since no dimensions are provided in the text, the simple presence of a veil can only be noted statistically as present or not present. This means that in frequency analysis this will be marked as simply needing to be present in the archaeological record. That is the most basic of analyses. The presence of blue, purple, and scarlet thread is also noted. The presence of the design of cherubim is also noted but without more description, their exact shape and depiction is unknown, although it is possible that this design was connected artistically to the cherubim on the Mercy Seat (see ark below). Also noted is 
the use of hooks and pillars to hang the veil. How the pillars were secured or attached to the frame (if at all), and the shape of the pillars and hooks is not described in the text.

\section{Tabernacle Statistical Analysis}

A pattern of 5:2 was discovered in the ratio of boards on the long and short side of the tabernacle and the sockets that held the boards up on the long and short sides was also 5:2. Because of the wording of the text regarding the west side of the tabernacle, there has been confusion as to how long it actually was (with the two corner boards providing room for interpretation). However, the exact same ratios for boards and sockets strongly suggest statistically, that the two corner boards on the west side were the same width as all the other boards (1.5 cubits). Combined with the statement that two sockets were set to hold up each board and there were 16 sockets for the west side and eight boards, leads to the tentative conclusion that the tabernacle frame was $30 \times 12$ cubits (a ratio of 15:6). When combined with a height of 10 cubits, the tabernacle was three times longer than it was tall and nearly the same height as it was wide. This is contrary to the scholarly consensus that the tabernacle was only 10 cubits wide (see above).

Because the text specifically says that the hair layer was to be one cubit longer and wider than the linen layer (see Appendix A, Figure 23), so that the linen layer was completely covered by the goat hair layer, there can be no statistical allowance for alternate understandings of how they were hung. In order for this to be accomplished, both woven layers had to be stretched out over the frame.

Further, the controversy over peaked or flat roof is settled as far as statistics are concerned. To get a peaked roof, proponents of this design must add pillars that do not exist in the text. The absence of pillars at any point in or around the frame itself, except 
for the hanging of the screen and veil, is a strong statistical indicator that the roof of the tabernacle was flat and not peaked.

The tabernacle frame had a width of 12 cubits (see above for discussion) and the woven layers that were to cover it had a width of 28 cubits and 30 cubits each (linen and hair respectively). This means that eight cubits were left on either side of the tabernacle for the linen layer and nine cubits for the hair layer. Since the tabernacle frame's boards were 10 cubits tall, neither woven layer would have reached the ground. On the other hand, the tabernacle frame was 30 cubits long and the linen and goat hair woven layers were 40 cubits and 42 cubits long respectively. If the reading of the $11^{\text {th }}$ goat hair woven strip (that was to be doubled over) has the meaning that it was to be the only portion to fall over the front face of the tabernacle, while still entirely covering the linen layer with one cubit to spare on all sides, then the linen layer would have extended nine cubits over the back and the hair layer 10 cubits, potentially reaching the ground (unless it was staked away from the frame at an angle, of which the text says nothing) depending on the width of the boards and how they were coupled at the corners. The text also says very little about the two layers of skins so nothing is known regarding how they were constructed or how they were connected to the structure.

Without statistical data (which is not inherent in the text) to work with, the four pillars that held up the veil could easily be understood either as just spanning the width of the tabernacle or as four corners to make the veil a canopy. Either interpretation is allowable in the text without more data regarding the length and height of the veil.

The use of sockets to stand the pillars up and the use of hooks to hold up the screen and veil are all mentioned. The text does not describe how anyone was to pass 
through, how the hangings avoided tearing on the hooks (eyelets?), what held up the pillars, if they were connected to the frame in some way, or the shape of any of these items. The text also does not describe the overlapping that must have occurred to some extent in the corners of the frame or how the gold was attached to the frame and pillars. The design of cherubim on the linen cloth layer and on the veil is also not mentioned in the text. Some of these logistical concerns will be addressed in Chapter 7, in the discussion at the end of the study. The presence of blue, purple, and scarlet thread is noted in some of the linen cloth features.

\section{Statistical Data Grouping}

In order for the data to be useful for comparison, they must be grouped into data sets. One set will be used for the ratios discovered in the text's description. A second set will be used for woven layers manufacturing preferences. A third set will be used for the presence of repeatedly-appearing items, which indicate frequency.

Table 1 contains the ratios within the text. These data will be useful for comparison with items discussed in Chapter 5.

Stem-and-leaf plots (Tables 2 and 3) checks for patterns of size (length and width) to determine if there is a typical range (determined by stems that cluster in greater 


\section{Table 1. Tabernacle ratios}

\begin{tabular}{lll}
\hline Item & Cubits & Ratio \\
\hline Courtyard perimeter length, width, height & $100 \times 50$ x 5 & $20: 10: 1$ \\
Courtyard perimeter length and width & $100 \times 50$ & $2: 1$ \\
Courtyard perimeter length and height & $100 \times 5$ & $20: 1$ \\
Courtyard perimeter width and height & $50 \times 5$ & $10: 1$ \\
Courtyard perimeter between pillars length and height & $5 \times 5$ & $1: 1$ \\
Courtyard gate & $20 \times 5$ & $4: 1$ \\
Courtyard gate/non-gate & $20 \times 30$ & $2: 3$ \\
Courtyard non-gate/gate/non-gate & $15 \times 20 \times 15$ & $3: 4: 3$ \\
Tabernacle boards length and width & $20 \times 8$ & $5: 2$ \\
Tabernacle sockets length and width & $40 \times 16$ & $5: 2$ \\
Linen cloth length and width & $40 \times 28$ & $10: 7$ \\
Linen cloth strips length and width & $4 \times 28$ & $1: 7$ \\
Linen cloth five strips length and width & $20 \times 28$ & $5: 7$ \\
Goat hair length and width & $42 \times 30$ & $7: 5$ \\
Goat hair strips length and width & $4 \times 30$ & $2: 15$ \\
Goat hair group five strips length and width & $20 \times 30$ & $2: 3$ \\
Goat hair group six strips length and width & $22 \times 30$ & $11: 15$ \\
Courtyard perimeter length and pillars & 100,20 & $5: 1$ \\
Courtyard perimeter width and pillars & 50,20 & $5: 1$ \\
Courtyard non-gate length and pillars & 15,3 & $5: 1$ \\
Courtyard gate length and pillars & 20,4 & $5: 1$ \\
Linen cloth loop and clasps/width & 50,28 & $25: 14$ \\
Goat hair loop and clasps/width & 50,30 & $5: 3$ \\
Courtyard hanging visible squares & 20,10 & $2: 1$ \\
\hline
\end{tabular}

Table 2. A stem-and-leaf plot of the length of the woven strips

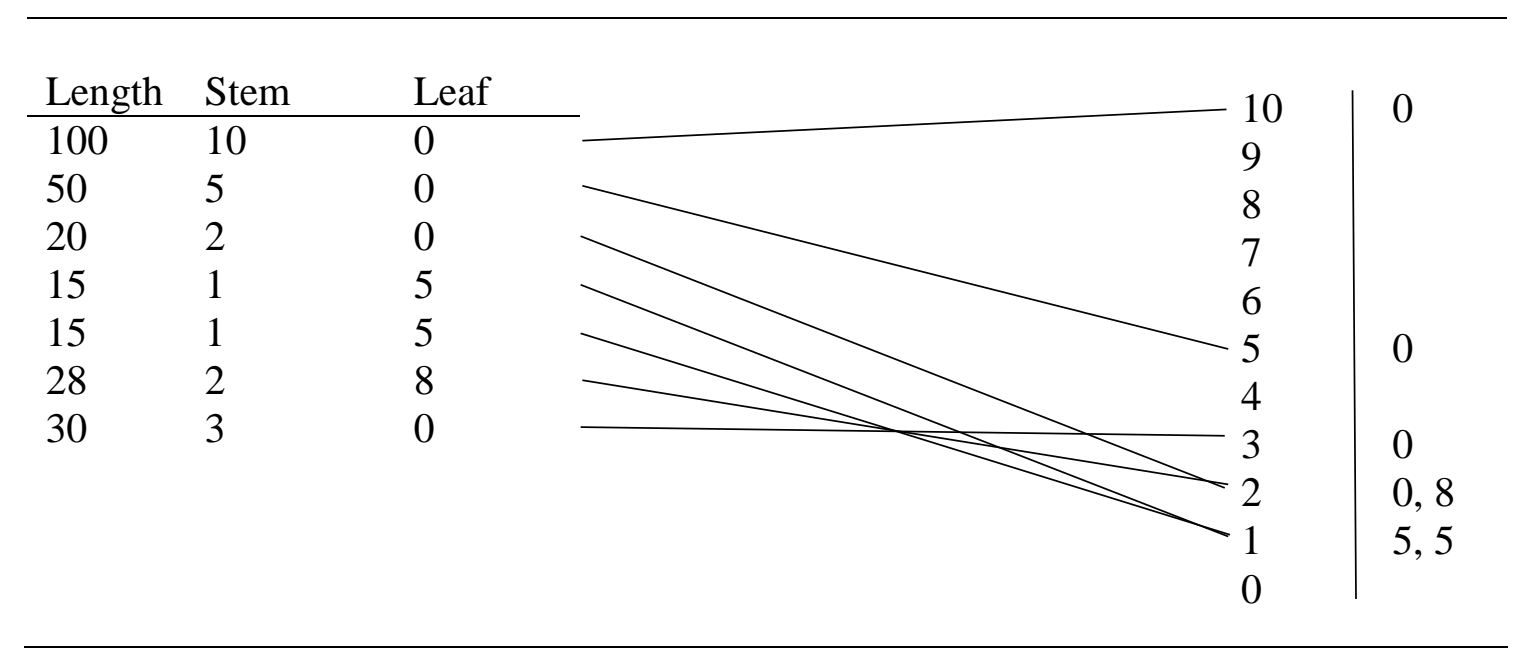


Table 3. A stem-and-leaf plot of the width of the woven strips

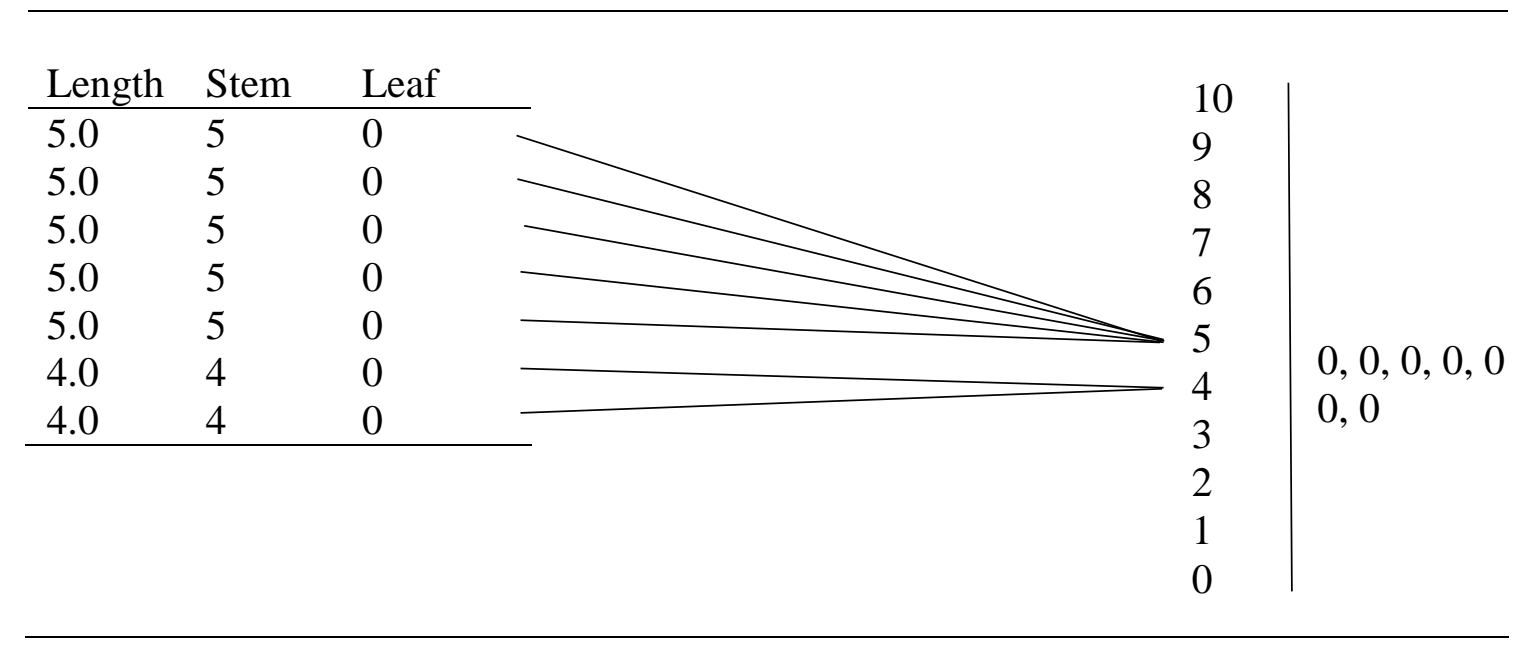

quantities from other stems) from which the woven strips may have been manufactured, using data from Table 1. Stem-and-leaf plots are a basic statistical tool (Drennan 1996: 4; see Chapter 1) that is made by splitting each data value into a "stem" (the first digit or digits) and a "leaf" (the remaining digit or digits) to reveal patterns that are not easily recognizable while still in a simple list. These data will be useful for comparison with items discussed in Chapter 5.

Table 2 shows a bunching of numbers between the range of 15-30, weighted toward the lower end of this range. Table 3 shows a bunching of numbers between the range of four to five with the weight being toward the higher end of this range. Together they indicate a manufacturing preference of lengths between 15-30 cubits and widths between four to five cubits, with an allowance for longer lengths, but not widths.

Tables 4 and 5 reflects the frequency of repeated features that appear in the text. These data will be useful for comparison with items discussed in Chapter 5 .

Tables 4 and 5 illustrates that certain features are unique to specific elements. 
Table 4. Frequency of repetition in Features $A$

\begin{tabular}{lccccccc}
\hline Element & Pillars & Sockets & Hooks & Capitals & Bands & Pegs & Overlay \\
\hline $\begin{array}{l}\text { Courtyard } \\
\text { Perimeter }\end{array}$ & $\mathrm{X}$ & $\mathrm{X}$ & $\mathrm{X}$ & $\mathrm{X}$ & $\mathrm{X}$ & $\mathrm{X}$ & \\
Courtyard Gate & $\mathrm{X}$ & $\mathrm{X}$ & $\mathrm{X}$ & $\mathrm{X}$ & $\mathrm{X}$ & & \\
$\begin{array}{l}\text { Frame } \\
\text { Tabernacle }\end{array}$ & $\mathrm{X}$ & $\mathrm{X}$ & $\mathrm{X}$ & & & $\mathrm{X}$ \\
$\begin{array}{l}\text { Screen } \\
\text { Linen Layer }\end{array}$ & & & & & & $\mathrm{X}$ \\
$\begin{array}{l}\text { Hair Layer } \\
1^{\text {st }} \text { Skin Layer }\end{array}$ & & & & & & \\
$2^{\text {nd } \text { Skin Layer }}$ & & & & & & \\
Veil & $\mathrm{X}$ & $\mathrm{X}$ & $\mathrm{X}$ & & & & \\
\hline
\end{tabular}

Table 5. Frequency of repetition in Features B

\begin{tabular}{lccccccc}
\hline Element & $\begin{array}{l}\text { Board } \\
\text { s }\end{array}$ & $\begin{array}{l}\text { Tenon } \\
\text { Joints }\end{array}$ & $\begin{array}{l}\text { Couplin } \\
\text { g Rings }\end{array}$ & Bars & $\begin{array}{l}\text { Artistic } \\
\text { Cherubim }\end{array}$ & Loops & Clasps \\
\hline Courtyard & & & & & & \\
$\begin{array}{l}\text { Perimeter } \\
\text { Courtyard Gate }\end{array}$ & & & & & & \\
Frame & $\mathrm{X}$ & $\mathrm{X}$ & $\mathrm{X}$ & $\mathrm{X}$ & & & \\
Tabernacle & & & & & & & \\
$\begin{array}{l}\text { Screen } \\
\text { Linen Layer }\end{array}$ & & & & $\mathrm{X}$ & $\mathrm{X}$ & $\mathrm{X}$ \\
Hair Layer & & & & & $\mathrm{X}$ & $\mathrm{X}$ \\
$1^{\text {st } \text { Skin Layer }}$ & & & & & & \\
$2^{\text {nd } \text { Skin Layer }}$ & & & & & & \\
Veil & & & & & & \\
\hline
\end{tabular}

Pegs are only mentioned in connection with the courtyard perimeter. Boards, tenon joints,coupling rings, and bars are only mentioned in connection with the frame. In a similar way, all four hanging elements (courtyard perimeter, courtyard gate, tabernacle screen, and veil) employ pillars with sockets and hooks. This appears to be a universal design feature. Other design features include: only wooden elements associated with the tabernacle are overlaid with gold, the tabernacle frame only on three sides without a 
ceiling, artistic cherubim appear only on linen features not seen outside of the tabernacle (i.e., only on linen cloth layer that is covered entirely by the goat hair layer so only those inside the tabernacle can see it, and the veil, which also can only be seen from inside the tabernacle), loops and claps are only mentioned in connection with the two woven layers (linen cloth and goat hair). The capitals were overlaid and only mentioned in connection with the pillars of the courtyard (perimeter and gate), and bands are only mentioned in connection with the pillars of the courtyard (perimeter and gate).

\section{Design of the Furnishings}

In order to assess a cultural influence (intended or unintended) the design elements of the furnishings must also be quantifiable (see Chapter 1). This section will follow the same steps as in the previous section. The first step will be to examine the textual record for data regarding the design elements. This will include brief summations of scholarly opinion as examples of work that has been done in the past. These examples are not comprehensive but rather are representative and will not inform the data set except to show gaps in usable data in the text. These gaps will be addressed, as much as possible, in Chapter 7. The second step will be to analyze these data. The third step will be to organize them into usable data sets.

\section{Furnishings Textual Record and Analysis of Data}

The furnishings included six items. Progressing inward from the gate, the six furnishings were: the bronze altar, the laver, the table, the lampstand, the gold altar, and the ark. The text is not clear on all aspects of this construction. Each element will be described as it is presented in the Hebrew text. This will be followed by a brief review of 
a few scholarly attempts to interpret the practical logistics of this description. It should be noted that this review is representative and not exhaustive since the statistical analysis is not based on data from the review of literature of scholarly opinion through the years but on that gleaned from the Hebrew text. The review is simply to illustrate that a variety of interpretations can, and have been, postulated from the data in the text. This is to underline the need for a comparison of the results of the statistical analysis with data from the archaeological record presented in Chapter 5. The comparison will take place in Chapter 7. Following the brief review of literature, an analysis of the data from the Hebrew text will then be presented. It is this analysis that will be compared with analysis yielded in Chapter 5. An analysis and discussion of the materials used in the construction of the tent-sanctuary will be considered in Chapter 4 so will not be done here.

\section{Bronze Altar}

A hollow altar (Heb. mizbēah) of acacia wood boards, five cubits long by five cubits wide by three cubits high, having horns on the four corners, overlaid with bronze (Exod 27:1-2, 8; 38:1-2, 7), was the first of the furnishings encountered after entering through the gate in the courtyard. How the bronze was attached to the boards is not made clear in the text. Pans (Heb. sir) for the collection of ashes, shovels (Heb. $y \bar{a}$ ), basins (Heb. mizrāq), forks (Heb. mazlēg), and firepans (Heb. mahtâ) were also made with bronze (Exod 27:3; 38:3). A grate (Heb. mikbār) consisting of a bronze network (Heb. ma ăśsh) with four bronze rings at the four corners was made to be put beneath the rim (Heb. karkōb) midway from the bottom of the altar (Exod 27:4-5; 38:4-5). Two poles (Heb. $b a d$ ), one for each side, to be used to carry the altar. These poles were to be made 
of acacia wood, overlaid with bronze, and were placed in the rings (Heb. tabba 'at) (Exod 27:6-7; 38:6-7).

Strong felt that the horns were most likely just "upright, tapering projections” (Strong 1952: 17). It is possible that he reached this conclusion based on horns discovered on altars from Beer-Sheba and Megiddo. This conclusion will be tested in part, when comparisons are made between the textual data from this chapter and the archaeological data of Chapter 5. Strong also speculates that there was no base to the altar (Appendix A, Figure 24) and that the rings were thin (Strong 1952: 17-18). Chambers (1958: 90) agreed with both of these surmisings (Appendix A, Figure 26). Both Zehr (1981: 37) and Kiene (1984: 19) hypothesized a ramp leading up to the altar (Appendix A, Figures 25 and 27). Strong (1952: 17) and Kiene (1984: 59) imagined the grate in slightly different ways (Appendix A, Figures 24 and 26). Chambers (1958: 90) and Kiene (1984: 19) both allowed the illustrations to show this item with the poles inserted (Appendix A, Figures 26 and 28), which only was the case when traveling (Num 4:6, 8, 11, 14). Noonan (2016: 52) points out that the Hebrew word for pole (bad) appears to be an Egyptian loanword $\left(b d_{3}\right)$.

Strong felt that the metal sheets, on all furnishings items, were tacked onto the wood in a way that would have held "the angles firm" (Strong 1952: 49). Nails are also his answer for attaching the rings (Strong 1952: 49). Neither of these methods are discussed in the text.

The bronze altar had a ratio of 5:5:3, where five is the length, five is the width, and three is the height (see Appendix A, Figure 29). The shape of the horns, poles, and rings is unknown; however, the poles needed to be longer than five cubits (the length of 
the sides) each to be of any use. How long the poles were, is not given. There were four rings fastened at the four corners. How this was done, is not discussed. The text also does not indicate where on the corner the rings were fastened (top, base, or some point in between). The presence of a rim is noted but it also has no description that can be used for statistical purposes. The bronze network was placed at the midpoint between the rim and the base. The design of the network beyond this is not given. Also, the presence of utensils is noted.

\section{Laver}

Progressing inward, the next of furnishings was the laver (Heb. kîyor). It and its base, were made from bronze mirrors (Heb. mar $^{\prime} \bar{a} h$ ) to hold water (Exod 30:18; 38:8). This was a container from which the priests were to draw water to washing their hands and feet before entering the tabernacle or officiating at the altar in the courtyard (Exod 30:19-21).

The shape of the laver is not given in the text. Strong speculates that the base had a turned-up rim to catch the spill from the basin (Strong 1952: 19 note) and believes that both parts were "obviously round" and suggests a shallow form based on the nature of use close to the ground (Strong 1952: 19). It is not clear why he thought it was obviously round. Zehr follows a modern style seen in Africa (Appendix A, Figure 30) that is raised a short distance from the ground, suggesting two cubits in height (Zehr 1981: 52) (but this is based on nothing more than preference and speculation respectively). Kiene (1984: 65) also suggested a round shape (Appendix A, Figure 31), as did Chambers (Appendix A, Figure 32).

No dimensions are given for the laver or its base. Thus, they are just noted as 
being present. There is also no description of how they were transported since there is no description of poles or rings, as in all of the other furnishings except the lampstand.

\section{Table}

In the tabernacle, along the northern side of the Holy Place (Exod 26:33, 35; 40:22), a table (Heb. šulhān) made from acacia wood overlaid with gold, was two cubits long, one cubit wide, and one and a half cubits high, with a molding (Heb. $z \bar{e} r$ ) of gold all around it (Exod 25:23-24; 37:10-11). The text does not describe how the gold was affixed to the wood. A frame (Heb. misgeret) of gold with a molding was also made for it, as were four gold rings to be put at the four corners on its legs (Heb. regel) but close to the frame to hold the overlaid gold acacia wood poles needed to carry it (Exod 25:25-28; 37:12-15). The text does not describe how long the legs were. Dishes (Heb. que ârâ), plates (also called cups or pans) (Heb. kēp), pitchers (Heb. qāšâ), and bowls (Heb. měnaqqît) were all made of pure gold (Exod 25:29; 37:16).

It is not clear what is meant by frame (Heb. misgeret). Sarna (1991: 162) suggested that may be a feature that closed or enclosed and pointed out that it is a word that is only ever used again for something associated with the laver of Solomon's temple. As for the tent-sanctuary, this word only appears with this item of furniture.

Strong points out that the ratio of two cubits long to one and a half cubits high is the same ratio in the Arch of Titus depiction of this item leading him to estimate that the thickness of the boards used in the construction of the table could not have been more than 1/12 of a cubit (Strong 1952: 41). It should be pointed out that the table was not carried by poles attached close to the frame in the Arch of Titus as seems to be meant in the Hebrew text, if the frame is to be associated with the table's top and the molding. The 
depiction of the Arch of Titus does demonstrate an ingenious method of storing the two silver trumpets (Num 10:2-10), which is not mentioned in the text and for which there is no biblical evidence. The two trumpets appear to be of slightly different lengths which would produce different tones, leading Strong to reject the depiction as simple foreshortening (Strong 1952: 48). Meyers points to numerous examples of offering tables in the archaeological record in Egypt (Meyers 1976: 66). Neither Kiene (1984: 107) nor Chambers (1958: 44) include the trumpets with the table in their models (Appendix A, Figures 33 and 34).

The table had a ratio of 4:2:3 ( $2 \times 1 \times 1.5$ cubits), where four is the length, two is the width, and three is the height (see Appendix A, Figure 35). The shape of the molding, poles, rings, legs, and utensils is unknown; however, the poles needed to be longer than two cubits (the length of the side) or one cubit (the width of the side) to be of any use. How long the poles were, is not given. There were four rings fastened at the four legs. The text does not indicate where on the legs the rings were fastened (top, base, or some point in between). Also, the presences of utensils is noted. It is unknown if the silver trumpets were a part of this furnishing from the earliest of times as there is no evidence in the Hebrew text that they were they clearly were in the $2^{\text {nd }}$ Temple Period.

\section{Lampstand}

A lampstand (Heb. měnôrâ), placed along the southern side of the Holy Place (Exod 26:33, 35; 40:24), was made from pure hammered gold so that it had a central shaft (Heb. yārēk) with six branches (Heb. qāneh), three to a side (so that there were seven places for lamps), each branch having three bowls (Heb. gäbîa) shaped like almond blossoms (Heb. šāqad) with an ornamental knob (Heb. kaptor) and a flower 
(Heb. perah), and the shaft having four almond blossom bowls with knobs and flowers so that a knob was under each set of branches, all one piece (Exod 25:31-36; 37:17-22). Seven lamps were to be made for it so that they could be arranged to give light in front of it (Exod 25:37; 37:23a). Its wick-trimmers (Heb. melqāh) and trays (Heb. mahtâ) were made of pure gold as well, so that the lampstand and its utensils all were made with one talent of gold according to the pattern (Exod 25:38-40; 37:23b-24).

The size of the lampstand is not given but based on the Arch of Titus depiction, Strong estimates that it was about three cubits high and two cubits wide (Strong 1952: 44). Nevertheless, this is entirely speculative. He also tried to identify the shapes of almond blossoms and ornamental knobs based on this depiction (Strong 1952: 44-48). The lampstand (called "menorah") has been used as a symbol, and is found in archaeological contexts through iconography in synagogues, graves (Appendix A, Figure 36), water cisterns (Appendix A, Figure 37), olive presses (Appendix A, Figure 38), lamps, glass vessels, seals, and amulets all dating after the fall of Jerusalem in A.D. 70 (Yarden 1971: 23-31). To what extent any of these are based on firsthand knowledge of the lampstand carried away by Titus or even the connection that they had with the original constructed in the tent-sanctuary, is unknown. This uncertainty has led to searches for parallels in other Ancient Near Eastern cultures (Meyers 1976).

Meyers has pointed out that in the description only the lampstand and the utensils are specifically described as made of gold; but the lamps are not, which she suspects is highly significant since stands do appear in the archaeological record holding a variety of objects. So the lamps may not have been gold, although it is possible that they were (Meyers 1976: 57-58). 
Surprisingly for Meyers, "there is no evidence of a lampstand of any kind in any cultic context” in Mesopotamia; this despite "an abundance of religious constructions" (Meyers 1976: 59). This said, there are some stands used for different functions, sometimes libation, sometimes incense. Some are decorated with palm branches in early periods and some with conical fires (often composed of seven flames) in later periods (Meyers 1976: 59-65) as in Syro-Palestine (Meyers 1976: 74-75). In Egypt, they are associated with food offerings (Meyers 1976: 65-68). She concludes that while lamps themselves are common in the Syro-Palestine archaeological record, with nearly all of them ceramic and none made of metal (Meyers 1976: 70-72), the stands that could have been used for lamps in these cultures are all quite consistent in that the base of the stem tends to be wider than the top, while none seemed to have feet, and nearly all were decorated (Meyers 1976: 81-84). These data led her to examine the concept of a sacred tree in these same cultures (Meyers 1976: 95-122). Averbeck considered the "technical terminology" used to describe the lampstand to be clear evidence of its Egyptian origin (Averbeck 2003: 815; cf. Sarna 1991: 164).

No dimensions are given for the lampstand. Thus, it is just noted as being present. There have been a number of attempts to reconstruct the lampstand but most follow one of two basic shapes: all lamps raise to the same level (Appendix A, Figure 39) or at various levels (Appendix A, Figure 40). Numbers 4:10 indicates that the lampstand and all of its utensils were transported in skins on a carrying beam. Like the laver, there is no description of poles or rings associated with it.

\section{Gold Altar}

An altar (Heb. mizbeah) for burning incense (Heb. qĕtret) with four horns (Heb. 
qeren) was made of acacia wood, one cubit long, one cubit wide, and two cubits high, and all overlaid with pure gold, complete with a gold molding all around (Exod 30:1-3; 27:25-26). Two acacia wood poles, overlaid with gold were placed in two gold rings that were fastened to two sides under the molding as a way to carry it (Exod 30:4-5; 37:2728). This altar was to be placed before the veil that was in front of the ark and that separated, with Most Holy Place from the Holy Place (Exod 30:6). Aaron was to burn sweet incense on it every morning and evening at the same time he trimmed the lamps on the lampstand (Exod 30:7-8). He was to burn only the specific incense on it and never any other incense or any other offerings (Exod 30:9-10), although once a year he was to place blood from the Day of Atonement service on its horns to purge it (Exod 30:10; cf. Lev 16:16). The incense was to be made from equal amounts of sweet spices, stacte, onycha, galbanum, and pure frankincense, salted, purified, made holy, and beaten very fine, with strict instructions to not use this recipe for any other purpose (Exod 30:34-38; $37: 29 b)$.

Strong considered that the gold altar for burning incense (aka. altar of incense, Exod. 30:27) was very similar in design to the bronze altar for making sacrifices except for its size and the absence of a grate (Strong 1952: 44). Since there were only two rings (one on each side), at least two variations have been suggested for the positioning of the poles. Kiene (1984: 120) argues that more rings must have been present so that the poles were level (Appendix A, Figure 41). Chambers (1958: 12) argues that the poles must have been position at a slant (Appendix A, Figure 42).

The golden altar had a ratio of 1:1:2, where one is the length, one is the width, and two is the height (see Appendix A, Figure 43). The shape of the horns, molding, poles, 
and rings is unknown; however, the poles needed to be longer than one cubit (the length of the sides) to be of any use. How long the poles were, is not given. There were two rings fastened on two sides. The text indicates that the rings were fastened under the molding. The text does not indicate how the poles rested.

\section{Ark}

The ark (Heb. 'ăôn) that was to hold the Testimony was to be placed behind the veil in the Most Holy Place (Exod 25:16; 26:34). It was to be made from acacia wood and overlaid with pure gold inside and out and had a gold molding all around it so that it was two and a half cubits long, a cubit and a half wide, and a cubit and a half high (Exod 25:10-11; 37:1-2). Four gold rings were placed at its corners so that two were on each side in order to hold the two acacia-wood poles overlaid with gold that would be used for carrying the ark (Exod 25:12-15; 37:3-5). The ark was topped with a cover called mercy seat (Heb. kapporet) that was made entirely of pure gold to fit the top, with two hammered-gold cherubim on each end, facing each other with their faces toward the mercy seat and stretching out their wings (Heb. kānāp) above it, all of one piece of gold (Exod 25:17-21; 37:6-9). It was between the two cherubim, above the mercy seat that God would speak to Moses (Exod 25:22).

Without guidance of some sort (e.g. from a potential cultural influence) the design of the ark can be understood in a number of different ways (see Alexander 2002: 17). Strong recognizes that composite creatures were popular both in Egypt and Assyria and that the cherubim fit with the culture of the time (Strong 1952: 55 note 3) but he considered them to be imaginary and not reflecting any sort of real creature (Strong 1952: 57 note 1). Strong also noted the obvious Egyptian connection in the depiction of the 
priests carrying the barque of Amun on poles where the presence of the god is between the wings of two protectresses over a box (Strong 1952: 56). Since the description of the Most Holy Place in Solomon's Temple mentions that the poles for the ark extended into the veil in a way that could be seen in the Holy Place (1 Kings 8:8), the Most Holy Place being 20 cubits by 20 cubits, some scholars (see Jacob 1992: 774; Pokrifka 2018: 307) have suggested that the poles of the ark were on its short sides (Appendix A, Figure 44). This is to suggest that the poles themselves were longer than 20 cubits, requiring wood to be available at that length. Others place the poles on the long sides (Appendix A, Figure 45).

Some scholars considered the ark to be a symbol of the throne, while a growing number appear to see it rather as a footstool to a throne; a feature they see as parallel to some cultures in the ancient Near East (Alexander 2017: 572).

The ark had a ratio of 5:3:3 ( $2.5 \times 1.5 \times 1.5$ cubits), where five is the length, three is the width, and three is the height (see Appendix A, Figure 46). The shape of the molding, poles, and rings is unknown. However, the poles needed to be longer than 2.5 cubits (the length of the side) or 1.5 cubit (the width of the side) to be of any use. How long the poles were, is not given. There were four rings fastened at the four corners. The text does not indicate where on the corners the rings were fastened (top, base, or some point in between) or even on which side they were. The presence of a Mercy Seat of solid gold is noted, as is the presence of two-winged cherubim. The cherubim faced each other, looking downward, and had their wings outstretched above the Mercy Seat. However, the position of the wings aside from this information is not given. 


\section{Furnishings Statistical Analysis}

The altars (bronze and gold) were the only furnishings that had a length to width ratio of $1: 1$. This data indicates a statistical design feature that is searchable on altars found in other cultures. It is also notable that the bronze altar was shorter than it was wide or long, whereas the gold altar was taller than it was wide or long. This measurement may have been a functional necessity based on the sheer size of the bronze altar. However, it is also a design element that can be compared with altars elsewhere.

The bronze altar also shares a parallel ratio 5:3 with the ark, where the length is five and the height is three. Because the altar has the ratio of 1:1 for length and width, and the ark has the ratio of 1:1 for width and height, although these items are of different sizes, these two furnishings share basic dimension ratios. This similarity allows for similar statistical comparisons in other cultures between similarly-functioning furnishings. Without this observation from ratios such a comparison would not have been immediately obvious because of the shape of the objects.

\section{Statistical Data Grouping}

In order for these data to be useful for comparison, they must be grouped into data sets. One set will track the ratios discovered on the basis of the text's description. A second set will suggest manufacturing preferences in volume objects (boxes and tables) in which the lengths, widths, and heights are plotted to determine likely design preferences. A third set will present the presence of repeatedly appearing items, indicating frequency.

Table 6 contains the ratios derived from the text. These data will be useful for comparison with items discussed in Chapter 5. 
Table 6. Furnishing ratios

\begin{tabular}{|c|c|c|}
\hline Item & Cubits & Ratio \\
\hline Bronze Altar length, width, height & $5 \times 5 \times 3$ & $5: 5: 3$ \\
\hline Bronze Altar length and width & $5 \times 5$ & $1: 1$ \\
\hline Bronze Altar length and height & $5 \times 3$ & $5: 3$ \\
\hline Bronze Altar width and height & $5 \times 3$ & $5: 3$ \\
\hline Table length, width, height & $2 \times 1 \times 1.5$ & $4: 2: 3$ \\
\hline Table length and width & $2 \times 1$ & $2: 1$ \\
\hline Table length and height & $2 \times 1.5$ & $4: 3$ \\
\hline Table width and height & $1 \times 1.5$ & $2: 3$ \\
\hline Gold Altar length, width, height & $1 \times 1 \times 2$ & $1: 1: 2$ \\
\hline Gold Altar length and width & $1 \times 1$ & $1: 1$ \\
\hline Gold Altar length and height & $1 \times 2$ & $1: 2$ \\
\hline Gold Altar width and height & $1 \times 2$ & $1: 2$ \\
\hline Ark length, width, height & $2.5 \times 1.5 \times 1.5$ & $5: 3: 3$ \\
\hline Ark length and width & $2.5 \times 1.5$ & $5: 3$ \\
\hline Ark length and height & $2.5 \times 1.5$ & $5: 3$ \\
\hline Ark width and height & $1.5 \times 1.5$ & $1: 1$ \\
\hline
\end{tabular}

The following Tables (7, 8, and 9) are stem-and-leaf plots that check for patterns of size (lengths, widths, and heights) to determine if there was a typical range for the items that are being compared. This can be used to determine possible cultural norms from which the four pieces of furnishing were manufactured. This test will use data from Table 6. These data will be useful for comparison with items discussed in Chapter 5.

Table 7 shows a bunching of the numbers between the range of one to two, weighted toward the higher end of this range. Table 8 shows a bunching of the numbers at one. Table 9 shows a bunching of all numbers between the range of one to three, weighted toward the lower end of this range. Together they indicate a manufacturing preference of lengths between one to two cubits, widths around one cubit, and heights between one to three cubits, with an allowance for longer lengths and widths, but not heights. Since this was a mobile camp, these small ranges are not unexpected. 
Table 7. A stem-and-leaf plot of the length of the volume

\begin{tabular}{lllll|l}
\hline & & & & \\
Length & Stem & Leaf & 0 & 4 & 0 \\
\hline 5.0 & 5 & 0 & & 3 & \\
2.0 & 2 & 0 & 2 & 0,5 \\
1.0 & 1 & 5 & 1 & 0 \\
2.5 & 2 & 5 & 0 & \\
\hline
\end{tabular}

Table 8. A stem-and-leaf plot of the width of the volume

\begin{tabular}{lllll|l} 
Length & Stem & Leaf & 0 & 5 & 0 \\
\hline 5.0 & 5 & 0 & 0 & 4 & \\
1.0 & 1 & 5 & 3 & \\
1.0 & 1 & 0 & 1 & $0,0,5$ \\
1.5 & 1 & 5 & 0 & \\
\hline
\end{tabular}

Table 9. A stem-and-leaf plot of the height of the volume

\begin{tabular}{|c|c|c|c|c|c|}
\hline Length & Stem & Leaf & & \\
\hline 3.0 & 3 & 0 & 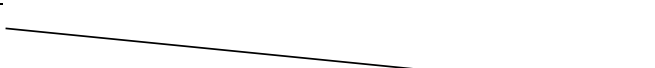 & \multicolumn{2}{|l|}{4} \\
\hline 1.5 & 1 & 5 & -2 & \multirow{2}{*}{3} & \multirow{4}{*}{$\begin{array}{l}0 \\
0 \\
5,5\end{array}$} \\
\hline 2.0 & 2 & 0 & $\mathrm{C}_{2}$ & & \\
\hline 1.5 & 1 & 5 & 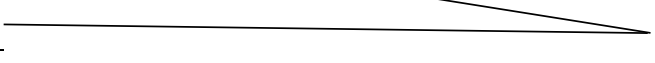 & 1 & \\
\hline & & & & 0 & \\
\hline
\end{tabular}

Tables 10 and 11 contains the frequency of repeated features that appear in the text. These should be useful for comparison with items discussed in Chapter 5. Tables 10 and 11 illustrates that certain features are unique to specific elements. Three elements had moldings (table, gold altar, and ark; all three located inside the tabernacle). The grate and 
Table 10. Frequency of repetition in Features $A$

\begin{tabular}{lccccccc}
\hline Element & Horns & $\begin{array}{c}\text { Overlay } \\
\text { Bronze }\end{array}$ & $\begin{array}{l}\text { Overlay } \\
\text { Gold }\end{array}$ & Poles & Molding & Rings & Utensils \\
\hline $\begin{array}{l}\text { Bronze Altar } \\
\text { Laver }\end{array}$ & $\mathrm{X}$ & $\mathrm{X}$ & & $\mathrm{X}$ & & $\mathrm{X}$ & $\mathrm{X}$ \\
$\begin{array}{l}\text { Table } \\
\text { Lampstand }\end{array}$ & & & $\mathrm{X}$ & $\mathrm{X}$ & $\mathrm{X}$ & $\mathrm{X}$ & $\mathrm{X}$ \\
$\begin{array}{l}\text { Gold Altar } \\
\text { Ark }\end{array}$ & $\mathrm{X}$ & & $\mathrm{X}$ & $\mathrm{X}$ & $\mathrm{X}$ & $\mathrm{X}$ & $\mathrm{X}$ \\
& & & $\mathrm{X}$ & $\mathrm{X}$ & $\mathrm{X}$ & $\mathrm{X}$ & \\
\hline
\end{tabular}

Table 11. Frequency of repetition in Features $B$

\begin{tabular}{lcccc}
\hline Element & Grate & Rim & Base & Legs \\
\hline Bronze Altar & $\mathrm{X}$ & $\mathrm{X}$ & & \\
Laver & & & $\mathrm{X}$ & \\
Table & & & & $\mathrm{X}$ \\
Lampstand & & & & \\
Gold Altar & & & & \\
Ark & & & & \\
\hline
\end{tabular}

rim are only mentioned in connection with the bronze altar even though there is another altar among the furnishings. Only one element had a base -the laver. And only the table had legs. In a similar way, all four elements (bronze altar, table, gold altar, and ark) that employed poles for transportation also were the only elements to have rings. This feature appears to be a universal design. Another design feature is the presence of horns that appeared on both altars. All six furnishings appeared to be metal (two were solid; four were overlaid). The two furnishings in the courtyard were bronze (one solid and one overlaid) and the four furnishings in the tabernacle were gold (one solid and three overlaid). Three of the furnishings (bronze altar, table, and lampstand) had accompanying utensils. 


\section{Summary of Design Data and Direction of Study}

The purpose of this chapter was only to collect data from the Hebrew text regarding the design elements involved in the construction of the Hebrew tentsanctuary's tabernacle (the central structure itself), its courtyard perimeter, and the furnishings within the courtyard and tabernacle. A representative (not comprehensive) review of literature was added to provide some perspective of the general opinions surrounding the options available for interpretation up to this point. It was the purpose of this chapter to provide statistical data from the Hebrew text that can be compared (in Chapter 7) with design data collected from Egyptian contexts from Chapter 5.

Not all of the collected data in this chapter will prove useful for the comparison with Egyptian design data collected in Chapter 5 and compared in Chapter 7. However, the data collected in this chapter can be used in other future studies that might seek to compare the data from the Hebrew text with other ancient Near Eastern contexts. That data here collected can also be used to inform other studies on the tent-sanctuary itself, be they theological, typological, symbolical, phenomenological, or perhaps even dealing with the interpretation of the construction.

This study demonstrated that the Hebrew tent-sanctuary was associated in various ways with three particular spheres of life: sacred, royal-domestic, and military. Sacred, because of the use of the term "sanctuary" (sacred space). Royal-domestic, because their God-King was to live among them in this sacred space. And military by its explicit location at the center of their army camp.

The use of ratios was one of the strengths of this study. It eliminated the need to work with either ancient or modern units of measurement by providing a universal 
measure of the design of the elements in the tent-sanctuary. This has the additional advantage of avoiding the discussion over the precise length of the cubit. Stem-and-leaf plots provided manufacturing design preferences for strips of woven layers and for elements of volume (such as boxes or tables). Frequencies in the repetition of design features in the elements of the tent-sanctuary also provided observational comparison points. Some observational features (such as the locations of the gate in the perimeter, the table and lampstand in the tabernacle, and the tent-sanctuary at the center of an army camp) also were recorded. Ratios can be obtained and similar plots and frequencies can be conducted in like manner from similar design elements in the Egyptian archaeological record (Chapter 5) that can then be compared with these features in Chapter 7.

There has been much speculation among scholars in regard to the details of the text, particularly due to the gaps in usable data in the text. This speculation has allowed for considerable variation in reconstruction. If cultural influence is identified in some or all of the design elements of the tent-sanctuary, much of this educated speculation could become further informed, a possibility discussed further in Chapter 8. At the very least, the data collected in this chapter will be useful on its own.

It is expected that when compared in Chapter 7, design data from the Egyptian archaeological record (identified in Chapter 5) can inform elements of the design of the tent-sanctuary (here in Chapter 3). Of particular note, research should look for the location relationship of courtyard barriers to central structures, access points through those barriers, the design of the central structure, and furnishings used within the 
courtyard and the central structure. And while all structures may be informative on some level, an eye should be focused on mobile structures particularly those connected with sacred, royal-domestic, and military spheres of ancient Egypt in the New Kingdom. 


\section{CHAPTER 4}

\section{MATERIAL ELEMENTS OF THE HEBREW TENT-SANCTUARY}

"Speak to the children of Israel

that they bring Me

an offering."

(Exodus 25:2a)

The purpose of this chapter is to collect data from the Hebrew Scriptures and organize them into usable sets that can be compared with the results of the statistical analysis conducted on the Egyptian data sets in Chapter 6. This comparison will take place in Chapter 7.

The data collected in this chapter will only be concerned with the material elements of the Hebrew tent-sanctuary. Since only nine materials are mentioned in the description of the construction of the tent-sanctuary in the text for the courtyard, tabernacle, and Furnishings, and the design elements are not the focus (see Chapter 3), the materials themselves will be listed with the organic materials listed first followed by the inorganic.

\section{Materials of the Tabernacle and Furnishings}

In order to assess a cultural influence (intended or unintended) the material elements must be present in the potentially influencing culture. To test this, those 
elements must be quantifiable. The first step will be to examine the textual record for data regarding each of the material elements. This will include brief summations of scholarly opinion as examples of work that have been done in the past - efforts to ascertain the exact nature of the materials in the text. These examples are not comprehensive but rather are representative and will not inform the data set except to show gaps in usable data in the text. These gaps will be addressed, as much as possible, in Chapter 7. The second step will be to analyze these data. The third step will be to organize them into usable data sets for the purpose of comparison, which will be done in Chapter 7 .

The purpose of this exercise is to identify, as precisely as possible, what should be looked for in the archaeological record in Egypt with the end goal to reach a binary statistic of present or not present. If these same materials are present in the archaeological record of Egypt in the New Kingdom (as delineated in Chapter 2), the text itself can be considered possible for cultural influence. If, on the other hand, the materials are not present in the archaeological record of Egypt in the New Kingdom, the text itself can be considered not possible. The comparison will take place in Chapter 7.

\section{Textual Record and Analysis of Data}

The tabernacle was constructed as a paneled frame overlaid by two layers of woven curtains (linen cloth and goats hair) further overlaid by two layers of skins. It was set within a courtyard defined by a perimeter of hangings held in place by pillars. The courtyard gate, tabernacle screen, linen cloth layer, and the veil were decorated with blue, purple, and scarlet thread. All of the wood used in the paneled frame, as pillars, as bars, as poles, or in pieces of furniture (bronze altar, table, gold altar, and ark) was acacia. When overlaid it was with gold or bronze. Bronze was used for sockets, pegs, clasps, 
utensils, the laver, and its base. Silver was used for sockets, hooks, bands, and capitals. Gold was used for rings, hooks, clasps, moldings, utensils, capitals, and two items of the furnishings (the lampstand and the mercy seat with cherubim). Each element will be described as it is presented in the Hebrew text. This will be followed by a brief review of a few scholarly attempts to interpret the precise nature of the materials mentioned. An analysis of the data will then be presented. Analysis of the design elements was considered in Chapter 3 so will not be done here.

\section{Acacia Wood - Tabernacle and Furnishings}

The wood used in all elements of the tent-sanctuary was acacia (Heb. šitțāh). It was the only wood requested as an offering to build the tent-sanctuary (Exod 25:5; 35:7, 24). As such, it was used for the pillars (Exod 26:32, 37; 36:36), the boards for the frame of the tabernacle (Exod 26:15; 36:20), bars for the frame (Exod 26:26; 36:31), poles (Exod 25:13, 28; 27:6; 30:5; 37:4, 15, 28; 38:6), the bronze altar (Exod 27:1; 38:1), the table (Exod 25:23; 37:10), the gold altar (Exod 30:1; 37:25), and the ark (Exod 25:10; $37: 1)$.

The Hebrew word šițtâh (Exod 25:5), is translated “acacia” based on its parallel with two other languages: Arabic sant or sunț and Egyptian šnd.t. (Zevit 1992: 138) and thus appears as an Egyptian loanword in the Hebrew Bible (Muchiki 1999: 256; Noonan 2016: 52). The presence of acacia, sometimes the only tree "that grow[s] in the Negev, Aravah, and Sinai” (Zevit 1992: 138), "can reflect the presence of copper and lead ore” (Ogden 2000: 148) and thus was used to identify potential sites for mines. Exodus 26:16 states that the acacia boards should be ten cubits in height and one and a half cubits in width. This would require (if the board was one piece of wood) a tree to have a trunk at 
least 10 cubits tall (thus at least 4.5 meters tall, depending on the cubit) and to have at least a diameter of 1.8 cubits because of bark thickness (depending on the cubit this would be just shy of one meter thick; Zevit 1992: 140). These dimensions may come in useful for identifying the tree.

There are over 700 kinds of acacias in the world today, half of which are in Australia (Zevit 1992: 140). They grow near wadis or oases in the desert in order to have access to a reliable enough supply of water all the year round (Zevit 1992: 140). The Acacia nilotica has hard timber and grows up to 25 meters, and thus is often the species identified with the construction of the tent-sanctuary, but is not found in the Sinai today (only in subtropical African and Asian varieties; Zevit 1992: 138, 140). Egyptians associated the acacia with Hathor, the goddess of the Sinai (Ogden 2000:148). Some acacia trees still grow in the Sinai, although it is a very small variety. Zevit argues, without considering a possible Egyptian connection (Hoffmeier 2005: 210), that the type of acacia mentioned in the text must be Acacia albida since it grows in the northern Negev (Zevit 1992: 140-41) and was the only acacia available in the Levant. Hoffmeier points out the flaws of this reasoning. First, the Hebrew text does not require that the boards be made of a single piece of wood each. Second, it cannot be assumed that the fauna of today was the fauna of the Late Bronze Age, since it is known that during the Ottoman period there was massive deforestation of trees in the Levant and the Sinai (Hoffmeier 2005: 210-11).

Strong (1952: 91) suggested that acacia was plentiful in the Sinai and could be easily accessible. However, acacia wood was an item for which offering donations were requested (Exod 25:5; 35:7), so this had to have been something the Hebrews possessed 
rather than something the construction crews procured in the Sinai, unless this is to be understood as donations of wood cut fresh. In Chapter 6, evidence will be sought to determine the species of acacia that were available in that part of the world in the New Kingdom period. Without evidence that acacia grew in the Sinai large enough to produce planks large enough, it must have been available in ancient Egypt (and thus available for the Hebrews to bring with them on carts to serve as an offering).

Statistically speaking, acacia is the only wood mentioned in the text. This gives it a 100\% frequency rating. In individual elements, $100 \%$ of all pillars, boards, bars, and poles were acacia and 66\% of all furniture items (four out of six) were constructed of wood (but $100 \%$ of furniture that was made with wood was acacia). As a result, this is a binary statistic: present or not present.

\section{Linen Cloth Layer - Tabernacle}

The cloth used in all elements of the tent-sanctuary was woven linen (Heb. šës). It was the only cloth requested as an offering to build the tent-sanctuary (Exod 25:4; 35:6, 23, 25, 35; 38:23). As such, it was used for the hangings of the perimeter (Exod 27:9, 18; 38:9, 16), the courtyard gate (Exod 27:16; 38:18), the tabernacle screen (Exod 26:36; 36:37), the first covering layer (Exod 26:1; 36:8), and the veil (Exod 26:31; 36:35).

The Hebrew word šëš (Exod 25:4), is a well-recognized Egyptian loanword (Eitan 1925; Hurvitz 1967: 119; Muchiki 1999: 257-58; Noonan 2016: 52). All of the biblical uses of this word, except two, come from the Pentateuch (Hoffmeier 2005: 212). The use of šĕš indicates both chronological and geographical distinctions that both point to Egypt (Hurvitz 1967: 119-20), since another word (pišteh) was used for linen after the exile. Based on the uses of linen throughout both Old and New Testament, The Dictionary of 
Biblical Imagery concludes that linen was a symbol of status (Ryken and Wilhoit 1998: 1739-41). Chambers (1958) estimates that between 4-5000 $\mathrm{ft}^{2}$ of finely woven linen were used in the construction the tent-sanctuary and the robes for the priests (Chambers 1958: 70). Strong (1952: 92-93) states that it was a symbol of cleanliness but does not give a reason.

Statistically speaking, linen is the only cloth (used for clothing) mentioned in the text. This gives it a 100\% frequency rating. In individual elements, $100 \%$ of all hangings were linen cloth and $25 \%$ of all tent coverings (one out of four) consisted of linen cloth (but $100 \%$ of curtain layers). As a result, this is a binary statistic: present or not present.

\section{Blue, Purple, and Scarlet Thread - Tabernacle}

The thread used in all artistic decorative elements of the tent-sanctuary on woven linen cloth were colored blue (Heb. těkēlet), purple (Heb. 'argāmān), and scarlet (Heb. $\check{s} \bar{a} n \hat{\imath})$. These were the only colors requested as an offering to build the tent-sanctuary (Exod 25:4; 35:6, 23, 25, 35; 38:23). As such, they were used for decorating the screen of the courtyard gate (Exod 27:16; 38:18), the tabernacle screen (Exod 26:36; 36:37), the linen cloth layer (Exod 26:1; 36:8), and the veil (Exod 26:31; 36:35); and blue was used for loops along the outer edge of the linen cloth layer (Exod 26:4; 36:11).

Strong (1952) speculated that wool was used for the embroidered threads (Strong 1952: 16), although he does not indicate why. He is not alone. Pokrifka, commenting on this, suggests that it was yarn woven from goats hair (Pokrifka 2018: 301). Perhaps, one of the reasons this has been maintained is that it was believed that linen could not be dyed (Milgrom 1996: 546). There was a prohibition against mixing cloth types (Lev 19:19; 
Deut 22:11), which makes this supposition suspect, unless the prohibition was only for materials outside of the tent-sanctuary (Gane 2004: 338). Also, this would be completely unnecessary since thread was used for the linen weaving and this would simply be dyed thread. Not many scholars appear to have spent much time with this topic.

Statistically speaking, the only colors used, in all four different elements (courtyard gate, tabernacle screen, linen cloth layer, and veil) that required dyed thread to be used, were these three colors. This gives these three colors, in combination, a $100 \%$ frequency rating for weaving. In terms of individual elements, $100 \%$ of all designs used these three dyed thread colors in combination and $100 \%$ of all the outer edges that were looped by dyed thread (one out of one) consisted of one of these three colors (but not all three). As a result, this is a binary statistic: present or not present.

\section{Goats Hair Layer - Tabernacle}

The material used in the $2^{\text {nd }}$ covering layer of the tabernacle was goats hair (Heb. 'êz). It was the only hair requested as an offering to build the tent-sanctuary (Exod 25:4; 35:6, 23, 26). As such, it was used for the goats hair layer (Exod 26:7; 36:14).

Few scholars appear to have discussed the nature of this element since sheep and goats are two very common animals throughout all time periods and goats hair is known to have been used for tent coverings (Hoffmeier 2005: 195) not only in the ancient world, but even today among Bedouin tribes.

Statistically speaking, goat is the only hair mentioned in the text. This gives it a $100 \%$ frequency rating. In individual elements, $100 \%$ of all hair coverings were goat and $25 \%$ of all tent coverings (one out of four) consisted of goats hair (but 100\% of hair layers). As a result, this is a binary statistic: present or not present. 


\section{Skin Layers - Tabernacle}

The material used in the third covering layer of the tabernacle was skins of rams (Heb. 'ayil). Dyed red, it was the first type of skins requested as an offering to build the tent-sanctuary (Exod 25:5; 35:7, 23). As such, it was used for the first (and inner) skins layer and third covering layer (Exod 26:14; 36:19; 39:34). There is very little discussion regarding the material described here as skins of rams. A much greater issue is the layer of skins that lay above it.

The material (Heb. taḥaš) used in the second (and outermost) skins layer and fourth covering layer of the tabernacle is debated. It was the second type of skin requested as an offering to build the tent-sanctuary (Exod 25:5; 35:7, 23). That it is a reference to leather is certain since all but two of the 14 occurrences in the Hebrew Bible appear in construct with “skin/hide” (Noonan 2012: 580). As such, it was used for the second (and outer) layer skins (Exod 26:14; 36:19; 39:34). All occurrences of this term appear in relation to the tent-sanctuary except one in Ezek 16:10, which describes it as skin used in connection with sandals.

The earliest translations (LXX and Vulgate) of tahaš translate it as a color (dark red or dark blue) or in the Peshitta, Targums, and Josephus as vermillion (Noonan 2012: 580). Modern translations have sought to associate it with the type of animal the skins may have come from, in the following ways: badger (KJV, NKJV), porpoise (NASB, NEB), dolphin (NJPS), goat (RSV), fine leather (JB, NJB, NRSV), dugong (NIV, REB), while other translators suggest seal (Homan 2000: 30; Hoffmeier 2005: 212). Forbes rejected seal as a possibility because it was unclean but supported dolphin or porpoise because they were clean and the Mishnah (M. Kel. XXX 4) says that fish skins were used 
(Forbes 1957: 38). Robinson (1841: 171) mentioned that some Bedouin used dolphinskin leather for sandals (Hoffmeier 2005: 213). The Talmud (BT. y. Šabb. 2:3) even suggested that it was a unicorn (Noonan 2012: 581). Strong believed that this outer-most layer of skins was possibly Angora goat hair, which he notes is fine, long, and silky (Strong 1952: 26 note) but gave no support for this. Martin Luther believed that the German language was derived from the Hebrew language so translated it as badger based on the similarity of the term with the German word for badger (Homan 2000: 30; Noonan 2012: 582). The translation of dugong is based on a parallel with the Arabic dahs or tahs (or tuhas) and is supported by the availability of dugong in both the Red Sea and Indian Ocean (Zevit, 1992; see also BDB 1065; Cross 2000: 88).

The most innovative idea is that tahaš is in reference to faience beadwork (Dalley 2000). The Egyptian word for faience is $\underline{t} h n$. However, since taḥas is associated with skins and sandals, it would have to be skins decorated with faience beadwork rather than just a layer of faience beads. Dalley (2000: 12-13) points to the earliest translations associating this term with a color and to beaded sandals in Tutankhamun's tomb (and other ANE examples). Noonan favors an Egyptian connection and rejects the idea of any connection tahaš might have with Akkadian or Hurrian dušû (as is generally maintained) based on linguistic grounds, since the Hebrew does not have the final $\hat{u}$ nor the initial $d$, which are a characteristics of other similar words that can be traced back to Akkadian in the Hebrew (Noonan 2012: 581, 584).

Forbes, based on the work of Cross (1947, 1961; work that he later abandoned in favor of a Phoenician explanation; Cross 1984) believed that taḥaš simply referred to “the Egyptian word for leather tḩ̌s” (Forbes 1957: 37, or thś; Dalley 2000: 3, or ths/thhs; 
Noonan 2016: 52, 55). It should be noted that $\underline{t} h s$ is not the ancient Egyptian word for leather but rather for stretching leather (Hoffmeier 2005: 212), which is actually what makes leather, “parchment” (Lucas and Harris 1999: 39). The Egyptian word thths was in use at least by the Old Kingdom and refers to a process that involves stretching and oilcuring an animal hide (Egyptian $\underline{h} n t$ ) over a wooden frame (Noonan 2012: 586). It is also found in connection with sandals (Egyptian $\underline{t} b w$ ), which probably explains its use in Ezekiel (Noonan 2012: 587). Noonan (2012: 589) argues that because of how tahaš is used in the text (both in connection to the tent-sanctuary and also in Ezekiel), the presence of so many other Egyptian loan words in connection to the tent-sanctuary (Noonan 2016), and it’s clear match semantically, the Egyptian word thth can be, phonologically, a loan word for taḥaš. Thus, it appears that tahaš should be translated “Egyptian leather” (Noonan 2016: 52, 55), or more properly “Egyptian-style leather” as a reference to the method that was used by Egyptians to stretch and oil-cure leather, not to the type of animal the leather came from, the color, or how it was decorated.

Statistically speaking, ram is the only skin identified in the text. This gives it a $100 \%$ frequency rating. In individual elements, $100 \%$ of all named skin coverings were ram and at least $50 \%$ of all skins coverings consisted of ram (one out of two; depending on what the $2^{\text {nd }}$ skin layer was made of). At last $25 \%$ (one out of four) tent covering layers was ram. As a result, ram skins is a binary statistic: present or not present.

If, as seems likely, the source animal of the second skin layer is not mentioned in the text, this layer could also be sheep or goat or any of the other speculated source animals. However, because modern methods using liquid chromatography and mass spectrometry (Izuchi, Takashima, and Hatano 2016) can identify the source animal of 
leather in Egyptian objects and much of this has been done (all leather scraps recovered have been catalogued), what can be sought is the presence of all of the proposed possibilities. For the purpose of statistical analysis, it seems fairly certain that tahaš should be translated "Egyptian-style leather," making this a binary statistic: present or not present.

\section{Bronze - Tabernacle and Furnishings}

Bronze (Heb. něhošet) was requested as an offering to build the tent-sanctuary (Exod 25:3; 31: 4; 35:5; 35:24, 32; 38:29). The total amount of bronze collected was 70 talents and 2,400 shekels (Exod 38:29). As such, it was used for clasps (Exod 26:11; 36:18), sockets (Exod 26:37; 27:10-11, 17-18; 36:38; 38:10-11; 38:17, 19, 30), overlay of altar (Exod 27:2; 38:2, 30; 39:39), overlay of poles (Exod 27:6; 35:16; 38:6), utensils (Exod 27:3; 35:16; 38:3, 30; 39:39), network grate (Exod 27:4; 35:16; 38:4, 30; 39:39), rings (Exod 27:4; 38:5), the laver and its base (Exod 30:18; 35:16; 38:8; 39:39), and pegs (Exod 27:19; 38:20).

One of the most persistent questions in scholarship concerning this material is whether bronze, brass, or copper was really meant. Chambers (1958) insisted that it must have been copper due to its ability to resist extremely hot temperatures, having a melting point of more than $1982^{\circ}$ Fahrenheit. He supports this point on the basis of the faulty assumption that the prohibition in Deut 22:9-11 against mixtures of materials applies to metals, so brass and (presumably bronze) was not possible (Chambers 1958: 92). He further supports his conclusion with two additional points. First, brass has a relatively low melting point, which, in his opinion, makes it unsuitable for burning sacrifices on the altar, and second, brass did not exist at that time in Egypt (Chambers 1958: 92). He is not 
alone in his belief that copper was meant (cf. Strong 1952: 92; Zehr 1981: 36, 38). Bronze is not a native substance, but rather, it is the combination of copper and tin. However, this narrow identification is a relatively modern one, so that most copper-alloys (and sometimes copper itself) were referred to in the recent past as "bronze" (Ogden 2000: 151). There has been an attempt to connect a protosinaitic inscription to the smelting of ore needed to make bronze at an alternative site for Mt. Sinai (Shea 1987). Chapter 6 will address whether bronze was available in the New Kingdom.

Statistically speaking, copper/bronze (possibly brass) is one of only three metals (bronze, silver, and gold) mentioned in the text. This gives copper/bronze a 100\% frequency rating, meaning that varieties of copper/bronze are not mentioned in the text. In individual elements, 33.33\% of all metals mentioned (one out of three) consisted of bronze. As a result, this is a binary statistic: present or not present. Bronze did not exist in any location inside of the tabernacle. As a result, it will be important, for comparisons in Chapter 7, to look for the location copper/bronze in relation to central structures in the Egyptian spheres, if this data exists, in Chapters 5.

\section{Silver - Tabernacle}

Silver (Heb. kesep) was requested as an offering to build the tent-sanctuary (Exod 25:3; 31:4; 35:5, 24, 32; 38:25, 27). The total amount of silver collected was 100 talents and 1,775 shekels (Exod 38:25) of which 100 talents were used for sockets (Exod 38:27). As such, it was used for sockets (Exod 26:19, 21, 25, 32; 36:24, 26, 30, 36), hooks (Exod 27:10-11; 38:10-12, 17, 19), bands (Exod 27:10-11; 38:10-12, 17, 19), and overlaying the capitals of the pillars in the perimeter (Exod 38:17, 19) of the tent-sanctuary. 
Strong (1952: 92) suggested that the silver would have been pure because of its "white lustre (sic).” Few scholars appear to have discussed the nature of this element since silver appears to be a material that has only a few options. However, the purity of the silver is a question that should be addressed when data from Egypt is available (from Chapter 6).

Statistically speaking, silver is one of only three metals (bronze, silver, and gold) mentioned in the text. This gives silver a 100\% frequency rating, meaning that varieties of silver are not mentioned in the text. In individual elements, 33.33\% of all metals mentioned (one out of three) consisted of silver. As a result, this is a binary statistic: present or not present. Silver is the only one of the three metals that existed both inside and outside of the tabernacle, although it was used in the fewest elements of the tentsanctuary. As a result, it will be important, for comparisons in Chapter 7, to look for the location silver in relation to central structures in the Egyptian spheres, if this data exists, in Chapters 5.

\section{Gold - Tabernacle and Furnishings}

Gold (Heb. $z \bar{a} h \bar{a} b$ ) was requested as an offering to build the tent-sanctuary (Exod 25:3; 31:4; 35:5, 22, 32; 38:24). The total amount of gold collected was 29 talents and 730 shekels (Exod 38:24). As such, it was used for overlaying the table (Exod 25:24;

37:11), overlaying the altar (Exod 30:3; 37:26; 39:38; 40:5, 26), overlaying the ark (Exod 25:11; 37:2), overlaying poles (Exod 25:13, 28; 30:5; 37:4, 15, 28), overlaying pillars (Exod 26:32, 37; 36:36), overlaying boards (Exod 26:29; 36:34), overlaying bars (Exod 26:29; 36:34), hooks (Exod 26:32, 37; 36:36), rings (Exod 25:12, 26; 26:29; 30:4; 36:34; 37:3,13, 27), molding (Exod 25:11, 24-25; 30:3; 37:2, 11-12, 26), utensils (Exod 25:29, 
38-39; 37:16, 23-24), the Mercy Seat and cherubim (Exod 25:17-18; 37:6-7), the lampstand (Exod 25:31, 36; 31:8; 37:17, 22; 39:17), clasps (Exod 26:6; 36:13), and overlaying the capitals of the pillars that were part of the tabernacle screen (Exod 36:38).

Hoffmeier (2005: 212) points out that gold beaten into thin sheets (Heb. pah) is only associated with the tent-sanctuary in the Hebrew Bible (Exod 39:3; Num 16:38) and is an Egyptian loanword (see also Noonan 2016: 52). Few scholars appear to have debated the nature of this element. This, in spite of the fact that "gold is the most frequently mentioned of all metals [in the Hebrew Bible]” (Altman 1979: 79). Strong (1952: 92) did not address the quality of the gold. The purity of the gold is a question that should be addressed when data from Egypt is available (from Chapter 6). When the text says, "pure gold," is it in reference to 24 karat gold, refined gold, or another option?

Statistically speaking, gold is one of only three metals (bronze, silver, and gold) mentioned in the text. This gives bronze a $100 \%$ frequency rating, meaning that varieties of silver are not mentioned in the text. In individual elements, 33.33\% of all metals mentioned (one out of three) consisted of gold. As a result, this is a binary statistic: present or not present. Gold did not exist in any location outside of the tabernacle. As a result, it will be important, for comparisons in Chapter 7, to look for the location gold in relation to central structures in the Egyptian spheres, if this data exists, in Chapters 5.

\section{Statistical Analysis}

All material elements of the tent-sanctuary can be considered as generating binary statistics: present or not present when considering their frequency. Thus the question that needs to be answered in the comparison (Chapter 7) is, "Were acacia wood; linen fabric; 
blue, purple, and scarlet thread; goats hair; rams skins dyed red; fine Egyptian leather; bronze; silver; gold all present in the New Kingdom of Egypt?”

There are a few other points that need to be addressed. If acacia wood was present in the New Kingdom of ancient Egypt, what type of acacia was it? Was acacia wood used for structures or furnishings? What was the material consistency of bronze, silver, and gold in the New Kingdom? When was copper mixed with tin to make bronze?

The Hebrew words associated with acacia wood, linen cloth, the outer layer of skins, and gold beaten into thin layers appear to be Egyptian loan words. How were these materials used in Egypt? Was linen cloth used by all classes in Egyptian society, or just the upper class? Was it ever used for tent coverings? Was leather ever used for tent coverings? How was goat hair used? What were the source animals for leather in ancient Egypt? Do they include sheep (rams)? Was leather ever dyed, and if so, was red one of the colors of dye?

In what ways were blue, purple, and scarlet colors used in ancient Egypt? When was dye used for fabric? Were individual threads dyed, or just the entire fabric after it was woven? Were there other colors available besides just these three colors? What kinds of materials for threads (linen, wool, etc.) could be dyed? From what were dyes made?

\section{Statistical Data Grouping}

In order to be useful for comparison, data must be grouped into sets. Since this chapter is only concerned with the frequency of materials, the only set needed will indicate frequency.

Table 12 contains the frequency of the materials as they were used in the tentsanctuary. These will be useful for comparison with items discussed in Chapter 6 . 
Table 12. Frequency of repetition in materials

\begin{tabular}{|c|c|c|c|c|c|c|c|c|c|}
\hline Element & $\begin{array}{l}\text { Acacia } \\
\text { Wood }\end{array}$ & $\begin{array}{l}\text { Linen } \\
\text { Cloth }\end{array}$ & $\begin{array}{l}\text { Blue, } \\
\text { Purple, } \\
\text { \& Red } \\
\text { Thread }\end{array}$ & $\begin{array}{l}\text { Goats } \\
\text { Hair }\end{array}$ & $\begin{array}{l}\text { Rams } \\
\text { Skins }\end{array}$ & $\begin{array}{l}\text { tahašs } \\
\text { Skins }\end{array}$ & Bronze & Silver & Gold \\
\hline Pillars & $\mathrm{X}$ & & & & & & & & $\mathrm{X}$ \\
\hline Sockets & & & & & & & & $\mathrm{X}$ & \\
\hline Hooks & & & & & & & & $\mathrm{X}$ & $\mathrm{X}$ \\
\hline Capitals & & & & & & & & $\mathrm{X}$ & $\mathrm{X}$ \\
\hline Bands & & & & & & & & $X$ & \\
\hline Pegs & & & & & & & $\mathrm{X}$ & & \\
\hline Overlay & & & & & & & $X$ & & $X$ \\
\hline Boards & $\mathrm{X}$ & & & & & & & & $X$ \\
\hline Tenon Joints & $\mathrm{X}$ & & & & & & & & \\
\hline $\begin{array}{l}\text { Coupling } \\
\text { Rings }\end{array}$ & & & & & & & & & $X$ \\
\hline $\begin{array}{l}\text { Rings } \\
\text { Bars }\end{array}$ & $\mathrm{X}$ & & & & & & & & $X$ \\
\hline Artistic & & & & & & & & & $\mathrm{X}$ \\
\hline Cherubim & & & & & & & & & \\
\hline Loops & & & & & & & & & $X$ \\
\hline Clasps & $X$ & & & & & & & & $\mathrm{X}$ \\
\hline Poles & $\mathrm{X}$ & & & & & & $\mathrm{X}$ & & $\mathrm{X}$ \\
\hline Bronze & $X$ & & & & & & $X$ & & \\
\hline Altar & & & & & & & & & \\
\hline Laver & & & & & & & $\mathrm{X}$ & & \\
\hline Table & $\mathrm{X}$ & & & & & & & & $\mathrm{X}$ \\
\hline Lampstand & & & & & & & & & $\mathrm{X}$ \\
\hline Gold Altar & $\mathrm{X}$ & & & & & & & & $\mathrm{X}$ \\
\hline Ark & $\mathrm{X}$ & & & & & & & & $\mathrm{X}$ \\
\hline Hangings & & $X$ & & & & & & & \\
\hline Courtyard & & $\mathrm{X}$ & $X$ & & & & & & \\
\hline Gate & & & & & & & & & \\
\hline Tabernacle & & $X$ & $\mathrm{X}$ & & & & & & \\
\hline Screen & & & & & & & & & \\
\hline Veil & & $X$ & $\mathrm{X}$ & & & & & & \\
\hline Covering & & $\mathrm{X}$ & $X$ & $\mathrm{X}$ & $X$ & $\mathrm{X}$ & & & \\
\hline Utensils & & & & & & & $\mathrm{X}$ & & $\mathrm{X}$ \\
\hline Network & & & & & & & $\mathrm{X}$ & & \\
\hline Grate & & & & & & & & & \\
\hline Molding & & & & & & & & & $\mathrm{X}$ \\
\hline Rim & & & & & & & $X$ & & \\
\hline Mercy Seat & & & & & & & & & $\mathrm{X}$ \\
\hline Rings & & & & & & & $\mathrm{X}$ & & $\mathrm{X}$ \\
\hline
\end{tabular}


The metals were the only materials of which more than one type was used (depending on the nature of the second skin layer) in the construction of the tentsanctuary. Table 12 shows that of the 26 elements that were constructed with metal, only nine were constructed with bronze (34.62\%), four were constructed with silver (15.38\%), and 19 were constructed with gold (73.08\%). Remembering that some elements were constructed with multiple metals (depending on the location of that element), gold was the metal that was used for the most elements.

The total frequency of metal use, taking into account the fact that utensils were constructed of both bronze and gold and so should be counted twice, was 32. Using this as a base, bronze was used $28.13 \%$ of the time, silver was used $12.5 \%$ of the time, and gold was used $59.37 \%$ of the time. Thus, while gold was the metal of which the least amount was collected (29 talents, 730 shekels), it was used in the most number of elements (19). Considering that two of those elements (lampstand and Mercy Seat) were entirely made of gold, this gives some indication that the majority of the use of gold was in small portions. Silver was the metal of which the greatest amount was collected (100 talents, 1775 shekels), but was used in the least number of elements (four). This indicates that, if all of it was used, a massive amount of silver was used in the elements (particularly in the sockets where one talent was used for each socket; Exod 37:27). Bronze was the metal of which the second greatest amount was collected (70 talents, 2400 shekels), and was used in about a third of all elements (nine). This indicates a more even distribution when compared to the results of gold and silver.

\section{Summary of Materials Data and Direction of Study}

Each material used for construction of the sanctuary had a binary statistic, present 
or not present, that will be used to compare with similar materials in the archaeological record of ancient Egypt in the New Kingdom (Chapter 6). Frequencies in the use of metals allow for a fuller understanding of the number of elements in which they appear in relation to the amounts collected. Similar frequency of use might be obtained from the archaeological record and will be useful for comparison in Chapter 7.

Particularly interesting are the debates among scholars regarding the nature of the second skin layer and the nature of copper/bronze. These have allowed for much variation in discussion. If some materials are present in ancient Egypt in the New Kingdom, much of this speculation may become informed and will be discussed in Chapter 8.

It is expected that when compared in Chapter 7, material data from the Egyptian archaeological record (identified in Chapter 6) will demonstrate whether all nine materials of the tent-sanctuary (here in Chapter 4) were available in the New Kingdom. Of particular note, research should look for the availability to refine metal, to dye linen thread and leather, source animals for leather, and types of wood available in Egypt and in the Sinai. 


\section{CHAPTER 5}

\section{DESIGN ELEMENTS IN THE ARCHAEOLOGICAL RECORD}

"[The New Kingdom] marked an era in architecture, which was...subjected to new influences, although they did not necessarily result in a higher level of achievement.”

(Badawy 1968: 1)

The purpose of this chapter is to identify Egyptian cultural design norms based on data collected from the archaeological record. Some of these data may be useful, when organized and converted into usable sets, for comparison with the results of the statistical analysis conducted on the Hebrew tent-sanctuary data sets of Chapter 3. This comparison will take place in Chapter 7.

The data collected in this chapter will primarily be concerned with the design elements of the sacred, domestic, and military spheres of New Kingdom Egypt as delineated in Chapter 2. For clarity, these data will be divided into two parts. The first will consider design elements of the courtyard and structures associated with the three spheres (sacred, domestic, and military, as identified in Chapter 3) with the primary focus of data collection on mobile elements in each of these (since the tent-sanctuary was mobile) where available. The second will consider the design elements of the furnishings associated with these spheres. This will be an unbiased analysis to determine if design 
trends can be identified by comparing simple measures of volume of items of furniture found in KV62 (Kings Valley, Tomb 62, i.e., the tomb of Tutankhamun) with similar items of furniture from the rest of the New Kingdom (both before and after) and all similar items of furniture from before the New Kingdom.

\section{Design of Egyptian Courtyard and Central Structure}

In order to assess a cultural influence (intended or unintended) the design elements (the immaterial culture) must be quantifiable. The first step will be to examine published archaeological records for data regarding the design elements of mobile courtyards and structures in the three spheres under study. This will include brief discussions of various features associated with permanent versions of the courtyards and structures that will act as data for baseline control. The examples discussed are not comprehensive but rather are representative of items that may or may not correspond to those in the Hebrew tent-sanctuary. Only those features related to mobile courtyards and structures within courtyards, as defined below, will inform the data set by providing data to analyze. Gaps in usable data should also be identifiable in the process. These gaps will be addressed, as much as is possible, in Chapter 7 as potential areas for future study. The second step will be to analyze these data using stem-and-leaf plots to determine design tendencies. This will be done separately for the courtyard and structures of all three spheres (sacred, domestic, and military). The third step will be to organize them into usable data sets.

The purpose of this exercise is to identify, as precisely as possible, what cultural design preferences are present in the design of mobile elements in each of the three spheres. The end goal is to produce statistics that can be compared with similar design 
elements in the textural record of the Hebrew Scriptures.

\section{Courtyard Archaeological Record}

Ancient life does not seem to have been delineated in the same discrete ways that are necessary for modern analysis. It appears that all life was sacred, including domestic and military (Assmann 2001; Wilkinson 2003). All available data seems to suggest that these boundaries (if any) seem to have been thought of in different ways than we do today. As a result, a courtyard will be defined here as any space delimited by a barrier that encloses a main structure whether or not it is an integral part of the structure.

There were walls around spaces set apart for the dwellings of the gods. There were barriers around property of those who could afford to have walled in property. There were even barriers around the mobile military encampments and the more permanent fortresses. Each of these physical boundaries existed for different purposes than to define a sphere of life, but regardless of their purpose, they existed. As a result, even though the three spheres identified in this study (Chapter 3) are somewhat arbitrary in the modern sense, they did exist as separate entities in the ancient world as well and they will be treated as separate to help demonstrate which (if any) of these spheres may have had cultural influence on the courtyard of the Hebrew tent-sanctuary.

Although permanent structures do exist in each of these spheres in ancient Egypt (some will be discussed here in an illustrative way) the Hebrew tent-sanctuary was a mobile structure and as a result mobile structures will be the focus of this study for the collection of data to analyze where they exist in the archaeological record. 


\section{Sacred Sphere}

Generally speaking, the permanent Egyptian sacred sphere was entered by passing through a gate in an enclosure wall. This enclosure wall both protected the sacred precinct as well as delineated the area that was the domain of the god (Wilkinson 2000: 56). The earliest example of this was a simple wood fence (Appendix A, Figure 51 below) found at Nekhen (aka Hierakonpolis) dating to the early dynastic period (Wilkinson 2000: 17). By the time of the New Kingdom, the standard barrier was a wall up to 10 meters thick, constructed of mudbrick sometimes over a wooden frame with reed mats (probably the same as materials used in the pre-dynastic period), and given the name sebty (Wilkinson 2000: 56). By this period, these walls were often undulating between concave and convex, and although theories have been presented, it is still unclear why this is so (Wilkinson 2000: 56).

The permanent temple structure itself also had an enclosure wall. This was nearly always constructed of stone, although in some cases mudbrick was also used. In such cases, the walls were not undulating. After entering into the temple typically through a massive pylon (gateway), an outer courtyard, surrounded by pillars, was the first area encountered. This outer courtyard was the more public area that was separated from the sanctified inner areas (Wilkinson 2000: 62).

All of these examples are of permanent structures. There is a clear gap in the archaeological record regarding mobile sacred spaces that include anything possible resembling a courtyard. As a result there is no usable data to analyze.

\section{Royal-Domestic Sphere}

Archaeological excavations have identified a few walled cities in Egypt (i.e., Tal 
el-Kahun, el-Amarna, Deir el-Medina). The permanent estates of the upper class (which included the royal family) often had a courtyard surrounded by a wall that enclosed structures and gardens. These vary based on topography and land ownership. There is a clear gap in the archaeological record regarding mobile domestic courtyards. It is possible that ancient tents did not typically have barriers around them, which may account for the gap. Another possibility is that mobile structures no longer existed and any texts that spoke of them also no longer exist or have not been identified as such. As a result, there is no usable data from the New Kingdom to analyze.

\section{Military Sphere}

The military sphere of ancient Egypt included outposts (which did not always have enclosure walls), temples (which did have enclosure walls), and fortified cities (which, when fortified, had enclosure walls). The Way of Horus route out of Egypt along the Mediterranean coast included at least 11 fortified migdol (fortress) outposts with at least nine having water sources and possibly as many as eighty New Kingdom sites from the Suez Canal to Gaza, not all of which were fortresses (Bárta 2003: 67, 70). These enclosure walls do not have a set design, let alone a design ratio but rather conform to the needs of the space inside and the topography where they are located.

Mobile Egyptian military camps from the New Kingdom no longer exist in the material culture of ancient Egypt (or have not been identified as such). However, they are depicted in iconographic representations. The most useful (for comparison and perhaps statistical analysis) is the war camp of Ramesses at the battle of Kadesh as represented iconographically on multiple temple walls. Long and a short textual versions of the battle exist. The best-preserved depictions are at Luxor ( $\mathrm{L}_{1}$, Appendix A, Figure 47), Abu 
Simbel (I; Christophe 1965; MacQuitty 1965; Desroches-Noblecourt, Donadoni, and Edel 1971, Appendix A, Figure 48), and the Ramesseum ( $\mathrm{R}_{1}$, Appendix A, Figure 49) walls (Spalinger 1985: 6). Those in poor condition are at Abydos (A), Karnak (K $\left.\mathrm{K}_{1}, \mathrm{~K}_{2}\right)$, and Luxor $\left(\mathrm{L}_{3}\right)$ (Spalinger 1985: 6-7). A depiction under $\mathrm{L}_{1}\left(\mathrm{~L}_{\mathrm{p}}\right.$, making $\mathrm{L}_{1}$ a second (altered) version) (Spalinger 1985: 12) also exists. Thus $\mathrm{L}_{1}$ is a palimpsest (Appendix A, Figure 47). A few lost depictions are known to have existed at the Ramesseum $\left(\mathrm{R}_{2}\right)$ and Luxor $\left(\mathrm{L}_{2}\right)$ (Spalinger 1985: 12). Versions I and $\mathrm{R}_{1}$, seem to be the most historically accurate (Spalinger 1985: 10-13) due to the exactness of the parallel. Version $L_{3}$, is the only version to depict the topography (Spalinger 1985: 14). There is also a papyrus shared by the British Museum and the Louve that describes the battle (Gardiner 1978: 260).

From the descriptions in the Annals of Thutmose III, the camp of Ramesses II was identical to those in the $18^{\text {th }}$ Dynasty (approx. $16^{\text {th }}$ to $14^{\text {th }}$ centuries B.C.), which is strongly supported by the language used for both (Hoffmeier 1977: 16, 2005: 206). The war camp of Ramesses II as depicted in its entirety $\left(L_{1}, I\right.$, and $R_{1}$; see Appendix A, Figures 57-59) shows two main entrances (east side which is the left side and bottom [north] of the camp) with guards. The camp is also protected by a shield wall (Spalinger 1985: 7-8). This wall of shields, apparently made of cowhide as many were in the New Kingdom (Bonnet 1926: 58), was likely higher than the soldiers themselves since most of the shields of this time were (Newberry 1894). While all three have slight differences (such as the ratio of the perimeter, the location of the north entrance, and small details in how the shields are represented), overall the camp is clearly delineated by an outer perimeter of shields arranged in a rectangular shape. 


\section{Courtyard Statistical Analysis}

Sacred and domestic mobile spheres did not seem to have any form of barrier that would then create a courtyard. As a result, there is no data to analyze. In the military sphere, there is data to analyze only from the mobile military camp of Rameses II. However, since the data comes from iconography and not from a text or material culture, the results must be considered approximate and any conclusions tentative.

That the illustrations of the military camp of Ramesses II intend to depict the same situation in the camp seems almost certain. In all three depictions there is a row of horses standing before the left side entrance (in grey ring), a lion with its trainer before the king's tent enclosure (in yellow ring), soldiers standing guard at both entrances (in orange and blue rings), the Hittites' attack from the upper right side of the camp (in purple ring), the same man is stabbed below the central structure (in green ring), and there is a man carrying something across his shoulders between two tents above the central structure (in red ring, see Appendix A, Figure 50). While many other details are included or not included in all three images, it seems fairly clear that this was meant to depict an actual moment in the same camp - the moment the Hittites attacked.

The depiction of the military camp’s perimeter from Luxor $\left(\mathrm{L}_{1}\right)$ shows 15 shields on the left side of the bottom entrance, 16 shields on the right side of the bottom entrance, and the bottom entrance being the width of one shield for a total of 32 shield widths. There are nine shields below the left side entrance, eight shields above the left side, and a possibility of two shields equivalent of space between these for the left side entrance for a potential total of 19 shield widths. This is a camp ratio of 32:19.

The bottom of the Abu Simbel (I) camp shows 27 shields on the left side of the 
bottom entrance, 13 shields on the right side of the bottom entrance, and no gap for a bottom entrance for a total of 40 shields. There are seven shields below of the left side entrance, eight shields above of the left side entrance, and the entrance is about three shields in width for a total of 18 shields. This is a ratio of $40: 18$ or 20:9 (slightly less than the 2:1 that Homan claims; Homan 2002: 66).

The bottom of the Ramesseum ( $\left.\mathrm{R}_{1}\right)$ camp depiction shows 14 shields on the left side of the lower entrance, 16 shields on the right side of the lower entrance, and one shield of a different color on either side of the lower entrance, which is also the width of one shield for a total of 33 shield widths. The left side of the camp is lost near the top but is a tentative 22 shields long (although it could be a shield or two longer). This is at least a ratio of 33:22 or 3:2.

The results are that the $\mathrm{L}_{1}$ depiction has a courtyard ratio of 32:19 shields, the I depiction has a ratio of 20:9, and the $\mathrm{R}_{1}$ has a tentative ratio of about 3:2. Space on a wall was a major factor that influenced both the spelling of words in a text and how things were depicted (shape and size). Therefore, it is not unlikely that this might account for the reason some of the dimensions and therefore ratios are not the same. Which depiction, if any, represents the correct ratios is not knowable from this data alone.

\section{Central Structures in the Archaeological Record}

It is acknowledged that the three spheres under study (sacred, royal-domestic, and military) are somewhat of a modern construct. However, they do exist in ancient Egypt and are thus recognizable and therefore can be studied. Also, while the focus of this study is on the mobile structures associated with the mobile courtyards of each of these spheres, some permanent structures will be discussed in an illustrative way. A structure will be 
defined here as any feature designed to be entered into as the main focus inside of a courtyard.

\section{Sacred Sphere}

The earliest excavated sacred sphere in Egypt was at Hierakonpolis (or Nekhen), which is dated to the early dynastic period. The rectangular structure was fronted by four large wooden pillars (Wilkinson 2000: 17; Appendix A, Figure 51) that are believed to have been retained in later temples by the large flagpoles attached to pylons (Appendix

\section{A, Figure 52).}

The permanent Egyptian sacred sphere was most often (by the New Kingdom) constructed of stone walls that only allowed passage through doorways. The doors themselves were probably not solid metal but metal overlaid on a wooden core (Wilkinson 2000: 67-68). These permanent temples were laid out on an axis and had subsidiary chambers to store goods, serve as crypts, and other undetermined purposes. They also had stairs leading to upper floors or the roof.

The innermost chamber was the sanctuary where the image of the god was housed in a shrine (Wilkinson 2000: 69). When the barque was not placed in the sanctuary, it rested in the room just before the sanctuary (Wilkinson 2000: 69). The sanctuary was often sealed off by a wooden door overlaid with either bronze or gold (Wilkinson 2000: 70). The shrine in the sanctuary was sometimes made of gold overlay on a wooden frame (Wilkinson 2000: 70). Because of the sacredness of the inner chamber (considered a part of the heavenly realm), all who entered it had to be ritually purified (Wilkinson 2000: 70). How this purification was accomplished is not entirely clear, but it included shaving of one’s body of all hair and ritually washing. 
Egyptian sacred spheres appear to have been oriented toward the east in the Old Kingdom period (Badawy 1968: 183). By the New Kingdom they appear to no longer to have had a standard direction of orientation (Appendix A, Figure 53), but rather appear to be oriented by the direction of the Nile river so that the entranced faced the river regardless of the bearing.

Shrines in early Egypt were made from perishable materials (Hoffmeier 2005: 205). At Nekhen, archaeologists have found evidence for one of these early shrines that extended beyond the southern side of the courtyard but was accessed from within the courtyard (Wilkinson 2000: 17, see Appendix A, Figure 51). The shrine was rectangular, a shape determined from post holes that remain (between 1.0 meter and 1.5 meters in diameter - suggesting a great height, which can only be determined through speculation; Wilkinson 2000: 17). Some ancient cultures in Mesopotamia and the Levant even had very large mobile shrines (Hoffmeier 2005: 205).

Mobile sacred spheres in Egypt were related to funerary contexts, tent shrines, and homes for the gods. Those in the funerary context were known as tents of the gods (sh ntrr) after the Old Kingdom or purification tents ('ibw) in the Old Kingdom, and they were used for embalming royalty (Homan 2002: 105). Although some scholars do not agree (i.e. Goedicke 1985: 48) that Egyptian nobles used tents to worship their gods, it is hard to understand what else could be meant in the Report of Wenamun, the Tale of Sinuhe, and the Contest of Horus and Seth (Homan 2002: 110-11).

Mobile shrines did exist in ancient Egypt, although most are attested only in iconography. In one illustration (Appendix A, Figure 54), workers scramble to put the 
finishing touches on a shrine of gilded wood framework covered by embroidered curtains for Amenhotep I (Kitchen 2000: 21).

The funeral tent of Queen Isetemkheb B (also Isemkhebe or Isimkheb) is a unique example of leather tapestry (Appendix A, Figure 55). The tent has been "described as a mosaic of leather work, consisting of thousands of pieces of gazelle hide, stitched together with threads of colours [sic] to match” (Stuart 1882: 5). The edges of the tent are bound by "a cord of twisted leather, sewn on with stout pink thread” (Stuart 1882: 5). The main section of the tent is 2.8 meters long and 2.4 meters wide (Brugsch 1889: 5). This main section has a flap attached to all four sides so that the end flaps are 2.4 meters wide by 2.16 meters long and the side flaps are 2.8 meters wide by 2.16 meters long (Brugsch 1889: plate 1). Thus, the entire structure had a ratio of 7:6 (length to width) and a ratio of 14:12:11 when height is added.

The gilded shrines of Tutankhamun, found in KV62 were nested around his sarcophagus. Around this was draped linen cloths over a wooden frame (Appendix A, Figure 56). The shrines were gilded wooden panels held in place by tenons and sockets that allowed for ease of dismantling and transportation.

Woodworking design has also been studied. In one example of a coffin, wood was fastened together so that the grains ran in opposite directions to produce a six-ply wood sarcophagus (Gale et al. 2000: 357; see Appendix A, Figure 57). From the earliest times, "Egyptians established the concept of constructing timber in one of three forms: box, frame, and stool (or a combination of all three using [specific] joints)" (Gale et al. 2000: 358). Because the strength of wood is along the grain, most solid boards were cut this way (Gale et al. 2000: 358). To affix boards together, Egyptians used a number of 
specific joints: butt, edge (with loose tenon or dowel), coppered, half-lap, housing, halving, mortise and tenon (common through with scribed shoulders, barefaced, stub, or dovetail-shaped), bridle, dovetail (simple, lapped, through, or half), mitre (simple, shoulder, double shoulder, or butt surmounting a long plain), scarf (with butterfly locking piece, tied hook, or spliced) (Gale et al. 2000: 358-66).

\section{Domestic Sphere}

In the Egyptian cities that have been excavated, homes often are found to have been built next each other, connected in a row-house style. They were longer than wide and often had a small room in the entrance, a larger room further in, a bedroom in front of the kitchen, which was at the back (Friedman 1994: 110; McDowell 1999: 12; Meskell 2002: 114-16; Snape 2014: 78-80; see Appendix A, Figure 58). Often there were stairs leading to the roof and stairs leading down into an earth-cut cellar. However, these are only design elements. The permanent residence of the god-king of Egypt and the royal family did not follow a standard design.

As for the mobile domestic sphere, Hoffmeier has been able to demonstrate from a number of sources that tents were used as dwellings not just in the Levant but also in Egypt (Hoffmeier 2005: 196-98). Wiseman (1978: 197-198) points to the letter from Šulgi of Ur to Puruš-Mumušada of Susa, the myth of Martu, and a number of other Mesopotamian texts that make it very clear that tents were also used in Mesopotamia and, not surprisingly, in Arabia.

Tent-like structures appear to also have been used in domestic settings long before the New Kingdom. The funerary equipment of Hetepheres I, wife of Sneferu (first king of the $4^{\text {th }}$ Dynasty, conventionally dated to approximately $26^{\text {th }}$ to $25^{\text {th }}$ centuries B.C.) and 
mother of Kufu, includes a bed canopy (Reisner and Smith 1955; see Appendix A, Figures 69 and 70) measuring 3.2 meters long, by 2.5 meters wide, by 2.2 meters high (Reisner and Smith 1955: 23) for a ratio of 32:25 (length to width) and a ratio of 32:25:22 (when height is added). This can help us understand some of the design elements that were present in this structures of wooden frames that were curtained and covered like a tent.

The wooden frame was overlaid by gold and found stored with the curtain in a box. Hooks were fastened to the top of the canopy at intervals, in such a way to allow the curtain to be hung on the inside of the walls and also to securely fix a roofing cloth (Reisner and Smith 1955: 23). The gold casing (all of a single sheet, except in two cases where it overlapped at the edges, Reisner and Smith 1955: 24) was preserved as was the copper sheathing (held onto the boards by copper tacks) along the base together with the tenon and socket joints, showing exactly how this structure was kept together (Reisner and Smith 1955: 23). The inside of the door frame had inscriptions with the titles and name of Snefru but all other surfaces were smooth (Reisner and Smith 1955: 23). The wood appears to have been shaped and inscribed before the long sheets of gold were beaten onto it (Reisner and Smith 1955: 24). Three copper flat-slotted bolts with beetleshaped heads fastened the corner boards to each other at the top, middle, and lower portions of the corner boards (Reisner and Smith 1955: 24). Heavy copper staples were used to secure the boards via ropes at all copper-coated dovetailed tenons and copper sockets were soldered together, with silver (Reisner and Smith 1955: 24) so precisely that the joints fit together so that only a thin piece of paper might be slipped in between (Reisner and Smith 1955: 25). Limestone bases were found nearby and have been 
understood to have been used as bases for the poles (Reisner and Smith 1955: 14).

The curtain storage box was constructed with a wooden knob at the center to lift the lid and the sides of the box were beveled and held together with wooden pegs (Reisner and Smith 1955: 26; see Appendix A, Figure 61). The wood was two mm thick to which was added another two mm of thickness of adhesive ("gum Arabic, gesso, and water”) and faïence (Reisner and Smith 1955: 26) as both the box and both sides of the lid were decorated. It is not clear if this configuration indicates that the entire structure was intended to be mobile or if this was just needed to store it.

\section{Military Sphere}

Permanent military structures did not follow a typical design plan. All, of course, had outer walls but these vary considerably (Badawy 1968: 446-74). Mobile military structures are much more informative regarding the tendency toward uniformity.

It is clear from iconographic representations that cloth was used for tent coverings, but no example has yet been recovered (or identified) to confirm this (Vogelsang-Eastwood 2000: 292). These tents, however, in shape and appearance were quite unlike the Bedouin tents in modern times (Hoffmeier 1977: 13). Hoffmeier (1977: 18) points out that hieroglyph $\mathrm{O} 22$ ( $\mathrm{zh}$, see Appendix A, Figure 62) is a representation of a tent which demonstrates that there was a center pole with a slightly-peaked roof and straight sides (see also Allen 2000: 438) in this he agreed with a point Dawson (1926) had made that not all tent representations had a central pole (see examples in Appendix A, Figure 63). The portable canopy found in Tutankhamun's tomb (Carter number 123) is just a frame consisting of gilded wood that obviously held a tent made of fabric of some kind to provide shade (James 2009: 294). 
According to the Memphis stele of Amenhotep II and an Amarna boundary stele, the king had his own tent in which he rested (Hoffmeier 1977: 14). In the Annals of Thutmose III the tent of the enemy was “decorated with silver” and had wooden poles that were overlaid with silver (Hoffmeier 1977: 14). During the reign of Hatshepsut, her tent was filled with precious metals and fine linen (Hoffmeier 1977: 15). Military tents seem to have been rolled for transport, as illustrated in the tomb of Horemheb at Saqqara (Vogelsang-Eastwood 2000: 292). Again, it is the military camp of Ramesses II at Kadesh that provides the most useful analytical data.

\section{Central Structure Statistical Analysis}

In this section, ratios will be substituted for units of measurement to allow for comparison. These ratios will be useful for comparison with those of the Tabernacle of the Hebrew tent-sanctuary.

The depiction of the military camp's center structure from the wall paintings in Luxor ( $\mathrm{L}_{1}$, Appendix A, Figure 47) shows a ratio of 11:6. Inside this rectangle, are three small tents for officials/princes on the south side and another rectangle. This inner rectangle has a ratio of 8:3. This inner structure clearly has a tent on the right side (the tent of the god-king, which in typical Egyptian fashion is larger than all other tents) and another rectangle on the left side to which it is attached. This inner structure (god-king's tent and attached rectangle) has a ratio of 3:1. The attached rectangle alone has a ratio of 2:1.

The depiction of the military camp’s center structure from the wall painting in Abu Simbel (I, Appendix A, Figure 48) yields a ratio of 2:1. The three tents belonging to officials/princes are inside the inner rectangle this time (as opposed to how this is 
represented on the $L_{1}$ and $R_{1}$ walls). The inner rectangle has a ratio of 9:4. Not surprisingly, the god-king's tent is larger than all others (this time on the right side) and is attached to a rectangle. This inner structure (god-king's tent and attached rectangle) has a ratio of 8:3 (contra the 2:1 ratio that Homan claims; Homan 2002: 66). The attached rectangle has a ratio of 20:11 (close, but also not 2:1).

The depiction of the military camp's center structure depicted on the wall in the Ramesseum ( $\mathrm{R}_{1}$, Appendix A, Figure 49) indicates a ratio of 11:6. Inside this rectangle, are the same three officials'/princes' tents on the south side and another rectangle. This inner rectangle has a ratio of 26:11. The god-king's tent is on the left side this time and is still typically the much larger tent. It has a rectangle attached to it in the same way as the other depictions. This inner structure (god-king's tent and attached rectangle) has a ratio of 19:7. The attached rectangle alone has a ratio of 11:7.

\section{Statistical Data Grouping}

The above results indicate that both the $\mathrm{L}_{1}$ and $\mathrm{R}_{1}$ depictions of the center structure have a ratio of 11:6 while the I-version ratio is a very close 2:1. All three depictions depict the three tents of the officials/princes (Hoffmeier 1977: 18, 2005: 206) on the south side, although they differ as to where these tents were located in the center structure with the $\mathrm{L}_{1}$ - and the $\mathrm{R}_{1}$-versions depicting them outside the inner rectangle and I-version having them inside. Version $\mathrm{L}_{1}$ yields a ratio of $8: 3$ for the inner rectangle, the $\mathrm{R}_{1}$-version yields the ratio 26:11, and the I-version a ratio 9:4. Version $\mathrm{L}_{1}$ has a combined inner structure (god-king's tent and attached rectangle) at a ratio of 3:1, the $\mathrm{R}_{1}$-version at 19:7, and I-version at a ratio of 8:3. The attached rectangle has a ratio in the $\mathrm{L}_{1}$-version of 2:1, the $\mathrm{R}_{1}$-version a ratio of 11:7, and the I-version at 20:11. 
While all three of these depictions yield slightly different ratios, one key point is that these ratios are exact by today's standards and are relatively close to each other in every case. So while Homan didn’t get it exactly right, if one is to take the collective spirit of the design, he was much closer to being correct. The center structure has about a 2:1 ratio, while the inner rectangle has about a 3:1 ratio (only the $\mathrm{R}_{1}$-version is skewed slightly from this); the combined inner structure (god-king's tent and attached rectangle) with about a 3:1 ratio, and the attached rectangle has about a ratio of approximately 2:1.

In all three depictions, the Egyptian tent, whether it is the god-king's, official's/prince's, or soldier's, is represented with the exact same design. The tent is slightly higher than it is wide and it has a peaked roof. This probably reflects the presence of a center pole, which is seen in the cross-section of a military tent in the tomb of Horemheb (see Appendix A, Figure 64).

Only in the I-version depiction is there a hint of the function of the spaces in the combined inner structure. The attached rectangle depicts five foreigners in the pose of the hieroglyph for adoration (Homan 2002: 113-14; Hoffmeier 2005: 208). The god-king’s tent is filled with an image that is generally seen on the barque of the gods - two kites (in this case but also shown elsewhere as winged protectresses) facing inward with their wings surrounding the name in a cartouche (in this case but also shown elsewhere as the image) of their god (in this case their god-king). The presence of religious elements in a domestic dwelling (i.e. a tent) is just one more reminder that while the divisions of various spheres in Egypt (sacred, domestic, and military) are necessary for the sake of study, they were much more fluid in ancient Egypt. In this case, a clearly military camp (complete with an actual battle) has at its center a clear association of worship for the 
god-king Ramesses. And in this case, the god-king is positioned (in all three depictions, $\mathrm{L}_{1}, \mathrm{I}, \mathrm{R}_{1}$ ) immediately between the calm and chaos of the camp (see Appendix A, Figure $65)$.

\section{Courtyard and Structure Design Comparison and Discussion}

Walls appear around the permanent sacred, domestic, and military spheres and the mobile military sphere. There is no extant evidence that they existed around the mobile sacred and domestic spheres. As we have found, there is iconographic evidence that during the New Kingdom at least one mobile military sphere had a barrier and courtyard. This was rectangular in nature and composed of leather shields.

Structures at the center of permanent sacred, domestic, and military spheres did not have a standard design. However, the permanent sacred sphere was on an axis and was composed of recognizable rooms in a recognizable order. Structures in the permanent domestic sphere also were generally composed of recognizable rooms sometimes in a recognizable order. Structures in the permanent military sphere changed depending on the needs of the location and the topography available.

Mobile sacred, domestic, and military structures consisted of tents over (sometimes with gilded) wooden frames. The tents typically were made of cloth but leather examples exist. These structures were rectangular.

\section{Design of Egyptian Furniture}

In order to assess a cultural influence (intended or unintended) in furniture the design elements (the immaterial culture) must be quantifiable. Furniture no longer exist in their original contexts. Analysis, therefore, must take place where the furnishings are 
in tombs. Tomb 62 in the King's Valley (KV62, Tomb number 62; the tomb of Tutankhamun of the $18^{\text {th }}$ Dynasty, approx. $16^{\text {th }}$ to $14^{\text {th }}$ centuries B.C.) is famous for being a nearly-complete burial of a king of Egypt, recovered and recorded by archaeologists. Since this is without question the most complete extant burial of any king of the New Kingdom and since kings were buried with furniture (and other items) that they appear to have wanted to use in the afterlife to recreate their comfort in this life and the assemblage of furniture constitutes a sample group, selectively chosen by the ancient Egyptians themselves (Price 2016: 281) and not modern archaeologists, it provides as good an example of the design of furniture as is available from the time period under study (albeit with the idiosyncratic Amarna art style skewing the data, which will need to be assessed).

The Amarna art style aspect may not accurately reflect the norms of the New Kingdom. Therefore, it is important that the statistical analysis of KV62 be compared with sampling from the rest of the New Kingdom. As a control, these should both be compared with sampling from all periods prior to the New Kingdom in order to assess design preference change. The king of Egypt was the center of all three of the spheres in question (sacred, domestic, and military) so it is hoped that this analysis will provide adequate data sets in at least some of the aspects studied to compare with the results of furniture analysis in Chapter 3.

The first step will be to examine published archaeological reports for data regarding the design elements of furniture in KV62 and other items for the control groups. Since there is slight academic variance in the reporting of the data (Amenta and De Luca [2005] and Hawass and Vannini [2007], for example do not agree and are representative of the norm) it is important for the sake of avoiding bias to collect all of 
the data for comparison from one comprehensive source. This source was found in the work of Killen (1980). No value judgment is made regarding this work as more authoritative than others. Killen (1980) is simply comprehensive. Gaps in usable data should also be identifiable in the process. These gaps will be addressed, as much as is possible, in Chapter 7, with the hopes that they will be explored in a future study. The second step will be to analyze these data. The third step will be to organize them into usable data sets.

\section{KV62 Archaeological Record}

Since the discovery and subsequent clearing of the tomb beginning November 4, 1922 (see Carter 1963) the furniture of KV62 has been discussed (and debated; see Krauss 1986) and presented often in scholarly (i.e., Desroches-Noblecourt 1969; Reeves 1990) and in popular publications (i.e., Edwards 1976; Amenta and De Luca 2005; Hawass and Vannini 2007) as has the discovery and exploration of the Valley of the Kings (for a good overview see Romer 1981; Reeves and Wilkinson 1996; 48-85; Weeks and De Luca 2001; Weeks 2005; Wilkinson and Weeks 2016). What is important for this study is that the furniture was left intact. Because thieves could only carry out what they could fit through the small tunnel holes they had dug, items of jewelry - as demonstrated in a small cloth (apparently dropped by the thieves) that contained some rings - and costly goods - such as oils, unguents, and perfumes, were conspicuously absent (Goelet 2016: 452). As a result, we can be fairly confident that the furniture that was discovered by Carter and his team is a near-complete representation of what was intended to be in the tomb at burial, with the caveat that we do not know if what was intended to be in the tomb by Tutankhamun's burial crew was a complete representation of what should have 
been there or even what he wanted to be there (see Hornung 1982). What can be studied is only what exists.

It is clear from iconography, texts, and partly material culture, that furniture in the sacred sphere included altars, tables, the barque of the gods, and some way to light dark rooms. There were no altars or tables identified in KV62. There also was not a barque of any god. However, there was a portable simulacrum (term referring to a small-scale image) of Anubis that has some similarities to a barque (minus, of course, the boat itself). The simulacrum (Carter 261) was $270 \mathrm{~cm}$ long (which is the length of the poles), 52 wide, and 118 high (including the image of Anubis; see Appendix A, Figure 66) and was found wrapped in a linen shroud dated by the inscription to the $7^{\text {th }}$ year of Akhenaten (Hawass and Vannini 2007: 158). Anubis is painted black with gold inner ears, eyebrows, eye liner, and collar, and its claws were made of silver (which is rare in the tomb; James 2009: 156). Between Anubis’s paws was a scribe’s palette that was inscribed for Tutankhamun’s sister, Meritaten. From this it is clear that the poles were more than twice as long as the simulacrum was high. The height (including the image of Anubis) was a little over twice the width. This piece of furniture (with the poles) is about a ratio of 4:1:2 $(l, w, h)$. The one item of furniture considered to be a chest (although some scholars have mislabeled other boxes as chests; see Hawass and Vannini 2007, this is the only furniture item that is a chest) also has carrying poles that are $1 / 4^{\text {th }}$ longer than the chest is high (see Appendix A, Figure 67) so the carrying poles are not always twice as long as the height of the object so about a ratio of 4:3:3 $(l, w, h)$.

Another design feature that is seen among the furniture is gold overlay on wood. This can be seen in the shrines. The shrines themselves were functional. The pylon- 
shaped shrine had several compartments containing pieces of jewelry (James 2009: 156). All of the jewelry was decorated with cut stones or faience of blue (faded to either light blue or blue-green), purple (now a dark blue), and scarlet colors set in a gold framework (Appendix A, Figure 68). Many of the ornaments indicate re-use and reflect design elements from earlier in the dynasty (James 2009: 236). All are symbolic. One common design feature seen on the jewelry (see Appendix A, Figure 69) and on the shrines (see Appendix A, Figure 70) is that of winged protectoresses.

Another design element that seems somewhat common is the shape of the legs of some items. Many of the legs of beds, chairs, and game boards are shaped like those of lions, whose paws are resting on what has been called “drums" but are really ringed tenons (James 2009: 264; see Appendix A, Figure 71).

Linen is another design element often associated with the gods. Gods in ancient Egypt were clothed in linen, which was changed daily (Vogelsang-Eastwood 2000: 294). Amun-Re had a white garment decorated with red and green additions (VogelsangEastwood 2000: 294). Two tunics were recovered from Tomb KV62, both of which were made for children. Item number 367j was embroidered (using the following stitches: outline, chain, split chain, button-hole, and "a form of isolated knot”) in panels that include hunting scenes, a sphinx, and griffins (Vogelsang-Eastwood 2000: 280) and also feature braided appliqué (Vogelsang-Eastwood 2000: 281). Item number 44t was embroidered with rosettes that surrounded gold rosettes using the chain stitch (Vogelsang-Eastwood 2000: 280).

The only lamp in KV62 was the calcite (Egyptian alabaster) chalice-shaped lamp that was so thin that the light from inside made a scene of Tutankhamun and 
Ankhesenamun visible. The scene is $51.4 \mathrm{~cm}$ high and $28.8 \mathrm{~cm}$ wide, numbered 173 by Carter (Amenta and De Luca 2005: 208; Hawass and Vannini 2007: 75, Appendix A, Figure 72). The oil lamps of the common people were bowls in which they burned sesame or castor oil, with a twisted wick floating on the surface (Hawass and Vannini 2007: 75). Vessels of glass, calcite, ivory, and metal were often made in the shape of a pomegranate in the New Kingdom (James 2009: 83, note 82). One example of a vase comes from KV62, made of silver mixed with gold.

Egyptians often used veneer to give the impression that an object was of more value than it was in reality (Gale et al. 2000: 366). In fact, a number of items from KV62 were finished with a wood veneer and others were "embellished using the techniques of marquetry [insertion of pieces of material, usually wood, shell, or ivory, in patterns] and parquetry [geometrically patterned wood inlay]” (Gale et al. 2000: 367). "The surface of the coffin had been carved with a corrugated pattern before being covered with gold sheet that was held in position along its edges with small gold nails” (Gale et al. 2000: 357). In some examples, gesso (plaster compound as a base for gilding on wood) was used to affix the gold leaf to the linen that was in turn attached to the wood (Gale et al. 2000: 367).

Gold was considered the skin of the gods. It is thought that the effort to cover items of furniture with gold leaf was to make it appropriate for use in the sacred sphere. Gold was fastened onto wood by small gold tacks or if gold leaf was employed by a fine plaster and held in place by "some kind of adhesive, the nature of which has not been established" (James 1972: 40-41), although a number of adhesives have been identified and techniques are beginning to be developed that allow scientists to identify these adhesives more reliably (Newman and Serpico 2000). The beating of gold into fine sheets 
was accomplished (according to tomb decorations) by means of anvil and hammer with some examples as thin at $0.006 \mathrm{~mm}$ (James 1972: 41). Moldings using the lost wax method are known to have produced at least small objects of solid gold (James 1972: 42). Tutankhamun’s famous gold mask (256A) was composed of two sheets of gold that were raised into shape, joined together by hammering, chased for detail (defining features by removing excess metal), and embellished by burnishing (James 2009: 94).

Many bronze objects (in general) were cast including weapons and tools, which then had to be sharpened and further worked (Ogden 2000: 157). Many vessels were hammered out (including mirrors) but vase stands were cast (Ogden 2000: 157). The most common cast was made from stone, pottery, or sand (Ogden 2000: 157). Although lost wax casting was in use at least by the Old Kingdom and hollow casting was common in the Middle Kingdom, solid cast was usually employed during the early New Kingdom (Ogden 2000: 158). By the end of the $18^{\text {th }}$ Dynasty (approx. $16^{\text {th }}$ to $14^{\text {th }}$ centuries B.C.), hollow casting was used again (Ogden 2000: 158).

A silver trumpet with gold mouth piece and gold rim to the bell (James 2009: 166) and painted wooden core $58.2 \mathrm{~cm}$ long, numbered 175 by Carter, was found in the tomb (Appendix A, Figure 73). The bell is decorated with engravings of lotus petals and a scene of Ptah (one of three army divisions [Amun and Ra the other two]; a fourth, Seth, was added “less than a century after Tutankhamun;” Hawass and Vannini 2007: 76), which may indicate that it was a military instrument (James 2009: 266). A second trumpet (Carter item number 50GG) made of a copper alloy partially overlaid with gold, was also recovered in the tomb of Tutankhamun that was $49.4 \mathrm{~cm}$ long (James 2009: 267). Both were "tuned to sound in fifths” (Hawass and Vannini 2007: 76). 
Standards were also found. These are poles, topped by a crossing flat top board, supported by a diagonal brace, and weighted by two shorter poles hanging parallel to the main pole, behind and opposite the brace (Appendix A, Figure 74). The flat top board was a cornice that supported the image of the deity of that nome (term used to designate a district or county in Egypt) or army unit with a raised notch just before the image (see James 2009: 154-55).

\section{KV62 Statistical Analysis}

The items of furniture in KV62 that are useful for this study can be grouped into five categories: bedframes, boxes, chairs, chests, and stools (a sixth category - tables exists in New Kingdom and pre-New Kingdom groupings - but there were no tables in KV62). The identification of the items of furniture are Killen's (1980). Each item will be described by the Carter number but will all be listed by the Museum (Cairo) inventory number for clarity and ease of duplication of research. The measurements that will be analyzed are units of volume (length, width, and height). Any item will be deemed unfit for analysis if two of these three units are missing from the data, in which case the item will not be listed in the study.

Stem-and-leaf plots will be used to organize the data into useable visual representations to show as clearly as possible the patterns of cultural preference in the data. The stem-and-leaf plots in this study will have the lower numbers at the lower portion of the plot, which makes it easier to discuss the numbers. Stem-and-leaf plots were chosen as they make comparison of multiple batches of similar data easy, which is necessary in this study. Ratios can be created from preferred stems (stems that exist at the greatest frequency). These ratios can be used to represent patterns of cultural preference 
in the data. The caveat will always be that the data is based on what is available for study. This means that any conclusions will be, of necessity, tentative.

Aside from identifying the preferred stem for each unit of measure (length, width, and height) in each item of furniture (bedframes, boxes, chairs, chests, stools, and tables) from each batch (KV62, New Kingdom [not including KV62], and pre-New Kingdom) the measure of central tendency will also be identified. These will be the standard mean, median, and mode. The results of the calculations for each will be reported for the sake of comparison. The mean will be represented by $\bar{X}$ (read "X bar") and will be used to show the average number in the unit of measure. The median will be represented as $M d$ and will be used to show the exact center of data for the unit of measure. The mode will be represented Mo and will be used to show the most frequently occurring number in the unit of measure. All three measures of central tendency will be compared with the preferred stem. Outliers will not be included in any of these measures of central tendency.

The five groups of furniture from KV62 with their corresponding units of measure, as identified by Killen, are listed in Table 13 (Killen 1980: 74-98). The units of measure will be analyzed in their own stem-and-leaf plots that correspond to this table. There was only one item of furniture identified as a chest. This does not constitute an appropriate sample (minimum of three examples) and thus is not included in the analysis. 
Table 13. KV62 furniture measurements

\begin{tabular}{|c|c|c|c|c|c|}
\hline a. Bedframes & Length & Width & Height & Museum & $\begin{array}{l}\text { Inventory } \\
\text { Number }\end{array}$ \\
\hline $18^{\text {th }}$ d. Carter 466 & 1750 & 835 & 685 & Cairo & 62014 \\
\hline $18^{\text {th }}$ d. Carter 377 & 1803 & 795 & 711 & Cairo & 62015 \\
\hline $18^{\text {th }}$ d. Carter 47 & 1840 & 901 & 749 & Cairo & 62016 \\
\hline $18^{\text {th }}$ d. Carter 80 & 1845 & 680 & 620 & Cairo & $62017 \mathrm{AB}$ \\
\hline $18^{\text {th }}$ d. Carter 586 folding & 1800 & 680 & 495 & Cairo & 62018 \\
\hline b. Boxes & Length & Width & Height & Museum & $\begin{array}{l}\text { Inventory } \\
\text { Number }\end{array}$ \\
\hline $18^{\text {th }}$ d. Carter 403 & & 438 & 679 & Cairo & 61446 \\
\hline $18^{\text {th }}$ d. Carter 56 & & 269 & 450 & Cairo & 61448 \\
\hline $18^{\text {th }}$ d. Carter 54ddd & 165 & 127 & 140 & Cairo & 61449 \\
\hline $18^{\text {th }}$ d. Carter 587 & 395 & & 570 & Cairo & 61451 \\
\hline $18^{\text {th }}$ d. Carter 54 & 400 & & 560 & Cairo & 61452 \\
\hline $18^{\text {th }}$ d. Carter 330 & 705 & 500 & & Cairo & 61453 \\
\hline $18^{\text {th }}$ d. Carter 50 & 1314 & 355 & 482 & Cairo & 61454 \\
\hline $18^{\text {th }}$ d. Carter 585 & 647 & 330 & 266 & Cairo & 61456 \\
\hline $18^{\text {th }}$ d. Carter 271 & 450 & 483 & 420 & Cairo & 61458 \\
\hline $18^{\text {th }}$ d. Carter 268 & 258 & 228 & 216 & Cairo & 61461 \\
\hline $18^{\text {th }}$ d. Carter 267 & 444 & 298 & 279 & Cairo & 61462 \\
\hline $18^{\text {th }}$ d. Carter 40 & & 177 & 258 & Cairo & 61466 \\
\hline $18^{\text {th }}$ d. Carter 21 & 610 & 420 & 444 & Cairo & 61467 \\
\hline $18^{\text {th }}$ d. Carter 316 & 596 & 406 & 495 & Cairo & 61474 \\
\hline $18^{\text {th }}$ d. Carter 44 & 495 & & 390 & Cairo & 61476 \\
\hline $18^{\text {th }}$ d. Carter 493 & 279 & 216 & 165 & Cairo & 61479 \\
\hline c. Chairs & Length & Width & Height & Museum & $\begin{array}{c}\text { Inventory } \\
\text { Number }\end{array}$ \\
\hline $18^{\text {th }} \mathrm{d}$. Carter 91 throne & & 533 & 1041 & Cairo & 62028 \\
\hline $18^{\text {th }}$ d. Carter 87 & & 476 & 965 & Cairo & 62029 \\
\hline $18^{\text {th }} \mathrm{d}$. Carter 351 faldstool & & 700 & 1020 & Cairo & 62030 \\
\hline $18^{\text {th }}$ d. Carter 82 & & 500 & 1010 & Cairo & 62031 \\
\hline $18^{\text {th }}$ d. Carter 349 & & 360 & 730 & Cairo & 62032 \\
\hline $18^{\text {th }}$ d. Carter 39 child's & & 368 & 711 & Cairo & 62033 \\
\hline d. Chests & Length & Width & Height & Museum & $\begin{array}{c}\text { Inventory } \\
\text { Number }\end{array}$ \\
\hline $18^{\text {th }}$ d. Carter 32 & & 592 & 622 & Cairo & 61445 \\
\hline e. Stools & Length & Width & Height & Museum & $\begin{array}{l}\text { Inventory } \\
\text { Number }\end{array}$ \\
\hline $18^{\text {th }}$ d. Carter 83 folding & 470 & 317 & 342 & Cairo & 62035 \\
\hline $18^{\text {th }}$ d. Carter 467 & & 450 & 450 & Cairo & 62038 \\
\hline $18^{\text {th }} \mathrm{d}$. Carter 84 lattice & & 304 & 292 & Cairo & 62040 \\
\hline $18^{\text {th }} \mathrm{d}$. Carter 81 lattice & & 380 & 305 & Cairo & 62041 \\
\hline $18^{\text {th }} \mathrm{d}$. Carter 412 3-legged & & 431 & 290 & Cairo & 62043 \\
\hline $18^{\text {th }} \mathrm{d}$. Carter 378 footstool & 584 & 317 & 76 & Cairo & 62045 \\
\hline
\end{tabular}




\section{KV62 Statistical Data Grouping}

The summary table lists all of the analyzed data. The letter (a, b, c, etc.) is a

reference to the item of furniture as listed in Table 13. Length is listed after the letter as “.1,” width as “.2,” and height as “.3.” These measurements correspond to the stem-andleaf plots below: bedframes (Tables 14-16), boxes (Tables 17-19), chairs (Tables 20-21),

Table 14. A stem-and-leaf plot of the length of the bedframes (KV62)

\begin{tabular}{|c|c|c|c|c|c|}
\hline Length & Stem & Leaf & & \multicolumn{2}{|l|}{20} \\
\hline 1750 & 17 & 50 & & $\begin{array}{l}20 \\
19\end{array}$ & \multirow{10}{*}{$\begin{array}{l}00,03,40,45 \\
50\end{array}$} \\
\hline 1803 & 18 & 03 & & $\begin{array}{l}19 \\
18\end{array}$ & \\
\hline 1840 & 18 & 40 & & $\begin{array}{l}10 \\
17\end{array}$ & \\
\hline 1845 & 18 & 45 & & 16 & \\
\hline \multirow[t]{2}{*}{1800} & 18 & 00 & & 15 & \\
\hline & & & & 14 & \\
\hline \multicolumn{3}{|c|}{$1807.6 \bar{X}$} & & 13 & \\
\hline \multicolumn{3}{|c|}{$1803 M d$} & & 12 & \\
\hline \multicolumn{2}{|c|}{$\mathrm{n} / \mathrm{a}$} & Mo & & 11 & \\
\hline \multicolumn{2}{|c|}{ 1750-1845 } & Frequency rang & (1800 Stem) & 10 & \\
\hline
\end{tabular}

Table 15. A stem-and-leaf plot of the width of the bedframes (KV62)

\begin{tabular}{|c|c|c|c|c|c|}
\hline Width & Stem & Leaf & & \\
\hline 835 & 8 & 35 & & $\begin{array}{l}10 \\
9\end{array}$ & 01 \\
\hline 795 & 7 & 95 & $\mathrm{COCO}$ & 8 & $\begin{array}{l}01 \\
35\end{array}$ \\
\hline 901 & 9 & 01 & (2) & 7 & 95 \\
\hline 680 & 6 & 80 & 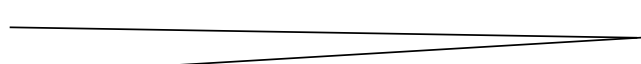 & 6 & 80,80 \\
\hline \multirow[t]{5}{*}{680} & 6 & 80 & & 5 & \\
\hline & & & & 4 & \\
\hline & 778.2 & $\bar{X}$ & & 3 & \\
\hline & 795 & $M d$ & & 2 & \\
\hline & 680 & Mo & & 1 & \\
\hline $680-90$ & & Frequency rang & 600 Stem & 0 & \\
\hline
\end{tabular}


Table 16. A stem-and-leaf plot of the height of the bedframes (KV62)

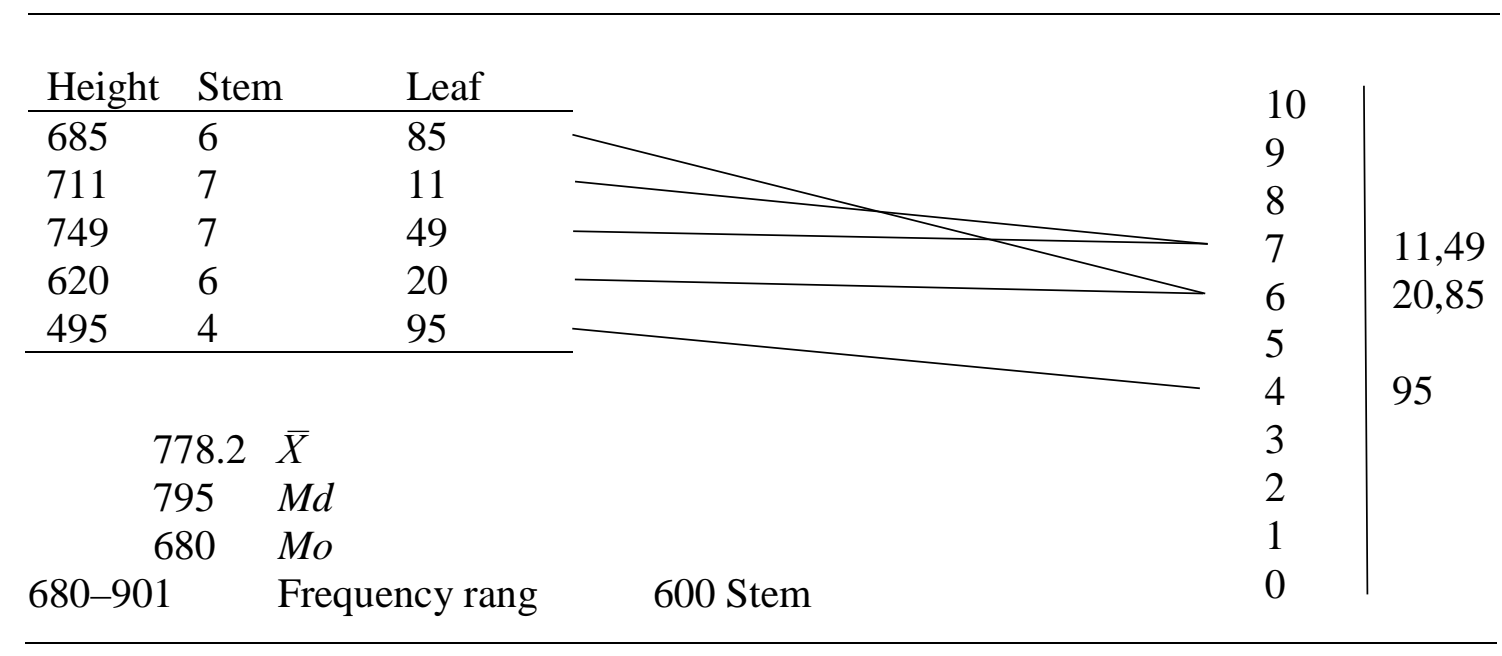

Table 17. A stem-and-leaf plot of the length of the boxes (KV62)

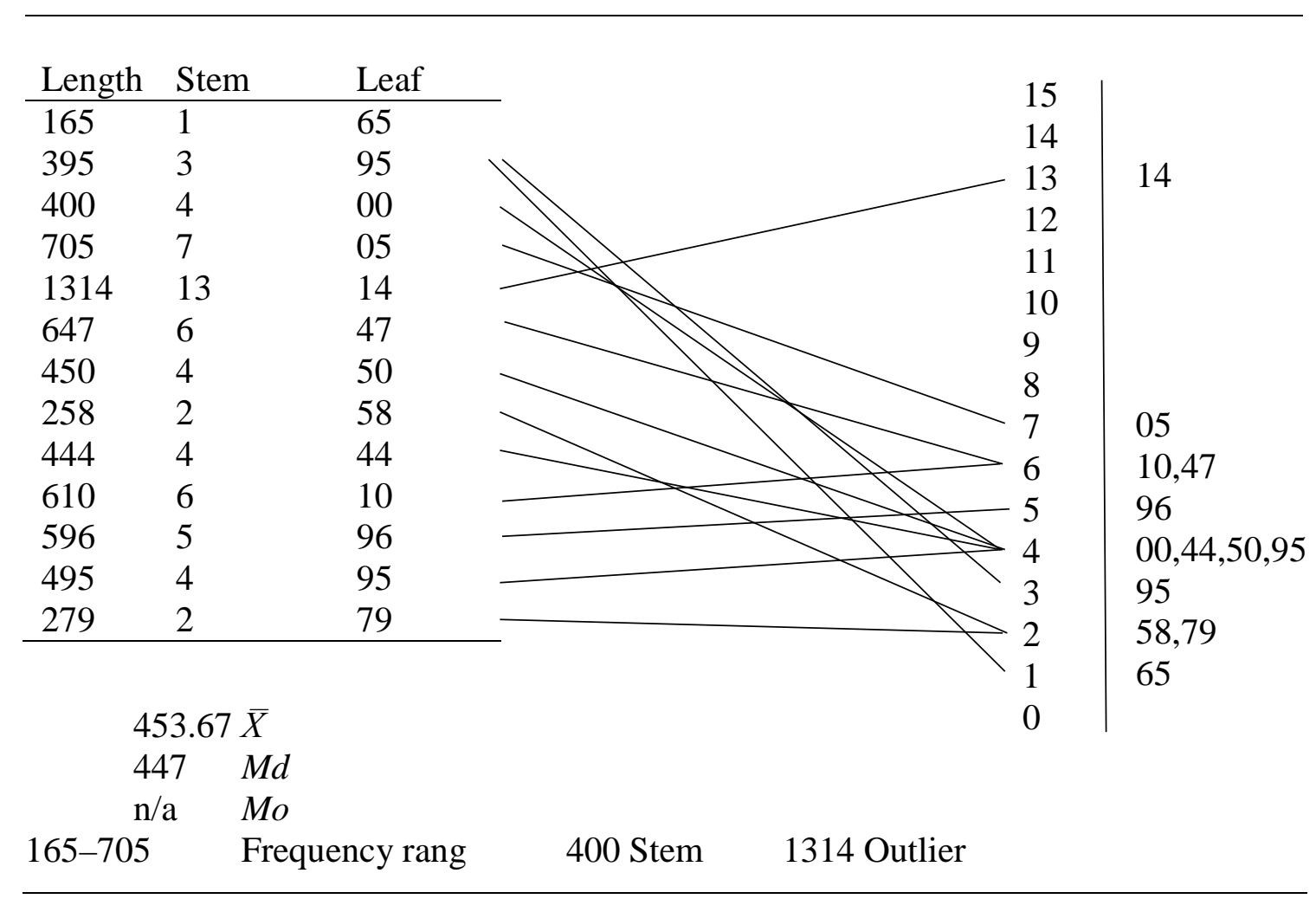


Table 18. A stem-and-leaf plot of the width of the boxes (KV62)

\begin{tabular}{|c|c|c|c|c|c|}
\hline Width & Stem & Leaf & & 10 & \\
\hline 438 & 4 & 38 & & 9 & \\
\hline 269 & 2 & 69 & & $\begin{array}{l}9 \\
8\end{array}$ & \\
\hline 127 & 1 & 27 & & $\begin{array}{l}8 \\
7\end{array}$ & \\
\hline 500 & 5 & 00 & & 7 & \\
\hline 355 & 3 & 55 & & 6 & \\
\hline 330 & 3 & 30 & & 5 & 00 \\
\hline 483 & 4 & 83 & & 4 & $06,20,38,83$ \\
\hline 228 & 2 & 28 & 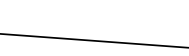 & 3 & 30 \\
\hline 298 & 2 & 98 & & 2 & $16,28,69,98$ \\
\hline 177 & 1 & 77 & & 1 & 27,77 \\
\hline 420 & 4 & 20 & & 0 & \\
\hline 406 & 4 & 06 & & & \\
\hline 216 & 2 & 16 & & & \\
\hline \multicolumn{6}{|c|}{$326.69 \bar{X}$} \\
\hline \multicolumn{2}{|c|}{330} & $M d$ & & & \\
\hline \multicolumn{2}{|c|}{$\mathrm{n} / \mathrm{a}$} & Mo & & & \\
\hline \multicolumn{2}{|c|}{$127-500$} & Frequency rang & 300 Stem & & \\
\hline
\end{tabular}

Table 19. A stem-and-leaf plot of the height of the boxes (KV62)

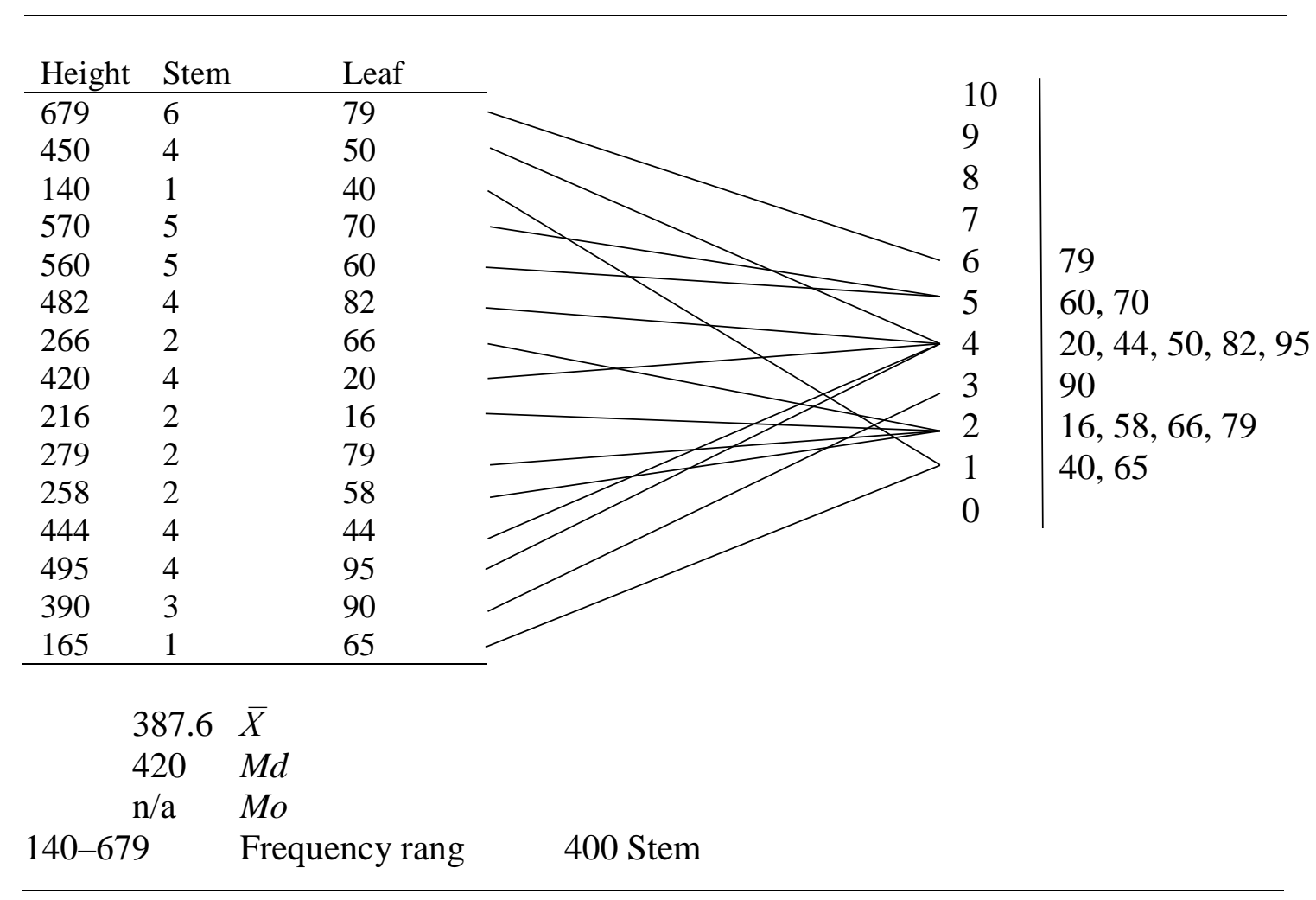


Table 20. A stem-and-leaf plot of the width of the chairs (KV62)

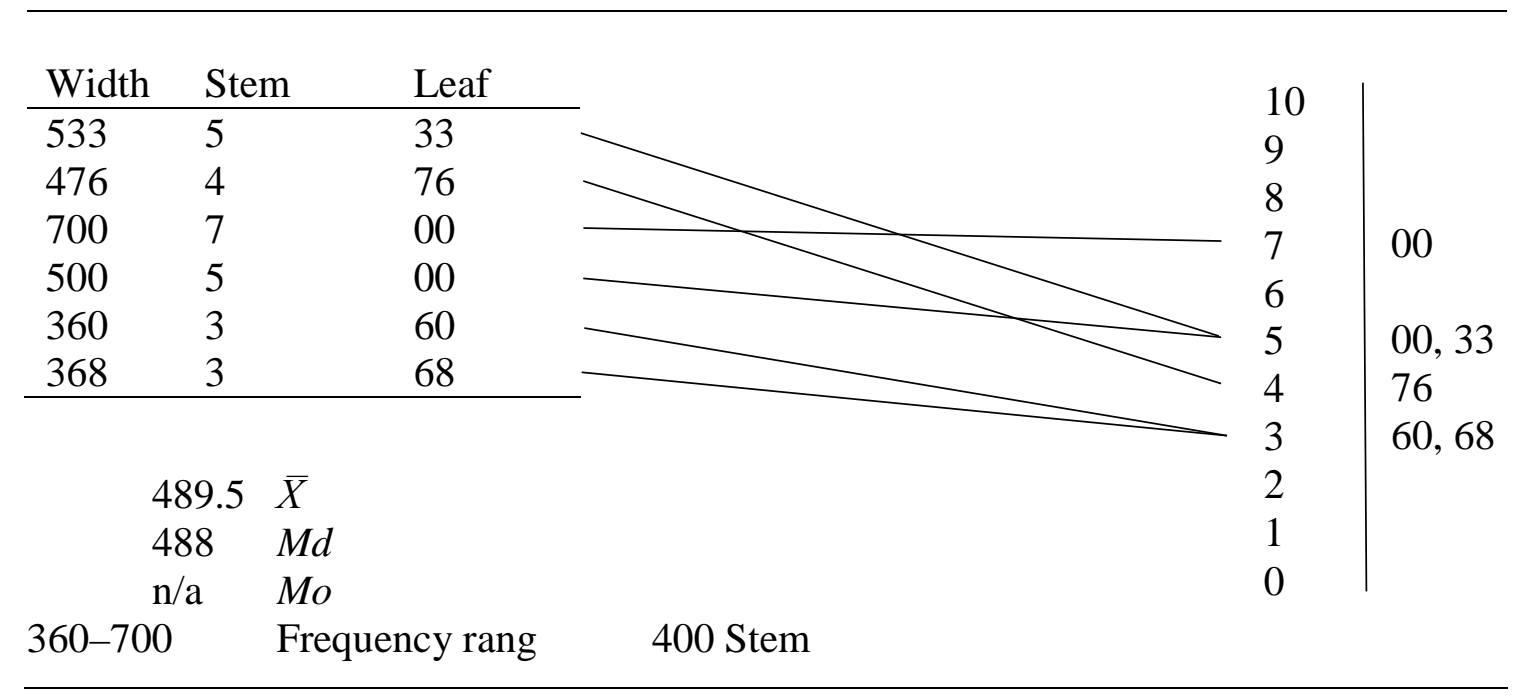

Table 21. A stem-and-leaf plot of the height of the chairs (KV62)

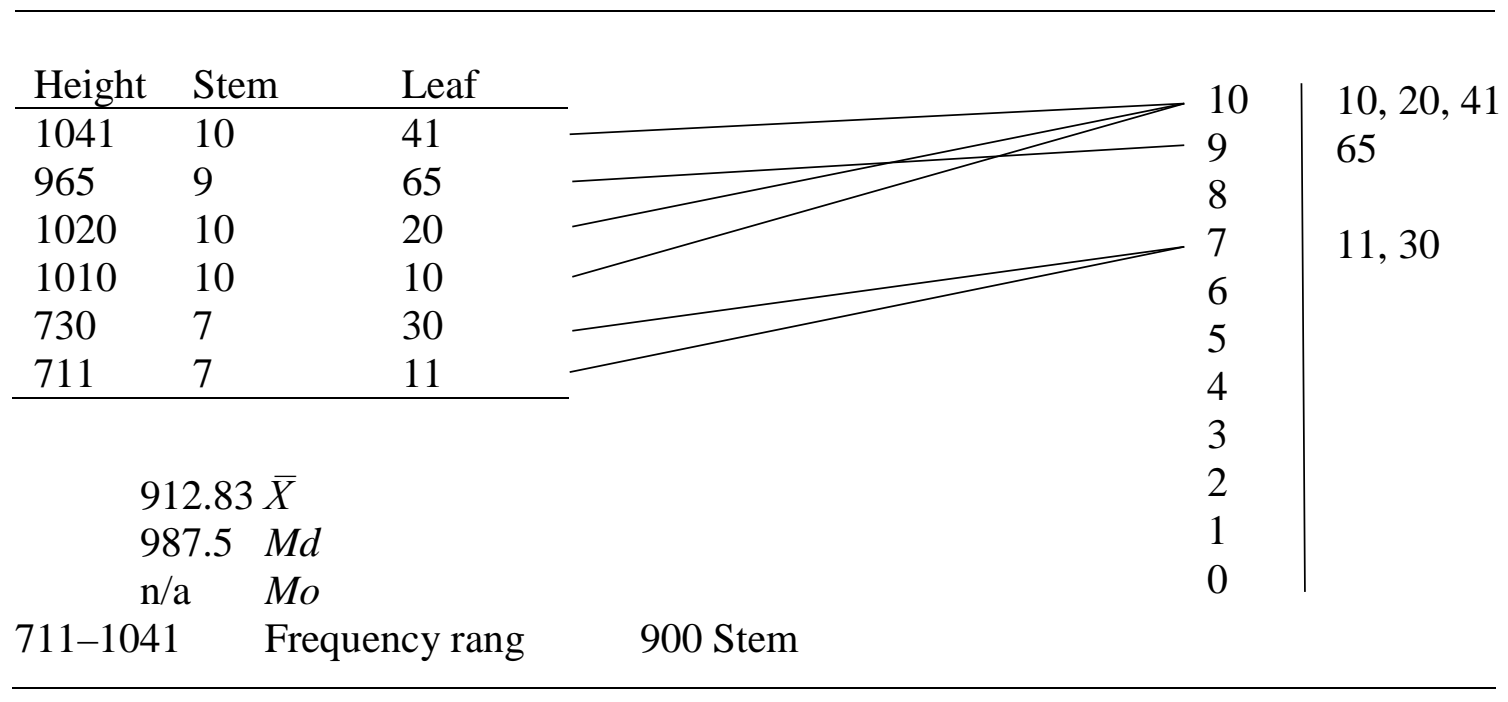

and stools (Tables 22-23). Sample size reflects the number of items sampled for each item of furniture. Table 24 will be used for comparison with items discussed in the other two batches below. 
Table 22. A stem-and-leaf plot of the width of the stools (KV62)

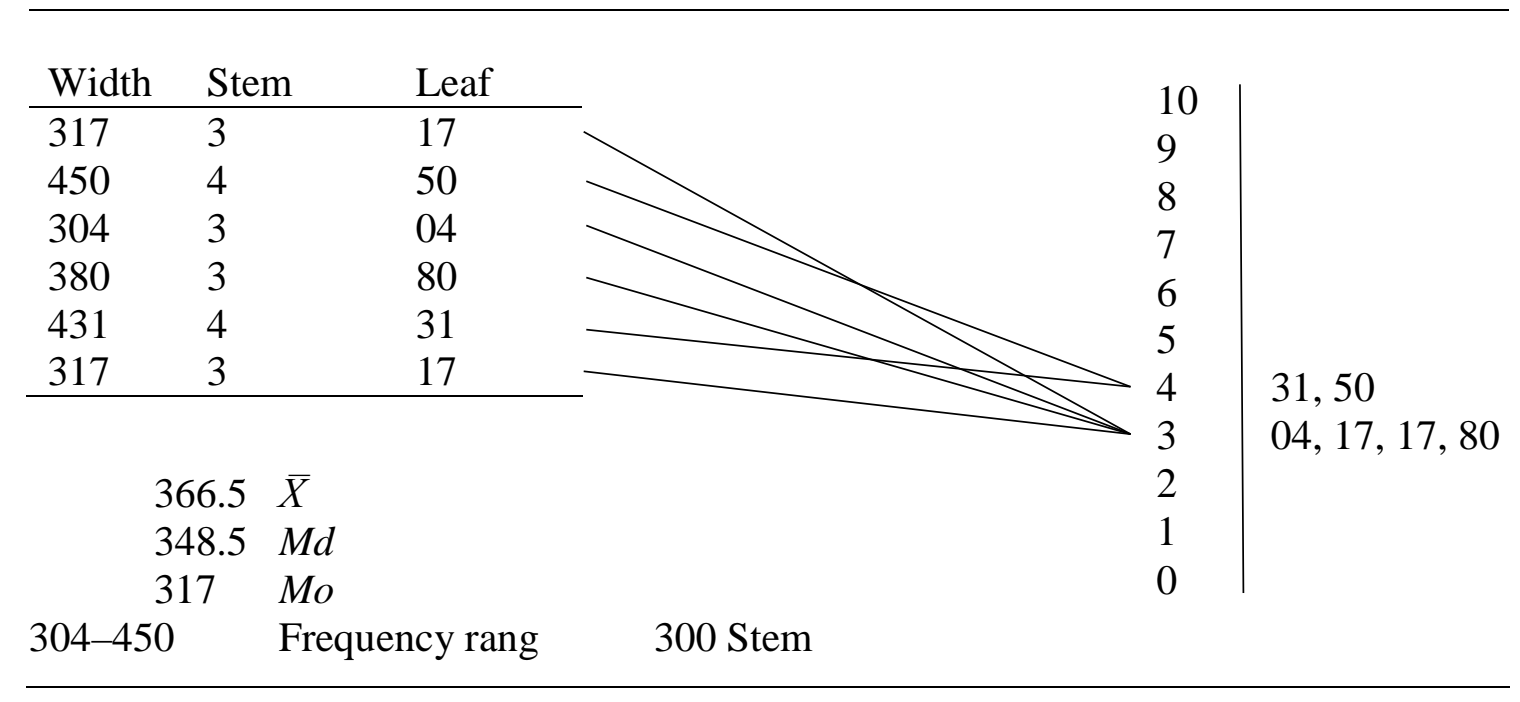

Table 23. A stem-and-leaf plot of the height of the stools (KV62)

\begin{tabular}{|c|c|c|c|c|c|}
\hline Height & Stem & Leaf & & \multicolumn{2}{|l|}{10} \\
\hline 342 & 3 & 42 & & $\begin{array}{l}10 \\
9\end{array}$ & \\
\hline 450 & 4 & 50 & & 8 & \\
\hline 292 & 2 & 92 & & 7 & \\
\hline 305 & 3 & 05 & & 6 & \\
\hline 290 & 2 & 90 & & 5 & \\
\hline 76 & 0 & 76 & & 4 & 50 \\
\hline \multicolumn{3}{|c|}{$292.5 \bar{X}$} & & 2 & 90,92 \\
\hline \multicolumn{3}{|c|}{$298.5 M d$} & & 1 & \\
\hline \multicolumn{2}{|c|}{$\mathrm{n} / \mathrm{a}$} & Mo & & 0 & 76 \\
\hline $076-450$ & & Frequency rang & 300 Stem & & \\
\hline
\end{tabular}


Table 24. KV62 furniture analysis

\begin{tabular}{lcccccccccc}
\hline & a.1 & a.2 & a.3 & b.1 & b.2 & b.3 & c.2 & c.3 & e.2 & e.3 \\
\hline Sample & 5 & 5 & 5 & 13 & 13 & 15 & 6 & 6 & 6 & 6 \\
Size & & & & & & & & & & \\
Mean & 1807.6 & 778.2 & 778.2 & 453.67 & 326.69 & 387.6 & 489.5 & 912.83 & 366.5 & 292.5 \\
Median & 1803 & 795 & 795 & 447 & 330 & 420 & 488 & 987.5 & 348.5 & 298.5 \\
Mode & n/a & 680 & 680 & n/a & n/a & n/a & n/a & n/a & 317 & n/a \\
Frequency & $1750-$ & $680-$ & $680-$ & $165-$ & $127-$ & $140-$ & $360-$ & $711-$ & $304-$ & $076-$ \\
Range & 1845 & 901 & 901 & 705 & 500 & 679 & 700 & 1041 & 450 & 450 \\
Preferred & 1800 & 600 & 600 & 400 & 300 & 400 & 400 & 900 & 300 & 300 \\
Stem & & & & & & & & & & \\
Outliers & n/a & n/a & n/a & 1314 & n/a & n/a & n/a & n/a & n/a & n/a \\
\hline
\end{tabular}

\section{Control Group Archaeological Record}

There were no stone statuary or altars found in Tomb KV62 but stone altars and statuary are known to have been part of the furniture in sacred spheres of ancient Egypt. Altars are also known to have been employed, often in outer courtyards and halls, while smaller altars were used closer to (or sometimes in) the inner sanctuary (Wilkinson 2000: 69), although few have been found. These altars were typically squared blocks that were decorated (see Appendix A, Figure 75, reconstructed) or flat slabs supported by round pillars, the larger ones with stairs (Wilkinson 2000: 69). The king is the one depicted as presenting the offering to the god in iconographic representations (Wilkinson 2000: 69). Often the statuary in the outer courtyards of temple precincts had the function of allowing the one they represented (almost always a man) to be present to perpetually worship their god, although some came to act as mediators between the visiting worshiper and the god (Wilkinson 2000: 63). When too many statues had been acquired, some were buried in the courtyard to put them out of the way (Wilkinson 2000: 64).

Non-stone statuary was accomplished almost exclusively by casting (as opposed to hammering) using wax models to produce both solid and hollow figures (Becker, 
Pilosi, and Schorsch 1994: 47). However, there are examples of hammered sheets that were raised to shape (Ogden 2000: 170). Although hollow casting requires greater skill in molding the wax model and core, there are less "shrinkage and porosity problems" and it “conserves resources” by not wasting metal (Becker, Pilosi, and Schorsch 1994: 47-8). After casting, flaws in the surface needed to be corrected by smoothing or filling (Becker, Pilosi, and Schorsch 1994: 48). Joins using pegs, dowels, or tenons were used to attach appendages to statues at least as far back as the Middle Kingdom so that the joins could be hidden by hammering, burnishing, or concealing, but never soldering or braising (Ogden 2000: 159). Any soldering detected on Egyptian objects was simply an indication of a repair (Ogden 2000: 159).

Wooden furniture often had legs. It seems that the design element of ringed tenon feet was used in furniture going back at least as far as the Old Kingdom as seen in the funerary equipment of Hetepheres (Amenta and De Luca 2005: 56; see Appendix A, Figure 76). Also, the concept of carrying as a mode of transportation existed long before the New Kingdom and in many ways other than the barque of the god. A wooden “carrying-chair” (also called "sedan chair," see Appendix A, Figure 77) was also discovered in the funerary equipment of Hetepheres. The two poles, connected to the long sides of the chair, had palm caps cased with gold (as was the entire structure) on both ends connected to the poles by a square tenon (Reisner and Smith 1955: 34). The poles were $206.5 \mathrm{~cm}$ in length including the palm caps, the chair with footrest was $99 \mathrm{~cm}$ long, $53.5 \mathrm{~cm}$ in front, $52 \mathrm{~cm}$ in back wide, and $52 \mathrm{~cm}$ high above the poles (Reisner and Smith 1955: 33). The exposed edges of the chair were covered with a gold molding and a strip of wood (possibly ebony) was decorated with solid gold "tiny" hieroglyphs along 
the back of the chair at arm height (Reisner and Smith 1955: 33). The sides of the boards were joined together with a double tenon system and a single tenon and peg were used to connect the pole (Reisner and Smith 1955: 33-34). In this case the poles were over twice the length of the chair and about four times either the width or the height. This item (with the poles) is about a ratio of 4:1:1 $(l, w, h)$.

Carrying chairs are also shown on the west wall (south of entrance), $2^{\text {nd }}$ register in the tomb of Khnumhotep II in Beni Hassan (Appendix A, Figure 78). In this scene, Khnumhotep is being carried on a palanquin by four men (Appendix A, Figure 79). A fifth man follows behind, carrying a sunshade (Kanawati and Evans 2014) believed to be made of animal skins and an axe for protection. Queen Nitokris (26 ${ }^{\text {th }}$ Dynasty, 664-525 B.C.) has also been depicted in a carrying chair (Badawy 1968: 11).

Linen was used long before and often in the New Kingdom and later. A blanket from the $23^{\text {rd }}$ Dynasty (approx. $11^{\text {th }}$ to $8^{\text {th }}$ centuries B.C.) uses blue (or purple) and red thread to make blocks (also undyed linen) around the armholes and neck-openings of tunics for the priests (Vogelsang-Eastwood 2000: 280). The name of Merenptah was embroidered using blue and red thread in a cloth that was wrapped around Seti II (Vogelsang-Eastwood 2000: 285), illustrating that words and not simply designs could be the subject of embroidery.

Pleating was also employed in Egyptian cloth to create chevron patterns (Vogelsang-Eastwood 2000: 281). Damaged cloth was often mended or patched rather than discarded (sometimes as much as three or four times; Vogelsang-Eastwood 2000: 281). Appliqué was also used to decorate cloth in the New Kingdom in which strips of blue and red cloth were attached in a decorative way by needlework. In one example, 
item number 101p, a bird (vulture) was created with these strips (Vogelsang-Eastwood 2000: 280). Examples of tapestry weaves (one warp and a weft composed of different colored threads to make a pattern) almost all come from royal tombs (including Tutankhamun's) mostly from the $18^{\text {th }}$ Dynasty, approx. $16^{\text {th }}$ to $14^{\text {th }}$ centuries B.C. (Vogelsang-Eastwood 2000: 275). Needles were made from bronze, copper, silver, or fish bone and ranged from a few millimeters to a centimeter in length, stored in small cases (Vogelsang-Eastwood 2000: 282). It is speculated that aside from tearing the cloth in straight lines, flint knives were used to cut out holes for the neck and arms (VogelsangEastwood 2000: 282). Seams and hems (Appendix A, Figure 80) consisted of only about six varieties: simple hem, rolled and whipped, simple seam, lap of seam, run and fell seam, and over cast seam (Vogelsang-Eastwood 2000: 283).

Natron, potash, and soapwort (Saponaria officinalis) were used for washing garments (Vogelsang-Eastwood 2000: 284). Apparently, these detergents could clean the cloth but were mild enough to not remove the weaver's mark, which was often made in ink (Vogelsang-Eastwood 2000: 285).

Folded cloth was stored and transported in sacks, boxes, or baskets (VogelsangEastwood 2000: 286). In fact, fold lines seem to have indicated wealth (as opposed, it is assumed to wrinkled fabric), which is illustrated in a $13^{\text {th }}$ Dynasty (approx. $18^{\text {th }}$ to $17^{\text {th }}$ centuries B.C.) statue (Vogelsang-Eastwood 2000: 286). It is assumed by scholars that Egyptians used curtains or wall hangings in their homes, but no examples have yet been recovered to confirm this assumption (Vogelsang-Eastwood 2000: 291).

Another item of furniture that was used after the New Kingdom is the basin. There are no examples before the New Kingdom but that doesn’t mean they didn't exist. 
A solid gold basin $17 \mathrm{~cm}$ tall with an edge diameter of $20.9 \mathrm{~cm}$ was recovered from Tanis by Montet in 1940 from the reign of Psusennes I of the $21^{\text {st }}$ Dynasty, approx. $11^{\text {th }}$ to $10^{\text {th }}$ centuries B.C. (Amenta and De Luca 2005: 238). A gold/electrum lobed cup of Undjebaunendjed that was also recovered from Tanis during the reign of Psusennes I that is $5.5 \mathrm{~cm}$ high with a diameter of $13.3 \mathrm{~cm}$ (Amenta and De Luca 2005: 240). So at least after the New Kingdom vessels used to hold liquids were sometimes made of metal.

\section{Control Group - New Kingdom (not KV62) Statistical Analysis}

The items of furniture in the batches for the New Kingdom (not including KV62) and pre-New Kingdom that are useful for this study as a control group can be grouped into the same six categories used for furniture from KV62: bedframes, boxes, chairs, chests, stools, and tables. These items of furniture will be described and measured in the same was, by units of volume (length, width, and height). Any item will be deemed unfit for analysis if two of these three units are missing from the data, in which case the item will not be listed in the study.

Stem-and-leaf plots will be used to organize the data into usable visual representations as those in the KV62 batch were. The caveat remains that the data is based on what is available to study. This means that any conclusions will, of necessity, be tentative.

Aside from identifying the preferred stem for each unit of measure (length, width, and height) in each item of furniture (bedframes, boxes, chairs, chests, stools, and tables) from each batch (KV62, New Kingdom [not KV62] and pre-New Kingdom) the measure of central tendency will also be identified. All three measures of central tendency will be 
compared with the preferred stem. Outliers will be identified and not included in any of these measure of central tendency.

The six groups of furniture from the New Kingdom (not KV62) batch with their corresponding units of measure as identified by Killen are listed in Table 25 (Killen 1980: 74-98). Since it is impossible to precisely identify the exact dynasty $(18,19$, or 20$)$ in which each of the items were made, they will be grouped as a whole. The units of measure will be analyzed in their own stem-and-leaf plots that correspond to this table.

\section{Control Group - New Kingdom (not KV62) Statistical Data Grouping}

The summary tables list all of the analyzed data. The letter (a, b, c, etc.) is a reference to the item of furniture as listed in Table 25. Length is listed after the letter as “.1,” width as “.2,” and height as “.3.” These correspond to the stem-and-leaf plots below: bedframes (Tables 26-28), boxes (Tables 29-31), chairs (Tables 32-34), chests (Tables 35-37), stools (Tables 38-40), and tables (Tables 41-43). Sample size reflects the number of items sampled for each item of furniture. Table 44 will be used for comparison with items discussed in the other two batches below. 
Table 25. New Kingdom (N.K.) furniture measurements

\begin{tabular}{|c|c|c|c|c|c|}
\hline a. Bedframes & Length & Width & Height & Museum & $\begin{array}{c}\text { Inventory } \\
\text { Number }\end{array}$ \\
\hline N. K. & 1190 & 560 & 180 & Vienna & 6128 \\
\hline $18^{\text {th }}$ d. Gen. Cat. 51108 & 1714 & & 558 & Cairo & 69066 \\
\hline $18^{\text {th }}$ d. Gen. Cat. 51109 & 1740 & & 584 & Cairo & 69067 \\
\hline $18^{\text {th }}$ d. Gen. Cat. 51110 & 1765 & & 762 & Cairo & 69068 \\
\hline $18^{\text {th }} \mathrm{d}$. & 1931 & 850 & 698 & Turin & 8327 \\
\hline $18^{\text {th }} \mathrm{d}$. & 1742 & 763 & 660 & Turin & 8629 \\
\hline N.K. & 1700 & 750 & 300 & Warszawie & 139068 \\
\hline $18^{\text {th }}$ d. royal & & 790 & 460 & London & 21574 \\
\hline $19^{\text {th }} \mathrm{d}$. & 1115 & 710 & 307 & London & 18196 \\
\hline b. Boxes & Length & Width & Height & Museum & $\begin{array}{c}\text { Inventory } \\
\text { Number }\end{array}$ \\
\hline $18^{\text {th }} \mathrm{d}$ & 60 & 52 & 56 & Brussels & 7667 \\
\hline $18^{\text {th }} \mathrm{d}$. Box w/ fine inlay & 193 & & 75 & Cairo & 57332 \\
\hline $18^{\text {th }}$ d. Gen. Cat. 51114 & 381 & 304 & 152 & Cairo & 69073 \\
\hline $18^{\text {th }}$ d. Gen. Cat. 51115 & 457 & 330 & 330 & Cairo & 69074 \\
\hline $18^{\text {th }}$ d. Gen. Cat. 51116 & 482 & 330 & 330 & Cairo & 69075 \\
\hline $18^{\text {th }}$ d. Gen. Cat. 51117 Jewel & 533 & 419 & 508 & Cairo & 69077 \\
\hline $18^{\text {th }}$ d. Gen. Cat. 51118 Jewel & 381 & 419 & 410 & Cairo & 69078 \\
\hline $18^{\text {th }}$ d. reed & 380 & 483 & 260 & London & 2560 \\
\hline $18^{\text {th }}$ d. jewelry & 198 & 230 & 150 & London & 5897 \\
\hline $18^{\text {th }} \mathrm{d}$. & & 90 & 155 & Manchester & 188 \\
\hline $18^{\text {th }} \mathrm{d}$. & 165 & 105 & 40 & Manchester & 543 \\
\hline $18^{\text {th }} \mathrm{d}$. & 330 & 330 & 127 & New York & 86.1 .8 \\
\hline $18^{\text {th }} \mathrm{d}$. Toilet gazelle & 195 & 64 & 65 & Brooklyn & $37.601 \mathrm{E}$ \\
\hline c. Chairs & Length & Width & Height & Museum & $\begin{array}{c}\text { Inventory } \\
\text { Number }\end{array}$ \\
\hline $19^{\text {th }}$ d. Sennedjem & 520 & 230 & 1600 & Cairo & 27256 \\
\hline $18^{\text {th }}$ d. Gen. Cat. 51111 & 355 & 393 & 595 & Cairo & 69069 \\
\hline $18^{\text {th }}$ d. Gen. Cat. 51112 & & 381 & 615 & Cairo & 69071 \\
\hline $18^{\text {th }}$ d. Gen. Cat. 51113 & & 508 & 792 & Cairo & 69072 \\
\hline $20^{\text {th }} \mathrm{d}$ & 330 & & 440 & Marseille & 287 \\
\hline $18^{\text {th }} \mathrm{d}$. & & 457 & 774 & Leiden & AH 52 \\
\hline $18^{\text {th }} \mathrm{d}$. & & 393 & 908 & Turin & 8333 \\
\hline $18^{\text {th }} \mathrm{d}$. & 470 & 570 & 600 & Oxford & 1890.859 \\
\hline $18^{\text {th }} \mathrm{d}$. & 490 & 410 & 730 & London & 2479 \\
\hline $18^{\text {th }} \mathrm{d}$ & 420 & 480 & 620 & London & 2480 \\
\hline $18^{\text {th }}-19^{\text {th }}$ d. low-back & & 458 & 610 & Edinburgh & 1956.106 \\
\hline Early $18^{\text {th }} \mathrm{d}$. & 305 & 305 & 127 & Edinburgh & 1956.110 \\
\hline $18^{\text {th }} \mathrm{d}$. & & 431 & 584 & New York & 12.182 .28 \\
\hline $18^{\text {th }} \mathrm{d}$. & & 456 & 900 & Brooklyn & $37.40 \mathrm{E}$ \\
\hline $19^{\text {th }} \mathrm{d}$. Sennedjem & 520 & 230 & 1600 & Cairo & 27256 \\
\hline $18^{\text {th }}$ d. Gen. Cat. 51111 & 355 & 393 & 595 & Cairo & 69069 \\
\hline
\end{tabular}


Table 25-Continued.

\begin{tabular}{|c|c|c|c|c|c|}
\hline d. Chests & Length & Width & Height & Museum & $\begin{array}{l}\text { Inventory } \\
\text { Number }\end{array}$ \\
\hline N. K. Shrine-shaped & 70 & & 85 & Cairo & 3318 \\
\hline $20^{\text {th }} \mathrm{d}$. Toilet & & 240 & 383 & Berlin & 1176 \\
\hline $18^{\text {th }} \mathrm{d}$. & 482 & 355 & 381 & Turin & 8617 \\
\hline $18^{\text {th }} \mathrm{d}$. & 482 & 355 & 381 & Turin & 8213 \\
\hline $18^{\text {th }} \mathrm{d}$. wig & 482 & 482 & 1155 & Turin & 8493 \\
\hline $18^{\text {th }} \mathrm{d}$. & 469 & 304 & 342 & Turin & 8514 \\
\hline $18^{\text {th }}$ d. & 698 & 361 & 438 & New York & 36.3.56 a,b \\
\hline $18^{\text {th }} \mathrm{d}$. & 762 & & 482 & New York & 36.5.A.B. \\
\hline e. Stools & Length & Width & Height & Museum & $\begin{array}{c}\text { Inventory } \\
\text { Number }\end{array}$ \\
\hline $18^{\text {th }}$ d. lattice & 440 & 400 & 456 & Brussels & 2411 \\
\hline N. K. 4-legged & & 375 & 171 & Ontario & 910.37 .16 \\
\hline $18^{\text {th }} / 19^{\text {th }}$ d. folding & 632 & 610 & 430 & Ontario & 914.2.1 \\
\hline N. K. 3-legged & 360 & & 320 & Cairo & 2030 \\
\hline $19^{\text {th }}$ d. Sennedjem & 360 & 360 & 320 & Cairo & 27255 A\&B \\
\hline N. K. folding & 670 & 300 & 300 & Cairo & 27288 \\
\hline N. K. low w/ animal legs & 300 & 340 & 125 & Cairo & 27289 \\
\hline N. K. lattice & 390 & 310 & 330 & Cairo & 27290 \\
\hline N. K. lattice & 480 & 300 & 340 & Cairo & 27291 \\
\hline N. K. reed and rush & 440 & & 450 & Cairo & 28989 \\
\hline N. K. 3-legged & & 480 & 750 & Cairo & 30008 \\
\hline N. K. 3-legged & 360 & 400 & 210 & Cairo & 30010 \\
\hline $20^{\text {th }} \mathrm{d}$. folding & 450 & & 330 & Marseille & 288 \\
\hline $18^{\text {th }} \mathrm{d}$. round-legged & & 374 & 209 & Berlin & 12553 \\
\hline $19^{\text {th }} \mathrm{d}$. & 342 & 371 & 158 & Berlin & 791 \\
\hline N. K. animal-legged & 410 & 340 & 185 & Berlin & 10741 \\
\hline N. K. animal-legged & 295 & 275 & 110 & Berlin & 12550 \\
\hline $18^{\text {th }} \mathrm{d}$. round-legged & & 465 & 450 & Leiden & AH 53 \\
\hline $18^{\text {th }}$ d. lattice & 419 & 330 & & Turin & 8511 \\
\hline $18^{\text {th }} \mathrm{d}$. lattice & 419 & 330 & & Turin & 8512 \\
\hline $18^{\text {th }} \mathrm{d}$. lattice & 393 & 330 & 381 & Turin & 8510 \\
\hline $18^{\text {th }}$ d. lattice & 381 & 342 & 368 & Turin & 8468 \\
\hline $18^{\text {th }} \mathrm{d}$. folding & 596 & & 533 & Turin & 8509 \\
\hline $18^{\text {th }}$ d. round-legged & 495 & 495 & 457 & Turin & 8507 \\
\hline $18^{\text {th }} \mathrm{d}$. animal-legged & 368 & 368 & 330 & Turin & 8614 \\
\hline $18^{\text {th }}$ d. 3-legged & 393 & 298 & 355 & Turin & 8505 \\
\hline $18^{\text {th }}$ d. 3-legged & 469 & 393 & 317 & Turin & 8506 \\
\hline N. K. concave seat & 380 & 370 & 300 & Warszawie & 141433 \\
\hline Late N. K. & 350 & 430 & 340 & London & 66652 \\
\hline $19^{\text {th }}$ d. lattice & 360 & 320 & 380 & London & 2476 \\
\hline $18^{\text {th }}$ d. 3-legged & 285 & 360 & 328 & London & 2481 \\
\hline $19^{\text {th }} \mathrm{d}$. folding & 550 & 490 & 470 & London & 2477 \\
\hline
\end{tabular}


Table 25-Continued.

\begin{tabular}{lccccc}
\hline $18^{\text {th }}$ d. folding & 450 & 350 & 380 & London & 29284 \\
$18^{\text {th }}$ d. folding & & 485 & 470 & London & 37406 \\
$18^{\text {th }}$ d. round-legged & 460 & 460 & 360 & London & 2472 \\
N. K. & 290 & 270 & 180 & Cambridge & EGA 4564 \\
$18^{\text {th }}$ d. & 350 & 275 & 135 & Manchester & 7206 \\
$18^{\text {th }}-19^{\text {th }}$ d. 3-legged & & 343 & 223 & Edinburgh & 1956.107 \\
N. K. square legs & 356 & 356 & 305 & Edinburgh & 1956.111 \\
$18^{\text {th }}-19^{\text {th }}$ d. round-legged & 362 & 330 & 229 & Edinburgh & 1956.109 \\
$18^{\text {th }}$ d. & 311 & 297 & 133 & New York & 14.10 .3 \\
$18^{\text {th }}$ d. round-legged & & 381 & 393 & New York & 14.10 .4 \\
$18^{\text {th }}$ d. small lattice & 267 & 229 & 243 & Brooklyn & $37.45 \mathrm{E}$ \\
\hline f. Tables & Length & Width & Height & Museum & Inventory \\
& & & & & Number \\
\hline $18^{\text {th }}$ d. & 698 & 381 & 469 & Turin & 8257 \\
$18^{\text {th }}$ d. & 749 & 381 & 476 & Turin & 8258 \\
$18^{\text {th }}$ d. & 690 & 495 & 381 & Turin & 8342 \\
$18^{\text {th }}$ d. & 787 & 539 & 298 & Turin & 8343 \\
$18^{\text {th }}$ d. & 469 & 558 & & Turin & 8432 \\
$18^{\text {th }}$ d. 3-legged & 680 & 460 & 490 & London & 2469 \\
$18^{\text {th }}$ d. & 521 & 255 & 303 & Brooklyn & $37.41 \mathrm{E}$ \\
\hline
\end{tabular}

Table 26. A stem-and-leaf plot of the length of the bedframes (N.K.)

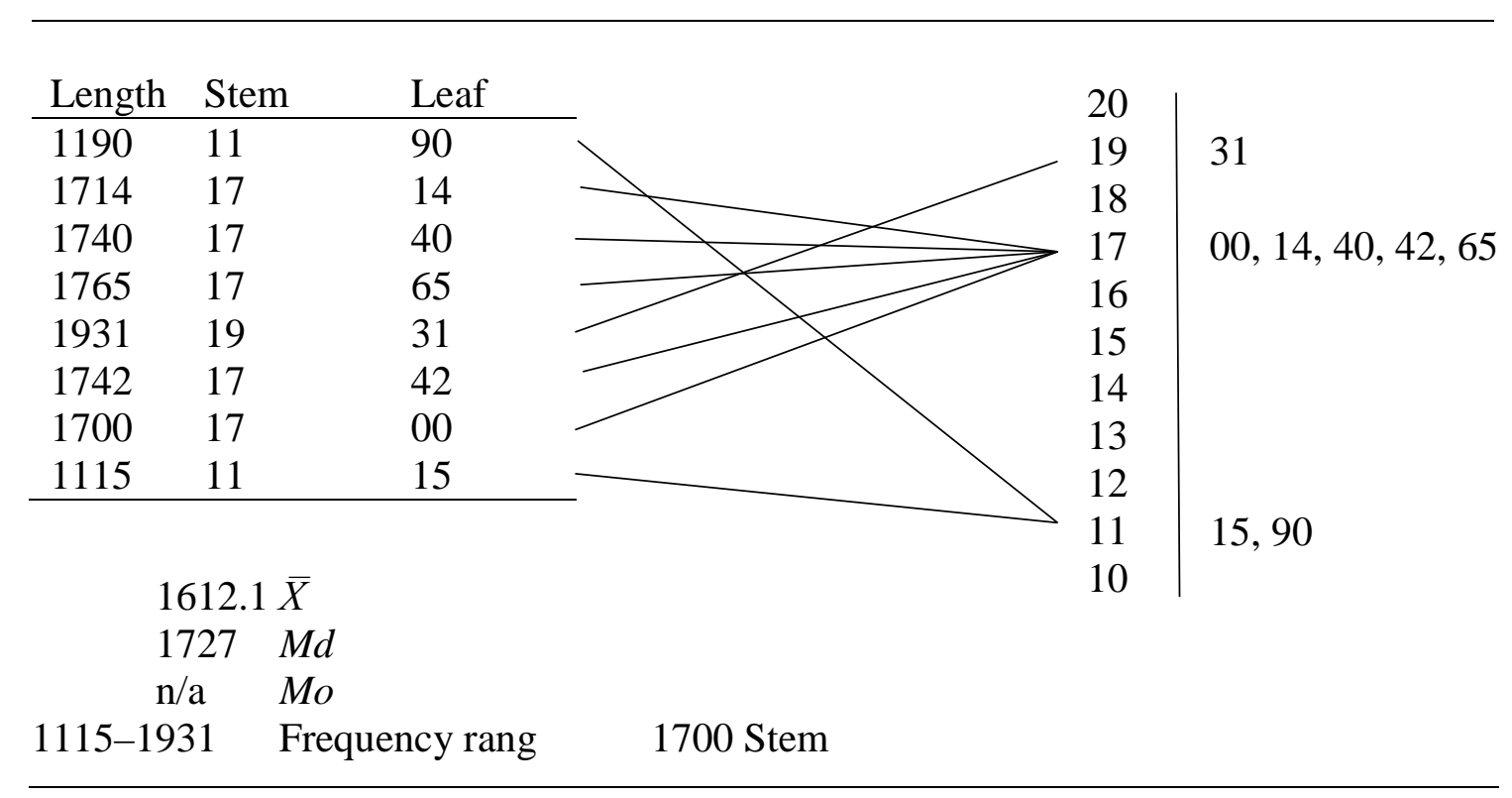


Table 27. A stem-and-leaf plot of the width of the bedframes (N.K.)

\begin{tabular}{|c|c|c|c|c|c|}
\hline Width & Stem & Leaf & & 10 & \\
\hline 560 & 5 & 60 & & 9 & \\
\hline 850 & 8 & 50 & 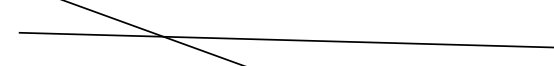 & 8 & 50 \\
\hline 763 & 7 & 63 & $\mathrm{X}^{2}$ & 7 & $10,50,63,90$ \\
\hline 750 & 7 & 50 & 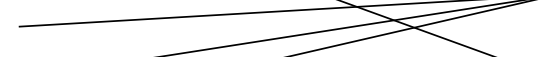 & 6 & \\
\hline 790 & 7 & 90 & & 5 & 60 \\
\hline 710 & 7 & 10 & & 4 & \\
\hline & & & & 3 & \\
\hline & 737.17 & & & 2 & \\
\hline & 756.5 & $M d$ & & 1 & \\
\hline & $\mathrm{l} / \mathrm{a}$ & Mo & & 0 & \\
\hline $560-850$ & & Frequency rang & 700 Stem & & \\
\hline
\end{tabular}

Table 28. A stem-and-leaf plot of the height of the bedframes (N.K.)

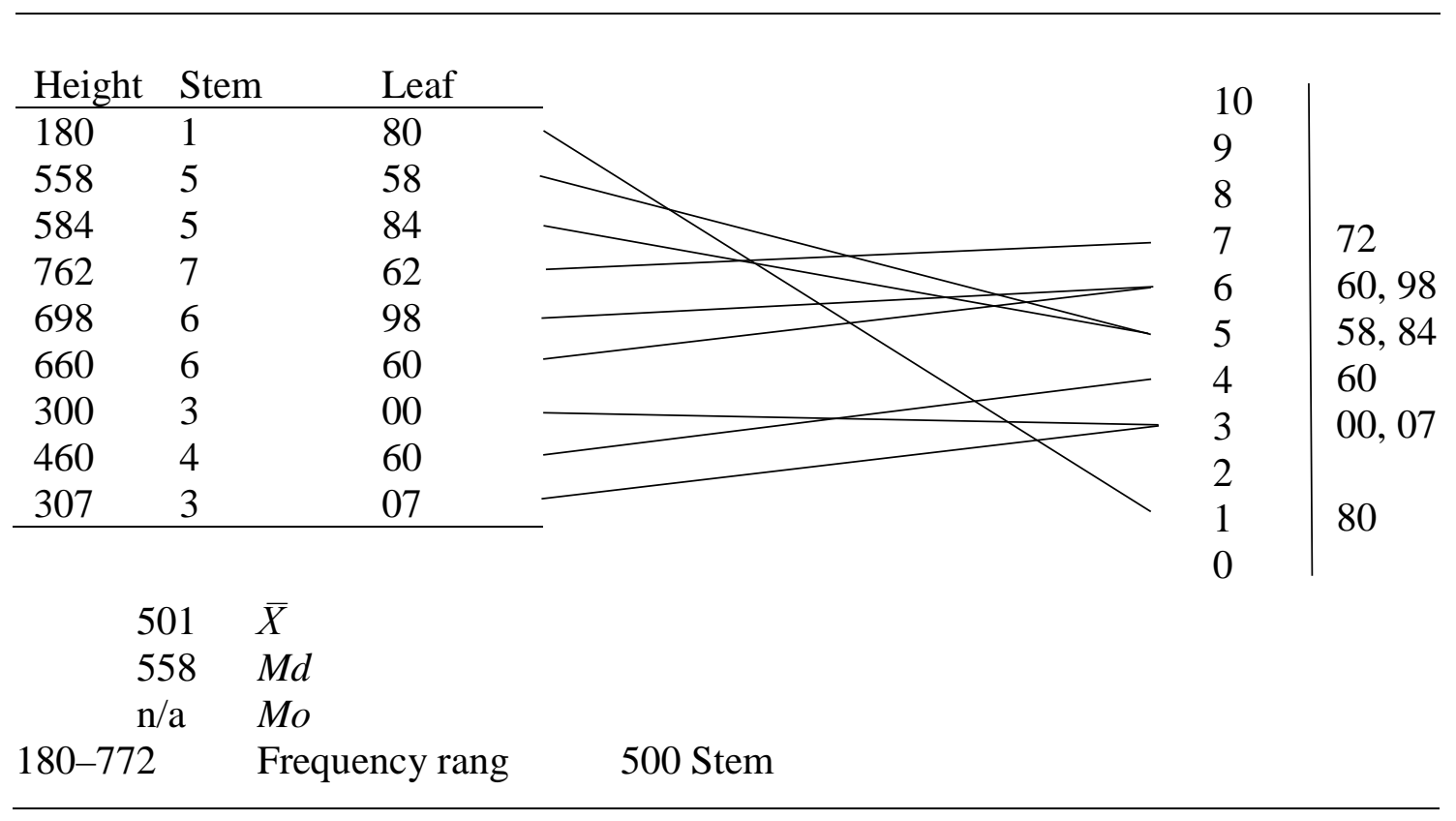


Table 29. A stem-and-leaf plot of the length of the boxes (N.K.)

\begin{tabular}{|c|c|c|c|c|c|}
\hline Length & Stem & Leaf & & \multicolumn{2}{|l|}{10} \\
\hline 60 & 0 & 60 & & $\begin{array}{l}10 \\
9\end{array}$ & \\
\hline 193 & 1 & 93 & & 8 & \\
\hline 381 & 3 & 81 & & 7 & \\
\hline 457 & 4 & 57 & & 6 & \\
\hline 482 & 4 & 82 & & 5 & 33 \\
\hline 533 & 5 & 33 & & 4 & 57,82 \\
\hline 381 & 3 & 81 & & 3 & $30,80,81,81$ \\
\hline 380 & 3 & 80 & & 2 & \\
\hline 198 & 1 & 98 & & 1 & 65, 93, 95, 98 \\
\hline 165 & 1 & 65 & & 0 & 60 \\
\hline 330 & 3 & 30 & & & \\
\hline 195 & 1 & 95 & & & \\
\hline & 12.92 & & & & \\
\hline & 55 & $M d$ & & & \\
\hline & 31 & Mo & & & \\
\hline 60-533 & & Frequency rang & 300 Stem & & \\
\hline
\end{tabular}

Table 30. A stem-and-leaf plot of the width of the boxes (N.K.)

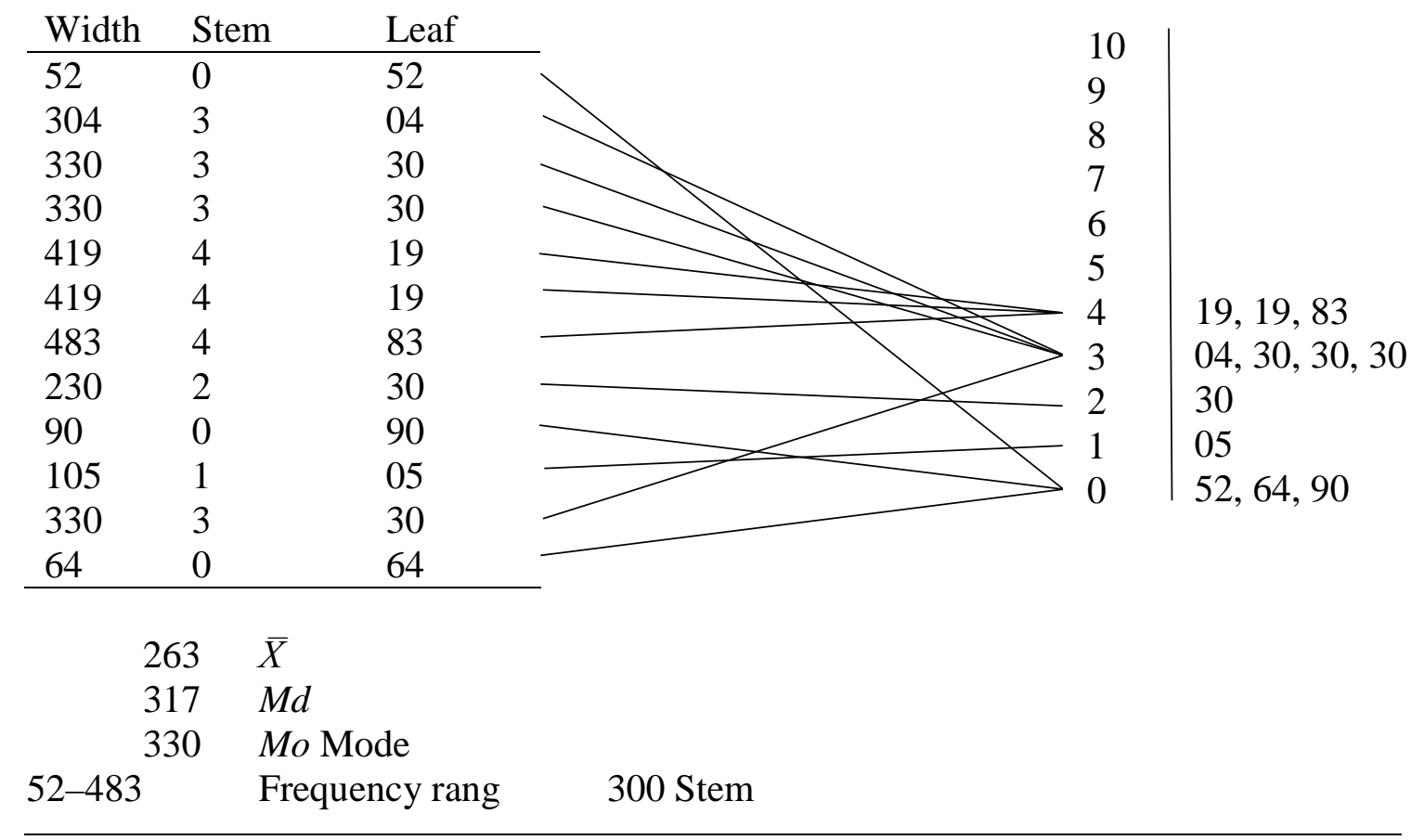


Table 31. A stem-and-leaf plot of the height of the boxes (N.K.)

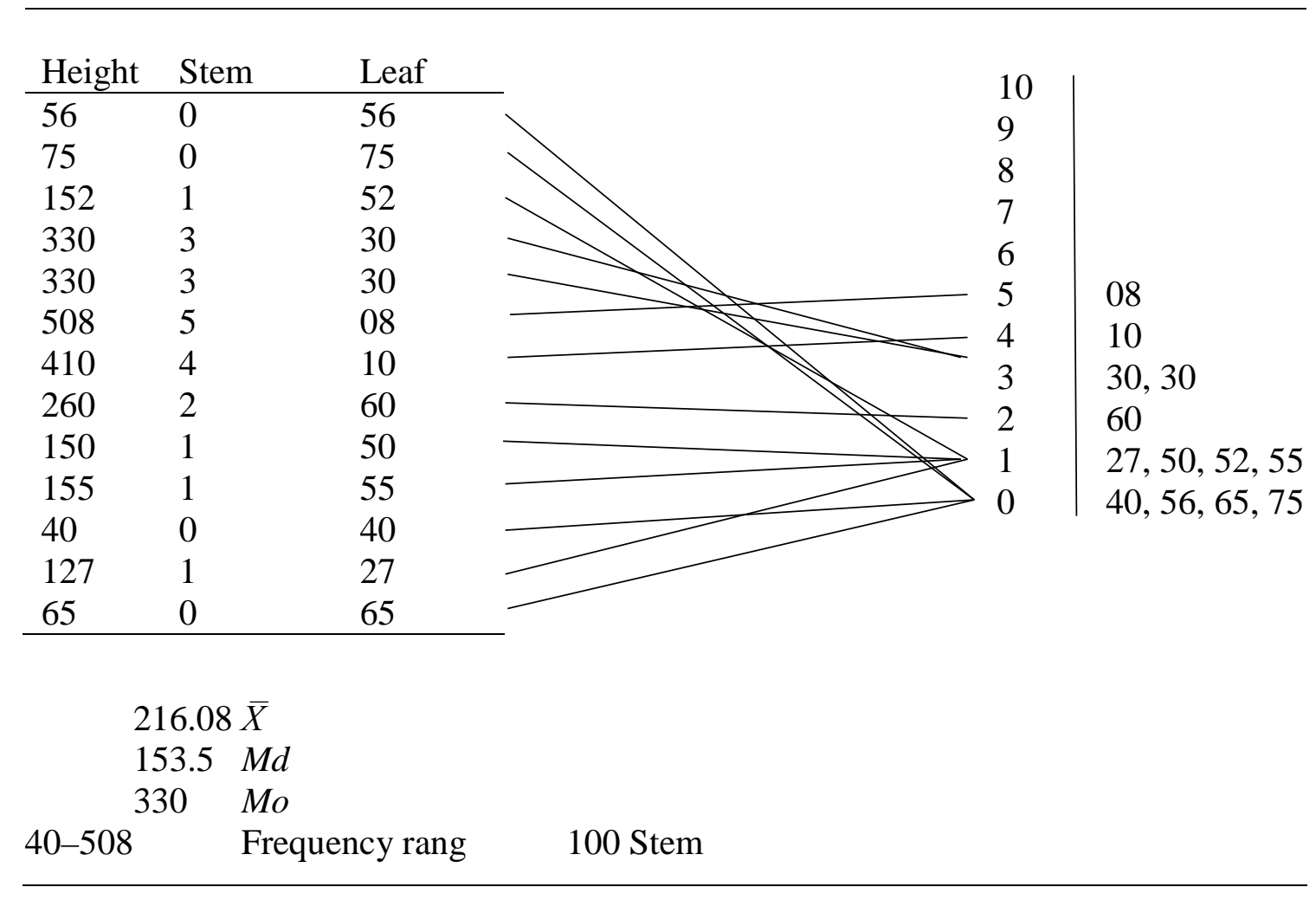

Table 32. A stem-and-leaf plot of the length of the chairs (N.K.)

\begin{tabular}{|c|c|c|c|c|c|}
\hline Length & Stem & Leaf & & 10 & \\
\hline 520 & 5 & 20 & & 9 & \\
\hline 355 & 3 & 55 & & 8 & \\
\hline 330 & 3 & 30 & & 7 & \\
\hline 470 & 4 & 70 & & 6 & \\
\hline 490 & 4 & 90 & & 5 & 20 \\
\hline 420 & 4 & 20 & & 4 & $20,70,90$ \\
\hline 305 & 3 & 05 & 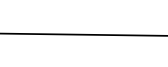 & 3 & $05,30,55$ \\
\hline & & & & 2 & \\
\hline & $2.86 \bar{X}$ & & & 1 & \\
\hline & & $M d$ & & 0 & \\
\hline & 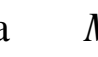 & Mo & & & \\
\hline $305-520$ & & Frequency rang & 400 Stem & & \\
\hline
\end{tabular}


Table 33. A stem-and-leaf plot of the width of the chairs (N.K.)

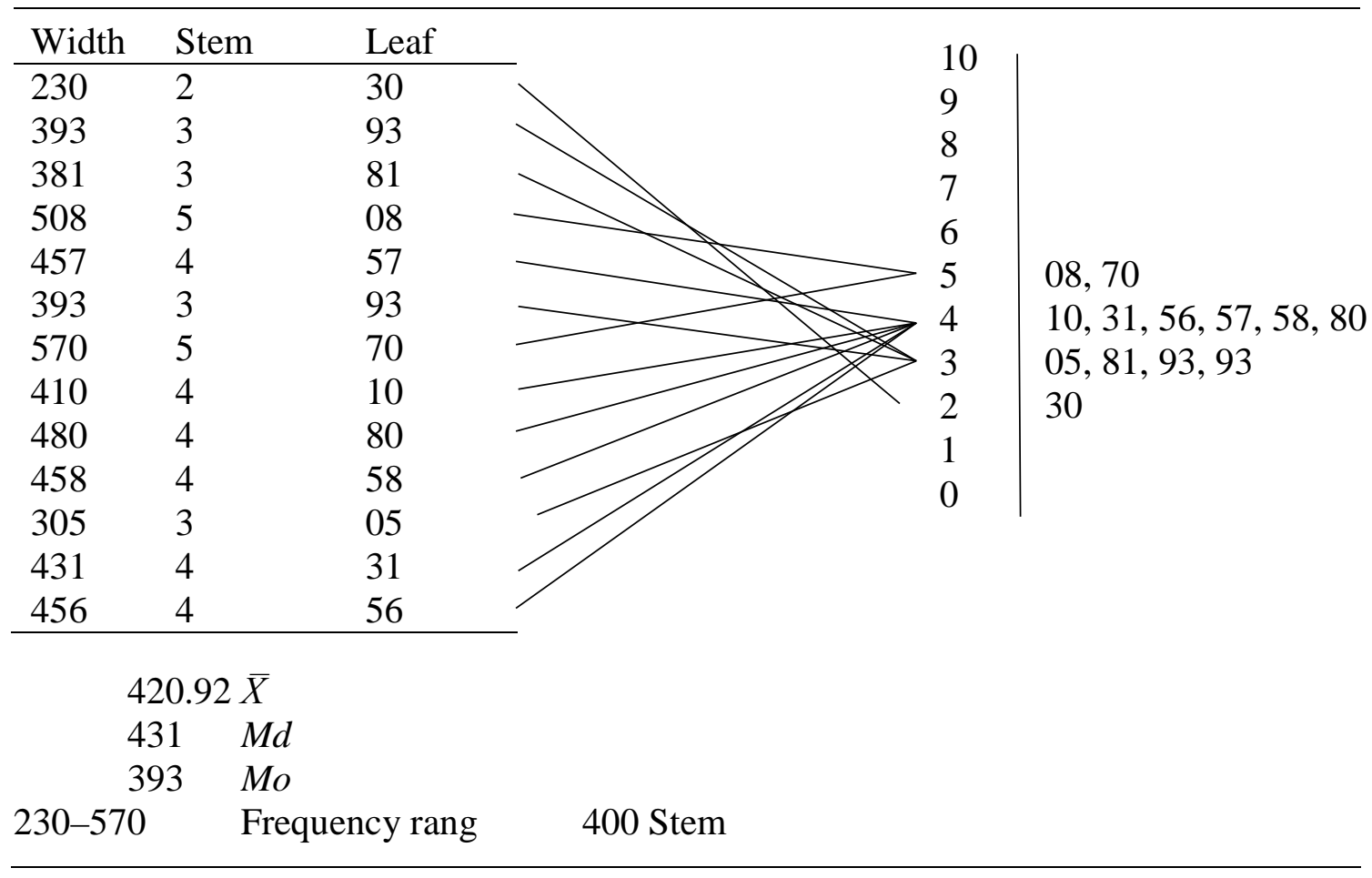

Table 34. A stem-and-leaf plot of the height of the chairs (N.K.)

\begin{tabular}{|c|c|c|c|c|c|c|}
\hline Height & Stem & Leaf & & & & \\
\hline 1600 & 16 & 00 & & & $\begin{array}{l}16 \\
15\end{array}$ & 00 \\
\hline 595 & 5 & 96 & & & 14 & \\
\hline 615 & 6 & 15 & & & 14 & \\
\hline 792 & 7 & 92 & & & 12 & \\
\hline 440 & 4 & 40 & & & 11 & \\
\hline 774 & 7 & 74 & & & 10 & \\
\hline 908 & 9 & 08 & & & 9 & 00,08 \\
\hline 600 & 6 & 00 & & & 8 & \\
\hline 730 & 7 & 30 & & & 7 & 30, 74, 92 \\
\hline 620 & 6 & 20 & & & 6 & $00,10,15,20$ \\
\hline 610 & 6 & 10 & & & 5 & 84,96 \\
\hline $\begin{array}{l}127 \\
584\end{array}$ & 1 & $\begin{array}{l}27 \\
84\end{array}$ & & & 4 & 40 \\
\hline $\begin{array}{l}584 \\
900\end{array}$ & $\begin{array}{l}5 \\
9\end{array}$ & $\begin{array}{l}84 \\
00\end{array}$ & & & $\begin{array}{l}3 \\
2\end{array}$ & \\
\hline \multirow{2}{*}{\multicolumn{3}{|c|}{$638.08 \bar{X}$}} & & & 1 & 27 \\
\hline & & & & & 0 & \\
\hline & 15 & Md & & & & \\
\hline $\begin{aligned} \mathrm{I} \\
127-908\end{aligned}$ & $\mathrm{a}$ & $\begin{array}{l}\text { Mo } \\
\text { Freguency rano }\end{array}$ & 600 Stem & 1600 Outliar & & \\
\hline
\end{tabular}


Table 35. A stem-and-leaf plot of the length of the chests (N.K.)

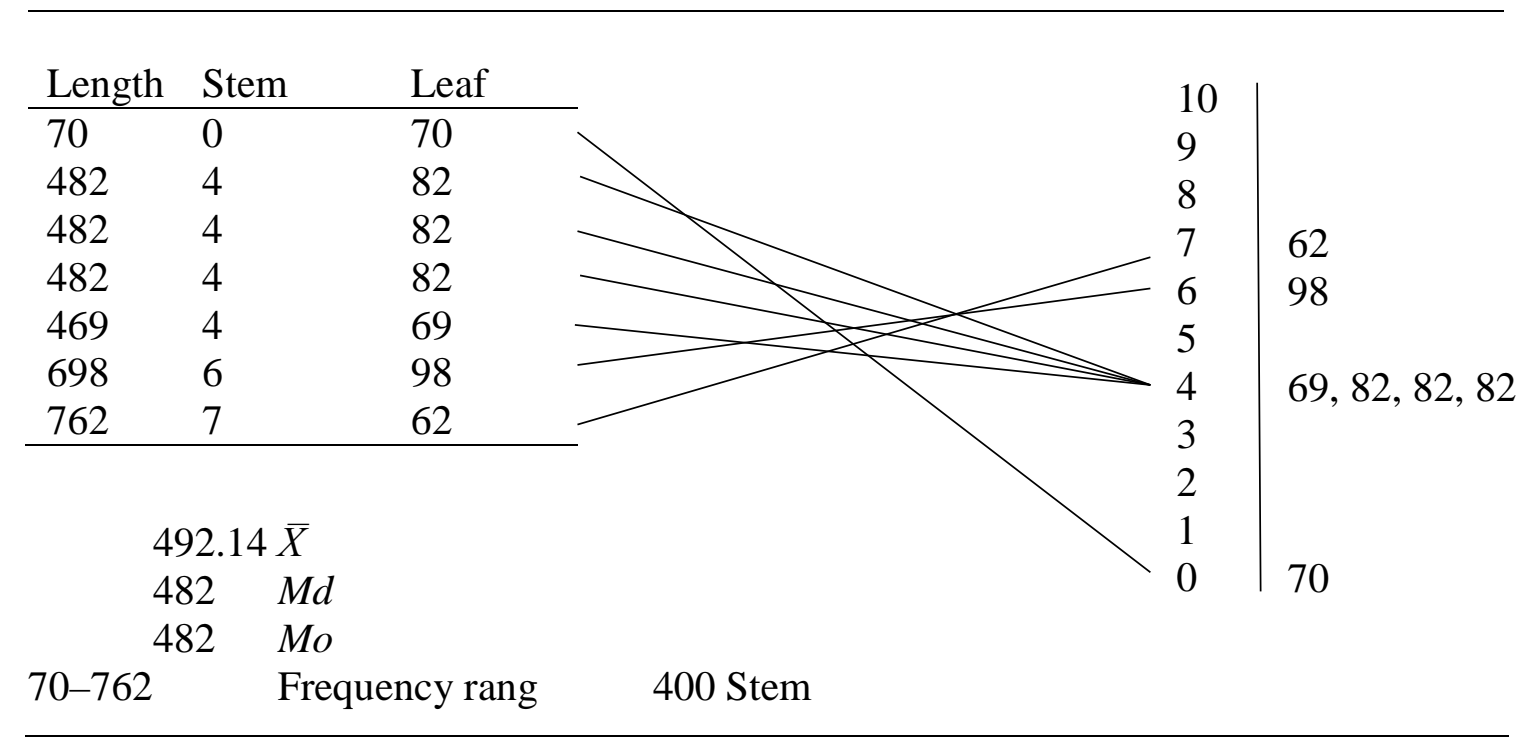

Table 36. A stem-and-leaf plot of the width of the chests (N.K.)

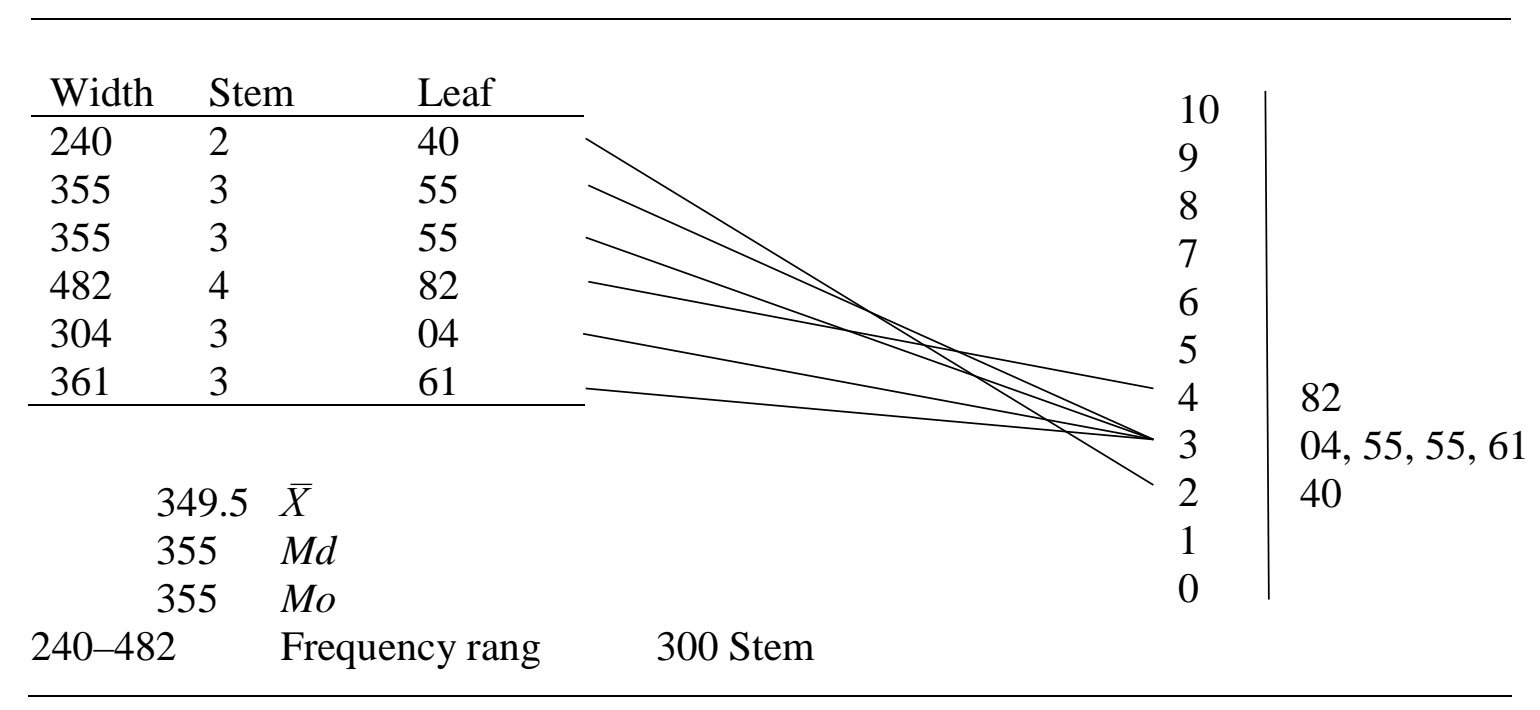


Table 37. A stem-and-leaf plot of the height of the chests (N.K.)

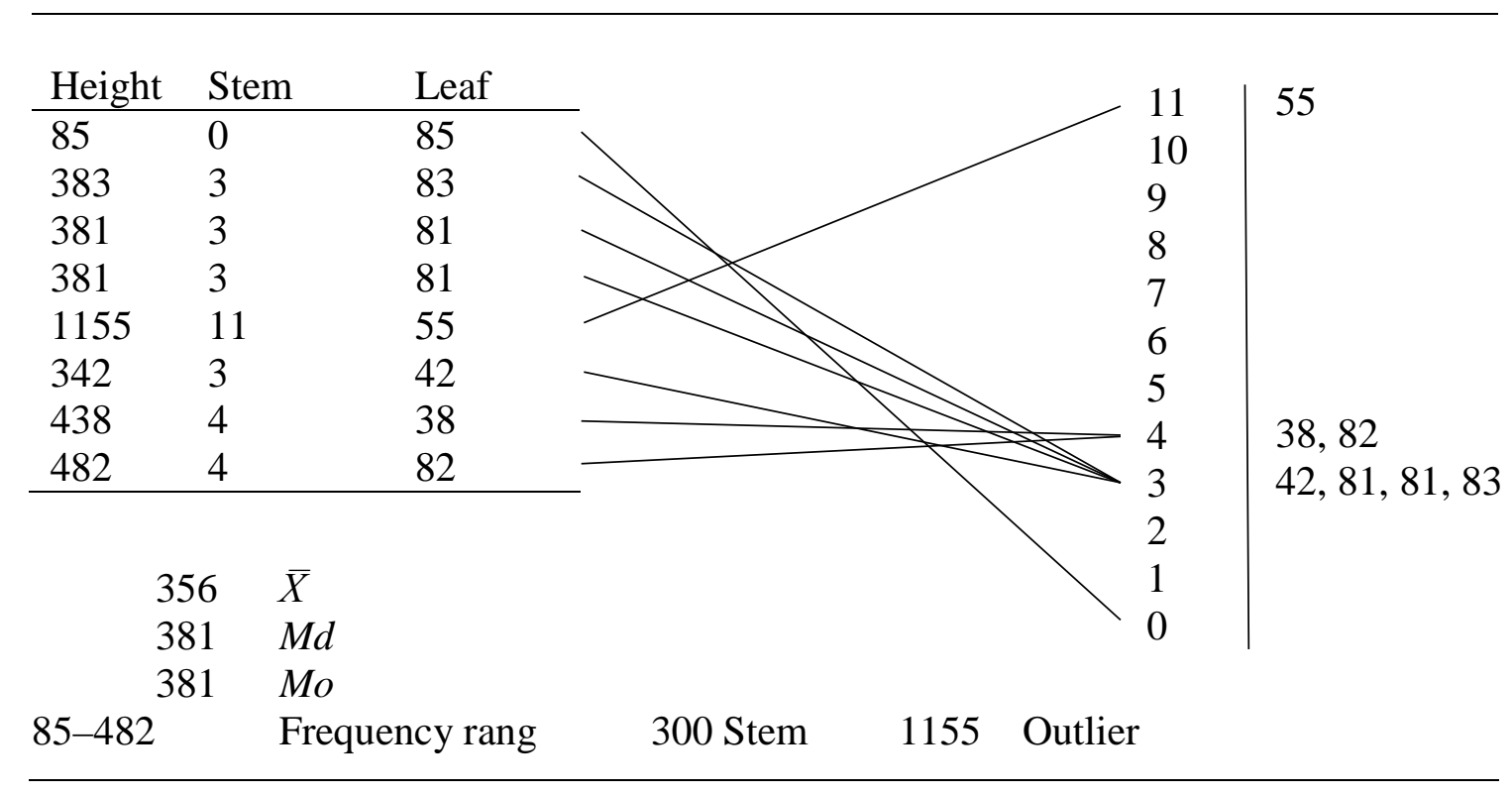


Table 38. A stem-and-leaf plot of the length of the stools (N.K.)

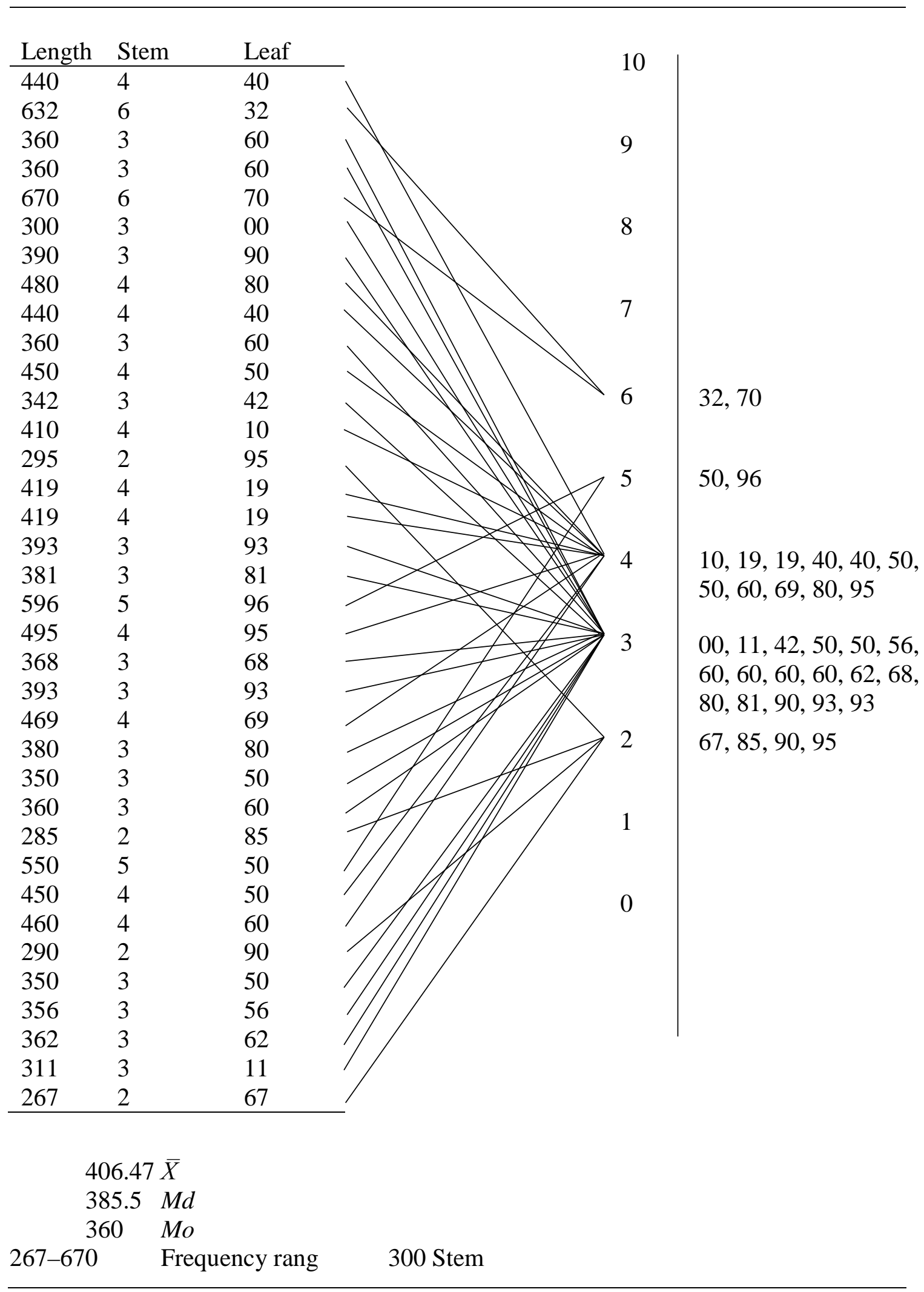


Table 39. A stem-and-leaf plot of the width of the stools (N.K.)

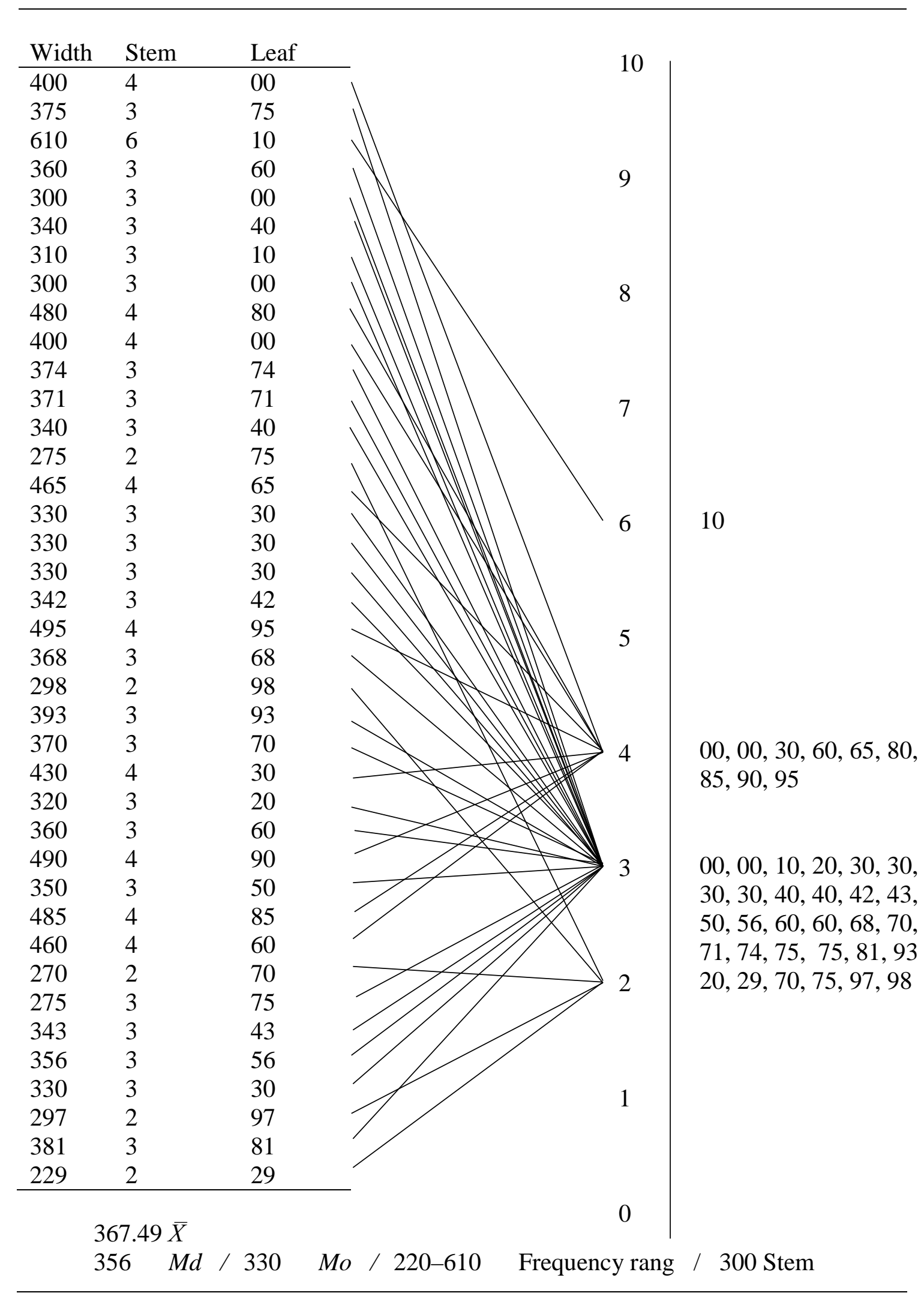


Table 40. A stem-and-leaf plot of the height of the stools (N.K.)

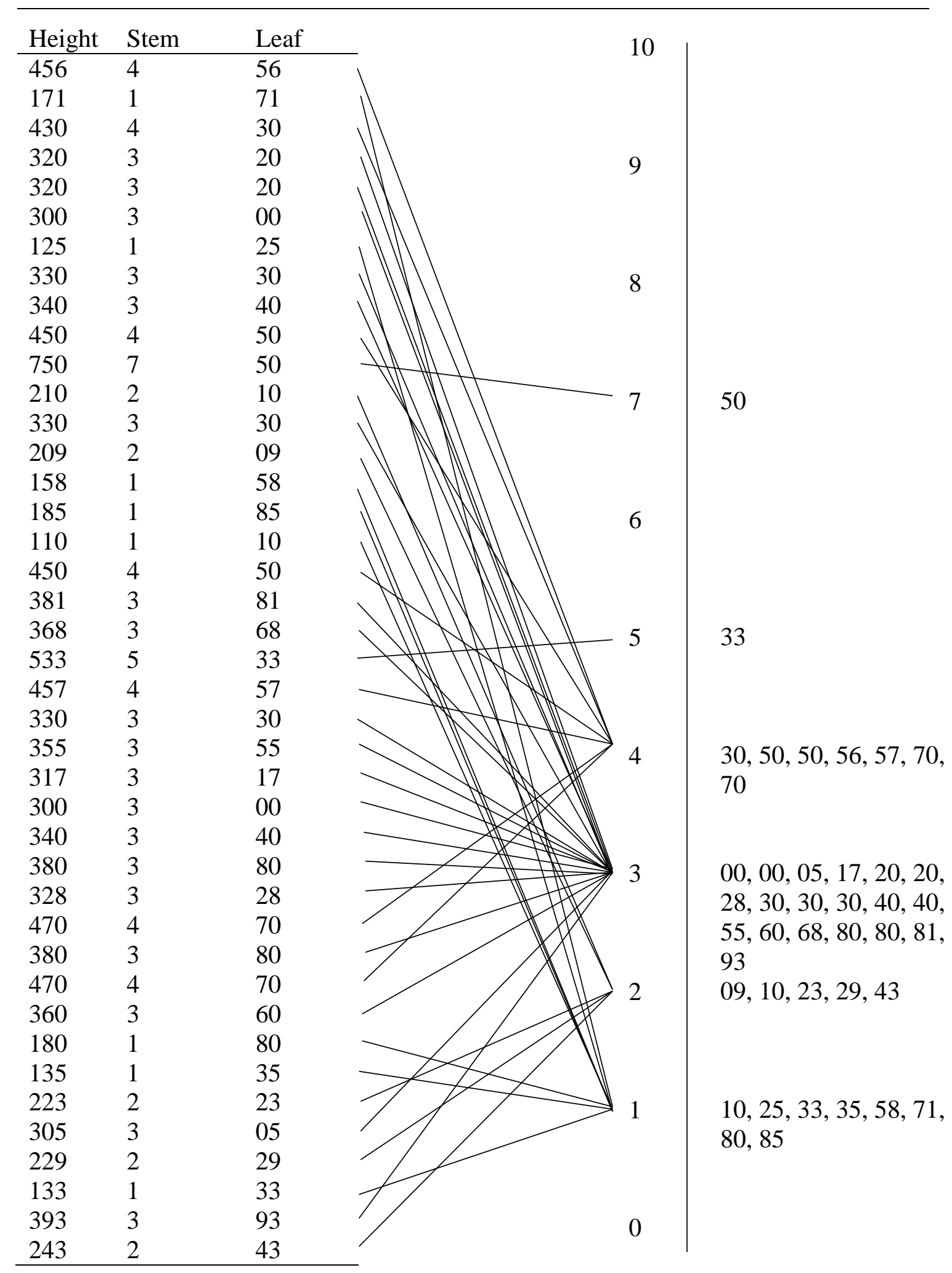

$312.6 \bar{X} / 329$ Md / 330 Mo / 110-533 Frequency rang \300 Stem / 750 Outlier 
Table 41. A stem-and-leaf plot of the length of the tables (N.K.)

\begin{tabular}{|c|c|c|c|c|c|}
\hline Length & Stem & Leaf & & \multicolumn{2}{|l|}{10} \\
\hline 698 & 6 & 98 & & 9 & \\
\hline 749 & 7 & 49 & $=$ & 8 & \\
\hline 690 & 6 & 90 & $\mathrm{~S}$ & 7 & 49,87 \\
\hline 787 & 7 & 87 & $\mathrm{~N}_{2}$ & 6 & $80,90,98$ \\
\hline 469 & 4 & 69 & $\mathrm{C}$ & 5 & 21 \\
\hline 680 & 6 & 80 & P 2 & 4 & 69 \\
\hline 521 & 5 & 21 & & 3 & \\
\hline & & & & 2 & \\
\hline & 566.29 & & & 1 & \\
\hline & 990 & Md & & 0 & \\
\hline & //a & Mo & & & \\
\hline $469-787$ & & Frequency rang & 600 Stem & & \\
\hline
\end{tabular}

Table 42. A stem-and-leaf plot of the width of the tables (N.K.)

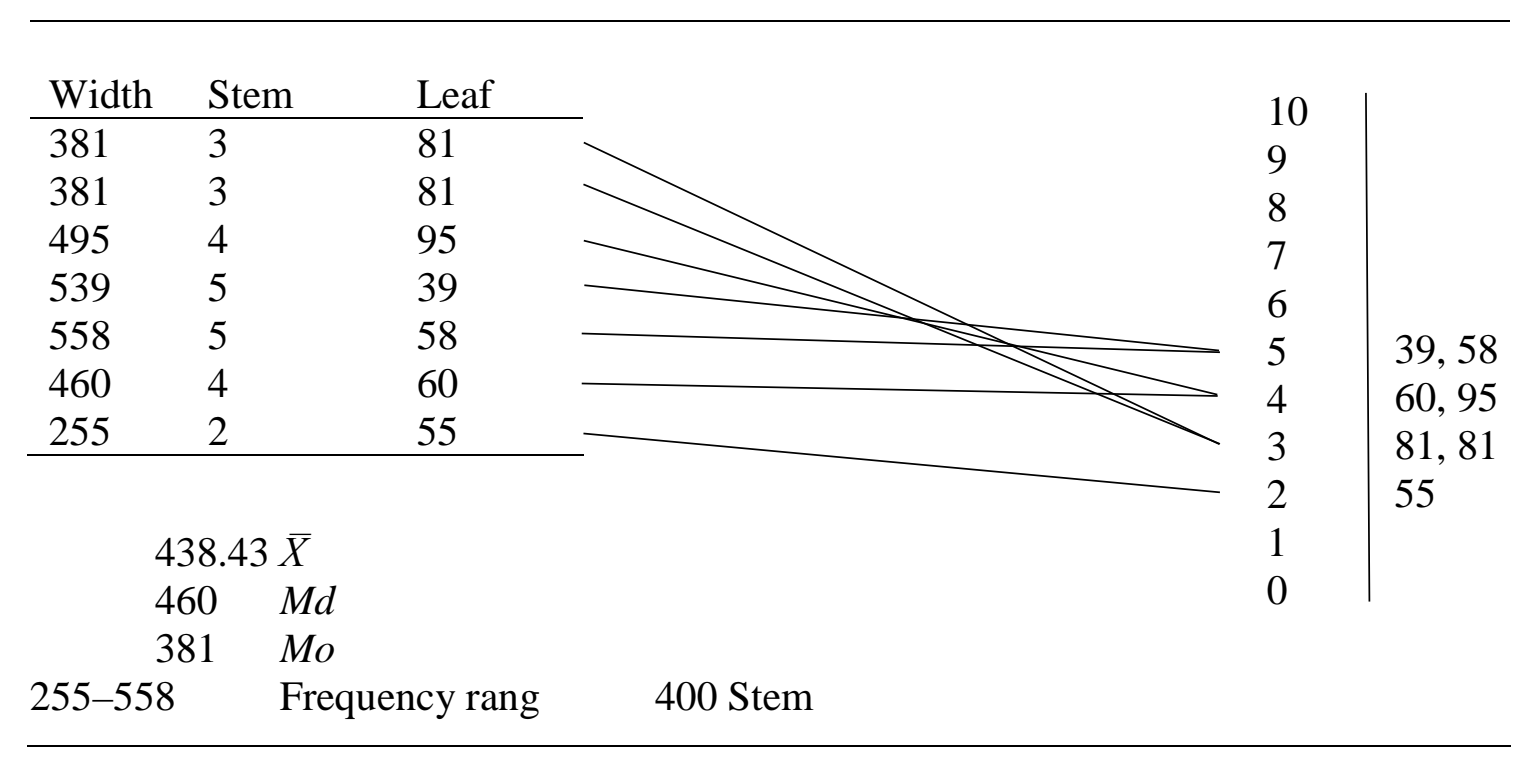


Table 43. A stem-and-leaf plot of the height of the tables (N.K.)

\begin{tabular}{|c|c|c|c|c|c|}
\hline Height & Stem & Leaf & & \multicolumn{2}{|l|}{10} \\
\hline 469 & 4 & 69 & & $\begin{array}{l}10 \\
9\end{array}$ & \\
\hline 476 & 4 & 76 & & 8 & \\
\hline 381 & 3 & 81 & & 7 & \\
\hline 298 & 2 & 98 & & 6 & \\
\hline 490 & 4 & 90 & & 5 & \\
\hline 303 & 3 & 03 & & 4 & $69,76,90$ \\
\hline \multicolumn{3}{|c|}{$402.83 \bar{X}$} & & 2 & 98 \\
\hline \multicolumn{2}{|c|}{425} & $M d$ & & 1 & \\
\hline \multicolumn{2}{|c|}{$\mathrm{n} / \mathrm{a}$} & & & 0 & \\
\hline $298-490$ & & icy rang & 400 Stem & U & \\
\hline
\end{tabular}

Table 44. New Kingdom furniture analysis $A$

\begin{tabular}{lccccccccc}
\hline & a.1 & a.2 & a.3 & b.1 & b.2 & b.3 & c.1 & c.2 & c.3 \\
\hline Sample & 8 & 6 & 9 & 12 & 12 & 13 & 7 & 13 & 14 \\
Size & & & & & & & & & \\
Mean & 1612.1 & 737.17 & 501 & 312.92 & 263 & 216.08 & 412.86 & 420.92 & 638.08 \\
Median & 1727 & 756.5 & 558 & 355 & 317 & 153.5 & 420 & 431 & 615 \\
Mode & n/a & n/a & n/a & 381 & 330 & 330 & n/a & 393 & n/a \\
Frequency & $1115-$ & $560-$ & $180-$ & $60-$ & $52-$ & $40-$ & $305-$ & $230-$ & $127-$ \\
Range & 1931 & 850 & 772 & 533 & 483 & 508 & 520 & 570 & 908 \\
Preferred & 1700 & 700 & 500 & 300 & 300 & 100 & 400 & 400 & 600 \\
Stem & & & & & & & & & \\
Outliers & n/a & n/a & n/a & n/a & n/a & n/a & n/a & n/a & 1600 \\
\hline
\end{tabular}


Table 45. New Kingdom furniture analysis B

\begin{tabular}{lccccccccc}
\hline & d.1 & d.2 & d.3 & e.1 & e.2 & e.3 & f.1 & f.2 & f.3 \\
\hline Sample & 7 & 6 & 8 & 36 & 39 & 41 & 7 & 7 & 6 \\
Size & & & & & & & & & \\
Mean & 492.14 & 349.5 & 356 & 406.47 & 367.49 & 312.6 & 656.29 & 438.43 & 402.83 \\
Median & 482 & 355 & 381 & 385.5 & 356 & 329 & 690 & 460 & 425 \\
Mode & 482 & 355 & 381 & 360 & 330 & 330 & n/a & 381 & n/a \\
Frequency & $70-$ & $240-$ & $85-$ & $267-$ & $220-$ & $110-$ & $469-$ & $255-$ & $298-$ \\
Range & 762 & 482 & 482 & 670 & 610 & 533 & 787 & 558 & 490 \\
Preferred & 400 & 300 & 300 & 300 & 300 & 300 & 600 & 400 & 400 \\
Stem & & & & & & & & & \\
Outliers & n/a & n/a & 1155 & n/a & n/a & 750 & n/a & n/a & n/a \\
\hline
\end{tabular}

Control Group - pre-New Kingdom Statistical Analysis

The six groups of furniture from the pre-New Kingdom batch with their corresponding units of measure as identified by Killen are listed in Table 46. The units of measure will be analyzed in their own stem-and-leaf plots that correspond to this table.

\section{Control Group - pre-New Kingdom Statistical Data Grouping}

The summary tables list all of the analyzed data. The letter (a, b, c, etc.) is a reference to the item of furniture as listed in Table 46. Length is listed after the letter as “.1,” width as “.2,” and height as “.3.” These correspond to the stem-and-leaf plots below: bedframes (Tables 47-49), boxes (Tables 50-52), stools (Tables 53-55), and tables (Tables 56-58). Sample size reflects the number of items sampled for each item of furniture. 
Table 46. Pre-New Kingdom (P-N.K.) furniture measurements

\begin{tabular}{|c|c|c|c|c|c|}
\hline a. Bedframes & Length & Width & Height & Museum & $\begin{array}{c}\text { Inventory } \\
\text { Number }\end{array}$ \\
\hline $1^{\text {st }} \mathrm{d}$. Tarkhan & 1920 & 860 & 350 & Brussels & 4503 \\
\hline $1^{\text {st }} \mathrm{d}$. Tarkhan & 1171 & 640 & 360 & Brussels & 4504 \\
\hline $4^{\text {th }}$ d. Queen Hetepheres & 1700 & 770 & 440 & Cairo & 53261 \\
\hline $1^{\text {st }} \mathrm{d}$. & 1760 & 840 & 250 & Manchester & 5429 \\
\hline $11^{\text {th }} \mathrm{d}$. & 1606 & 694 & 279 & New York & 86.1 .39 \\
\hline b. Boxes & Length & Width & Height & Museum & $\begin{array}{l}\text { Inventory } \\
\text { Number }\end{array}$ \\
\hline Unknown date box & 240 & 250 & 140 & Cairo & 27215 \\
\hline M. K. & 1350 & 85 & 450 & Cairo & 92967 \\
\hline M. K. & 770 & 680 & 490 & Cairo & 92968 \\
\hline $12^{\text {th }} \mathrm{d}$. wooden & 148 & 83 & & Manchester & 75 \\
\hline $12^{\text {th }}$ d. small & 110 & 56 & & Manchester & 76 \\
\hline $12^{\text {th }} \mathrm{d}$. & 550 & 410 & & Manchester & 254 \\
\hline $12^{\text {th }} \mathrm{d}$. & 370 & 240 & 250 & Manchester & 255 \\
\hline $12^{\text {th }} \mathrm{d} . \mathrm{w} / \mathrm{lid}$ & 670 & 165 & 320 & Manchester & 256 \\
\hline $12^{\text {th }} \mathrm{d}$. & 540 & 250 & 370 & Manchester & 257 \\
\hline $12^{\text {th }} \mathrm{d}$. & 390 & 160 & 240 & Manchester & 259 \\
\hline $12^{\text {th }} \mathrm{d}$. & 360 & 110 & 245 & Manchester & 258 \\
\hline $13^{\text {th }}-14^{\text {th }} d$. & 315 & 105 & 440 & Manchester & 6198 \\
\hline M. K. Toilet & 75 & & 53 & Brooklyn & 16.77 \\
\hline $3^{\text {rd }} \mathrm{d}$. storage & 285 & 270 & 10 & Berkeley & $6-2164$ \\
\hline $8^{\text {th }}-12^{\text {th }}$ d. no lid Naga-ed-Der & 350 & 240 & 85 & Berkeley & $6-16010$ \\
\hline $8^{\text {th }}-12^{\text {th }}$ d. no lid Naga-ed-Der & 330 & 225 & 80 & Berkeley & $6-16011$ \\
\hline $8^{\text {th }}-12^{\text {th }}$ d. no lid Naga-ed-Der & 405 & 325 & 22 & Berkeley & $6-16012$ \\
\hline $8^{\text {th }}-12^{\text {th }}$ d. no lid Naga-ed-Der & 410 & 310 & 180 & Berkeley & 6-17147 a,b \\
\hline c. Chairs & Length & Width & Height & Museum & $\begin{array}{c}\text { Inventory } \\
\text { Number }\end{array}$ \\
\hline $\begin{array}{l}4^{\text {th }} \text { d. Queen Hetepheres arm } \\
\text { chair }\end{array}$ & 520 & 230 & 1600 & Cairo & 27256 \\
\hline $2^{\text {nd }}$ d. Naga-ed-Der & 355 & 393 & 595 & Cairo & 69069 \\
\hline d. Chests & Length & Width & Height & Museum & $\begin{array}{c}\text { Inventory } \\
\text { Number }\end{array}$ \\
\hline $12^{\text {th }} \mathrm{d}$. & 440 & & 490 & Marseille & 281 \\
\hline
\end{tabular}


Table 46-Continued.

\begin{tabular}{|c|c|c|c|c|c|}
\hline e. Stools & Length & Width & Height & Museum & $\begin{array}{c}\text { Inventory } \\
\text { Number }\end{array}$ \\
\hline Early d. & 826 & 482.5 & 260.5 & Ontario & 910.37 .14 \\
\hline M. K. folding & 508 & 482.5 & 470 & Ontario & 910.37 .17 \\
\hline M. K. & 368.3 & 368.3 & 130 & Stockholm & MM 10122 \\
\hline M. K. lion paw feet & 435 & 430 & 375 & Uppsala & B-2 \\
\hline $12^{\text {th }} \mathrm{d}$. & 440 & 165 & 270 & Manchester & 261 \\
\hline $1^{\text {st }} \mathrm{d}$ & & 610 & 305 & UCL & 17173 \\
\hline M. K. w/ three legs & & 440 & 180 & UCL & 16532 \\
\hline $12^{\text {th }} \mathrm{d}$. & 345 & 290 & 145 & $\mathrm{UCL}$ & 16530 \\
\hline $12^{\text {th }} \mathrm{d}$ & & 100 & 370 & UCL & 7110 \\
\hline $12^{\text {th }} \mathrm{d}$. folding & & 317 & 355 & New York & 12.182 .58 \\
\hline f. Tables & Length & Width & Height & Museum & $\begin{array}{c}\text { Inventory } \\
\text { Number }\end{array}$ \\
\hline Unknown date dish table & 360 & 390 & 85 & Cairo & 26609 \\
\hline Unknown date low table & 460 & 378 & 115 & Cairo & 26610 \\
\hline Unknown date dish table & 380 & 280 & 100 & Cairo & 26677 \\
\hline Unknown date table & 310 & 170 & 150 & Cairo & 46578 \\
\hline $1^{\text {st }} \mathrm{d}$. Tarkhan table & 236 & & 36 & Cairo & 46590 \\
\hline $1^{\text {st }} \mathrm{d}$. low & 381 & 298 & 88 & Berlin & 10772 \\
\hline $1^{\text {st }} \mathrm{d}$. small & 480 & 278 & 60 & Manchester & 5456 \\
\hline $1^{\text {st }} \mathrm{d}$ & 450 & 333 & & UCL & 17012 \\
\hline $17^{\text {th }} \mathrm{d}$. & 635 & 311 & 1550 & New York & 14.10 .5 \\
\hline
\end{tabular}

Table 47. A stem-and-leaf plot of the length of the bedframes (P-N.K.)

\begin{tabular}{|c|c|c|c|c|c|c|}
\hline Length & Stem & Leaf & & & \multicolumn{2}{|c|}{20} \\
\hline 1920 & 19 & 20 & & & $\begin{array}{l}20 \\
19\end{array}$ & \multirow{2}{*}{20} \\
\hline 1171 & 11 & 71 & & & $\begin{array}{l}19 \\
18\end{array}$ & \\
\hline 1700 & 17 & 00 & & & 17 & \multirow{3}{*}{$\begin{array}{l}00,60 \\
06\end{array}$} \\
\hline 1760 & 17 & 60 & 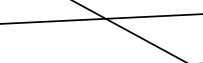 & & 16 & \\
\hline \multirow[t]{2}{*}{1606} & 16 & 06 & & & 15 & \\
\hline & & & & & 14 & \multirow{5}{*}{71} \\
\hline \multicolumn{3}{|c|}{$1746.5 \bar{X}$} & & & 13 & \\
\hline \multicolumn{3}{|c|}{$1730 \quad M d$} & & & 12 & \\
\hline $\mathrm{n} /$ & \multicolumn{2}{|c|}{ Mo } & & & 11 & \\
\hline $1606-192$ & & Frequency rang & 1700 Stem & 1171 Outlier & 10 & \\
\hline
\end{tabular}


Table 48. A stem-and-leaf plot of the width of the bedframes (P-N.K.)

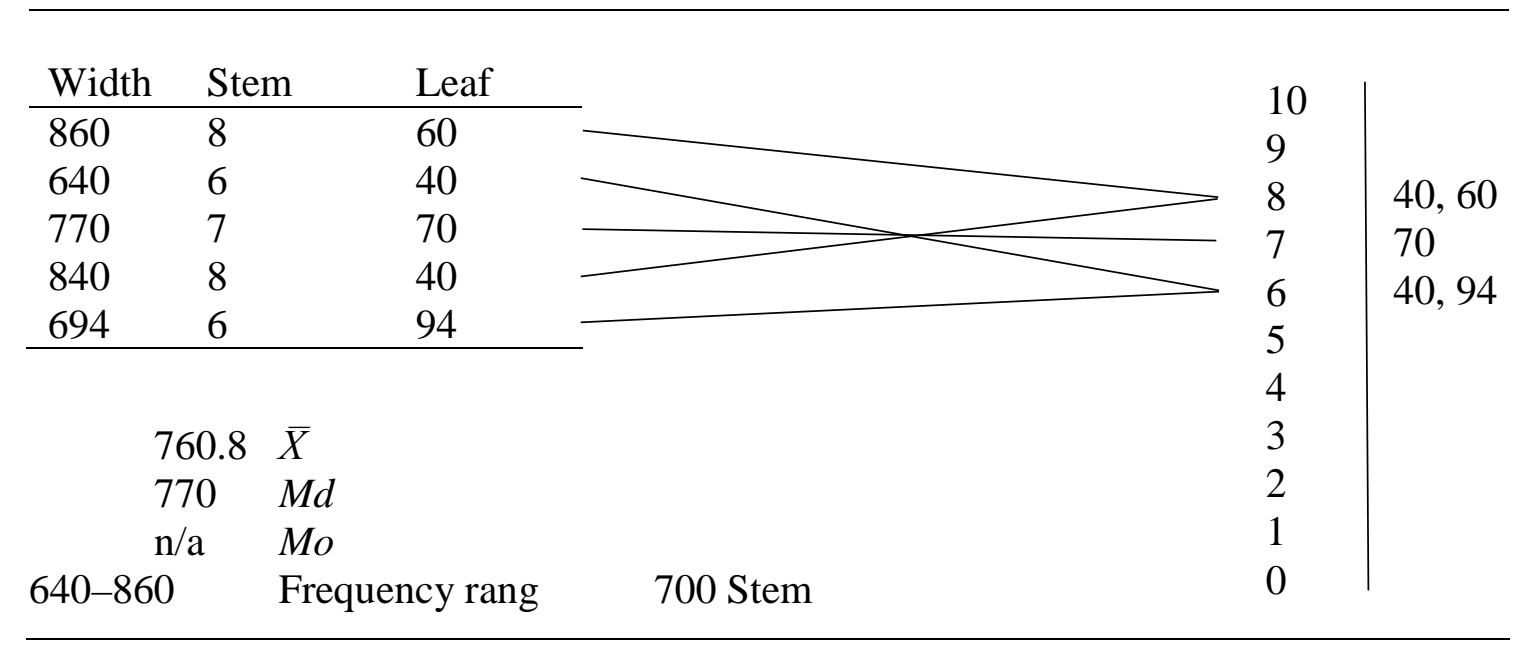

Table 49. A stem-and-leaf plot of the height of the bedframes (P-N.K.)

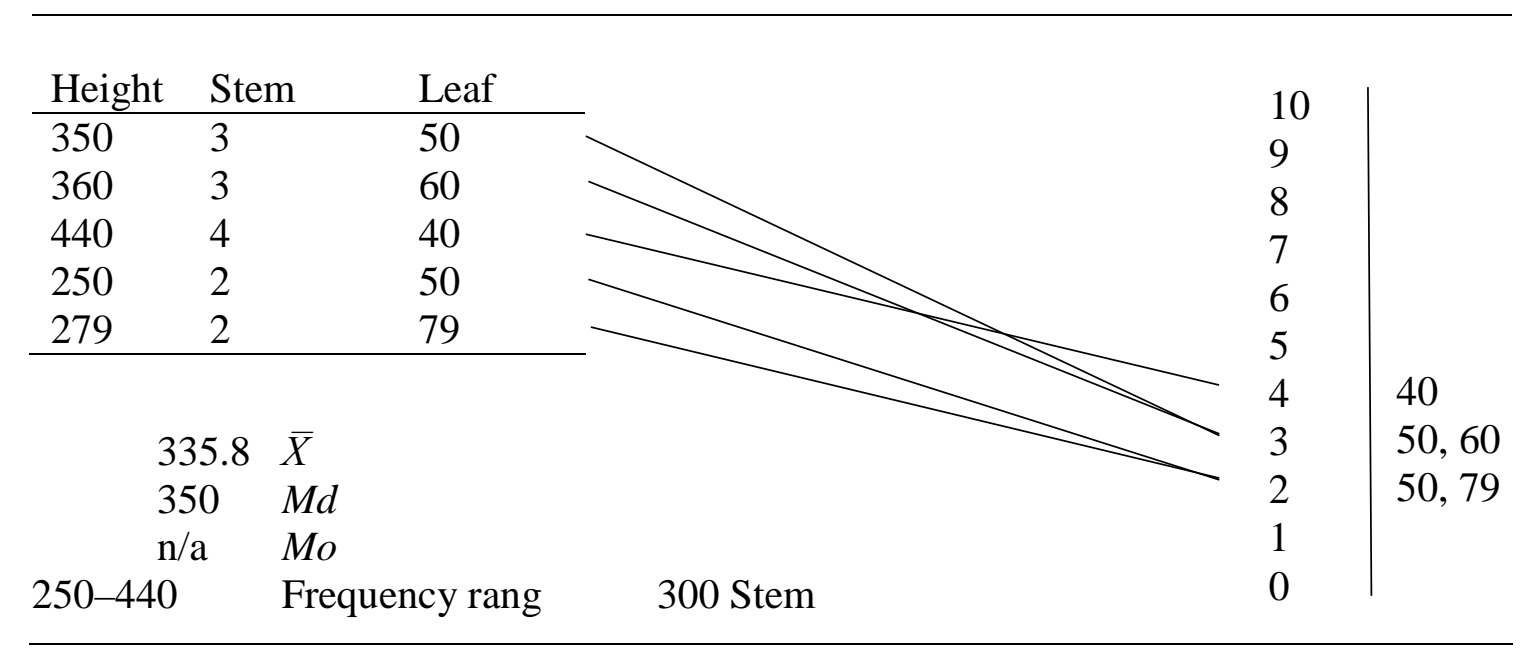


Table 50. A stem-and-leaf plot of the length of the boxes (P-N.K.)

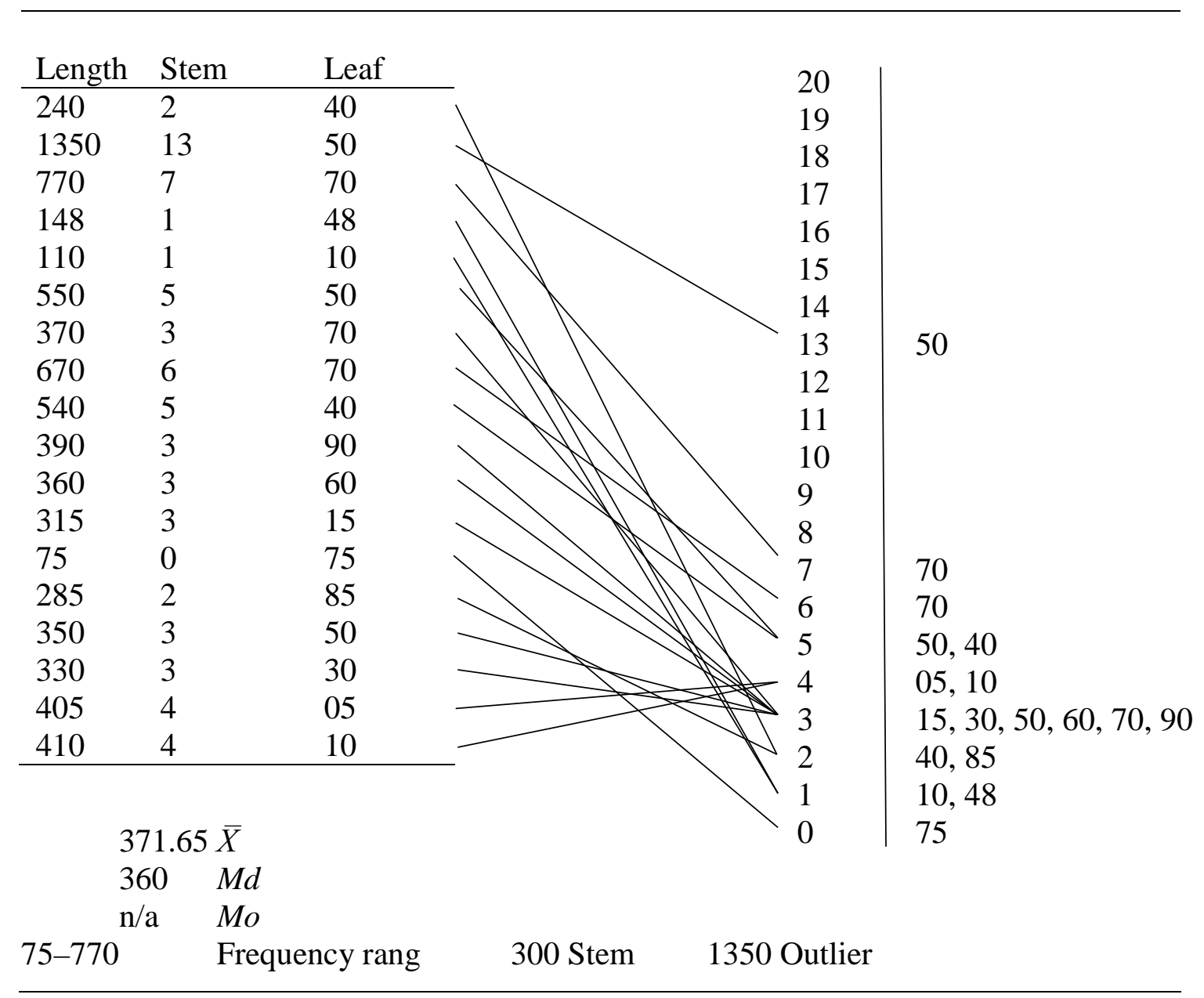


Table 51. A stem-and-leaf plot of the width of the boxes (P-N.K.)

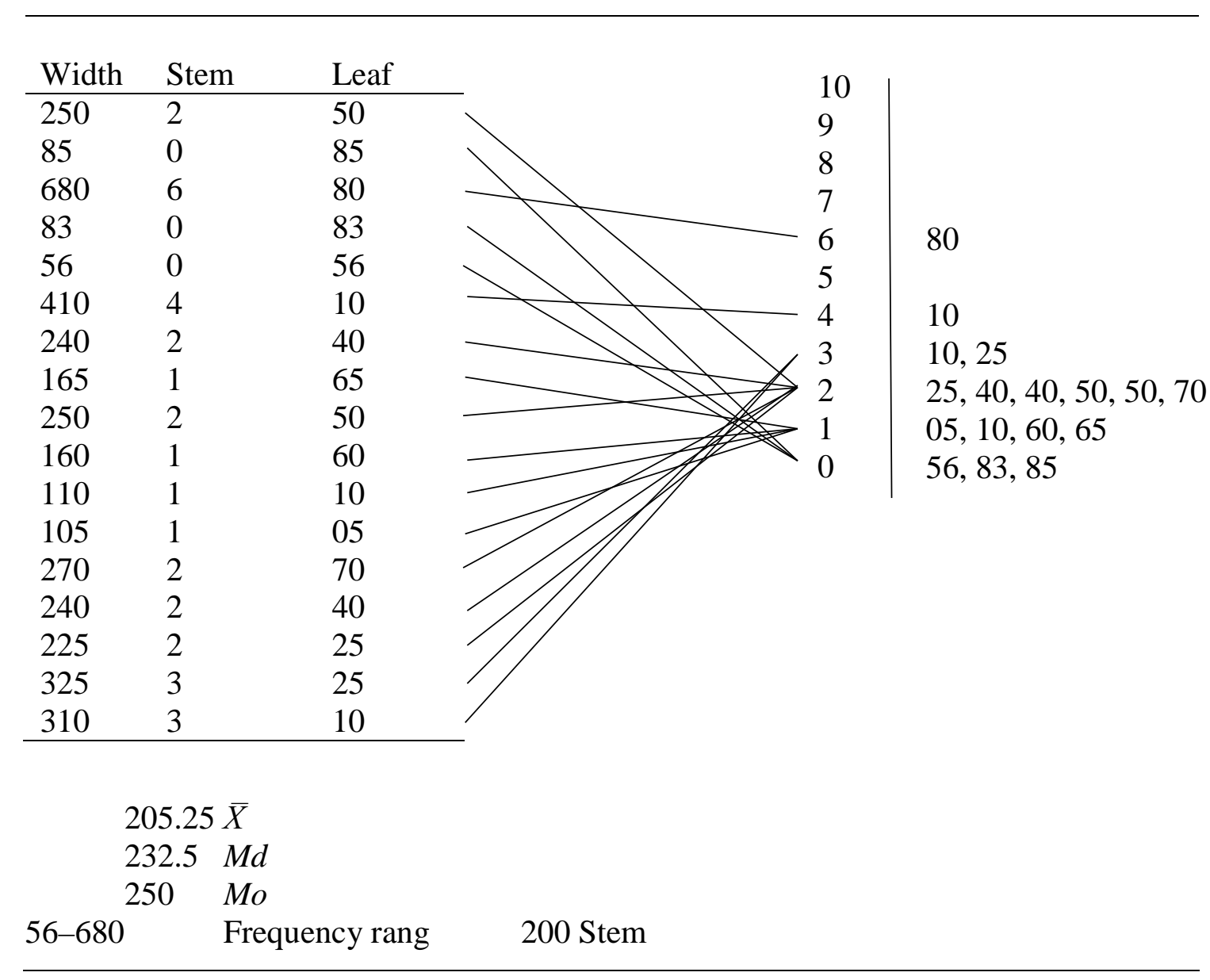


Table 52. A stem-and-leaf plot of the height of the boxes (P-N.K.)

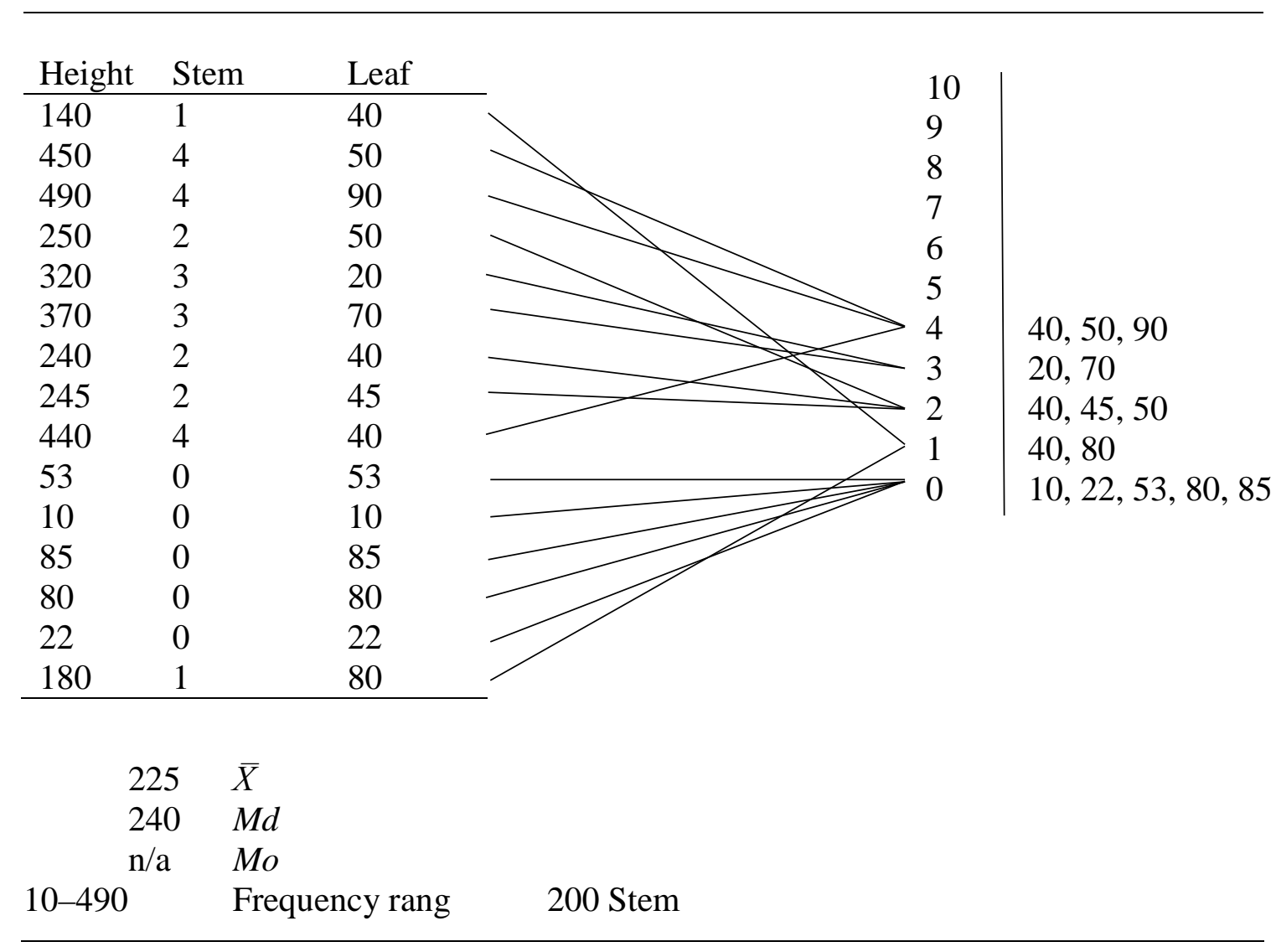

Table 53. A stem-and-leaf plot of the length of the stools (P-N.K.)

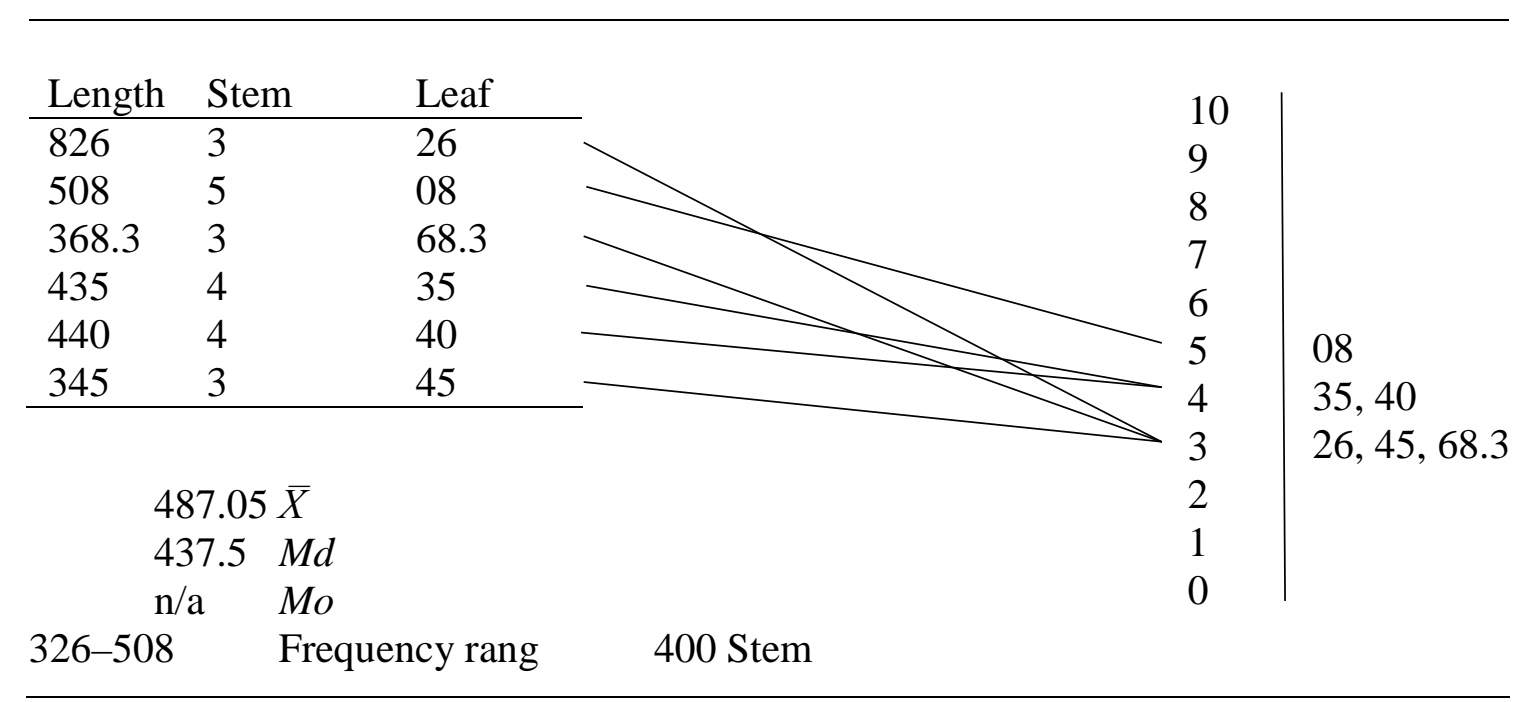


Table 54. A stem-and-leaf plot of the width of the stools (P-N.K.)

\begin{tabular}{|c|c|c|c|c|c|}
\hline Width & Stem & Leaf & & 10 & \\
\hline 482.5 & 4 & 82.5 & & 9 & \\
\hline 482.5 & 4 & 82.5 & & 8 & \\
\hline 368.3 & 3 & 68.3 & & 7 & \\
\hline 430 & 4 & 30 & & 6 & 10 \\
\hline 165 & 1 & 65 & & 5 & \\
\hline 610 & 6 & 10 & & 4 & $30,40,82.5,82.5$ \\
\hline 440 & 4 & 40 & & 3 & $17,68.3$ \\
\hline 290 & 2 & 90 & & 2 & 90 \\
\hline 100 & 1 & 00 & 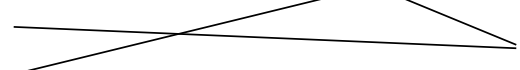 & 1 & 00,65 \\
\hline 317 & 3 & 17 & & 0 & \\
\hline \multicolumn{6}{|c|}{$368.53 \bar{X}$} \\
\hline \multicolumn{6}{|c|}{$399.15 M d$} \\
\hline \multicolumn{6}{|c|}{482.5 Mo } \\
\hline $100-610$ & 1 & Frequency rang & 400 Stem & & \\
\hline
\end{tabular}

Table 55. A stem-and-leaf plot of the height of the stools (P-N.K.)

\begin{tabular}{|c|c|c|c|c|c|}
\hline Height & Stem & Leaf & & 10 & \\
\hline 260.5 & 2 & 60.5 & & 9 & \\
\hline 470 & 4 & 70 & & 8 & \\
\hline 130 & 1 & 30 & & 7 & \\
\hline 375 & 3 & 75 & & 6 & \\
\hline 270 & 2 & 70 & & 5 & \\
\hline 305 & 3 & 05 & & 4 & 70 \\
\hline 180 & 1 & 80 & & 3 & $05,55,70,75$ \\
\hline 145 & 1 & 45 & & 2 & $60.5,70$ \\
\hline 370 & 3 & 70 & & 1 & $30,45,80$ \\
\hline 355 & 3 & 55 & & 0 & \\
\hline \multicolumn{6}{|c|}{$286.05 \bar{X}$} \\
\hline \multicolumn{6}{|c|}{$287.5 M d$} \\
\hline \multicolumn{6}{|c|}{$\mathrm{n} / \mathrm{a} \quad M o$} \\
\hline $130-470$ & & Frequency rang & 300 Stem & & \\
\hline
\end{tabular}


Table 56. A stem-and-leaf plot of the length of the tables (P-N.K.)

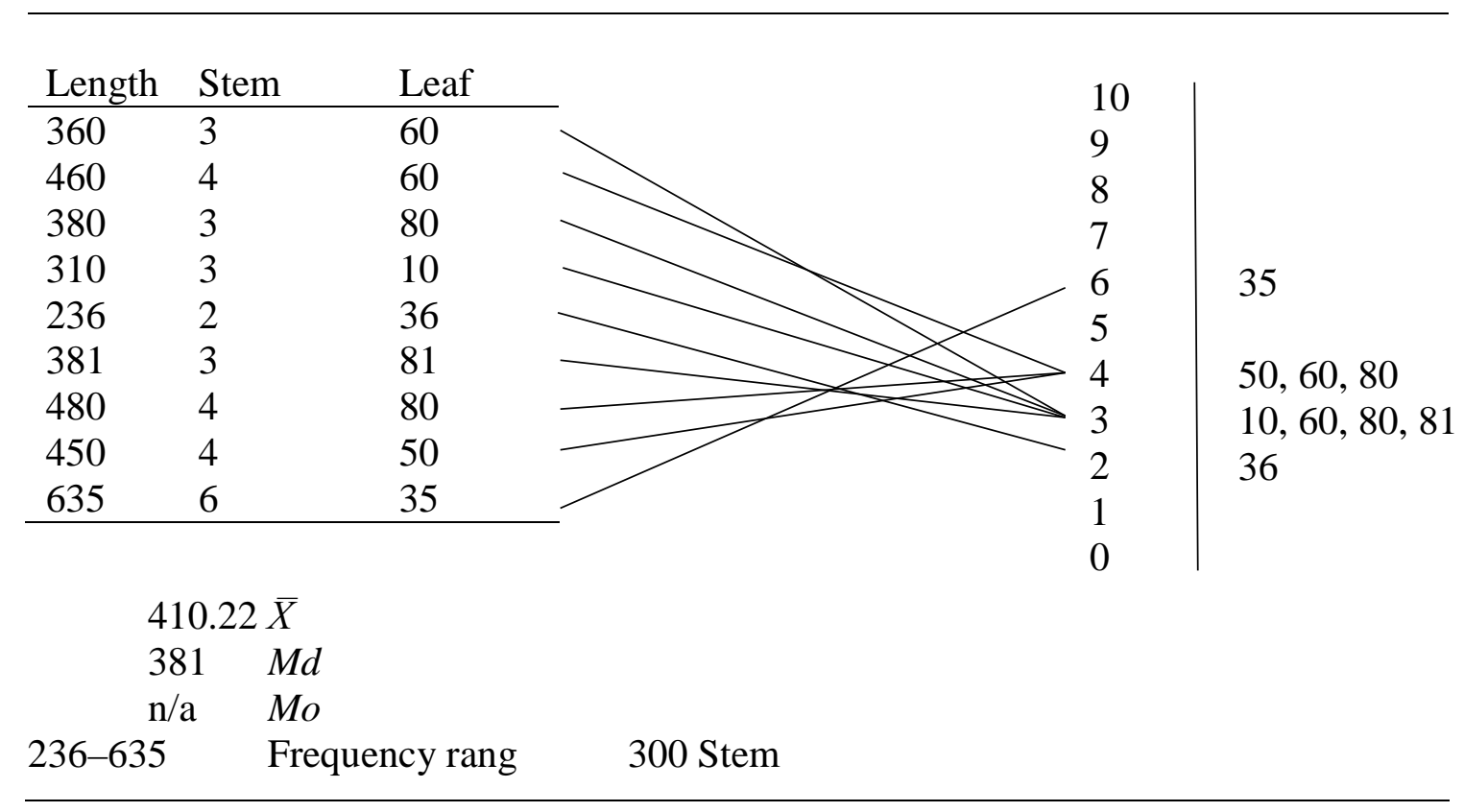

Table 57. A stem-and-leaf plot of the width of the tables (P-N.K.)

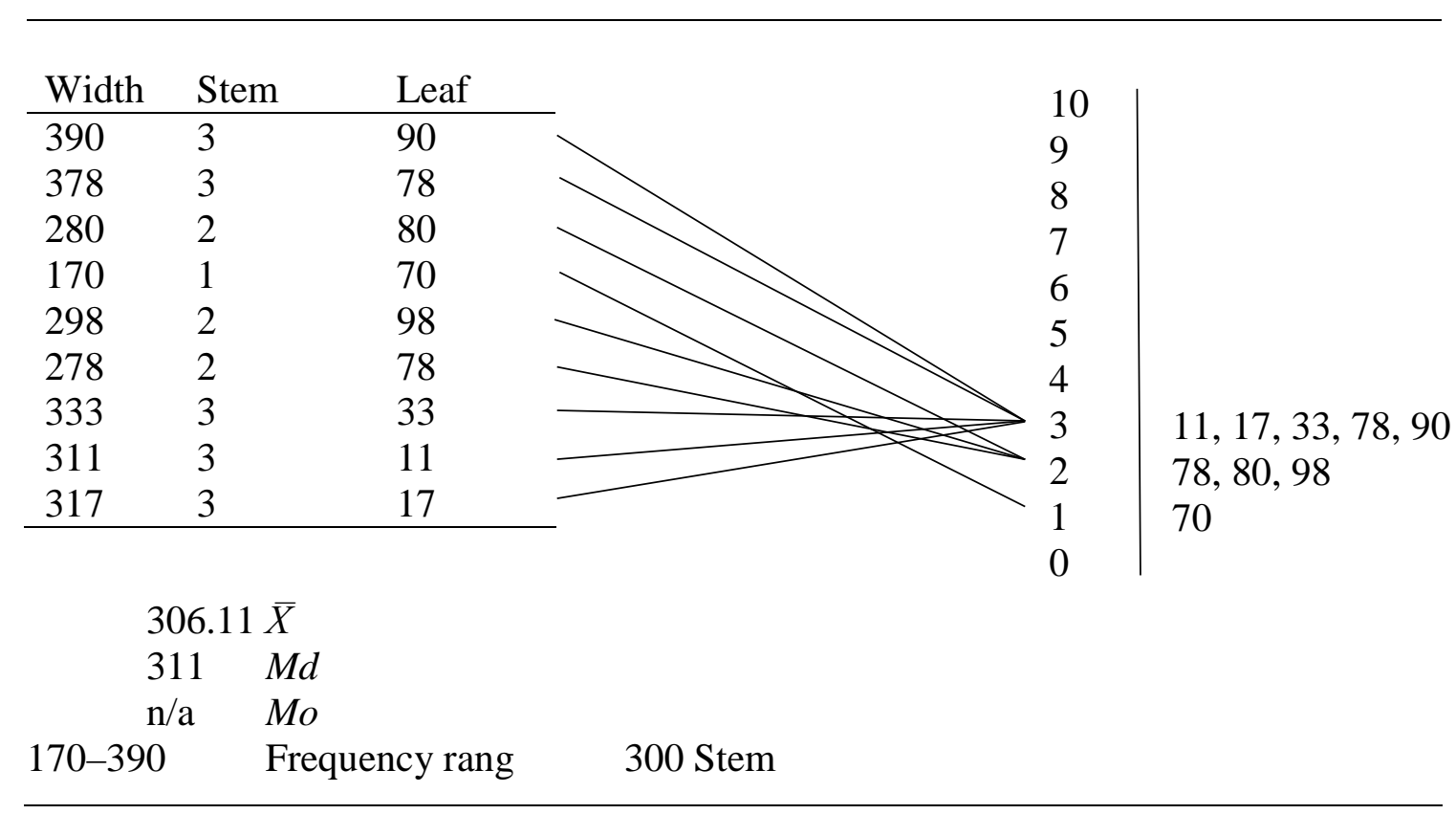


Table 58. A stem-and-leaf plot of the height of the tables (P-N.K.)

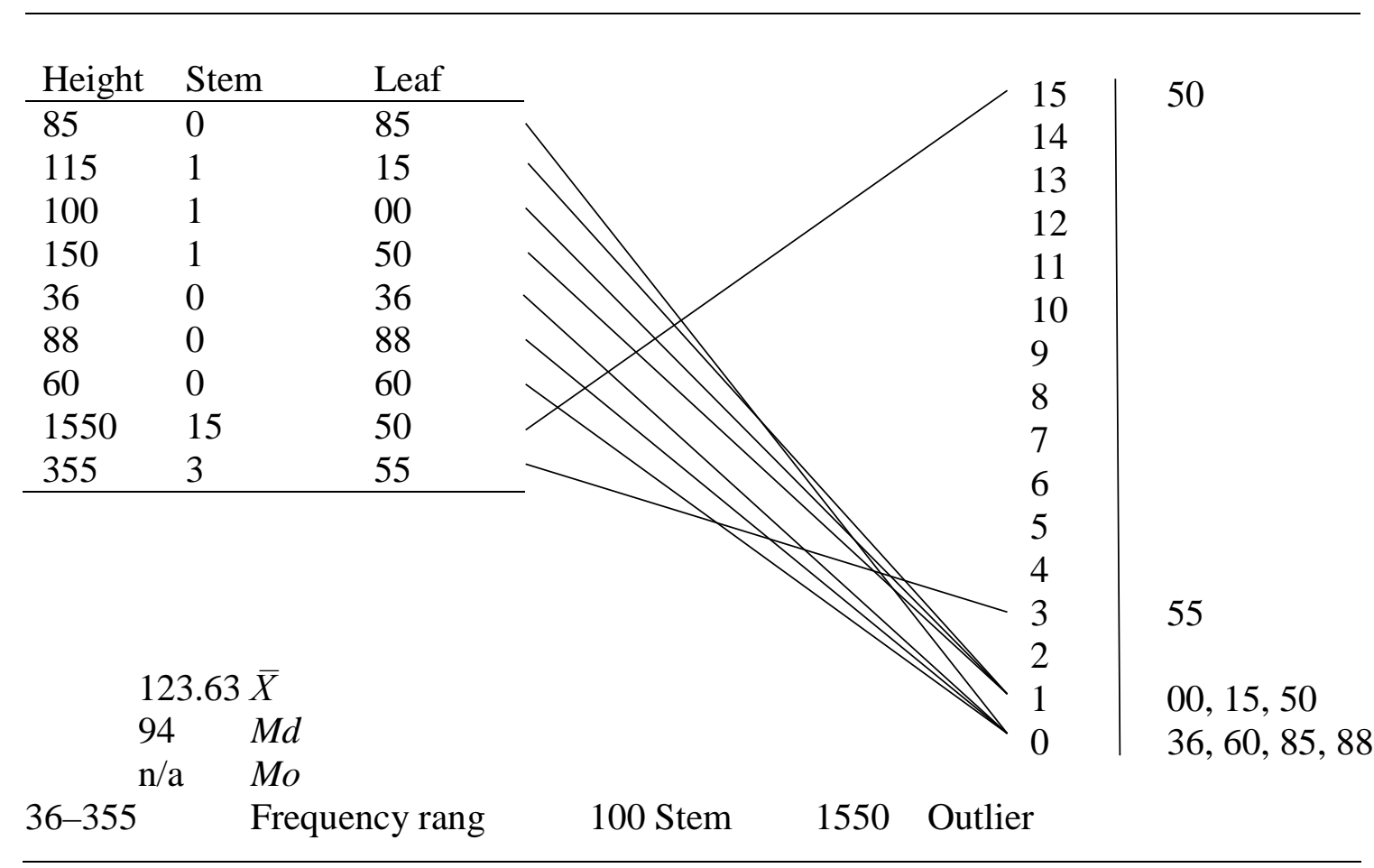

Tables 59 and 60 will be used for comparison with items discussed in the other two batches below. Results are highlighted with the darkest shade to make it easy to spot the transition between units of measure.

This comparison shows that the bedframes in Tomb KV62 are longer, wider, and higher on average $(\bar{X})$ then bedframes before and after this period. Also, the preferred stem (apparent cultural norm) of KV62 bedframes was longer and higher but more narrow than the preferred stem of bedframes up to that point in Egyptian history. Bedframes had shortened and narrowed in the New Kingdom from those before. What stands out is the change in preferred height. 
Table 59. Pre-New Kingdom furniture analysis A

\begin{tabular}{lcccccc}
\hline & a.1 & a.2 & a.3 & b.1 & b.2 & b.3 \\
\hline Sample & 5 & 5 & 5 & 18 & 17 & 15 \\
Size & & & & & & \\
Mean & 1746.5 & 760.8 & 335.8 & 371.65 & 205.25 & 225 \\
Median & 1730 & 770 & 350 & 360 & 232.5 & 240 \\
Mode & n/a & n/a & n/a & n/a & 250 & n/a \\
Frequency & $1606-$ & $640-$ & $250-$ & $75-$ & $56-$ & $10-$ \\
Range & 1920 & 860 & 440 & 770 & 680 & 490 \\
Preferred & 1700 & 700 & 300 & 300 & 200 & 200 \\
Stem & & & & & & \\
Outliers & 1171 & n/a & n/a & 1350 & n/a & n/a \\
\hline
\end{tabular}

Table 60. Pre-New Kingdom furniture analysis B

\begin{tabular}{lcccccc}
\hline & e.1 & e.2 & e.3 & f.1 & f.2 & f.3 \\
\hline Sample & 6 & 10 & 10 & 9 & 9 & 9 \\
Size & & & & & & \\
Mean & 487.05 & 368.53 & 286.05 & 410.22 & 306.11 & 123.63 \\
Median & 437.5 & 399.15 & 287.5 & 381 & 311 & 94 \\
Mode & n/a & 482.5 & n/a & n/a & n/a & n/a \\
Frequency & $326-$ & $100-$ & $130-$ & $236-$ & $170-$ & $36-$ \\
Range & 508 & 610 & 470 & 635 & 390 & 355 \\
Preferred & 400 & 400 & 300 & 300 & 300 & 100 \\
Stem & & & & & & \\
Outliers & n/a & n/a & n/a & n/a & n/a & 1550 \\
\hline
\end{tabular}

This comparison shows that the boxes in KV62 are longer, wider, and higher on average $(\bar{X})$ than then boxes before and after this period. Also, the preferred stem (apparent cultural norm) of KV62 boxes was longer and higher than the preferred stem of boxes up to that point in Egyptian history. However, the preferred stem width of KV62 boxes is in line with other boxes of the New Kingdom that are slightly wider than those in periods before the New Kingdom. What stands out is the tremendous difference in preferred height of boxes in KV62. It is possible that this might reflect a functional 
change (meaning, the purpose for which the boxes were created).

Furniture Design Comparison and Discussion

It is necessary at this point to compare the statistical results of all three batches to determine design tendency. This will be done in the same alphabetical order by item of furniture as they were analyzed above. This data is presented in Tables 61 through 65. In each of these tables, KV62 is highlighted with the lightest shade and pre-New Kingdom

Table 61. Bedframes analysis

\begin{tabular}{lccccccccc}
\hline & $\begin{array}{c}\text { KV62 } \\
\text { length }\end{array}$ & $\begin{array}{c}\text { NK } \\
\text { length }\end{array}$ & $\begin{array}{c}\text { P-NK } \\
\text { length }\end{array}$ & $\begin{array}{c}\text { KV62 } \\
\text { width }\end{array}$ & $\begin{array}{c}\text { NK } \\
\text { width }\end{array}$ & $\begin{array}{c}\text { P-NK } \\
\text { width }\end{array}$ & $\begin{array}{c}\text { KV62 } \\
\text { height }\end{array}$ & $\begin{array}{c}\text { NK } \\
\text { height }\end{array}$ & $\begin{array}{c}\text { P-NK } \\
\text { height }\end{array}$ \\
\hline Sample & 5 & 8 & 5 & 5 & 6 & 5 & 5 & 9 & 5 \\
Size & & & & & & & & & \\
Mean & 1807.6 & 1612.1 & 1746.5 & 778.2 & 737.17 & 760.8 & 778.2 & 501 & 335.8 \\
Median & 1803 & 1727 & 1730 & 795 & 756.5 & 770 & 795 & 558 & 350 \\
Mode & n/a & n/a & n/a & 680 & n/a & n/a & 680 & n/a & n/a \\
Frequency & $1750-$ & $1115-$ & $1606-$ & $680-$ & $560-$ & $640-$ & $680-$ & $180-$ & $250-$ \\
Range & 1845 & 1931 & 1920 & 901 & 850 & 860 & 901 & 772 & 440 \\
Preferred & 1800 & 1700 & 1700 & 600 & 700 & 700 & 600 & 500 & 300 \\
Stem & & & & & & & & & \\
Outliers & n/a & n/a & 1171 & n/a & n/a & n/a & n/a & n/a & n/a \\
\hline
\end{tabular}

Table 62. Boxes analysis

\begin{tabular}{lccccccccc}
\hline & $\begin{array}{c}\text { KV62 } \\
\text { length }\end{array}$ & $\begin{array}{c}\text { NK } \\
\text { length }\end{array}$ & $\begin{array}{c}\text { P-NK } \\
\text { length }\end{array}$ & $\begin{array}{c}\text { KV62 } \\
\text { width }\end{array}$ & $\begin{array}{c}\text { NK } \\
\text { width }\end{array}$ & $\begin{array}{c}\text { P-NK } \\
\text { width }\end{array}$ & $\begin{array}{c}\text { KV62 } \\
\text { height }\end{array}$ & $\begin{array}{c}\text { NK } \\
\text { height }\end{array}$ & $\begin{array}{c}\text { P-NK } \\
\text { height }\end{array}$ \\
\hline Sample & 13 & 12 & 18 & 13 & 12 & 17 & 15 & 13 & 15 \\
Size & & & & & & & & & \\
Mean & 453.67 & 312.92 & 371.65 & 326.69 & 263 & 205.25 & 387.6 & 216.08 & 225 \\
Median & 447 & 355 & 360 & 330 & 317 & 232.5 & 420 & 153.5 & 240 \\
Mode & n/a & 381 & n/a & n/a & 330 & 250 & n/a & 330 & n/a \\
Frequency & $165-$ & $60-$ & $75-$ & $127-$ & $52-$ & $56-$ & $140-$ & $40-$ & $10-$ \\
Range & 705 & 533 & 770 & 500 & 483 & 680 & 679 & 508 & 490 \\
Preferred & 400 & 300 & 300 & 300 & 300 & 200 & 400 & 100 & 200 \\
Stem & & & & & & & & & \\
Outliers & 1314 & n/a & 1350 & n/a & n/a & n/a & n/a & n/a & n/a \\
\hline
\end{tabular}


Table 63. Chairs analysis

\begin{tabular}{|c|c|c|c|c|c|c|c|c|c|}
\hline & $\begin{array}{l}\text { KV62 } \\
\text { length }\end{array}$ & $\begin{array}{c}\text { NK } \\
\text { length }\end{array}$ & $\begin{array}{l}\text { P-NK } \\
\text { length }\end{array}$ & $\begin{array}{l}\text { KV62 } \\
\text { width }\end{array}$ & $\begin{array}{c}\mathrm{NK} \\
\text { width }\end{array}$ & $\begin{array}{l}\text { P-NK } \\
\text { width }\end{array}$ & $\begin{array}{l}\text { KV62 } \\
\text { height }\end{array}$ & $\begin{array}{c}\text { NK } \\
\text { height }\end{array}$ & $\begin{array}{l}\text { P-NK } \\
\text { height }\end{array}$ \\
\hline Sample & & 7 & & 6 & 13 & & 6 & 14 & \\
\hline Size & & & & & & & & & \\
\hline Mean & & 412.86 & & 489.5 & 420.92 & & 912.83 & 638.08 & \\
\hline Median & & 420 & & 488 & 431 & & 987.5 & 615 & \\
\hline Mode & & $\mathrm{n} / \mathrm{a}$ & & $\mathrm{n} / \mathrm{a}$ & 393 & & $\mathrm{n} / \mathrm{a}$ & $\mathrm{n} / \mathrm{a}$ & \\
\hline Frequency & & $305-$ & & $360-$ & $230-$ & & 711- & 127- & \\
\hline Range & & 520 & & 700 & 570 & & 1041 & 908 & \\
\hline $\begin{array}{l}\text { Preferred } \\
\text { Stem }\end{array}$ & & 400 & & 400 & 400 & & 900 & 600 & \\
\hline Outliers & & $\mathrm{n} / \mathrm{a}$ & & $\mathrm{n} / \mathrm{a}$ & $\mathrm{n} / \mathrm{a}$ & & $\mathrm{n} / \mathrm{a}$ & 1600 & \\
\hline
\end{tabular}

Table 64. Stools analysis

\begin{tabular}{|c|c|c|c|c|c|c|c|c|c|}
\hline & $\begin{array}{l}\text { KV62 } \\
\text { length }\end{array}$ & $\begin{array}{c}\text { NK } \\
\text { length }\end{array}$ & $\begin{array}{l}\text { P-NK } \\
\text { length }\end{array}$ & $\begin{array}{l}\text { KV62 } \\
\text { width }\end{array}$ & $\begin{array}{c}\text { NK } \\
\text { width }\end{array}$ & $\begin{array}{l}\text { P-NK } \\
\text { width }\end{array}$ & $\begin{array}{l}\text { KV62 } \\
\text { height }\end{array}$ & $\begin{array}{c}\text { NK } \\
\text { height }\end{array}$ & $\begin{array}{l}\text { P-NK } \\
\text { height }\end{array}$ \\
\hline $\begin{array}{l}\text { Sample } \\
\text { Size }\end{array}$ & & 36 & 6 & 6 & 39 & 10 & 6 & 41 & 10 \\
\hline Mean & & 406.47 & 487.05 & 366.5 & 367.49 & 368.53 & 292.5 & 312.6 & 286.05 \\
\hline Median & & 385.5 & 437.5 & 348.5 & 356 & 399.15 & 298.5 & 329 & 287.5 \\
\hline Mode & & 360 & $\mathrm{n} / \mathrm{a}$ & 317 & 330 & 482.5 & $\mathrm{n} / \mathrm{a}$ & 330 & $\mathrm{n} / \mathrm{a}$ \\
\hline $\begin{array}{l}\text { Frequency } \\
\text { Range }\end{array}$ & & $\begin{array}{c}267- \\
670\end{array}$ & $\begin{array}{c}326- \\
508\end{array}$ & $\begin{array}{c}304- \\
450\end{array}$ & $\begin{array}{c}220- \\
610\end{array}$ & $\begin{array}{c}100- \\
610\end{array}$ & $\begin{array}{c}076- \\
450\end{array}$ & $\begin{array}{c}110- \\
533\end{array}$ & $\begin{array}{c}130- \\
470\end{array}$ \\
\hline $\begin{array}{l}\text { Preferred } \\
\text { Stem }\end{array}$ & & 300 & 400 & 300 & 300 & 400 & 300 & 300 & 300 \\
\hline Outliers & & $\mathrm{n} / \mathrm{a}$ & $\mathrm{n} / \mathrm{a}$ & $\mathrm{n} / \mathrm{a}$ & $\mathrm{n} / \mathrm{a}$ & $\mathrm{n} / \mathrm{a}$ & $\mathrm{n} / \mathrm{a}$ & 750 & $\mathrm{n} / \mathrm{a}$ \\
\hline
\end{tabular}


Table 65. Tables analysis

\begin{tabular}{|c|c|c|c|c|c|c|c|c|c|}
\hline & $\begin{array}{l}\text { KV62 } \\
\text { length }\end{array}$ & $\begin{array}{c}\text { NK } \\
\text { length }\end{array}$ & $\begin{array}{l}\text { P-NK } \\
\text { length }\end{array}$ & $\begin{array}{l}\text { KV62 } \\
\text { width }\end{array}$ & $\begin{array}{c}\text { NK } \\
\text { width }\end{array}$ & $\begin{array}{l}\text { P-NK } \\
\text { width }\end{array}$ & $\begin{array}{l}\text { KV62 } \\
\text { height }\end{array}$ & $\begin{array}{c}\text { NK } \\
\text { height }\end{array}$ & $\begin{array}{l}\text { P-NK } \\
\text { height }\end{array}$ \\
\hline Sample & & 7 & 9 & & 7 & 9 & & 6 & 9 \\
\hline \multicolumn{10}{|l|}{ Size } \\
\hline Mean & & 656.29 & 410.22 & & 438.43 & 306.11 & & 402.83 & 123.63 \\
\hline Median & & 690 & 381 & & 460 & 311 & & 425 & 94 \\
\hline Mode & & $\mathrm{n} / \mathrm{a}$ & $\mathrm{n} / \mathrm{a}$ & & 381 & $\mathrm{n} / \mathrm{a}$ & & $\mathrm{n} / \mathrm{a}$ & $\mathrm{n} / \mathrm{a}$ \\
\hline Frequency & & 469- & 236- & & $255-$ & $170-$ & & 298- & $36-$ \\
\hline Range & & 787 & 635 & & 558 & 390 & & 490 & 355 \\
\hline $\begin{array}{l}\text { Preferred } \\
\text { Stem }\end{array}$ & & 600 & 300 & & 400 & 300 & & 400 & 100 \\
\hline Outliers & & $\mathrm{n} / \mathrm{a}$ & $\mathrm{n} / \mathrm{a}$ & & $\mathrm{n} / \mathrm{a}$ & $\mathrm{n} / \mathrm{a}$ & & $\mathrm{n} / \mathrm{a}$ & 1550 \\
\hline
\end{tabular}

This comparison shows that the chairs in KV62 are wider and higher on average $(\bar{X})$ than the other chairs in the New Kingdom. Also, the preferred stem (apparent cultural norm) of KV62 chairs was substantially higher than the preferred stem of chairs in the New Kingdom but in line with the width. What stands out is the lack of data for a comparison with length or any comparison at all with pre-New Kingdom design.

This comparison shows that the stools in KV62 are identical in width on average $(\bar{X})$ to stools in the New Kingdom and pre-New Kingdom. They also split the difference on average $(\bar{X})$ with stools in the New Kingdom and pre-New Kingdom. Also, the preferred stem (apparent cultural norm) of KV62 stools was apparently identical to the width and height of preferred stem of stools in the New Kingdom and pre-New Kingdom. What stands out is the lack of data for a comparison with length or any comparison at all with New Kingdom or pre-New Kingdom design.

There was no table data from KV62 to compare with New Kingdom or pre-New Kingdom tables. However, New Kingdom tables on average $(\bar{X})$ were longer, wider, and 
substantially higher than tables before the New Kingdom. The preferred stem (apparent cultural preference) is also higher.

\section{Summary of Design Data and Direction of Study}

There were no data available to analyze sacred and domestic mobile courtyards. It is not even known if these existed in any period of ancient Egypt. A courtyard did exist in a mobile military camp of Egypt. Because the depiction of this camp is represented in three separate locations, an analysis was possible for its perimeter (although only via iconography) for comparison. The results are that the $\mathrm{L}_{1}$ depiction has a courtyard ratio of 32:19 shields, the I depiction has a ratio of 20:9, and the $\mathrm{R}_{1}$ has a tentative ratio of about 3:2 so that $\mathrm{L}_{1}$ and $\mathrm{R}_{1}$ have about a 3:2 ratio and I has about a 2:1 ratio. It is unknown if either of these ratios was standard.

The material used for the perimeter was shields (probably of leather) likely taller than a man, since Egyptian shields were that large. This would have provided a way to store shields and at least some sort of barrier. There is nothing in the depictions or the text that suggests how they were connected to each other (if they were). Obviously they did not keep the Hittites out. As a result, it appears to have been a simple barrier to direct peaceful traffic through guard-controlled entrances on two sides, slow down any attackers, and to keep creatures from wandering into the camp.

Sacred space in ancient Egypt did employ tents. These were sometimes used for worship and sometimes for funerary purposes. One tent discovered from a time period later than the New Kingdom had a ratio of 7:6 (length to width) and a ratio of 14:12:11 when height is added. A wooden frame overlaid with gold and covered with linen appeared in KV62 and in a bed canopy from a period earlier than the New Kingdom. This 
bed canopy had a ratio of 32:25 (length to width) and a ratio of 32:25:22 when height is added. However, since none of these canopies were used for the same purpose or from the same period it is hard to form any conclusions regarding design tendencies.

The military camp of Ramesses II, however, does provide some data that, while tentative, at least is of the same object from the period under study. The results were that both the $L_{1}$ and $R_{1}$ depictions of the center structure has a ratio of 11:6 and the I ratio is a very close $2: 1$. Version $L_{1}$ has the inner rectangle at a ratio of $8: 3$, the $R_{1}$-version has the ratio 26:11, and I-version has a ratio of 9:4. Version $\mathrm{L}_{1}$ has the combined inner structure (god-king's tent and attached rectangle) at a ratio of 3:1, the $\mathrm{R}_{1}$-version at 19:7, and Iversion at a ratio of $8: 3$ (all very close to a 3:1). The attached rectangle has a ratio in the $\mathrm{L}_{1}$-version of 2:1, the $\mathrm{R}_{1}$-version has a ratio of 11:7, and I-version has 20:11 (all very close to a 2:1). It is unknown if any of these ratios were standard.

Both leather and cloth have been found to have covered tents in ancient Egypt. Most tents appear to have had a center pole. The coverings also appear to have been hung on a wooden frame. When this frame was associated with divine royalty, the wood was overlaid with gold. The coverings were hung on the frame sometimes on the inside, sometimes on the outside. The inside coverings were hung on hooks attached to the frames. Very specific joints and woodworking techniques were used to construct the frames and hold them together. It is possible that wooden boxes were used for storage and possibly transportation of the cloth.

In the furniture of KV62 was a simulacrum of Anubis that, with the poles, has about a ratio of 4:1:2 $(l, w, h)$. There was also a chest with carrying poles with a ratio about 4:3:3 $(l, w, h)$. A carrying chair from before the New Kingdom had a ratio (with the 
poles) of about 4:1:1 $(l, w, h)$, closer to that of the simulacrum of Anubis.

Legs of furniture often ended with paws of lions resting on ringed tenons. Linen often covered furniture items and it was also often embroidered, sometimes with words. Very specific stiches were used. Linen was folded and stored in boxes (the folds indicting wealth). Lamps do not appear to have had any set design. Basins also appear to have been made of many materials (including metal). Jewelry in KV62 belonging to the god-king of Egypt was primarily of three identifiable colors blue, purple, and red set in gold. These items of jewelry often had winged protectresses represented on them (as did shrines and other elements).

Cultural preference can be assessed using measures of central tendency for the volume of objects. The analysis shows that there is a tendency for most of the furniture to be slightly bigger during the Amarna period (as represented in KV62) than furniture during the rest of the New Kingdom. The New Kingdom furniture was also slightly larger in most cases than the examples studied from periods before the New Kingdom.

Two of the items of furniture that would seem to measure the size of a person (bedframes and stools) show contradictory data. Bedframes during the New Kingdom tended to have smaller dimensions than those in earlier times, while stools remained remarkably consistent. (There wasn't enough data to analyze from periods before the New Kingdom.) This result seems to suggest that there was a preference for bedframes to occupy less space but the people sleeping on them didn’t necessary get smaller.

It needs to be noted that these conclusions are based on accidents of survival and discovery and must remain tentative for that reason. There simply is not enough data (except perhaps with stools) to form any hard conclusions. However, it is clear that 
design preference change did occur between eras and that it can be measured. This was necessary to establish so that intangible cultural heritage could be identified. Now that it has been established that design preference in furniture did change between periods of time in ancient Egypt (as is generally recognized that it has with other material culture such as pottery) the results of this study can be compared with data gathered from the text (Chapter 3) to determine if what is described in the text may or may not reflect Egyptian cultural preference in design from any of the periods studied in this chapter. That will be done in Chapter 7 and discussed in Chapter 8. 


\section{CHAPTER 6}

\section{MATERIAL ELEMENTS IN THE ARCHAEOLOGICAL RECORD}

"Many new analytical techniques have been developed... [with respect to ancient Egyptian materials]... providing a great deal more precision than was previously imaginable."

(Nicholson and Shaw 2000: 1)

The purpose of this chapter is to collect data from the archaeological record and organize them into usable sets that can be compared with the results of the statistical analysis conducted on the Hebrew tent-sanctuary data sets of Chapter 4. This comparison will take place in Chapter 7. The data collected in this chapter will only be concerned with the material elements of the sacred, royal-domestic, and military spheres of New Kingdom Egypt as delineated in Chapter 2.

These material elements will further be limited to just the nine materials mentioned in the construction of the tent-sanctuary as a comparison is desired with those and beyond those nine there is nothing to compare. It should be said, however, that there are many more materials that were used in the three spheres of Egyptian life that are sampled in this study (sacred, domestic, and military) beyond just these nine. The design elements are not the focus in this chapter but were dealt with in Chapter 5 . The materials themselves will be listed in the same order as they are listed in Chapter 4, beginning with 
the organic materials and finishing with the inorganic.

\section{Materials of Sacred, Royal-Domestic, and Military Spheres}

In order to assess a cultural influence (intended or unintended) the material elements must be present in the potentially influencing culture on which this chapter is focused. To test this, those elements must be quantifiable. The first step will be to examine the archaeological record for data regarding each of the nine material elements identified in Chapter 4. This will include brief summations of the broad range of materials found in each of those spheres (although the spheres themselves may not be mentioned in particular unless there is something unique about the appearance of that material in a particular sphere) before narrowing down to a specific type of material (if applicable). The second step will be to analyze these data. The third step will be to organize them into usable data sets.

The purpose of this exercise is to identify, as precisely as possible, what appears in the archaeological record in Egypt as published by experts with the end goal to reach a binary statistic of present or not present, if possible, for each of the nine materials, using the understanding of these materials as presented in Chapter 4. If these same materials are present in the archaeological record of Egypt in the New Kingdom (as delineated in Chapter 2), the Egyptian culture can be considered the possible conduit for cultural influence. If, on the other hand, the materials are not present in the archaeological record of Egypt during the New Kingdom, potential reasons will need to be ascertained in relation to the accident of survival. The comparison, resulting determination, and discussion will all take place in Chapter 7. 
Archaeological Record and Analysis of Data

The New Kingdom's expansion of controlled territory brought with it the resources of those lands, providing an abundance of materials (such as precious gems, special types of woods, and valuable metals) that could be used in Egypt (Badawy 1968: 2). The abundance of archaeological remains from the New Kingdom provide an ample data set from which to sample and make statistical analyses.

Each element will be described based on all available scholarly data for each type of material. An analysis of the data will then be presented.

\section{Acacia Wood}

The first material to be considered is wood, specifically acacia. From, at least, as early as the $4^{\text {th }}$ Dynasty (reign of Snofru, conventionally dated to approximately the $25^{\text {th }}$ century B.C.), as stated on the Palermo Stone, the supply of wood in Egypt relied to some extent on the practice of importation (Lucas and Harris 1999: 429), although some suggest that wood used for furniture was imported in the $3^{\text {rd }}$ Dynasty, conventionally dated to approx. the $27^{\text {th }}$ to $26^{\text {th }}$ centuries B.C. (Killen 1980: 1 ). The identity of some of the wood in Egyptian texts still remains in doubt. However, what is known now is that this was almost certainly a reference to special wood types not locally grown in ancient Egypt but brought to Egypt as specialty wood. Table 66 contains a list of those specialty wood types that have been identified in the archaeological record and that were used before or during the New Kingdom (Lucas and Harris 1999: 429-39).

Cedar and Ebony were the most common specialty wood used in Egypt, as reflected in funerary items. That said, most items listed as cedar in museums and excavation reports are actually not cedar, but are labeled this way because this was the 
Table 66. Specialty wood and their uses

\begin{tabular}{|c|c|c|}
\hline $\begin{array}{l}\text { Specialty } \\
\text { wood }\end{array}$ & Uses & Scientific name and Source \\
\hline Ash & $\begin{array}{l}\text { compound bow and parts of a chariot: } \\
\text { axle, felloes, and frame of floor }\end{array}$ & Fraxinus ornus from Lebanon \\
\hline Box & chair, razor handle and inlay & $\begin{array}{l}\text { Buxus longifolia from Syria and } \\
\text { southern Levant }\end{array}$ \\
\hline Cedar & $\begin{array}{l}\text { boxes, coffins, dowels, fragments, } \\
\text { sarcophagus, and shrine panels }\end{array}$ & Cedrus Libani from Lebanon \\
\hline Cypress & $\begin{array}{l}\text { coffin, coffin lid, fragments, and small } \\
\text { boxes }\end{array}$ & Not determined \\
\hline Ebony & $\begin{array}{l}\text { arrowheads, beds, bolts for the shrine } \\
\text { doors, chairs, chests, coffins, cylinder } \\
\text { seal fragment, footstools, frames of } \\
\text { boxes, a harp, headrests, inlay, shrines, } \\
\text { a stand for a gaming board, statues, } \\
\text { staves, a stool, tablets, veneer, and } \\
\text { whips }\end{array}$ & $\begin{array}{l}\text { Dalbergia melanoxylon entering } \\
\text { Egypt from lands to the south }\end{array}$ \\
\hline Elm & $\begin{array}{l}\text { parts of a chariot: axle, body, handrail, } \\
\text { wheel, and yoke }\end{array}$ & $\begin{array}{l}\text { Ulmus campestris from the } \\
\text { Levant }\end{array}$ \\
\hline Fir & dummy vase and fragment & $\begin{array}{l}\text { Abies cilicica from Asia Minor } \\
\text { and Syria }\end{array}$ \\
\hline Juniper & coffin and small lid & $\begin{array}{l}\text { probably Juniperus phoenicea } \\
\text { from Syria (although a different } \\
\text { juniper grows there today) }\end{array}$ \\
\hline Liquidambar & shaped fragment & $\begin{array}{l}\text { Liquidambar orientalis from } \\
\text { Asia Minor }\end{array}$ \\
\hline Mapel & piece of a chariot: frame of floor & $\begin{array}{l}\text { probably Acer campestre from } \\
\text { western Asia }\end{array}$ \\
\hline Oak & dowel & $\begin{array}{l}\text { Quercus Cerris from Egypt } \\
\text { possibly from the Theban area }\end{array}$ \\
\hline Pine & $\begin{array}{l}\text { base of a nilometer, coffin, model of a } \\
\text { brick mold, and trimmed fragment }\end{array}$ & $\begin{array}{l}\text { Pinus halepensis from Syria or } \\
\text { Asia Minor }\end{array}$ \\
\hline Plum & piece of a chariot: spokes & $\begin{array}{l}\text { Prunus domesticus from western } \\
\text { Asia }\end{array}$ \\
\hline Yew & $\begin{array}{l}\text { coffin fragments, coffin peg, and head } \\
\text { of Queen Tiy }\end{array}$ & $\begin{array}{l}\text { Taxus baccata from western } \\
\text { Asia }\end{array}$ \\
\hline
\end{tabular}


default label when the samples were recovered but before they could be precisely identified (Lucas and Harris 1999: 432). Cedar wood was imported from Byblos as early as the Old Kingdom (attested to by the dismantled ships at Giza and a traveling chest with carrying poles [Carter catalogue item 32] which also included ebony imported from Nubia, from KV 63; Hawass and Vannini 2007: 28), indicating that objects made of this substance were valuable. Tutankhamun's dowels were made from cedar, sidder, oak, and acacia (Lucas and Harris 1999: 434). That said, identification is only really possible at these basic levels. In general, ancient wood "retains its original volume and shape while its weight and density may be very much diminished” (Gale et al. 2000: 334). That being the case and because the anatomical structure of wood can vary greatly, depending on the conditions in which the tree grew, caution is urged when trying to identify wood more specifically (Gale et al. 2000: 334).

The wood of trees that grew in Egypt was generally used for less valuable items. The wood used most frequently for structures and furnishings were locally-grown acacia, sycamore fig, and tamarisk (Lucas and Harris 1999: 439). Rarely, yet occasionally, the wood of the almond, carob, date palm, the dom palm, the persea, the sidder, and the willow were used (Lucas and Harris 1999: 439). Table 67 contains a list of those native woods that have been identified (Lucas and Harris 1999: 440-48; Gale et al. 2000: 335). Ancient Egyptian wood cutting scenes demonstrate that "woodcutting” was a profession in Egypt. The woodcutter chopped a deep notch at the base of the trunk (see Appendix A, Figure 81) to fell a tree away from him (sometimes with a rope tied to the tree so it could be lowered down in order to avoid the "thunder shakes" in the wood), then the branches were lopped off, and sometimes these logs were floated to a location 
Table 67. Native Egypt wood and their uses

\begin{tabular}{|c|c|c|}
\hline $\begin{array}{l}\text { Egyptian } \\
\text { wood }\end{array}$ & Uses & Scientific name \\
\hline$\overline{\text { Acacia }}$ & $\begin{array}{l}\text { logs, charcoal, beams, coffin pegs, } \\
\text { sarcophagus dowels, coffin dowels, box } \\
\text { dowels, knobs, pieces of chariots: body, } \\
\text { bolts, boat-building, construction work, } \\
\text { furniture, bows, and arrows }\end{array}$ & $\begin{array}{l}\text { Acacia tortilis, Acacia } \\
\text { raddiana, Acacia nilotica, and } \\
\text { Acacia albida. Acacia nilotica }\end{array}$ \\
\hline Almond & walking stick handle & Not listed \\
\hline Carob & a bow & Ceratonia Siliqua \\
\hline Date Palm & a box and joiners & Phoenix dactylifera \\
\hline Dom Palm & doors & Hyphaene thebaica \\
\hline Persea & a headrest & Mimusops Schimperi \\
\hline Sidder & coffins, bows, sticks, and dowels & probably Zizyphus spina Christi \\
\hline $\begin{array}{l}\text { Sycamore } \\
\text { Fig }\end{array}$ & $\begin{array}{l}\text { dummy vases, column bases, } \\
\text { sarcophagi, coffins, tenons, boxes, } \\
\text { statuettes. models, and miniature coffins }\end{array}$ & Ficus sycomorus \\
\hline Tamarisk & $\begin{array}{l}\text { worked sticks, charcoal, walking sticks, } \\
\text { throw sticks, a lid of a box }\end{array}$ & $\begin{array}{l}\text { Tamarisk nilotica and Tamarisk } \\
\text { articulata }\end{array}$ \\
\hline Willow & $\begin{array}{l}\text { a knife handle, parts of a box, and parts } \\
\text { of a chariot }\end{array}$ & Salix safsaf \\
\hline
\end{tabular}

for creating planks (Gale et al. 2000: 353). The process of producing timber was done by cleaving the wood, as can be seen in tomb scenes (see Appendix A, Figure 82; Gale et al. 2000: 354). The drying of the wood after it had been cut into planks was also carefully monitored to avoid warping. This drying could reduce the wood moisture to 8-12\% (Gale et al. 2000: 355).

There are a variety of acacia that were grown in ancient Egypt and used from the earliest of times (Lucas and Harris 1999: 442). Acacia "grew abundantly in Egypt until the early medieval period" and was one type of the wood used to build boats (along with Ficus sycamore and Tamarisk nilotica; Gale et al. 2000: 367). But the acacia wood used in making ships was also imported from Nubia in later times, a fact that Greek visitors extensively chronicled later in history (Lucas and Harris 1999: 442). From the 
archaeological record it is clear that acacia wood could be cut into planks that were 12 Egyptian cubits long (Gale et al. 2000: 267). In addition to the use of wood for furniture, construction, weapons, and specialty items, acacia (probably nilotica or raddiana) also provided charcoal for smelting (Gale et al. 2000: 335, 354). When used for items that had value, the color and substance of acacia had value. The heartwood of Acacia was "red, hard, and durable” (Gale et al. 2000: 335).

\section{Woven Linen}

The next material to be considered is woven linen, a material that is abundantly attested in the archaeological record. A number of tombs illustrate the weaving process that followed spinning, of which the most detailed is the Meketre model in Cairo from the Middle Kingdom (see Appendix A, Figure 83; Vogelsang-Eastwood 2000: 268). Weaving is illustrated as being done on two ground looms where the beams are fastened to pegs on the floor (Lucas and Harris 1999: 141; Vogelsang-Eastwood 2000: 277). To weave, the women needed "heddle jacks, shed sticks, weavers' swords or beaters in,” and shuttles (Lucas and Harris 1999: 141). The spun thread was arranged "into warps on pegs on the wall” where it was wound into "a figure of eight" (Lucas and Harris 1999: 141). A ground loom woven linen can always be identified since they always have weft-fringe (aka selvedge) on the left-hand side (Vogelsang-Eastwood 2000: 277). Ground weaving (see Appendix A, Figure 84) was popular because it was easily transportable, so was the nearly-exclusive method used by nomadic peoples (Vogelsang-Eastwood 2000: 277).

Ground looms were used exclusively before the New Kingdom, when vertical looms (see Appendix A, Figure 85) were first introduced in iconographic representations (suggested to have been introduced by the Hyksos, but this is only a theory; Lucas and 
Harris 1999: 142; Vogelsang-Eastwood 2000: 276, 278). These vertical looms seem to have been tall (perhaps as much as five meters) but since none have been found in the archaeological record it is impossible to know for sure (Vogelsang-Eastwood 2000: 278).

One of the most important linen fragments recovered from archaeological excavation comes from the tomb of Thutmoses IV, excavated by Davis in 1903 and appears to have been woven on a vertical loom. The fragment contains the cartouche of Thutmoses’s father, Amenhotep II (Appendix A, Figure 86). At the time it was discovered, it was 1000 years older than the oldest tapestry known (Carter and Newberry 1904: 143). “The warp-strings [number] about sixty in the space of one inch" and the "weft is appreciably thicker than the warp,...leaving no doubt that an upright loom was used.” (Carter and Newberry 1904: 143). It was decorated with hieroglyphs using red, blue, green, yellow, brown, and black thread (Carter and Newberry 1904: 143).

Linen was cared for by professional launderers. Before the New Kingdom, launderers are depicted in tomb paintings washing fabrics on the bank of the river, wearing aprons, whereas after the beginning of the New Kingdom, they seem to have washed laundry in large pots (Forbes 1964b: 82). In the New Kingdom the linen was soaked in cold water, then boiled (with potash), rinsed in flowing water, and finally hung to dry where it was bleached (Forbes 1964b: 82). Aside from potash, natron, soapwort, and asphodel are also known to have been used (Forbes 1964b: 82).

\section{Blue, Purple, and Scarlet Thread}

Closely related to woven linen is the thread used for weaving. Three colors of dyed thread are specifically mentioned, so these are the next materials to be considered. Before the Late Period, linen was the primary fabric in ancient Egypt (wool was 
considered ceremonially unclean by the Egyptians; Lucas and Harris 1999: 142). In the New Kingdom (and before), linen thread was made as a product of the flax plant. Flax was sown in mid-November (see Appendix A, Figure 87) and took about three months to mature (Vogelsang-Eastwood 2000: 270). Flax (Linum humile) was harvested at various times, based on the purpose for which it needed to be used (fabric, basketry, cordage, or matting) so that the younger the plant the finer the weaving, such as for clothing; and the older the more rustic, such as for rope (Lucas and Harris 1999: 143; Vogelsang-Eastwood 2000: 270).

After the plant was dried and the seeds were removed (for planting the following year), the flax plants were retted in slow-moving water for about two weeks to break down the outer shell (Vogelsang-Eastwood 2000: 270-71). Then the plant was removed from the water and beaten to separate out the fibers, which sometimes required an additional step of scotching to remove those fibers that still remained (VogelsangEastwood 2000: 271).

A number of tombs illustrate the spinning process that precedes weaving, of which the most detailed is the Meketre model in Cairo (see Appendix A, Figure 83). It shows three women doing the work on the ground. Piles of flax (Linum angustifolium; Vogelsang-Eastwood 2000: 270) are loosely twisted by rolling them on their left knees (called "a rove) into a ball from which the thread is drawn (after the ball is placed into a tension pot or spinning bowl) and spun (Lucas and Harris 1999: 141). Aside from spinning (see Appendix A, Figure 88), thread could also be obtain through splicing (Vogelsang-Eastwood 2000: 271). Since flax naturally twists to the left (into a "s” shape) when drying, this was the direction that all Egyptian fibers were spun (Lucas and Harris 
1999: 141). Individual fibers are about one $\mathrm{cm}$ long before they are spun together with others (Vogelsang-Eastwood 2000: 271). Spinning was done by hand, by grasped spindle, supported spindle, or suspended spindle (this last was the most common) with the use of two or more spindles being introduced by the Hyksos (Lucas and Harris 1999: 141). By the New Kingdom period, dome-shaped whorls (see Appendix A, Figure 89, where the whorl is used in the drop-spindle spinning method) was "in widespread use" so that in Egypt the whorl was "placed at the top of the shaft" (Vogelsang-Eastwood 2000: 273).

Thread found associated with leather has been identified as either being made from sinew or flax (Veldmeijer 2011: 19). Sinew (Van Driel-Murray 2000: 301) was used when strength was the main need and flax (linen) thread was used for applique work (Veldmeijer 2011: 33, note 22). Often this appears in a running stitch when used for decorating purposes where the decorated sides appear short and the back sides appear long (Veldmeijer 2011: 20). Edges were often whip stitched and the whip stich was also used to fasten layers of leather one on top of another (Veldmeijer 2011: 20). Both of these stitch types were in common use long before the New Kingdom. The sailor stitch is rare in the New Kingdom, with only one example coming from Amarna that was used to repair a torn seam (Veldmeijer 2011: 21).

The most common decoration pattern in leather in the New Kingdom's $18^{\text {th }}$ Dynasty (approx. $16^{\text {th }}$ to $14^{\text {th }}$ centuries B.C.) is the overlap stitch where one color thread (or leather strap) is laid over another (Veldmeijer 2011: 22). Stair-step overlap is also found (Veldmeijer 2011: 23). The intricacy of design was an indication of wealth (Van Driel-Murray 2000: 309)

Because flax is a cellulose substance, it is difficult to dye, so that most linen 
textiles recovered from ancient Egypt were not dyed, and it was not until the New Kingdom that linen threads were commonly dyed (Vogelsang-Eastwood 2000: 278). Dyes were made either from ochreous earths (earth mixed with hydrated oxide), producing yellow (which was turned red by heating), orange, and brown colors; or plants, producing blue or red colors (Vogelsang-Eastwood 2000: 278). Blue was produced by indigo, woad, or sunt and the deepness of the shade depended on how many times it was dipped into the dye (Vogelsang-Eastwood 2000: 278-79). Red (from a plant) was produced from madder and was introduced into Egypt in the $18^{\text {th }}$ Dynasty (VogelsangEastwood 2000: 279).

Purple thread was created by double dying, where threads were first dyed red and then blue (Vogelsang-Eastwood 2000: 279). Green thread was produced by first dying the thread yellow and then blue (Vogelsang-Eastwood 2000: 279). In both cases, blue was the last color used. Egyptians did not generally dye fibers but rather dyed after it was spun thread or woven into cloth (Vogelsang-Eastwood 2000: 279). Bleach (exactly how is unknown, but sun bleaching is suspected) was also used to make the fabrics more white (a status symbol indicating social rank), which the Egyptians viewed as a sign of purity and cleanliness (Vogelsang-Eastwood 2000: 280). Beadwork was used to decorate cloth for a variety of social ranks, but embroidery was reserved for royalty until the medieval period (Vogelsang-Eastwood 2000: 280).

These same three colors (blue, purple, and scarlet) are the three colors used almost exclusively in the colored glass (faience) in Tutankhamun's finely-decorated middle coffin, the inner gold coffin, his famous gold mask, and every piece of fine jewelry found in KV62. The blue faience was to mimic turquoise, the purple (or deeply 
dark blue) was to mimic lapis-lazuli in its darkest version, and the scarlet was mimic red jasper or carnelian (James 2009: 89). Due to fading over time, some of the blue has a greenish hew. Gold was attached (soldered) in thin strips that formed a design cell or cloisons and then filled with individually-cut faience or quartz crystal (James 2009: 89). The repeated presence of these three colors seems to indicate that they were associated with the divine king, although more work needs to be done in this area.

\section{Goat Hair}

The next material to be considered is the hair of goats. Dark brown or creamcolored goat hair is known in Egypt during the Middle and New Kingdoms (Lucas and Harris 1999: 32; Vogelsang-Eastwood 2000: 269). Hair was used to make cloth for tents and sacks, but the few remaining samples appear to be made from camel hair (Forbes 1956: 5). The lack of evidence is not surprising, considering the easily disintegrating nature of organic materials.

Another animal closely related to the goat is the sheep. Sheep hair was used from the earliest periods (e.g. Naqada), although it was not until the development of a new breed (Ovis platyura aegyptiaca), which had fleece rather than hair, that the wool was useful for weaving and is seen on "lay-people," but perhaps not on priests (VogelsangEastwood 2000: 269). Such wool was not commonly used until the New Kingdom. The earliest sheep in Egypt was the hairy breed called "steppe sheep,” which seems to have come from the Urial area of Mesopotamia (Forbes 1964b: 3). This type of sheep "seems to have become extinct about 1500 B.C.” toward the end of the $2^{\text {nd }}$ Intermediate Period and early New Kingdom when the "heavy-horned fleecy species” was introduced (Forbes 1964b: 3), almost certainly by the Hyksos and other Asiatic immigrants to Egypt. Wool 
was forbidden in religious services or even temples (Forbes 1964b: 5). It seems likely that by the New Kingdom, if hair was used, it would have been from goats rather than sheep.

\section{Skins}

The last organic material to be considered is skin. Skin can be used as hide or turned into either basic leather or the finer parchment. There are four Egyptian words for leather during and before the New Kingdom, and one word for skin (which can refer to both human and animal). Pyramid texts in the New Kingdom use: msk3; New Kingdom and later texts use: $m s k$; Middle Kingdom texts use: $\underline{d} \underline{h}$; and Middle Kingdom and later texts use: $d h r$ (all basically meaning "animal hide” from which leather is deduced; Veldmeijer 2008: 6-7). The Egyptian word for skin in all Pharaonic periods was jnm.

Egyptian leathercraft progressed when the Egyptians came in contact with foreign pastoralists (Van Driel-Murray 2000: 299). The belief expressed in scholarly literature that the Egyptians were advanced in leatherwork is incorrect (Van Driel-Murray 2000: 299). The reality is that there is not enough evidence from each period to understand how leathercraft developed over time, since the best preserved samples come from the Roman period (Van Driel-Murray 2000: 300). However, both leather and skins were used as garments (not shrouds) to wrap dead in the earliest periods in Egypt (Forbes 1957: 21), and also as garments for the living (Forbes 1957: 22).

The process of producing skins for use in parchment, or leather (as footwear, weaponry, clothing, bags, straps, belts, cordage, and possibly for use on chariots) included "slaughtering the animal, depilating the skin (removal of hair and the like), curing/tanning” (during Pharaonic Egypt oils were employed in curing - and this only 
lightly; Van Driel-Murray 2000: 299), coloring of the skin, and then manufacturing into an object (Veldmeijer 2011: 18). In Pharaonic Egypt, skins do not appear to have been tanned (Veldmeijer 2008: 1). Most of this process (minus the messy parts; see Van DrielMurray 2000: 303, for a detailed description) has been deduced from illustrations accompanied by descriptive Egyptian writing that explain the scenes (Davies 1943; Van Driel-Murray 2000: 302-04; Schwarz 2000: 39-70; Veldmeijer 2008; Veldmeijer and Laidler 2008: 1216). Van Driel-Murray (2000: 303) points out that the leather sandals found by Carter in KV62, that were stuck to the bottom of a basket, provide evidence of "gelatinous decay and hence, indirectly, of oil curing.” Another often-cited part of this process, but without actual evidence until late times, was the use of alum for tawing (term referring to tanning skins by drying them with alum or salt) the skin (Van Driel-Murray 2000: 304).

Of the more than six hundred ninety-six leather fragments registered, not much has been learned of the process of producing leather skins because of the poor conditions of most of the fragments and the destructive nature of the sampling that has since been rejected in favor of preservation (Veldmeijer 2011: 18). This is also the case for determining the identification of animal species from which the skins came, except in a few cases “due to different properties of skins” (Veldmeijer 2011: 18).

Only twenty fragments of leather shoes have been found so far in Egypt (Van Driel-Murray 2000: 315-16; Veldmeijer 2009a, 2009b), which is not surprising because sandals appear to have been more common (Veldmeijer 2011: 17). Most leather footwear was made from cow leather, although more rare examples were made from goatskin (Van Driel-Murray 2000: 302; Veldmeijer 2009a) or gazelle (Schwarz 2000: catalogue c, entry 
16). In general, Egyptian "leather was most commonly made from the skins of cow [sic], sheep, goat, and gazelle, although those of more exotic species such as lion, panther, cheetah, antelope, leopard, camel, hippopotamus, crocodile, and possibly elephant have been identified” (Veldmeijer 2008: 3). Van Driel-Murray (2000: 302) also notes that the “complete back leg of a small rodent” was also used. Pig skin was not used in Egypt until the medieval period, most likely due to the depth to which the hairs penetrate the hide (Van Driel-Murray 2000: 302).

Green, red, yellow, and possibly white dyes (white made from pastes of chalk; Veldmeijer 2008: 5) have been recognized on skin samples (Van Driel-Murray 2000: 306; Veldmeijer 2011: 19). The green dye (made from a copper compound of 30-35 grams of copper/skin; Van Driel-Murray 2000: 306) flakes off because it was not absorbed by the leather, but rather exists in a thin film on the skin, unlike the red dye that soaked into the skins and does not flake as a result (Veldmeijer 2011: 19). This seems to indicate that red dye was superior to other dyes in terms of durability. Red dye made from madder (ip) and alum (ibnw) (Van Driel-Murray 2000: 306; Veldmeijer 2008: 5) or from iron and possibly lead (Van Driel-Murray 2000: 306) may have been the first dye used for skins in Egypt (Lucas and Harris 1999: 35). Madder is obtained from the roots of both the Rubia tinctorium and Rubia peregrina trees (Lucas and Harris 1999: 36). Blue may have been a color for dying of skins, but it is very susceptible to discoloration over time and has been difficult to identify (Van Driel-Murray 2000: 306; Veldmeijer 2008: 4). However, it is known to have been made from indigo (Van Driel-Murray 2000: 306; Veldmeijer 2008: 5). Yellow and black were made from pomegranate rinds (Lucas and Harris 1999: 35; Van Driel-Murray 2000: 306; Veldmeijer 2008: 5). 
During the $18^{\text {th }}$ Dynasty (approx. $16^{\text {th }}$ to $14^{\text {th }}$ centuries B.C.), the Egyptian Book of the Dead was the first document that appears to have been written on parchment in Egypt (Van Driel-Murray 2000: 303), although parchment (stretched leather) was in use before this as covers for drums and other musical instruments are known (Lucas and Harris 1999: 39). Apparently, the phrase "writing on leather” was common in Egypt (Forbes 1957: 28). A 19th Dynasty (approx. $14^{\text {th }}$ to $12^{\text {th }}$ centuries B.C.) inscription (dating to an invasion by the Libyan’s in the reign of Merenptah; Forbes 1957: 31) mentions tents of skins, and an actual preserved example of a leather tent from the $21^{\text {st }}$ dynasty (approx. $11^{\text {th }}$ to $10^{\text {th }}$ centuries B.C.) was recovered (Lucas and Harris 1999: 37). The canopy or funerary tent of Queen Isetemkheb (also Isemkhebe or Isimkheb, in the Cairo museum) is made of "a mosaic of thousands of pieces of leather" (possibly gazelle) "stitched together and decorated with punched an applique work in several colors" (pink, yellow, primrose, green, and blue; Lucas and Harris 1999: 37).

\section{Bronze}

The first inorganic material to be examined is bronze. There is not a lot of evidence to explain how the ancient Egyptians prospected for metal in general. However, they seem to have been very good at finding metalliferous deposits, which was a profession (cf. Thuthotep “a reckoner of gold,” see de Bruyn 1955, for the report; see also Ogden 2000: 148). The Egyptians were among the first (if not the first) ancient civilizations to mine and work copper (Forbes 1964b: 46). The wealth of Egyptian words (see Table 68) associated with copper testifies to the development of coppersmithing and its role in ancient Egyptian culture (Forbes 1964b: 53).

There is some disagreement on how copper was originally used in Egypt, with 


\section{Table 68. Egyptian terms for copper in Erman Grapow's Egyptian dictionary}

\begin{tabular}{|c|c|}
\hline Egyptian & Meaning \\
\hline ipwt & state-planned expedition for the extraction and smelting in Sinai \\
\hline bjow & yield of copper ore \\
\hline bj3 & copper (later bronze or metal in general) \\
\hline$h_{3 w} n b_{j 3}$ & granulated copper \\
\hline bj3 $\mathrm{km}$ & black copper \\
\hline hsmn & bronze \\
\hline hmt n' $\underline{d} n . t$ & "medical” copper (against the ' $\underline{d} n$-demon) \\
\hline hmt & (copper) ore \\
\hline stf.w & to smelt (cast ingots) \\
\hline$w d h$ & melting or casting copper (alloys) \\
\hline$n b j$ & melting, smelting, casting \\
\hline hrj.t & metallurgical furnace (late term) \\
\hline mn.t & melting (charcoal) fire \\
\hline mnd.t & part of furnace (“eye”) \\
\hline wdj $r \underline{t} b t . f$ & remove plug from tap-hole \\
\hline$h s^{\prime}$ & scoria ("excrements") \\
\hline wrmw & scum of copper, dross ("brain-mass”) \\
\hline$\underline{h} w$ & furnace man, stoker \\
\hline sm3.w & (join) alloy (metals) \\
\hline ḩmt.n.̌̌m3 & smelters of the smelting house \\
\hline$p r$ & \\
\hline$h m t j$ & metallurgist, coppersmith \\
\hline hmm & copperworker \\
\hline$k_{3} m_{3}(w)$ & metal-worker \\
\hline$k h k h$ & to emboss \\
\hline$k m_{3}$ & to hammer \\
\hline$d b n$ & ingots (bars of 91 grams) \\
\hline$n m s ́ . t$ & bars of metal \\
\hline$\underline{d} b . t$ & bars of metal \\
\hline
\end{tabular}

some suggesting that as early 2000 B.C. it occurred in a metallic state "especially in the form of its alloy bronze, which contains copper and tin” (Partington 1921: 805). Others point out that while this might have been the case originally, "in all subsequent periods it was derived entirely from the smelting of ores,” based on a reassessment of the objects in question in light of current knowledge of copper mines in the south-eastern desert (Lucas and Harris 1999: 200). That copper ore existing as malachite (which occurs naturally in 
Egypt) was present from the earliest times is not doubted since eye-paint was made from it, and therefore Lucas and Harris felt that there is no reason to "postulate the occurrence and use of the native metal” when there is not a lot of evidence for it (Lucas and Harris 1999: 201). In the mines in the eastern dessert, gold was often mixed in with the copper (Ogden 2000: 151).

Copper ore was mined in the eastern desert and the Sinai (Forbes 1964b: 11; Lucas and Harris 1999: 201) and also was obtained both in the Serabit el-Khadim region (southwest) and near Timna in the Wadi Arabah, where extensive excavation has occurred revealing that mining was at its height in the New Kingdom there (Ogden 2000: 149-150). Mine shafts are linked underground in a way that does not appear to reveal any strategy or knowledge of ventilation or drainage (Ogden 2000: 150). Although the Egyptians did sink shafts, they appear to have "preferred open-cut mining” (Forbes 1963: 126). Copper was also imported from Cyprus in the New Kingdom (Ogden 2000:151).

Although it is commonly thought to have been the case, it is doubtful that miners were slaves. More work needs to be done on slavery in ancient Egypt, but all of the evidence seems to point toward an understanding that Egyptians worked as miners. The reference (that is always quoted) to slave minors in Egypt is actually from a Hellenistic period text, and Forbes points out that there is no archaeological or textual data that indicates that this was the case during the Pharaonic period (Forbes 1963: 130). This is not to say that it is not the case; that there simply is no evidence that it is.

Native copper appears pinkish-yellow and is found locally in the eastern desert and in the Sinai (Ogden 2000: 149). When a pure copper surface is new it appears to be light-red, but the true color is a deep rose that can best be seen in the crease of a sheet of 
copper folded into a "V" shape after light has been reflected many times before being seen, while the "complementary color, green, is seen in the light transmitted through thin leaves of the metal” or in light that is emitted at high temperatures (Partington 1921: 810). "Copper rapidly tarnishes, becoming covered with a very thin adherent brown film of oxide or sulphide" when left out in the open air and to moist air, and it produces "a green film of basic carbonate” (Partington 1921: 811).

Neither native nor smelted copper is $100 \%$ pure. Thus, by identifying and measuring the substance of the impurities, the chronological and geographical record of the copper can be established (Ogden 2000:151). "Pure copper is very malleable and ductile," which allows it to be "rolled into sheets, hammered into thin leaves, and drawn into wire” but copper with even small quantities of impurities becomes much less malleable (Partington 1921: 810). Pure copper's melting point is $1083^{\circ}$ Celsius (Partington 1921: 811). Pure (or as near as can be obtained) copper is hard to cast due to the tendency to shrink or have gas bubbles; difficulties that were eventually overcome by skilled workmen (Ogden 2000: 152). Much of the copper that is recovered in archaeological excavations is normally something less than pure.

Flux materials were used to smelt ore. The flux material used in smelting of ore was generally iron oxide, which resulted in slag produced at high temperatures with the use of blowpipes or bellows (see Appendix A, Figure 90) that first appeared in the Middle Kingdom (Ogden 2000: 151). Smelted copper is never pure copper, which allows for dating and even the identification of the location where the copper was mined (Ogden 2000: 151). The purest copper that was obtained comes from the late New Kingdom, when tapped-slag furnaces that allowed the slag to run off were used producing copper 
that only had a 0.14 per cent iron level, improving the Old Kingdom level of 0.7 per cent (Ogden 2000: 152). In the New Kingdom, it is estimated that a plano-convex copper ingot weighed 3-4 kg (compare Tylecote 1981; Merkel 1995: 22).

Copper alloys vary in composition (Ogden 2000: 148). Both bronze (copper plus tin) and brass (copper plus zinc) are "made by heating copper with [the oxide (tin or zinc)], in the presence of carbon” and then reducing the oxide (Partington 1921: 810). Brass (or orichalcum) was prepared "by heating copper with an ore known as cadmia and charcoal,” making the copper turn a golden-yellow color (Partington 1921: 859).

When tin was combined with copper, the resulting bronze object was harder and could be sharpened to a more precise point (Ogden 2000: 153) than the original copper. Another benefit from adding tin is that the melting temperature drops from $1,083^{\circ} \mathrm{C}$ to 1,005 ${ }^{\circ}$ C, which was significant (Ogden 2000: 153) to the ancient Egyptians. Most Egyptian bronze examples have around 10\% tin to 90\% copper, the standard for the rest of the ancient near eastern civilizations (Ogden 2000: 154).

Still, even with the proportions being relatively stable, there were fluctuations in the proportions that now appear to have been deliberate. Young suggests that bronze objects from Egypt were deliberately manufactured using “alloys of differing proportions and properties" for their different parts, based on "differing kinds of wear or secondary treatment” (Young 1959: 104-05). Metal work even became more technical as advancements in the skill improved. There is evidence, based on spectrographic analysis, that at some point in Egyptian metallurgic history, bronze objects were coated with a different alloy of the same metal (Young 1959: 105-06). It is not clear what advantage 
this would have had, but it appears to have been done deliberately and so needs more study.

Copper with tin (bronze) became common in Egypt during the New Kingdom (replacing the copper-arsenic alloy that had dominated Egypt before) so that by the $19^{\text {th }}$ Dynasty (approx. $14^{\text {th }}$ to $12^{\text {th }}$ centuries B.C.), bronze was the most common metal (Ogden 2000: 153) in Egypt. This was long after bronze became common in the Levant (during the Middle Bronze Age, with some incipient use in the Early Bronze IV period in that territory). In this way, it appears that Egypt lagged behind in adopting it. Even though tin first occurred "in copper-based pigments" during the reign of Thutmose III, there was still more copper than bronze in Tutankhamun's tomb, indicating that the $18^{\text {th }}$ Dynasty (approx. $16^{\text {th }}$ to $14^{\text {th }}$ centuries B.C.) was the transition period (Ogden 2000: 153). A largescale (over 30,000 $\mathrm{m}^{2}$ ) "factory" discovered at Qantir was in existence from the late-18 Dynasty to early $19^{\text {th }}$ Dynasty (Ogden 2000: 155). Studies have demonstrated that beginning in the $18^{\text {th }}$ Dynasty of the New Kingdom, "bronze scrap was the primary source of tin" in the manufacture of faience, which leads to the conclusion that metalworking and faience manufacture occurred near each other (Ogden 2000: 157). Aside from obvious uses in metallurgy, copper was also used in medicine, pigments, and as a coloring agent in glass and glaze (Ogden 2000: 149). Although smiths were very skilled, the Papyrus Sallier seems to suggest that they were not "highly honored" (Forbes 1964b: 63). Copper with zinc (brass) was not in deliberate use until the Ptolemaic period (Ogden 2000: 155).

\section{Silver}

Silver ( $h \underline{d}$ in ancient Egyptian, meaning "white”), along with gold, copper, 
mercury, and platinum "occur in the metallic, or native, state;” but also "as ores, mostly oxides and sulphides, or carbonates and sulphates” (Partington 1921: 764). Most silver (nearly all in use before the New Kingdom; Forbes 1964a: 209) was obtained in gold mines and contained as much as 50\% gold (5-50\% gold in silver is called aurian silver). Some was derived from lead ores and some was imported, as has been demonstrated in recent metal tests (Ogden 2000: 170). Silver was first used in combination with lead ore (galena) for eye paint (Forbes 1964a: 198).

Most silversmithing was probably done by goldsmiths who also worked with silver (Forbes 1964a: 209). Because there are only a few terms used for silver (unlike those used for gold; see Table 69), including silver dust ( $h \underline{h}$ ' $r f$ ) and the best quality silver (hạ $n k n$ ) (Forbes 1964a: 241), it can be deduced that working with it was not thought of as a separate type of smithing. "Silver is very malleable and ductile [and] can be beaten into leaves $0.00025 \mathrm{~mm}$ thick, which becomes somewhat transparent on heating” (Partington 1921: 824). It does not oxidize in the air but does slowly tarnish (Partington 1921: 818; Ogden 2000: 171). Its melting point is 956 Celsius (Partington 1921: 832).

"Until the Middle Kingdom, silver was more highly valued than gold, as evidenced by its primacy over gold in texts” (Becker, Pilosi, and Schorsch 1994: 45). Silver objects appear more plentiful, however, in the New Kingdom, when it was half as valued as gold (Becker, Pilosi, and Schorsch 1994: 45). In the Amarna period, it seems that silver was imported and Egyptian gold was exported (Forbes 1964a: 220).

Textual references from the early $18^{\text {th }}$ Dynasty speak of silver statuary, but large figures are rare (Becker, Pilosi, and Schorsch 1994: 45-6; Ogden 2000: 171), which seems to suggest that large silver statuary were destroyed at some point. The Egyptians 
Table 69. Egyptian terms for gold in Erman Grapow's Egyptian dictionary

\begin{tabular}{|c|c|}
\hline Egyptian & Meaning \\
\hline$n b$ & gold \\
\hline$n b n s t$ & reef gold \\
\hline$n b n m w$ & alluvial (river) gold \\
\hline$n b$ hr h3ś.t.f & gold-bearing rock \\
\hline$n k r$ & (sieved) gold-dust \\
\hline$n b n$ nśtnj & excellent gold \\
\hline$n b n f r$ & beautiful gold \\
\hline$n b s p 2$ & second-quality gold (twice refined?) \\
\hline$n b s p 3$ & third-quality gold (thrice refined?) \\
\hline$n b \underline{h} \underline{d}$ & white gold, electrum \\
\hline$n b n$ & multicolored gold \\
\hline$n b n k n j$ & yellow gold \\
\hline$\dot{s}_{3} w j$ & "two-thirds" gold from Nubia \\
\hline ktm.t & Nubian gold \\
\hline$\underline{d}{ }^{\prime} m$ & light-colored gold, electrum \\
\hline$k w r$ & gold-miner \\
\hline i’j $n b$ & wash native gold \\
\hline$n k r n b$ & gold dust \\
\hline ' $r f n n b$ & special pouch for gold \\
\hline krśn n $n$ & special pouch for gold \\
\hline h.t $n b$ & place where gold is worked (jeweler shop?) \\
\hline hmw nb & worker in gold (goldsmith) \\
\hline$m r$ w'nt $n$ nbj.w & master goldsmith \\
\hline b3km nb & sheath or cover with gold \\
\hline nbd & sheath or cover with metal \\
\hline$d g_{3}$ & sheath or cover with metal \\
\hline$m k$ & cover with gold \\
\hline gnh & gold-sheathed (wooden object) \\
\hline śśr m nb & to gild \\
\hline tjśm $m n b$ & to gild \\
\hline$m h$ & inlay \\
\hline$h t$ & inlay with copper-gold alloy \\
\hline s'b m nb & to decorate with gold \\
\hline imз $m n b$ & to beautify with gold \\
\hline$\underline{t} 3 j$ & to engrave metals \\
\hline $3 h$, & to engrave or incise signs \\
\hline$s k r$ & to beat gold \\
\hline$d k^{\prime}$ & to polish \\
\hline$s n^{\prime \prime}$ & to polish \\
\hline
\end{tabular}


eventually reached a "high level of achievement" in working with silver (Becker, Pilosi, and Schorsch 1994: 42).

\section{Gold}

"Gold is a bright yellow metal” that has a melting point of $1064^{\circ}$ Celsius (Partington 1921: 834). It is not corrupted by oxygen as are many other metals (Partington 1921: 834).

"Most of our knowledge of gold working in antiquity comes from Egypt...[since Egypt was] the source of gold in the ancient Near East” (Meyers 1976: 41) as analysis of gold samples from ancient contexts shows (Forbes 1954: 580). Gold was obtained from natural sources in two forms: "the breaking down of gold-bearing rocks...or as gold ore" (Meyers 1976: 42) and was represented in two separate Egyptian phrases [Egyptian words] (Harris 1961: 33).

Gold was said in ancient Egypt to come from three sources: Gebtu (modern Qift; aka Koptos), Wawat (modern area south of Aswan in Egypt and northern Sudan, between the $1^{\text {st }}$ and $3^{\text {rd }}$ Cataracts), and Kush (modern Sudan from the $3^{\text {rd }}$ Cataract south). Gebtu gold came from between the Wadi Hammamat to the Abbad regions of the eastern desert; Wawat gold came from Wadis Allaqi and Gabbaba; and Kush gold came from all parts south of Karmah (a city just south of the $3^{\text {rd }}$ Cataract) (James 1972: 38; Ogden 2000 : 161). By the Middle Kingdom, nearly all Gebtu gold had been thought to be exhausted, making Nubia (Wawat and Kush) the primary source (Ogden 2000: 161). Toward the end of the New Kingdom ( $20^{\text {th }}$ dynasty, approx. $12^{\text {th }}$ to $11^{\text {th }}$ centuries B.C. $)$ interest in Gebtu gold was reignited (Ogden 2000: 161). Most gold discovered in the New Kingdom was alluvial gold (obtained through gold washing methods; see Appendix A, Figure 91) not 
vein gold (obtained through mining), although mines were active (Ogden 2000: 162). Gold-bearing rocks would have had to be washed to remove the gold, a process only possible at the Nile River some 80-160 km (fifty to one hundred miles) from the deposits (James 1972: 39).

From objects recovered from $1^{\text {st }}$ Dynasty (conventionally dated to approximately $30^{\text {th }}$ to $28^{\text {th }}$ centuries B.C.) tombs it is clear that from early times, Egyptians already "understood the possible uses of gold" and had a "mastery of techniques" that allowed gold to be made into wire or to be beaten into foil to cover objects (James 1972: 38). There was a royal monopoly on gold (James 1972: 42) and it was believed to be the skin of the gods. Therefore, gold was tightly regulated so that artisans had to obtain it from the government to use it in private projects or work for the priests directly to make items for the government (Forbes 1954: 581). The Papyrus Harris (Schaedel 1935) indicates that “enormous amounts of gold” were stored in temples (Forbes 1963: 127), which is, of course, impossible to corroborate. However, to illustrate how much gold Egypt possessed, two solid gold obelisks, seven meters high erected in the Temple of Karnak (Desroches-Noblecourt 1951) represented about 38 tons of gold (Forbes 1964a: 180). Gold is sometimes referred to as pure, but pure had two possible meanings. "Pure gold” could mean either refined gold or gold not artificially mixed with any other element, yet still containing the naturally found impurities (Meyers 1976: 41). Gold completely free of impurities is malleable and thus "always workable," so that some impurity is desirable for holding the shape of a golden object (Meyers 1976: 55, note 133). Forbes suggested that some form of refining took place in Egypt, possibly earlier than the New Kingdom, but concludes that real chemical refinement did not take place 
until the Persian period because it was so costly (Forbes 1964a: 170). Refined gold "is too soft for use as ornaments" (Partington 1921: 834). How pure refined gold could be depends on what period of time the gold was refined, and this is a heavily-debated topic (Ogden 2000: 163). Some scholars have pointed to the New Kingdom tombs at Thebes as evidence that this was happening in the New Kingdom. However, the silver mixed with gold was not removed through the simple melting of gold with bellows or blowpipes until better refinement processes were developed in the Late Period, probably by the Persians (Ogden 2000: 163). Metal testing has shown that purity of gold over 85\% was "rare" until the Late Period (Ogden 2000: 163). Table 69 contains terms used for gold throughout Egyptian history illustrating the specialization of the craft of goldsmithing (Forbes 1964a: 170).

Silver was the element that most accompanied gold in its native state so that gold with less than $25 \%$ silver is still called "gold," gold with $25-50 \%$ silver is called “electrum,” gold with 50-95\% silver is called "aurian silver," and silver with less than 5\% gold is simply called "silver" (Lucas 1962: 214, 233; Ogden 2000: 162-63). Gold objects from Egypt during the New Kingdom contain trace elements (Meyers 1976: 41). Inconveniently, most Egyptian gold was right around 25\% in silver content and often had copper added to it to "improve” its color and “apparent purity” (Ogden 1983, 1993), usually at levels far above the natural occurrence of copper (although always below the level of silver - true for nearly all gold until the Roman period), which demonstrates that it was included intentionally (Ogden 2000: 163). If the trace element is copper, the gold is more reddish in color than normal, but if it is silver, the gold is paler (Partington 1921: 834). 
If objects in Tutankhamun's tomb can be taken as representative of royal culture in the New Kingdom (Carter 1963; Edwards 1976; Allen 2006), some objects were solid gold and some gilded with gold foil or gold leaf. Thus, "the contents of the tomb provide a wonderful field for the study of gold technology in the ancient world” (James 1972: 38). Egyptian rings were typically high in copper content, as this made it easy to cast and melt at a much lower temperature so that the gold appeared reddish or burnished (Ogden 2000: 164). Gold used for coinage or monetary exchange did not take place until the Persians (and especially Alexander the Great, who released the gold stores of the Persians to the world), so during the New Kingdom it was simply a precious metal (Forbes 1964a: 180-81).

Thin gold leaf was held in place by adhesives and thicker gold leaf was attached by small nails (Ogden 2000: 164). Most objects made of gold were made by hammering, not casting (Ogden 2000: 165). If casting was done, it was through the lost wax method, which resulted in a lot of excess metal (Ogden 2000: 165). Also, gold working was done in a way that was different than copper working since gold required soldering and also since mechanical joints are rare (Ogden 2000: 165).

\section{Review of Data}

The nine material elements identified in the construction of the tent-sanctuary must for the purposes of this study be considered as a binary statistic: present or not present in the Egyptian archaeological record from the New Kingdom when considering their frequency. A brief review of the key points will be presented here.

Although many types of wood were available in Egypt in the early New Kingdom, most types were specialty wood that was important from other locations. Of 
the local wood types, acacia was common in the New Kingdom. Further, it was the most utilized type of wood, albeit from a variety of acacia species, depending on the intended use.

Linen was woven from the earliest periods. Vertical looms had only just been introduced to Egypt and were the new technology. Ground looms on the other hand, were used in Egypt at that time, and because of their mobility they seem to have been the loom type of choice for nomads.

Thread of a variety of colors was in use by the early New Kingdom. These colors included blue, red, and purple thread (along with some others). Red was a new color and was just introduced to Egypt in the $18^{\text {th }}$ Dynasty (approx. $16^{\text {th }}$ to $14^{\text {th }}$ centuries B.C.). These three colors appear to be associated with divine royalty in the $18^{\text {th }}$ Dynasty. On the other hand, bleaching was also used at this time. It appears to have been a status symbol associated with purity.

Goats hair was used in Egypt at this time, but records of its use for tents are scarce. All available data points to tents of hair mostly being constructed from camel hair. Goats hair was used for burlap. The hairy sheep breed was extinct in Egypt by the New Kingdom. The wooly sheep breed had been introduced during the $2^{\text {nd }}$ Intermediate Period. As a result, sheep hair would not have been used for tents in the New Kingdom or any later periods in Egypt.

Leather (mostly cow, but also sheep; i.e., ram) was present in Egypt. Skins were used for tents. A few examples both in texts and in a later period in the archaeological record have been identified. It is not clear how common this was, however. These skins were most commonly dyed red due to the superiority of the red dye, but other dyes were 
also used. Parchment (skins produced in a way that is called tahaš) was also in use in the New Kingdom, although it is not clear if this was ever used for tents.

Bronze became common in the New Kingdom because it had a lower melting temperature and could be more finely shaped than copper. Pure copper was not often used in objects because it was very malleable and hard to cast due to shrinkage and gas bubbles. However, of the three copper metals (copper, bronze, and brass), brass is ruled out because it did not appear in Egypt until a much later period, bronze was available but scarce in the $18^{\text {th }}$ Dynasty, and copper was more common in the $18^{\text {th }}$ than the $19^{\text {th }}$ (and later) Dynasties.

Silver was rarely pure but contained gold. Most commonly it was cast, but some hammered examples exist. It was abundant in the New Kingdom.

Gold was not refined until the Late Period by the Persians and often was under 85\% pure. The term "pure gold" most likely referred to the gold that did not have copper added to it to make it look more pure and give it more strength. As a result, "pure gold" contained trace elements, including silver that gave it a paler appearance. Gold was most often hammered and not cast, although hollow casting was available.

\section{Statistical Analysis and Data Grouping}

In order to be useful for comparison, data must be analyzed and grouped into sets. Since this chapter is only concerned with the frequency of materials, the only analysis needed will indicate frequency, which will be the only data set. Using this information, the binary statistic, present or not present, can be applied to each of the nine materials 
discussed above. Table 70 contains the frequency of the materials as they occur in the archaeological record during the New Kingdom. This information will be useful for comparison with Chapter 4.

Table 70. Frequency of materials in New Kingdom Egypt

\begin{tabular}{|c|c|c|c|}
\hline Element & Present & Not Present & Inconclusive \\
\hline Acacia Wood & $\mathrm{X}$ & & \\
\hline Linen & $\mathrm{X}$ & & \\
\hline Blue, purple, red thread & $\mathrm{X}$ & & \\
\hline Goats Hair & $\mathrm{X}$ & & \\
\hline Rams skins & $\mathrm{X}$ & & \\
\hline taḥaš skins & $\mathrm{X}$ & & \\
\hline Bronze & $\mathrm{X}$ & & \\
\hline Silver & $\mathrm{X}$ & & \\
\hline Gold & $\mathrm{X}$ & & \\
\hline
\end{tabular}

All nine materials are clearly present in New Kingdom Egypt. There is inconclusive evidence regarding two of the materials that need further research. It is certain that goats existed in Egypt in the New Kingdom, but it is not certain that goat hair was used for tents. Camel hair was used for tents, but few tents are preserved, so it is difficult to say with any certainty that goat hair was not used. Also, taking the meaning of taḥaš skins to be an Egyptian style of dealing with skins and not an indication of the animal from which the skin came makes it certain that those style of skins existed in Egypt. However, it is not certain that they were used in this way for tents in the New Kingdom. Thus, the frequency of appearance for all is $100 \%$, with caution in certainty recommended for goats hair and taḥaš skins. That said, it should also be pointed out that some materials are more common in the archaeological record than others. However, rarity does not negate presence, as the two inconclusive materials are both organic and 
likely to deteriorate and so not be preserved.

\section{Summary of Materials and Direction of Study}

All materials have a binary statistic, present or not present, that will be used to compare with similar materials in the textual record of the Hebrew Scriptures (Chapter 4). Acacia wood and linen both had high frequencies of appearance during the New Kingdom. Silver appears to have been nearly twice as frequent as gold in the New Kingdom. Copper/bronze was the most common metal in use. All other materials do not have high frequencies of appearance in the archaeological record.

There were questions raised in Chapter 4 that may be informed by these data. These data will be compared with those of Chapter 4 in Chapter 7 and discussed in Chapter 8. 


\section{CHAPTER 7}

\section{SYNTHESIS OF DATA}

"Analysis is now an integral and

useful part of archaeology

and art history."

(Ogden 2000: 148)

In archaeology, target populations "about which we wish to make inferences [are] seldom fully available either to study in [their] entirety or to select a sample from,” (Drennan 1996: 94) due to the accidents of survival and the realization of the limitations in representation of the ancient past from what has been recovered of all that has survived. In this way, sampling bias is unavoidable. The available material that makes up the population from which a random sample can be taken is itself a sample (biased by many factors outside of any study) of the target population. Because of this, dogmatic declarations are a misrepresentation of the results of any effort to visualize the past. With this as a necessary caveat, some potentially-useful things can be discovered in any study, even if there is not enough data to make a definitive comparison and the study has made those gaps recognizable for further research.

In this study, the target populations were all meant to reflect as accurately as possible a picture of New Kingdom Egyptian culture (recognizing that the Amarna period is a unique part of this culture) but this is not possible with any degree of certainty 
because of sampling bias. So it is with caution and tentative steps that the results of this study will be synthesized.

\section{Synthesis of Data for Design Elements}

To be useful for comparison, design data was grouped into sets in both Chapters 3 and 5 . These data will be synthesized here so determinations can be made regarding their relationship. Ratios, measures of frequency, and central tendencies were the most usable data. The discussion of these results, along with observational parallels and other useful insights will be reserved for the discussion section below.

\section{Courtyard Statistical Comparison}

This study searched for design elements that might be comparable through statistical analysis regarding these perimeter barriers. One aspect was the size and shape most accurately compared through ratios. Another aspect was the frequency of the presence of design elements (measured as present or not present).

The Hebrew tent-sanctuary had a perimeter that was rectangular in shape. It had a length and width ratio of 2:1. There was no data on mobile courtyards for either sacred or domestic spheres in ancient Egypt (although both permanent spheres had perimeter barriers around structures belonging to those members of the populous of high standing; i.e. gods, royalty, nobility, and the like, and as such would be recognized as not being associated with the common people of the lower classes). The only data available for mobile military courtyards came from iconographic depictions on three temple walls. Since this was the same military camp (and arguably the same moment in time within that camp) it was useful to compare the three depictions. This comparison resulted in two 
approximate ratios. The Luxor and Ramesseum depictions had a perimeter length and width ratio of approximately 3:1, while the Abu Simbel depiction had a perimeter length and width ratio of approximately 2:1. All three versions were rectangular. The Hebrew tent-sanctuary courtyard compares favorably in shape and ratio to the Abu Simbel depiction and in shape but not in ratio to the Luxor and Ramesseum depictions.

There was no height data for the Egyptian mobile military courtyard, but evidence exists that the shields, of which it was composed, were typically, in this time period, higher than a man. At five cubits (regardless of the exact intended length of the cubit), the Hebrew tent-sanctuary's courtyard perimeter barrier was also higher than a man is tall. How these compare cannot be determined by the available data.

It is also nearly impossible to judge the width of the courtyard gate in the Egyptian military camp depictions. The Hebrew tent-sanctuary had a gate that was $1 / 3^{\text {rd }}$ the width of the perimeter barrier, although it was really an opening in the perimeter barrier designated as an entrance and doesn't conform to modern concepts of what might constitute a gate. In none of the Egyptian iconographic depictions was either the north or east gate close to that wide. Being a military camp, this would be expected. The Hebrew tent-sanctuary also had only one gate, while there were two gates in the Egyptian military camp. So the courtyard gate of the Hebrew tent-sanctuary is quite dissimilar to the Egyptian military camp’s gates.

The Egyptian perimeter barrier was composed of shields with the obvious intended purpose to provide some protection (although in all three depictions the shield barrier failed to keep out the attacking Hittite soldiers). The barrier for the Hebrew tentsanctuary was composed of cloth, hung on hooks, which were attached to pillars, and 
thus it seems to have been intended as a barrier with realistic expectations only to limit the direction of access rather than to serve as a protective barrier in a military sense. Presumably it could have served to keep wandering animals or people out, although it must be realized that cloth would not keep either out if they were determined to enter. Cloth cannot be considered a defensive material. In this way, the Hebrew tent-sanctuary is unlike the Egyptian military camp.

The design of the Hebrew tent-sanctuary perimeter barrier is seemingly unique to anything found thus far in the archaeological record, aside from the overall shape and its association with the Hebrew armies. The Hebrew text suggests a military context because of the language used and the Egyptian camp is a soft parallel. The Egyptian camp is not a hard parallel for all of the reasons listed above, but the most obvious is that the Egyptian military camp was within the courtyard perimeter, while the Hebrew armies were camped on the outside of the courtyard perimeter. Thus, there are enough dissimilarities to consider the Hebrew tent-sanctuary courtyard barrier to be distinct from the Egyptian military camp's exterior barrier except in the similarity of shape (rectangle) and ratio (about 2:1 - for the Abu Simbel depiction). However, there is another option in the Egyptian military camp that may be a closer parallel for comparison.

If the outer rectangle of the central structure (see Appendix A, Figure 92) was a perimeter barrier that separated the Egyptian army from their god-king's central structure, due to its location between the armies of Egypt and the god-king's central structure, it would be a closer parallel for comparison. That outer rectangle had a perimeter ratio of about 2:1 (2:1 at Abu Simbel, 11:6 in both Luxor and the Ramesseum, which is about 2:1). This ratio compares favorably to the Hebrew tent-sanctuary. Also, this outer 
rectangle does not appear to be made up of shields but rather a solid line. It is unclear what materials and construction techniques of which the outer rectangle is composed. If it was composed of a similar material to that of the god-king's tent (also represented by a solid straight line) then it would compare favorably to the cloth perimeter barrier of the Hebrew tent-sanctuary. If the Hebrew tent-sanctuary was intended to be recognized by the newly-liberated Hebrews as a parallel to the mobile Egyptian military camp, it is possible that the similarities in the ratio of length to width, may indicate that the Abu Simbel ratio is the more accurate and that the iconographic depictions at Luxor and the Ramesseum were truncated slightly for space reasons.

There are too many possibilities to form any solid conclusions. However, the outer rectangle of the central structure is an intriguing possibility as a closer perimeter parallel to the Hebrew tent-sanctuary than the exterior perimeter barrier of the Egyptian military camp. Although both perimeters have the same shape and ratio, the outer rectangle parallels the location of the Hebrew tent-sanctuary's perimeter in regard to the army camp and potentially in regard to the material of which it was composed and does not allow for much room in what would be the courtyard, however, but this may be accounted for by the need to expand the god-king's presence by magnifying his central structure. This enlarging of something associated with the king was a standard iconographic practice. There is no data for an entrance into the outer rectangle around the central structure of the military camp so nothing can be compared to the gate statistics of the tent-sanctuary. Overall, there are enough similarities to suggest that Egyptian cultural influence is possible in regard to the courtyard perimeter of the Israelite sanctuary, but there is not enough data to be certain. 


\section{Central Structure Statistical Comparison}

The tabernacle had a rectangular shape. It was 30 cubits long $\mathrm{x} 12$ cubits wide $\mathrm{x}$ 10 cubits high, giving it ratios of 3:1 (length to height), 6:5 (width to height), and 5:2 (length to width). There was one example of a temple in the permanent sacred sphere from the Old Kingdom and one from the New Kingdom that had a ratio of about 5:2 and two from the New Kingdom that did not (about 13:6 and 6:1). These results do not provide enough data to form any conclusions regarding cultural tendency, but it does show that at least two examples compare fairly closely to the tabernacle. However, the tabernacle was mobile and the Egyptian structures were permanent. There are no data to which ratios could be compared from the domestic or sacred mobile spheres of New Kingdom Egypt. The only data available for analysis came from mobile military central structures. However, these data came from iconographic depictions on three temple walls not from any physical remains. Since these representations were of the same military camp (arguably representing the same moment in time in the camp), it is useful to compare the three depictions.

Identifying the central structure in these depictions is a little more difficult. There are two options. The tent of the god-king and the attached rectangle (as seen in Appendix A, Figure 94) is the first option. The second option is the inner rectangle that surrounds the tent of the god-king and the attached rectangle which is inside the outer rectangle (see Appendix A, Figure 93).

If the central structure is meant to include the god-king's tent with the attached rectangle, then the comparison resulted in three ratios. Luxor had a ratio of 3:1, Abu Simbel had a ratio of 8:3 (which is about 2:1 but not exactly), and the Ramesseum had a 
ratio of 19:7 (which is about 3:1 but not exactly). All three were rectangular. The Hebrew tent-sanctuary's tabernacle had a ratio of 5:2 (about 3:1 but not exactly). In this way the size and shape of the Hebrew tent-sanctuary's tabernacle compares favorably to the Egyptian military camp's central structure. However, the god-king's tent may be a side view rather than a top view as the attached rectangle almost certainly is. The other tents in the depiction of the army camp are all shown from a side view and the god-king's tent does have a triangle at the top (Luxor and the Ramesseum) as do the other tents, which supports this interpretation. If this interpretation is correct, the ratio probably still holds since the length would remain the same regardless of if it were a top or side view and the width can be discerned by the attached rectangle.

It is also impossible to discern the exact nature of the construction of the attached rectangle to the god-king's tent. It is certainly possible that it was another open-air courtyard with a perimeter. Its location and seemingly larger size ratio to the god-king's tent does make it an obvious observational parallel to a seemingly standard scholarly consensus that the outer compartment (Holy Place) of the tabernacle was larger than the inner compartment (Most Holy Place). The Hebrew text, however, did not provide the necessary data to determine the exact spaces of the inner compartments of the tabernacle. As a result, there is nothing to compare in this regard and thus a determination cannot be made beyond what has already been said.

If the Egyptian central structure is meant to include the inner rectangle that encloses the god-king's tent and attached rectangle, then the Luxor version had a ratio of 5:2, the Ramesseum had a ratio of 5:2, and Abu Simbel had a ratio of 2:1. The tabernacle 
does favorably compare to the inner rectangle ratio of the Luxor and Ramesseum depictions.

The tabernacle had a frame that was constructed with boards. The ratio of the occurrence of boards to sockets of 5:2. There is no data to compare this result to in any of the Egyptian spheres. As a result, cultural influence is not determinable at this time.

The tabernacle had two woven coverings (linen cloth and goat hair) that were sown in strips. There is no data to compare this data to in any of the Egyptian spheres, so none of the associated ratios from the tabernacle are useful. As a result, cultural influence is not determinable at this time. If data becomes available, the design tendency from the stem-and-leaf plots shows that the cloth strips tended to be between 15-30 cubits long and four to five cubits wide.

Frequency of repetition in features shows that only pillars were used in the construction of the tent-sanctuary when associated in the Hebrew text with sockets and hooks for holding cloth hangings. When associated in the Hebrew text with the tabernacle, the pillars were overlaid, but when associated with the courtyard they were not. When not overlaid, the pillars had capitals and bands. Artistic cherubim were only associated in the Hebrew text with cloth in the inner part of the tabernacle (not in the screen or any outside layer of covering and not in the courtyard gate). Loops and clasps were associated in the Hebrew text only with the two woven layers (linen cloth and goat hair). This data will be useful to compare if data becomes available in the archaeological record.

\section{Furniture Statistical Comparison}

Within the Hebrew tent-sanctuary's courtyard (bronze items) and tabernacle (gold 
items) there were six of items of furniture: the bronze altar, the bronze laver, the gold table, the gold lampstand, the gold altar, and the gold ark. The altars both had a ratio of 1:1 (length to width). The larger bronze altar was shorter than it was long or wide. The smaller gold altar was higher than it was long or wide. The bronze altar and the gold ark also had the same ratio 5:3 (length to height). Both of these items also had a 1:1 ratio. The bronze altar (as stated) had a ratio of 1:1 (length to width), while the ark had a ratio of 1:1 (width to height). The shapes of these objects are not the same, but these shared ratios appear to be a design feature. The table had a ratio of 2:1 (length to width), which is similar to the 2:1 ratio of the gold altar (height to length/width). Only the table's ratios of 4:3 (length to height) and 2:3 (width to height) were unique. There are not any measurable data for the laver or the lampstand (the only two items of furniture constructed without wood).

One design ratio that appears to be common in both the tent-sanctuary furniture (generally) and all the Egyptian furniture (from all periods) is the use of 1:1 ratios. The 2:1 ratio does not appear in any of the Egyptian furniture ratios but the 2:3 and 3:4 ratios do.

The stem-and-leaf plots revealed an overall design tendency ratio for all items of furniture of 2:1 (length to width), 2:1 (length to height), and 1:1 (width to height). This is, however, a very small sampling of only four items of furniture with very different purposes (except possibly the altars, although an argument could be made that they had different purposes as well).

Both Hebrew altars were constructed with horns. Each wooden item was carried by poles attached to the item of furniture with rings. All gold overlaid items of furniture 
had a molding (the bronze overlay did not, but rather had a rim). All six items of furniture were constructed with metal (either entirely or with overlay). Three items had accompanying utensils.

The ark had a ratio of 5:3 (length to height). The barque of the god in the godking's tent of the Egyptian military camp (at Abu Simbel) was depicted from the side and the box portion has a ratio of 2:1. These ratios are similar but not exact. Both ark and barque were carried on poles by priests, had winged creatures protecting the space that contained the presence or name of the deity, both were wooden overlaid with gold, and both were boxes (although the barque [boat] that carried the box in Egypt is absent from the Hebrew design of the ark). Certainly, the observational parallel between the ark and the barque is clear, and will be addressed in the discussion of Chapter 8. It appears possible that the Israelite design was influenced by Egyptian culture. The ark is the most obvious item of furniture that was influenced by the culture of New Kingdom Egypt.

Six items of ancient Egyptian furniture were also analyzed in the present study: bedframes, boxes, chairs, chests, stools, and tables. These six were grouped into three periods: Pre-New Kingdom, New Kingdom (not Tomb KV62), and KV62. This analysis was done to determine if there exists a central tendency for measures of volume in each of these items of furniture and to determine how these measures of central tendency compare between the three periods. Tomb KV62 was set apart from the rest of the New Kingdom furniture as a near-complete sample from the Amarna Period of the New Kingdom (testing if the Amarna period was out of sync with the rest of the New Kingdom - before and after it). The Egyptians during the New Kingdom period represent is the general culture selected for this study, so it was necessary to compare tendencies of 
New Kingdom period design with those in periods before this period to see if trends could be identified.

Using stem-and-leaf plots, cultural preference was identified using rounded numbers that can be transformed into ratios. Tomb KV62 bedframes were outside of an identified cultural norm that clearly existed during the New Kingdom and that was reflected in all periods before the New Kingdom as well. Boxes in all three periods (KV62, New Kingdom not counting KV62, and all periods before the New Kingdom) always had at least one square (both sides of equal length) end and one side that was longer or shorter than either of the square sides. Which side (length, width, or height) was the odd side out differed in all three periods. From the limited data available it could be determined that KV62 chairs were outside of the cultural norm for the New Kingdom. Tomb KV62 stools were within the cultural preference during the New Kingdom, which had changed slightly from all periods before the New Kingdom. Cultural norms also changed regarding design aspects of tables from the periods before the New Kingdom to the New Kingdom itself. There were no identified tables in KV62.

The only item of furniture that could be identified in the Hebrew tent-sanctuary that was also identifiable in the New Kingdom archaeological record was the table in the tabernacle. The tabernacle's table had a ratio of 2:1 (length to width) and the New Kingdom preferred stem table ratio was 3:2 (length to width). The tabernacle's table had a ratio of 4:3 (length to height) and the New Kingdom preferred stem table ratio was 3:2 (length to height). The tabernacle's table had a ratio of 2:3 (width to height) and the New Kingdom preferred stem table ratio was 1:1.

The sampling was small (only seven New Kingdom tables and only nine Pre-New 
Kingdom tables were recorded), but based on these results, the ratios do not match. However, all of the Israelite and Egyptian tables (tabernacle and New Kingdom) were longer than wide and longer than high, so in this way the tables were comparable. Tables before the New Kingdom were also longer than they were high. Tables before the New Kingdom were considerably shorter. It is not beyond reason to suspect that the tabernacle's table would match with some tables in the New Kingdom even if the stem ratios somewhat differed, since they were close. But to determine this observation, more precise analysis is needed.

To determine if any of the design characteristics of the tabernacle's table can be considered "Egyptian,” analysis can be carried out (Chapter 1) using a trimmed mean and trimmed standard deviation to compare the tabernacle's table with tables from the two identified periods (New Kingdom [not KV62] “NK” and Pre-New Kingdom “P-NK”). A trimmed mean $\left(\bar{X}_{T}\right)$ is calculated to systematically remove "extreme values from both the upper and lower ends of a batch in a balanced fashion” (Drennan 1996: 21) so that they don't have an “undue effect on the result” (Drennan 1996: 33) by eliminating far outliers. This is done as a control against values that do not adequately represent tendency for one reason or another, which may be unknowable with the current data. The median, for example, is the ultimate trimmed mean in that it has trimmed half of the numbers above and half of the numbers below so that only the midpoint remains (Drennan 1996: 23). But the median is still skewed by those far-outlying numbers. For the present analysis, it is important to be sure that what is identified represents mainstream-Egyptian cultural-design tendencies in order to evaluate cultural influence as closely as possible. 
It is common, when calculating the trimmed mean, to use either $5 \%$ or $25 \%$ to trim off the top and bottom values. In this study, in order to provide a more unique number from either the mean or the median, $25 \%$ will be used (meaning $25 \%$ of the numbers at the top and $25 \%$ of the numbers at the bottom will be eliminated to establish the trimmed mean). This method also has the advantage of being the midspread (the range of the middle half of the numbers, also called interquartile range; Drennan 1996: 28-9). From this midspread the trimmed standard deviation can be calculated.

In this study, there were seven values in the sample size for the length of NK tables, seven values for the width, and six values for the height. These were all measured in millimeters. One-fourth of seven is 1.75 and one-fourth of six is 1.5. Using the standard rule to always round up when trimming, the top two and bottom two numbers will be removed. The mean (average) of the remaining numbers provides us with the trimmed mean $\left(\bar{X}_{T}\right)$.

New Kingdom (not KV62, of which there weren’t any tables) average $(\bar{X})$ length of tables was 656.29. The trimmed mean $\left(\bar{X}_{T}\right)$ of the same data is 689.33 (the top and bottom two numbers were trimmed away before the mean was calculated). The $\bar{X}$ width was 438.43 and the $\bar{X}_{T}$ is 445.33 . The $\bar{X}$ height was 402.83 and the $\bar{X}_{T}$ is 425 . In all three cases the trimmed mean is higher. This result indicates that the low values in the data set were dropping the mean of the original batch in each instance.

There were nine values in the sample size for the length of P-NK tables, nine values for the width, and nine values for the height. These were all measured in millimeters. One-fourth of nine is 2.25 . Using the standard rule to always round up when trimming, the top three and bottom three numbers will be removed. The mean (average) 
of the remaining numbers provides us with the trimmed mean.

Pre-New Kingdom average/mean $(\bar{X})$ length of tables was 410.22 . The trimmed mean $\left(\bar{X}_{\mathrm{T}}\right)$ of the same data is 403.67 (the top and bottom three numbers were trimmed away before the mean was calculated). The $\bar{X}$ width was 306.11 and the $\bar{X}_{T}$ is 308.67 . The $\bar{X}$ height was 123.63 (after the obvious outlier was removed; the mean with the outlier was 282.11) and the $\bar{X}_{T}$ is 101. In the length and height the trimmed mean was lower, indicating that there were values in the data set that were skewing the mean high. The trimmed mean for the width is higher, but not by much.

The trimmed standard deviation requires that the size of the batch remain the same by replacing the trimmed values with the last value not removed. In the NK length batch, 698 is repeated twice at the top and 680 is repeated twice at the bottom. In the NK width batch, 495 is repeated twice at the top and 381 is repeated twice at the bottom. In the NK height batch, 469 is repeated twice at the top and 381 is repeated twice at the bottom. In the P-NK length batch, 450 is repeated thrice at the top and 380 is repeated thrice at the bottom. In the P-NK width batch, 317 is repeated thrice at the top and 298 is repeated thrice at the bottom. In the NK height batch, 115 is repeated thrice at the top and 88 is repeated thrice at the bottom. These two new batches are called Winsorized batches with a Winsorized mean $\left(X_{W}\right)$, named for the one who designed this analysis (Drennan 1996: 33).

The Winsorized mean $\left(\bar{X}_{W}\right)$ for NK table length is 689.14; its width being 441.1429, and its height 425 . These figures are very close to the trimmed mean values for each type. The $\bar{X}_{W}$ for P-NK table length is 411.22; its width being 307.89, and its height 101.33. Except for the length, these results are very close to the trimmed mean values for 
each batch. This result allows the deviation from the mean to be calculated by simply subtracting the value of the $\bar{X}_{W}$ from the $X_{W}$ for each value in the batch. The sum ( $\Sigma$ ) of which should be zero $\left(\Sigma\left(X_{W-} \bar{X}_{W}\right)=0.00\right)$.

After checking that it is 0.00 in all cases, each deviation from mean is squared $\left(X_{W-} \bar{X}_{W}\right)^{2}$. The sum of these squares $\left(\Sigma\left(X_{W-} \bar{X}_{W}\right)^{2}\right)$ can then be calculated by simply adding them up. Calculating the trimmed standard deviation $\left(S_{T}\right)$ is not difficult and it will provide us with a tool that will accurately measure deviation from central tendency. It first requires that the variance of the Winsorized batch $\left(S_{W}{ }^{2}\right)$ is known for each batch using the formula: $S_{W}{ }^{2}=\left(\Sigma\left(X_{W}-\bar{X}_{W}\right)^{2}\right) /(n-1)$ where $n$ is the number of the untrimmed batch (for NK length/width that was seven, NK height that was six, and P-NK length/width/height it was nine). Then the trimmed standard deviation can be calculated using the formula: $S_{T}=\sqrt{ }\left((n-1) S_{W}{ }^{2}\right) /\left(n_{T}-1\right)$, where $n_{T}$ is the number of the remaining numbers that made up the trimmed batch (for NK length/width and P-NK length/width/height that was three and for NK height that was two).

The trimmed standard deviation $\left(S_{T}\right)$ for the NK table length is 15.60; its width being 99.77, and its height 107.78. The trimmed standard deviation $\left(S_{T}\right)$ for the P-NK table length is 73.58; its width being 19.14, and its height 27.02. Standardized scores (or z scores) can then be calculated by subtracting the trimmed mean $\left(\bar{X}_{\mathrm{T}}\right)$ from every number ( $n$ ) in the original batch and then dividing that by the $S_{T}$. Then, using the standard rule of thumb that any number lying at 1.5 midspreads outside either quartile (upper or lower half of the midspread) is an outlier we can determine the centrality or peripheralness of each number, including those from the tabernacle's table (compared with the NK and the P-NK results). Thus, using the standard $0-1.5$ for midspread, $1.51-3.0$ for adjacent 
values, 3.01-4.5 for outlier, and 4.51-infinity for far outlier, we can determine, through statistical analysis, if the tabernacle's table can be considered influenced by Egyptian culture (midspread is a strong design preference, adjacent value is within the design preference, the outlier is on the edge of design preference, and far outlier is beyond design preference). Table 71 contains the results.

It should be recognized that even within objects that are known to be Egyptian, there are far-outlying determinations. This indicates that while there was a clear design preference, there was also room for variety beyond these preferences.

In order to compare the tabernacle's table with this study of New Kingdom and Pre-New Kingdom tables, the units of measure recorded in the Hebrew text (cubits) need to be converted into the unit of measure in the study (millimeters). There are four known Egyptian cubit lengths for royal activities: Nilometer at Elephantine averages 523.93 millimeters; the Copper Rule in the Turin Museum is 519.91 millimeters; the Wooden Rule in the Turin Museum is 522.30 millimeters; and the Stone Rule in the Turin Museum is 523.82 millimeters (see Chapter 5). Since the tent-sanctuary concerned the God-King of the Hebrews, the shorter, common use cubit measurements are most likely irrelevant. It should be noted, whether the Egyptian tables in this study were for royal or common use, may skew the results. For the purposes of this study, the royal seemed appropriate since it cannot be known for certain which cubit length was in use. 
Table 71. Z-scores

\begin{tabular}{|c|c|c|c|c|c|c|}
\hline Batch & Number & $-\bar{X}_{\mathrm{T}}$ & Results & $/ S_{T}$ & $Z$ score & Determination \\
\hline \multirow[t]{7}{*}{ NK length } & 787 & 689.33 & 97.67 & 15.6 & 6.26 & Far Outlier \\
\hline & 749 & 689.33 & 59.67 & 15.6 & 3.83 & Outlier \\
\hline & 698 & 689.33 & 8.67 & 15.6 & 0.56 & Midspread \\
\hline & 690 & 689.33 & 0.67 & 15.6 & 0.04 & Midspread \\
\hline & 680 & 689.33 & -9.33 & 15.6 & -0.6 & Midspread \\
\hline & 521 & 689.33 & -168.33 & 15.6 & -11 & Far Outlier \\
\hline & 469 & 689.33 & -220.33 & 15.6 & -14 & Far Outlier \\
\hline \multirow[t]{2}{*}{ NK length } & 787 & 689.33 & 97.67 & 15.6 & 6.26 & Far Outlier \\
\hline & 749 & 689.33 & 59.67 & 15.6 & 3.83 & Outlier \\
\hline \multirow[t]{7}{*}{ NK width } & 558 & 445.33 & 112.67 & 99.77 & 1.13 & Midspread \\
\hline & 539 & 445.33 & 93.67 & 99.77 & 0.94 & Midspread \\
\hline & 495 & 445.33 & 49.67 & 99.77 & 0.5 & Midspread \\
\hline & 460 & 445.33 & 14.67 & 99.77 & 0.15 & Midspread \\
\hline & 381 & 445.33 & -64.33 & 99.77 & -0.6 & Midspread \\
\hline & 381 & 445.33 & -64.33 & 99.77 & -0.6 & Midspread \\
\hline & 255 & 445.33 & -190.33 & 99.77 & -1.9 & Midspread \\
\hline \multirow[t]{6}{*}{ NK height } & 490 & 425 & 65 & 107.78 & 0.6 & Midspread \\
\hline & 476 & 425 & 51 & 107.78 & 0.47 & Midspread \\
\hline & 469 & 425 & 44 & 107.78 & 0.41 & Midspread \\
\hline & 381 & 425 & -44 & 107.78 & -0.4 & Midspread \\
\hline & 303 & 425 & -122 & 107.78 & -1.1 & Midspread \\
\hline & 298 & 425 & -127 & 107.78 & -1.2 & Midspread \\
\hline \multirow[t]{5}{*}{ P-NK length } & 635 & 403.67 & 231.33 & 73.58 & 3.14 & Outlier \\
\hline & 480 & 403.67 & 76.33 & 73.58 & 1.04 & Midspread \\
\hline & 460 & 403.67 & 56.33 & 73.58 & 0.77 & Midspread \\
\hline & 450 & 403.67 & 46.33 & 73.58 & 0.63 & Midspread \\
\hline & 381 & 403.67 & -22.67 & 73.58 & -0.3 & Midspread \\
\hline
\end{tabular}


Table 71-Continued.

\begin{tabular}{|c|c|c|c|c|c|c|}
\hline Batch & Number & $-\bar{X}_{\mathrm{T}}$ & Results & $/ S_{T}$ & $Z$ score & Determination \\
\hline & 380 & 403.67 & -23.67 & 73.58 & -0.3 & Midspread \\
\hline & 360 & 403.67 & -43.67 & 73.58 & -0.6 & Midspread \\
\hline & 310 & 403.67 & -93.67 & 73.58 & -1.3 & Midspread \\
\hline & 236 & 403.67 & -167.67 & 73.58 & -2.3 & Adjacent Value \\
\hline \multirow[t]{9}{*}{ P-NK width } & 390 & 308.67 & 81.33 & 19.14 & 4.25 & Outlier \\
\hline & 378 & 308.67 & 69.33 & 19.14 & 3.62 & Outlier \\
\hline & 333 & 308.67 & 24.33 & 19.14 & 1.27 & Midspread \\
\hline & 317 & 308.67 & 8.33 & 19.14 & 0.44 & Midspread \\
\hline & 311 & 308.67 & 2.33 & 19.14 & 0.12 & Midspread \\
\hline & 298 & 308.67 & -10.67 & 19.14 & -0.6 & Midspread \\
\hline & 280 & 308.67 & -28.67 & 19.14 & -1.5 & Midspread \\
\hline & 278 & 308.67 & -30.67 & 19.14 & -1.6 & Midspread \\
\hline & 170 & 308.67 & -138.67 & 19.14 & -7.2 & Far Outlier \\
\hline \multirow[t]{9}{*}{ P-NK height } & 1550 & 101 & 1449 & 27.02 & 53.6 & Far Outlier \\
\hline & 355 & 101 & 254 & 27.02 & 9.4 & Far Outlier \\
\hline & 150 & 101 & 49 & 27.02 & 1.81 & Adjacent Value \\
\hline & 115 & 101 & 14 & 27.02 & 0.52 & Midspread \\
\hline & 100 & 101 & -1 & 27.02 & 0 & Midspread \\
\hline & 88 & 101 & -13 & 27.02 & -0.5 & Midspread \\
\hline & 85 & 101 & -16 & 27.02 & -0.6 & Midspread \\
\hline & 60 & 101 & -41 & 27.02 & -1.5 & Midspread \\
\hline & 36 & 101 & -65 & 27.02 & -2.4 & Adjacent Value \\
\hline
\end{tabular}

The tabernacle's table was two cubits in length, one cubit in width, and 1.5 cubits in height. Table 72 contains the results of the conversion to the four known Egyptian cubits. 
Table 72. Tabernacle table conversion to known Egyptian cubits

\begin{tabular}{lllll}
\hline Cubit & Nilometer (N) & Copper R. (CR) & Wooden R. (WR) & Stone R. (SR) \\
\hline 2 (length) & 1047.86 & 1039.82 & 1044.60 & 1047.64 \\
1 (width) & 523.93 & 519.91 & 522.30 & 523.82 \\
1.5 (height) & 785.90 & 779.87 & 783.45 & 785.73 \\
\hline
\end{tabular}

These values can now be compared with the above z-score calculations in the same way to determine their centrality or peripheralness. Each Egyptian cubit will be abbreviated to match Table 72 and will include either NK (for New Kingdom) or P-NK (for Pre-New Kingdom) and the unit of measure (length, width, or height). Table 73 contains the results.

The results for comparison with Pre-New Kingdom period culture are stunning. The tabernacle's table does not compare favorably with any of the units of measure for the Pre-New Kingdom period. Although there are only nine known tables recorded from this period, the tabernacle's table is not like them. In fact, there is only one value for one Pre-New Kingdom table that is a further outlier than the tabernacle's table. This seems to conclusively suggest (recognizing the sampling size limitations of the Pre-New Kingdom batch) that the tabernacle's table was not influenced by Pre-New Kingdom Egyptian culture.

The results for comparison with New Kingdom period culture are mixed. The tabernacle's table does not compare favorably with the length of those seven tables in the New Kingdom's batch in that it appears to be beyond the design preference. However, it is a perfect match for the width of those same seven tables in the New Kingdom, indicating that is within the strong design preference of the New Kingdom. The height of 
Table 73. Z-scores for tabernacle’s table

\begin{tabular}{|c|c|c|c|c|c|c|}
\hline Egyptian cubits & Number & $-\bar{X}_{\mathrm{T}}$ & Results & $/ S_{T}$ & $Z$ score & Determination \\
\hline NK N length & 1047.86 & 689.33 & 358.53 & 15.6 & 23 & Far Outlier \\
\hline NK CR length & 1039.82 & 689.33 & 350.49 & 15.6 & 22.5 & Far Outlier \\
\hline NK WR length & 1044 & 689.33 & 355.27 & 15.6 & 22.8 & Far Outlier \\
\hline NK SR length & 1047.64 & 689.33 & 358.31 & 15.6 & 23 & Far Outlier \\
\hline NK N width & 523.93 & 445.33 & 78.60 & 99.77 & 0.79 & Midspread \\
\hline NK CR width & 519.91 & 445.33 & 74.58 & 99.77 & 0.75 & Midspread \\
\hline NK WR width & 522.30 & 445.33 & 76.97 & 99.77 & 0.77 & Midspread \\
\hline NK SR width & 523.82 & 445.33 & 78.49 & 99.77 & 0.79 & Midspread \\
\hline NK N height & 785.90 & 425 & 360.90 & 107.78 & 3.35 & Outlier \\
\hline NK CR height & 779.87 & 425 & 354.87 & 107.78 & 3.29 & Outlier \\
\hline NK WR height & 783.45 & 425 & 358.45 & 107.78 & 3.33 & Outlier \\
\hline NK SR height & 785.73 & 425 & 360.73 & 107.78 & 3.35 & Outlier \\
\hline P-NK N length & 1047.86 & 403.67 & 644.19 & 73.58 & 8.75 & Far Outlier \\
\hline P-NK CR length & 1039.82 & 403.67 & 636.15 & 73.58 & 8.65 & Far Outlier \\
\hline P-NK WR length & 1044 & 403.67 & 640.93 & 73.58 & 8.71 & Far Outlier \\
\hline P-NK SR length & 1047.64 & 403.67 & 643.97 & 73.58 & 8.75 & Far Outlier \\
\hline P-NK N width & 523.93 & 308.67 & 215.26 & 19.14 & 11.2 & Far Outlier \\
\hline P-NK CR width & 519.91 & 308.67 & 211.24 & 19.14 & 11 & Far Outlier \\
\hline P-NK WR width & 522.30 & 308.67 & 213.63 & 19.14 & 11.2 & Far Outlier \\
\hline P-NK SR width & 523.82 & 308.67 & 215.15 & 19.14 & 11.2 & Far Outlier \\
\hline P-NK N height & 785.90 & 101 & 684.90 & 27.02 & 25.3 & Far Outlier \\
\hline P-NK CR height & 779.87 & 101 & 678.87 & 27.02 & 25.1 & Far Outlier \\
\hline P-NK WR height & 783.45 & 101 & 682.45 & 27.02 & 25.3 & Far Outlier \\
\hline P-NK SR height & 785.73 & 101 & 684.73 & 27.02 & 25.3 & Far Outlier \\
\hline
\end{tabular}


the tabernacle's table is also on the edge of the New Kingdom design preference. These results suggest that it is possible that the tabernacle's table was influenced by New Kingdom culture. With more data (more tables), this relationship could be better defined.

\section{Design Data Comparison}

In summary, the results show that in some ways the Hebrew tent-sanctuary compares favorably to some design aspects of the ancient Egyptian culture and does not in other areas. The courtyard compares favorably in shape and ratio to various perimeter barriers in the mobile military sphere of New Kingdom Egypt. The outer rectangle surrounding the central structure in the military camp is a better parallel. In this way, the tent-sanctuary's perimeter barrier also compares favorably in location (i.e., at the center of the army camp). The ratio of the size of the gate of the Hebrew tent-sanctuary does not compare favorably to any known gate ratio in New Kingdom Egypt. If the shield perimeter is the correct parallel for the tent-sanctuary's courtyard, the gate size is much too small in the Egyptian military camp.

The Hebrew tent-sanctuary’s tabernacle compares favorably to the central structure of the mobile Egyptian military camp in shape, regardless of which option (the inner rectangle or the god-king's tent with attached rectangle) is the correct. It only compares favorably to the Egyptian ratio if the inner rectangle (that surrounds the godking's tent and attached rectangle) is the correct parallel. It is close but not the exact same ratio, if the correct parallel is only the god-king's tent and attached rectangle.

There were no data available to compare the tent-sanctuary's courtyard or tabernacle to the mobile sacred or mobile domestic spheres. The Egyptian permanent sacred, domestic, and military spheres all had perimeter barriers surrounding a central 
structure. It is possible, but unknowable, if the mobile sacred or mobile domestic spheres had perimeter barriers. The tabernacle did compare favorably in terms of shape and ratio to two permanent central structures (temples) in the sacred sphere, but not in others. This comparison is intriguing but not conclusive for cultural influence without more data.

There is also no data from the size of the two compartments in the tabernacle with which to compare to any sphere in ancient Egypt.

The Hebrew tent-sanctuary’s furniture could not conclusively be compared with furniture in the New Kingdom primarily because parallels could not be identified based on the accidents of survival. However, the Hebrew and Egyptian tables did have a general shape that was similar, although it was not an exact match with ratios of the identified preferred stems. This approximate similarity indicates the possibility that the design of the table in the Hebrew tabernacle was influenced by New Kingdom design preference. There were similar appearing ratios in general between the tent-sanctuary and the Egyptian furniture in this study. However, they do not necessary reflect cultural influence because parallel items could not be identified.

There was only one identifiable item of furniture associated with the Egyptian military camp’s central structure: the barque of the god-king represented as a box with two winged creatures overshadowing it on two sides. The position of this item resting in the inner-most (or nearest) room of the sacred sphere and its obvious parallel to the ark is remarkable.

\section{Synthesis of Data for Material Elements}

To be useful for comparison, data regarding material elements was grouped into sets in both Chapters 4 and 6 . These data will be synthesized here so determinations can 
be made regarding their relationship. Measures of frequency were the most usable data. The discussion of these data, along with observational parallels and other useful insights will be reserved for the discussion section below.

\section{Acacia Wood Statistical Comparison}

Acacia wood is the only type of wood mentioned in association with the construction of the Hebrew tent-sanctuary. All wooden elements in the courtyard and tabernacle (pillars, boards, bars, and poles) and all four items of furniture that had wood elements (both altars, the table, and the ark) were made from acacia wood. There were at least five varieties of acacia wood present in ancient Egypt that grew there until the medieval period. Acacia wood was used in ancient Egypt for beams, furniture, boatbuilding, and in construction. The Acacia nilotica could be cut up to 12 Egyptian cubits in length. The longest item of wood needed in the tent-sanctuary was 10 cubits. Without knowing for certain how long the Hebrew cubit was, it is reasonable to expect that it would not have been longer than the 12 Egyptian cubits, and thus this wood could have been cut to the required length.

Based on this information, it is likely that it was the Acacia nilotica, which grew along the Nile, was the variety intended. Statistically speaking, there is a $100 \%$ statistical certainty that acacia wood was available in ancient Egypt in the New Kingdom so that it would have been available for use in the construction of the Hebrew tent-sanctuary if it was taken out of Egypt with the Hebrews. This possibility will be addressed further in the discussion in Chapter 8. Acacia that grew in the Sinai was too small to have been long enough for the pillars (although it could have been cut into pieces to form boards). 


\section{Woven Linen Cloth Statistical Comparison}

Woven linen is the only type of linen cloth mentioned in association with the construction of the Hebrew tent-sanctuary. It was used as the cloth hanging for the perimeter, the courtyard gate, the tabernacle screen, the first layer of coverings for the tabernacle, and the veil. The most frequently-used cloth in Egypt was woven linen. Linen was a status symbol because of the cost in manufacturing it, and white linen was considered a sign of purity and cleanliness, making it ideal for the tent-sanctuary. Linen was stored in chests, as seen in the tomb of Hatnefer and Ramoses (Theban Tomb 71, now in the Metropolitan museum; see Appendix A, Figure 94) and the folds even seem to have conveyed the idea of wealth apparently because it was a garment that could be stored (poor people apparently didn’t have extra changes of clothes).

Vertical looms were present in ancient Egypt in the New Kingdom, so it is possible that any linen that was taken out of Egypt during the Exodus was woven on a Vertical loom. However, since such looms were up to five meters high, it is unlikely that they would have been taken on the trip. It appears that any linen woven at Mt. Sinai almost certainly would have been woven on a ground loom.

The Hebrew word for linen (šëš) is a well-recognized Egyptian loanword. Statistically speaking, there is a $100 \%$ statistical certainty that woven linen was available in ancient Egypt in the New Kingdom so that it would have been available for use in the construction of the Hebrew tent-sanctuary.

\section{Blue, Purple, and Scarlet Thread Statistical Comparison}

The only colors of thread used for embroidery in the tent-sanctuary were blue, purple, and red (scarlet). Embroidery only appeared on the courtyard gate, the tabernacle 
screen, the inside covering of the tabernacle, and the veil. Blue thread was also used to loop along the outer edge of the inside covering of the tabernacle.

Dyed thread was common only starting in the New Kingdom. Blue, red, and purple (a combination of blue and red) were dyes that were used at that time. The linen cloth embroidered with the name cartouche of Amenhotep II shows that linen was embroidered in the New Kingdom for the god-king with colored threads. This included patterns, pictures, and words. Among other colors, blue and red thread were used in this tapestry. Embroidery was reserved for royalty in the New Kingdom, so the presence of embroidery on the cloth that served as entrance points (courtyard gate, and tabernacle screen) and on the inside covering and veil would remind all who wished to enter and all who were inside that they were in the presence of their divine King.

The presence of just these three colors seems to indicate divine royalty. Blue was the color of the gods, purple was the color of royalty, and red was the color of protection against supernatural forces. All three were associated with the purpose of the tentsanctuary. Statistically speaking, there is a $100 \%$ statistical certainty that blue, purple, and red (scarlet) thread was available in ancient Egypt in the New Kingdom so that it would have been available for use in the construction of the Hebrew tent-sanctuary.

\section{Woven Goats Hair Statistical Comparison}

The only hair mentioned in association of with the tent-sanctuary was goat hair. It was used only in one layer (the second one) covering of the tabernacle. Dark brown or cream-colored goat hair does appear in the New Kingdom. Sheep wool was forbidden for use in religious services or in temples in ancient Egypt. Modern Bedouin tents use goat hair, but there does not exist any known reference or material example of goat hair used 
for tents in ancient Egypt, although other kinds of hair were used (e.g., camel hair). Although there are no extant examples of goat hair used for this purpose in ancient Egypt, it is conceivable and even likely that it could have been used.

Goat hair was clearly present in the New Kingdom. Statistically speaking, there is a 100\% statistical certainty that goat hair was available in ancient Egypt in the New Kingdom so that it would have been available for use in the construction of the Hebrew tent-sanctuary.

\section{Skins Statistical Comparison}

There were two types of skins mentioned in the Hebrew text and both were used only as coverings for the tabernacle. Rams skins dyed red were used in the third covering of the tabernacle. Red dye was considered the most superior color since by its nature it soaked into the leather rather than simply being a paint on the surface of the leather. Sheep skins were used in ancient Egypt for leather, although many other animal skins were also used. Leather was used to cover tents in the $19^{\text {th }}$ Dynasty (approx. $14^{\text {th }}$ to $12^{\text {th }}$ centuries B.C.) and in later periods.

There has been a lot of debate regarding the nature of the tahaš skins used in the outermost covering of the tabernacle. Of all of the possibilities, the most likely appears to be that this is an Egyptian loanword associated with the process of stretching skins to make parchment-quality fine leather. The Egyptian Book of the Dead was the first document in Egypt to have been written on parchment in the $18^{\text {th }}$ Dynasty (approx. $16^{\text {th }}$ to $14^{\text {th }}$ centuries B.C.). This quality of leather was available before the New Kingdom for covering musical instruments such as drums.

Statistically speaking, there is a $100 \%$ statistical certainty that sheep skins dyed 
red were available in ancient Egypt in the New Kingdom so that it would have been available for use in the construction of the Hebrew tent-sanctuary. Statistically speaking, while it is not certain that the outermost covering of the tabernacle was parchment quality leather, there is a $100 \%$ statistical certainty that parchment-quality leather was available in ancient Egypt during the New Kingdom so that it would have been available for use in the construction of the Hebrew tent-sanctuary, if this is what was meant by tahaš skins.

\section{Bronze Statistical Comparison}

Bronze (or copper) was used in the construction of the tent-sanctuary for clasps, sockets, overlay of the outer altar, overlay of poles, utensils, a network grate, rings, the laver and its base, and pegs. Bronze was used in the courtyard, the sockets for the pillars at the open end of the tabernacle, the fifty clasps for the goat hair covering of the tabernacle, and in both items of furniture used in the courtyard (altar and laver), but was not used for any item of furniture inside the tabernacle. Bronze was available in the New Kingdom and was the most common metal by the $19^{\text {th }}$ Dynasty (approx. $14^{\text {th }}$ to $12^{\text {th }}$ centuries B.C.). It was not used much before the New Kingdom, before which time copper-arsenic alloy was used.

Copper was still more common in the $18^{\text {th }}$ Dynasty than in the $19^{\text {th }}$ Dynasty. However, in all New Kingdom dynasties $\left(16^{\text {th }}\right.$ to $11^{\text {th }}$ centuries B.C.), bronze was available. Thus, while it is possible that copper is meant in the biblical text rather than bronze, statistically speaking, there is a $100 \%$ statistical certainty that both bronze and copper were available in ancient Egypt in the New Kingdom so that it would have been available for use in the construction of the Hebrew tent-sanctuary. 


\section{Silver Statistical Comparison}

Silver was used in the construction of the tent-sanctuary for sockets, hooks, bands, and overlaying the capitals of the pillars of the courtyard perimeter barrier. Silver was used in elements in the courtyard and tabernacle but not in any of the furniture. Silver had half the value of gold by the New Kingdom because it had become plentiful. This was a change, since it was more valuable than gold in earlier periods.

Silver without impurities was not possible with the technology available in the New Kingdom. Silver typically had some amount of gold in it, but other impurities were also typical. Statistically speaking, there is a $100 \%$ statistical certainty that silver was available in ancient Egypt in the New Kingdom so that it would have been available for use in the construction of the Hebrew tent-sanctuary.

\section{Gold Statistical Comparison}

Gold was used in the construction of the tent-sanctuary for overlaying the table, one altar, the ark, poles, boards, bars, and capitals of the pillars associated with the tabernacle Screen. It was used as the sole material for the lampstand, the mercy seat, hooks, rings, molding, and utensils. In ancient Egypt, gold was considered the skin of the gods, and as such, was reserved for royalty. Artisans had to obtain gold from the government or work for a priest in order to be a goldsmith in the New Kingdom.

Gold without impurities was not possible with the technology available in the New Kingdom. The term "pure gold” appears to mean gold as it was mined (with its natural impurities remaining - mostly silver that made it appear pale) and did not have

copper added to it (as was done to make it look more robust). Objects made of gold were often hammered, not cast. This is the method mentioned (Exod 25:18) in the making of 
the Mercy Seat. Gold leaf was attached to wood with an adhesive if the gold was thin enough, or with small tacks (nails) if it was too thick.

The Hebrew word used for beaten gold sheets is an Egyptian loanword. Statistically speaking, there is a $100 \%$ statistical certainty that gold was available in ancient Egypt in the New Kingdom so that it would have been available for use in the construction of the Hebrew tent-sanctuary.

\section{Material Data Comparison}

It appears that all of the materials listed in the construction of the Hebrew tentsanctuary were available in Egypt in the New Kingdom. It is, however, not as certain what quality some of these (the metals) may have been or the identification of the tahaš skins.

\section{Summary of Synthesis of Data}

There is a remarkable similarity between the Egyptian military camp’s central structure to the Hebrew tent-sanctuary in both design elements such as ratios and in the location relative to the Egyptian army. This relationship needs further discussion, which will take place in Chapter 8. It has also been established that design preferences in furniture changed over time and that the table of the tent-sanctuary compares favorably with New Kingdom culture but does not compare favorably with pre-New Kingdom culture. This also requires some discussion.

There were nine materials, which all appear only in the New Kingdom. Each of these materials can inform sanctuary studies, which will be addressed in Chapter 8. 


\section{CHAPTER 8}

\section{DISCUSSION, IMPLICATIONS AND RECOMMENDATIONS}

"In Egypt...the ubiquity of the king in the decoration instilled in the observer the idea that the king alone was the mediator between the people and the gods, between order and chaos.”

(Hundley 2013: 6)

The mobile military camp of New Kingdom Egypt is the closest parallel to the Hebrew tent-sanctuary. This concept was first identified through observation by Michael Homan (2000). This study, inspired by current archaeological thought primarily in Europe, sought to discover, identify, analyze, and record intangible cultural heritage as it relates to design elements. Ratios were used for comparison showing that indeed in some of the structural elements between the tent-sanctuary and the military camp there is a match. Stem-and-leaf plots helped to establish that there was change in design preferences in furniture over time. These data were then compared with data collected from the description of the construction of the Hebrew tent-sanctuary from the Hebrew text to establish that, at least in the only item that could be compared (the table), design preferences more closely matched New Kingdom Egyptian design than any period prior. Materials used in the construction also only all occurred in New Kingdom Egypt. All of the nine materials were not available before the New Kingdom or after that period. Thus, 
by using archaeological statistical techniques, data from the archaeological record could be compared with the description of similar data in a text to identify in a quantitative way, design preference. As a result, Egyptian cultural influence could be identified in the Hebrew tent-sanctuary.

This study resulted in some interesting parallels that require discussion. This discussion in turn leads naturally to implications for understanding the text. And the results leave this study with recommendations for further work in other possible avenues of exploration that are beyond the scope and nature of this study.

\section{Discussion}

Because the iconography of the military camp at Kadesh on the walls at Abu Simbel (I), Luxor $\left(\mathrm{L}_{1}\right)$, and the Ramesseum $\left(\mathrm{R}_{1}\right)$ has so many elements that are nearly identical and in nearly the same location in each depiction (see Appendix A, Figure 50), it is almost certain that there must have been a template that was followed by the ancient artists. It is interesting then to note the slight variations in ratios between the three depictions. Those variations in ratios aside, it is equally impactful to consider the nearly identical design and location of the central structure in the camp as well as its other variations.

Abu Simbel and the Ramesseum both depict the god-king's tent on the west side of the central structure. The Luxor depiction shows it on the east side and the attached rectangle on the west side, exactly the reverse of the other two. On the other hand, it is the Luxor and Ramesseum depictions that show the three official's/princes' tents between the outer and inner rectangles but Abu Simbel that shows them inside the inner rectangle.

It is more likely that a deviation from the template occurred only once, so it might 
tentatively be concluded that the god-king's tent was on the western side of the central structure and that the three official's/princes' tents were between the outer and inner rectangles. In other words, the depiction at the Ramesseum appears to be the more accurate using this method. Naturally, this is not a firm conclusion. Abu Simbel does show activity inside the god-king's tent and attached rectangle that the other two do not. However, as was noted in Chapter 5 the ratios show that Luxor and the Ramesseum are most often in harmony suggesting that they may tend to reflect the template more faithfully. This assumption is tentative.

Because of the similarities (as noted in Chapter 7), the Hebrew tent-sanctuary may provide some insight as to the nature of the three rectangles associated with the central structure (outer, inner, and attached). The outer rectangle was the only rectangle that matched the ratio of the tent-sanctuary perimeter barrier exactly (or nearly so at 2:1) in all three depictions. This might indicate a similar function. Since it is the barrier that is shown to immediately separate the space associated with the god-king Ramesses from his army camp it can be suggested that it may have been made up of similar material and design to that of the tent-sanctuary’s perimeter barrier.

The inner rectangle had a slightly higher than 3:1 ratio where the short end was slightly more than a third that of the long side. The tent-sanctuary's tabernacle also had a nearly 3:1 ratio where the short side (12 cubits) was slightly longer than a third that of the long side (30 cubits). Both the tent-sanctuary’s tabernacle and the central structure of the Egyptian military camp also have two spaces inside of this where the outer of the two (the attached rectangle and the Holy Place) were longer (or presumed to be so) than the inner of the two (the god-king's tent and the Most Holy Place). 
The design preference of a tent or canopy in the Egyptian mobile sacred sphere combined with the very clear worship/adoration scene in the attached rectangle at Abu Simbel suggests the possibility that the tabernacle's veil may have been a canopy. Since no measurement data appears in the text for the construction of the tent-sanctuary, it is difficult to know. However, all of the data that is present in the text does allow for this possibility.

The Hebrew text does not provide the dimensions of the most Holy place (aside from those given for later similar spaces, see 1 Kings 6:20). One of the appealing aspects of Wellhausen's theory is that the most Holy Place (in the tent-sanctuary) would have been 10x10x10 (length, width, height) making all measurements half of what they were in a similar space in the later temple. It must be remembered, however, that while Wellhausen postulated that the tabernacle was exactly half of the measurements of Solomon's temple, this was not actually the case (see Homan 2000). 1 Kings 6:2 says that Solomon's temple was 60 cubits long, 20 cubits wide, and 30 cubits high. It can quickly be seen that the 30-cubit length of the tabernacle was half of Solomon's temple. However, the height of Solomon's temple (30 cubits) was three times the height of the tabernacle (10 cubits), not two times. As a result, it should not be generally assumed that the width should be half if only one of the other two measurements was half (see Homan 2000 for more). It is possible that the most Holy Place could have been 10x10x10, if the veil was on the four pillars as a canopy (rather than a single curtain stretched from north to south across the width of the tabernacle; Exod 30:6; 40:3). The veil (in canopy shape) could have been placed in the back side of the tabernacle using any dimensions. Thus, it could have been 10x10x10, for example. This certainly would fit better with the Egyptian 
design as seen often in mobile sacred iconography and in the god-king's tent of the mobile Egyptian military camp. Whether or not the veil was in a straight line across the width of the tabernacle or a canopy in the back of the tabernacle, there is no indication of how one entered the space behind it (i.e., lifted up to pass under or around one end by pulling it back at the side). Either design fits with the textual description so neither can be settled upon or dismissed.

Since the tabernacle's frame was 10 cubits tall, the two cloth coverings would not have reached the ground on either side of the tabernacle. However, the goat hair could have touched in the back. If, however, these coverings were staked out away from the frame they would have provided potential ventilation, although the text does not indicate that this was the practice. Tents in New Kingdom Egypt appear to drop straight to the ground on each side. This may inform how they were handled in the tent-sanctuary.

One seemingly very visible design change was the location of the official's/princes' tents. In the military camp, they are quite clearly inside the outer rectangle of the central structure. If that outer rectangle is to be equated with the tentsanctuary's perimeter barrier as the ratios suggest is likely, the Hebrew text does not mention any other structure inside the courtyard aside from the tabernacle. In fact, Moses and Aaron did have their tents pitched outside the entrance gate (Chapter 1). This move may have had major significance for the Hebrews who may have not expected this. This would certainly have signaled the holiness of the space inside the perimeter barrier in a way not conveyed in the military camp iconography.

The Hebrew text does not provide construction details in a number of areas. These include the shape of the tenons, the exact nature of the sockets, how the bars were 
attached, the shape of the hooks, and if ropes were present or not. Because Egyptian cultural influence has been identified in many of the features of the tent-sanctuary's construction, what is known of these techniques from the archaeological record may provide the needed details. For example, all pillars and boards in the Hebrew tentsanctuary were connected with sockets upon which they were mounted. It seems likely from the Egyptian examples (cylinders with unequal bases, meaning that the diameter of each end is different; i.e., a conical frustum) that sockets were sunk into the ground for stability (the smaller end downward). A significant amount of silver was used for this purpose and may have provided the weight necessary.

Also, the purpose of the five pillars at the tabernacle's entrance may be revealed in a study of the flag poles on pylons in the sacred spheres of Egypt going back to the earliest sacred spaces.

Major design features from Egypt also were missing or changed. Egyptian tents featured a central pole. No such pole appears in the description of the tent-sanctuary. Also, the tabernacle had multiple layers of coverings, whereas, Egyptian tents had a single layer either of cloth or leather. The most obvious furniture parallel was the ark with the barque of the gods. However, two obvious details are missing. There is no boat associated with the ark (although the name implies it) and there was no idol present.

The ark had a compartment that held the Ten Commandments written on stone, and a few other items. It is not clear if the box associated with the barque of the gods had a compartment or not. If it did, there is no indication of what it may have held. It is possible that should this become known, important insights may be gained from a comparison of the contents. 
Winged creatures facing each other with wings extended over a central space above the ark/barque certainly is a clear design element that is shared and indicates Egyptian cultural influence. The observational parallel between the ark and various chest objects on poles in the tomb of Tutankhamun has been noted (Enns 2000: 511).

There is a question about which side of the ark that the poles were attached to (long or short) since the Hebrew text does not indicate. Some scholars (Chapter 3) felt that the way the text describes the poles extending into the Holy place from within the most Holy place later in Solomon's temple (1 Kings 8:8) required the poles to be mounted on the short side of the ark (Chapter 3). However, Egyptian design almost always mounted the poles to the long side of each object (Chapter 5). If the poles were mounted to the short side it would be outside of Egyptian norms. Further, while this study does not deal directly with Solomon's temple design, the most Holy place was 20 cubits deep (1 Kings 6:20). This length would require poles longer than 20 cubits. No acacia wood from Egypt is currently known to be longer than 12 cubits (Chapter 6). It is possible, of course, that the poles of this later temple-sanctuary were replaced by that time with another wood that could provide poles longer than 20 cubits. However, this does not appear to have been possible in an Egyptian context.

Two furnishing items did not have a clear Egyptian parallel although it is likely that they were present in some way. The lampstand and the laver. What they were or how they were constructed is not known.

The lampstand seems to be unique. Although almond buds are found in designs in Egypt and thus can be used to understand how these may have looked in the lampstand, and solid gold items were also made in Egypt, there are very few items identified as 
lamps and no comparable lampstands in ancient Egypt to compare this to (for more discussion see Chapter 5). Whether this is due to the accidents of survival or simply a reflection of New Kingdom Egyptian culture is unknown. There must have been light in the sacred spheres (both permanent and mobile) of Egypt. The utensils used in the lampstand may provide some insight into those used in New Kingdom Egypt.

Also, washing to be pure is known to have existed with the permanent sacred spheres of Egypt. It can be safely assumed that they would also have been a part of the mobile sacred spheres. However, no data is known. It is possible that in both of these the tent-sanctuary may provide some insight into what may have occurred in Egypt.

Coincidentally, the lampstand and laver were the only two (of the six) furnishings of the tent-sanctuary that were not described as having poles to be carried. The other four furnishings had poles. This is a clear Egyptian design feature. The poles seem to have served the purpose of transport, although transport was possible in other ways. Therefore, poles seem to have served a possibly more important role of not allowing the item being carried to be touched. This would certainly have been the case for a royal official. The poles also served (in Egypt as in most other cultures where they were used) to show honor to the one being carried.

All four furnishings that used poles also used rings. These rings were long cylinders, unlike the small item that fits on a person's finger. This helped for stability. Still another clear design parallel is the covering of furniture with cloth when it was on the move, as illustrated in KV62 and other tombs. This is not to say that this practice was uniquely Egyptian, just that it existed in Egypt and in the movement of the furniture of the tent-sanctuary. All of this shows clear Egyptian cultural influence. 
The Egyptian practice of overlaying wood with gold to indicate the presence of the divine may be the reason God instructed the Hebrews to do the same with the tentsanctuary furnishings. The gold table, the gold altar, and the gold ark were all constructed from wood overlaid with gold.

Colors had meaning in ancient Egypt (see Chapter 6). White was associated with purity, virtue, and the elite in society. Only those of high rank would have the finest linen cloth that was bleached white. Blue (turquois) was associated with the domain of the gods. Temples and tombs had ceilings painted blue for the purpose of conveying this concept. Purple (or lapis lazuli - a deep blue) was associated with royalty. This seems to be why Tutankhamun's famous mask was gold and lapis lazuli (skin of the gods and royalty). Scarlet (carnelian) was associated with power over the supernatural world. Red dye was used in both the threads and the ram's skins. Acacia wood also had a red core. The people could be illiterate and recognize by the presence of these colors that their God-King had his royal dwelling behind that curtain or screen. This is clear Egyptian cultural influence.

The presence of cherubim (winged creatures) only on elements that could be seen from inside the tabernacle linen cloth covering, veil, and mercy seat parallels the use of winged protectresses on many iconographic elements of temples and tombs. Their presence would remind the priests of the presence of the divine. In Egypt, embroidery was reserved for royalty, so the presence of embroideries in the Hebrew tent-sanctuary probably would have reminded the people of the presence of their King. This design element is a clear Egyptian cultural influence.

The worshiping figures in the attached rectangle of the Egyptian military camp 
indicate the presence of the sacred sphere. No altars are illustrated. However, if they were present in the reality behind the iconography, they would have had to be mobile. In this way it is possible that the Hebrew tent-sanctuary could provide some data for understanding how they might have been taken along with the Egyptian army for sacrificial purposes.

Egyptian altars had horns. Egypt was not unique in this practice, but they should be present in New Kingdom Egypt for it to be considered a cultural influence on the Hebrew tent-sanctuary. These horns were more like raised triangles at the corners than anything shaped like the horns of an animal. A reconstructed altar (Appendix A, Figure 96) in the permanent sacred sphere has stairs so the priest could get to the top and it is open at the side, presumably to manage the ash from the fire. How this might inform the design of either the bronze or the gold altar is unknown. The utensils used in the bronze altar may provide some insight into those used in New Kingdom Egypt.

The iconography of the Arch of Titus suggests that the table in the Second Temple Period was used to store the trumpets. It is unknown if this was the case in the original table of the tent-sanctuary. Trumpets were discovered in KV62 (the tomb of Tutankhamun) and are known to have been used in Egyptian military camps to signal messages to the army. The presence of these trumpets in the tent-sanctuary is a clear Egyptian parallel. How they were stored in relation to the table is open for conjecture. The utensils used with the table may provide some insight to those used in New Kingdom Egypt.

The gold altar did not appear to use fuel in the same way that the bronze altar did in that there was no provision for the gathering of ashes. It is likely, since it is associated 
with the burning of incense, that this description indicates a smaller flame, of which the ash could be managed in another way. The location of this altar may inform the use of altars in similar locations in the Egyptian sacred sphere.

Of the three main positions regarding potential cultural influence in the construction of the Hebrew tent-sanctuary (no cultural influence, Mesopotamian/Levantine cultural influence, and Egyptian cultural influence), the third is the position that this study was designed to evaluate. It can now be determined that the extent of statistical and observational parallels is far enough to claim clear Egyptian cultural influence.

Wellhausen's assertion that the tent-sanctuary was a copy of the temple-sanctuary and not the prototype (Chapter 1), if true, would show that a basic element in the Israelite religion to be fraudulent in the sense that it was invented to provide fictitious support for the religion. It is directly "due to Wellhausen's influence" that "it has become widely accepted that" the chapters in Exodus that deal with the construction of the tent-sanctuary are attributed to the priestly source (Alexander 2017: 562). This study evaluated the claims of the Hebrew text that the materials and design elements used in the construction of the tent-sanctuary came from Egypt. Aside from clear cultural influence is the presence of Egyptian loanwords, but not a single Mesopotamian or Persian loanword. The results show that Wellhausen's assertion was in error. If the tent-sanctuary was merely a literary invention during or after the Babylonian captivity, in the sixth century B.C., how do multiple elements of New Kingdom Egyptian culture appear so clearly and definitely in the materials, design elements, and even language used to describe the construction of the tent-sanctuary at that late date, and far removed from the country and 
culture of Late Period Egypt? Why would there be any Egyptian cultural influence for people coming entirely out of a Mesopotamian culture? And how would there be anyone who could so adequately represent New Kingdom Egyptian culture in the text? The composition of the Pentateuch is a complicated topic, regarding which this study may provide some useful implications.

On the other hand, in the biblical worldview, why would God bring his people out of an idolatrous, polytheistic culture in order to teach them how to worship him, but employ so much cultural influence for his tent-sanctuary from the very culture out which he brought them? It could be argued that he needed to communicate with them in a language that they could understand. By using a culture with which they were familiar, he could alter and introduce elements where they would expect something else, and then those changes and introductions of new elements would gain tremendous meaning. However, this question is better answered by theologians.

This study provides sanctuary scholars with actual data that can be used to evaluate typological and theological studies. It also provides those who would like to "build" a more accurate representation of the tent-sanctuary data and potentially provide even more insights.

It has been the general practice, when discussing the construction of the tentsanctuary, to do so in the context of Mesopotamian and Levantine backgrounds. Examples from these cultures are provided rather than from Egypt, for such things as the origin of dies for the threads, the concept of a god dwelling among his/her people, the cherubim, and the lampstand (Milgrom 1990: 127; Sarna 1991: 157; Wells 2009: 247- 
49). Even when an Egyptian connection is noted, an example in the Levant is often provided (Wells 2009: 250-553).

\section{Implications}

A study like this is rich with data. Implications of a typological, symbolic, theological, phenomenological, and potentially archaeological survey nature can be made. What follows is a sampling of what might be implied from the results of this study.

All three metals had to be melted in order to be overlaid on the acacia wood or shaped for the laver, lampstand, mercy seat, grate, bars, bands, capitals, hooks, sockets, and utensils. This was work that was directed to be done at the foot of Mt. Sinai. The implications of this is that the technology for achieving the high temperatures also needed to be present at Mt. Sinai, as well as a good supply of fuel. The advantage of using bronze rather than copper, in this regard, was that bronze had a melting temperature $\left(1,005^{\circ} \mathrm{C}\right)$, which is $80^{\circ} \mathrm{C}$ less than copper. And since copper is hard to cast because of the gas bubbles and shrinkage, bronze would have proven to be the more ideal metal. Silver's melting temperature is $956^{\circ} \mathrm{C}$ and gold's is $1064^{\circ} \mathrm{C}$. This means, that while the camp (mostly a tent city) of the Hebrews is not likely to have left an archaeological footprint, the smithies needed to accomplish this work are much more likely to have left an archaeological footprint. In the Bronze Age smithies consisted of "a paved hearth, casting pit, pounding stone with stone mullers, [a stone] anvil," surrounded by a dry stone wall to keep the heat in (Forbes 1964b: 131). So from a survey persepective, the discovery of the remains of smithies may help in the identification of the location of Mt. Sinai.

As this study discussed in Chapter 6, in New Kingdom Egypt, gold was naturally 
pale because of the quantity of silver in it. Felipe Masotti reminded me that in the Amarna letters, rulers from Mesopotamia complained about the poor quality of gold that they received from Egypt. To overcome this problem in Egypt, copper was added to make the gold look more robust (i.e. redder, see Chapter 6). The Hebrew text mentions that the gold used in the tent-sanctuary was to be "pure.” This cannot mean refined to remove all impurities, since refining techniques were not available until after the New Kingdom. The implication then is that the term "pure" meant that nothing was added to the gold to change its appearance. It is likely that the Hebews could have drawn certain theological insights from this. One such insight might be that "purity" precludes any action to manipulate results. In other words, the gold was to remain as it was and the Hebrew artisans were not to add anything to it to make it look as they desired.

The lampstand and the mercy seat were both to be made of hammered work. Gold was more often shaped in this way in the New Kingdom. Casting, when done, was accomplished through the lost wax method which resulted in the waste of metal. This too has implications. In Egypt, gold was closely associated with the gods. The Hebrew God associated Himself with that metal as well in that all of the furnishings inside of the tabernacle and even the frame of the tabernacle itself were made of gold or overlaid with gold. As a result, the required method of hammering would have conveyed the idea that nothing associated with God should be wasted.

The golden calf on the other hand was cast and not hammered. It appears that Aaron shaped the calf (Exod 32:4) in wax, created the clay mold (Exod 32:8), and tossed the melted gold jewelry into the mold and, when the mold was broken, the calf came out of the mold (Exod 32:24). In this way, the image of God (Exod 32:4-5) that they created, 
used the method that wasted material, meanwhile God was instructing Moses that they should use the hammering method so as to not waste material.

Theologically, it is important to note that the text describes two events happening at the same time. While Moses is receiving instruction from God concerning materials to be used for the construction of the tent-sanctuary, the Hebrews, tired of waiting for the end of that meeting, chose to use some of the same materials to construct an image of the God who was talking with Moses. The implications of this, theologically, are that impatience can lead to God's people using the very resources that He intended for them to use to help Him live among them. Instead, they wanted to make an idol to live among them.

Since this is described as having taken place in Sinai (Exod 19), the territory of Hathor, and since it was after they arrived in the Sinai that they began to be nourished by manna that appeared on the land each morning (Exod 16), it would not be hard to understand why they chose a cow to represent God. Even the noise that sounded like war (metal clanking against metal and screaming; Exod 32:17-18) were methods used to worship Hathor (the sistra). Hathor was worshiped by sexual union since she was the mother goddess (Wilkinson 2003: 141) and this appears to be the activity that was taking place (Exod 32:6, 25). Ptah, the creator god who spoke the world into existence, also was manifested on the earth as the Apis bull (Wilkinson 2003: 170). In post-New Kingdom periods, the Apis bull even had the solar disk affixed between his horns (Wilkinson 2003: 171). However, it likely was not Hathor or Ptah that they were worshiping (at least not alone) but rather a form of Anubis. Anubis was the jackal god of the dead who was the god of the lands beyond the fertility of Egypt proper. They were in just that sort of land. 
And Anubis was the son of Hesat, the cow goddess. She was the mother of the new king. When combined in this way, Anubis was represented as a golden calf (Wilkinson 2003: 173). Hesat also suckled the Apis bull (Wilkinson 2003: 174). It is probable that all of these beliefs were combined in a syncretistic way to represent the Hebrew God, something that they had been expressly forbidden to do (Exod 20:4).

The only image that was to be created were the cherubim. They were to be hammered as part of one piece with the mercy seat (Exod 25:18-19). The winged protectresses that are seen in Egyptian iconography illustrate well the most likely position that these cherubim were in with their outstretched wings (one high and the other low). One change was to be made. Whereas the Egyptian protectresses (goddess in human form or as kites) had their heads held high gazing into each other eyes across from each other. While the cherubim were to face each other on the mercy seat, they were to have their faces directed downward (Exod 25:20). Few would have seen the ark since it was always covered except when it was in the Most Holy Place, however, they would have been told about it. Perhaps even during the construction of it, many would have come by to see it. This being the case, all who were familiar with Egyptian convention would have noticed the change. While subtitle, the implication would have been clear. The cherubim were to reflect that they were in the presence of someone greater than they. The Egyptian protectresses were goddesses usually protecting another god or the god-king (in form or in name). However, the cherubim, by being positioned in this way communicated that they were not gods at all. Not much in known about the covering cherubs that surround the throne of God in heaven, but this association with something in Egypt gives a small glimpse of heavenly realities. 
The cherubim were also to be embroidered on two items: the linen cloth layer and the veil. The linen cloth layer and the tahaš skins were the two quality versions of both sets of layers (taking the tahaš skins as meaning premium fine leather). Of the two cloth layers, only the linen would have been seen and then only by the priests who entered the tabernacle. Of the two skins layers, the tahaš skins only would have been seen and then by anyone close enough to see the roof of the tabernacle over the perimeter barriers (and possibly from the courtyard gate depending on how much access they were granted to roam about the courtyard). The implication being that only the two quality layers were visible, thus communicating the special nature of the tabernacle, while the other two layers (the goats hair cloth layer and the rams skins dyed red layer) did the heavy lifting (the real work of protecting the tabernacle). It is possible that this would have communicated the concept of cooperation. The visible element in leadership clearly was Moses. However, he had a team behind him that made what he did possible.

It is clear that the tent-sanctuary was to be considered by the Hebrews as something special (as opposed to simply a rugged wilderness tent). Aside from the way the layers were presented, tahaš skins was a relatively new technology, as was bronze, the dying of linen thread, and red dye in general. Before the New Kingdom, none of these were common. Red dye, aside from its newness, also was the superior dye for leather since it soaked into the leather rather than just coating the surface (as discussed in Chapter 6). While pure conjecture, it is possible that this understanding helps readers today understand what the original audience may have understood intuitively; namely, that God orchestrated the adoption of those new technologies in New Kingdom Egypt so that they could be used for His tent-sanctuary. Another way of looking at it would be that 
God used the new technologies to convey the "special" aspect of his dwelling.

The colors also had meaning (as discussed in Chapters 6 and 7). The colors associated with the tent-sanctuary conveyed ideas of purity (white), cosmic divinity (blue), royalty (purple), and supernatural protection (red). Gold also communicated the idea of divinity. Embroidery was reserved for royalty in the New Kingdom (see Chapter 6). As a result, it is important to notice where embroidery was located from a phenomenological (what would be experienced) perspective. The only gate in the perimeter barrier was embroidered with the three colors that appear exclusively in many of Tutankhamun's jewelry items (see Chapter 6), conveying the idea that the powerful divine king lived beyond it. Courtyards seem to have only existed for the prestigious in Egyptian society so that, in itself would have conveyed the idea that the one living behind the barrier was important. If the perimeter barrier was undulating (alternating inside and outside of the pillars that held up the linen cloth) that would have meant something to them. Since Egyptologist are unsure of the meaning in the Egyptian setting, it is not possible to explain what that meaning might have been with any certainty.

In a similar way, the same is true for entering into the tabernacle. There was only one way in and the screen that served as a barrier to that entrance also was embroidered with the same three colors conveying that the same idea; that the powerful divine king of the Hebrews dwelt inside. Then, in the Holy Place, the only room the majority of priests were allowed to enter, the ceiling (10 cubits above the floor, which is roughly 17 feet) was also embroidered with the same three colors and with cherubim. That cloth, was also edged with loops of blue thread but these would not have been visible. The walls of the tabernacle were gold (overlay of acacia) with the only light being from the lampstand, 
which, along the south wall, would have cast shadows on the north wall. At 12 cubits in width (about 20.5 feet) the size of the room would have dwarfed the small table 1.5 cubits tall (about 2.5 feet), only a cubit wide (about 1.7 feet), and two cubits long (about 3.4 feet), the lampstand, and the golden altar at the back of the room, which was two cubits tall and only one cubit wide and long. The result would be the conveyance of grandure in scale of the dwelling of their God.

Beyond the altar, at the back of the room (most likely about 20 cubits away, or about 34 feet), the veil, also embroidered with the same three colors, hid from view the Most Holy Place, in which was the actual location of the presence of their God between the cherubim on the mercy seat of the ark. The Hebrews, coming from an Egyptian context would have certainly understood the grandeur of this repeated imagery.

To accomplish this large scale construction would have required the abilty to weave large strips of linen and goat hair. New Kingdom Egypt had new technology for weaving large pieces of fabric. Vertical looms were massive in size and not easily transported. Bedouin used ground looms as Egyptians had before the Hyksos introduced the vertical looms to Egypt. But it was much harder to weave lengthy pieces of cloth with the ground looms. Vertical looms were also able to produce a much higher quality of cloth (as discussed in Chapter 6). It doesn’t seem likely that these vertical looms were carried out of Egypt, which would mean that the long strips would have had to have been woven in Egypt.

However, it is clear from the offerings given that massive amounts of metal were carried out of Egypt. Metal is very heavy. Fabric is also quite heavy. And fabric was transported in boxes, which themselves are heavy. Also the Hebrews traveled with all of 
their possessions. They would have used carts certainly in a similar way to how the Egyptians did when their military traveled. Oxen pulled carts. Therefore, while it seems unlikely, it is not impossible that a few vertical looms were taken out of Egypt. But is there any suggestion, in the Hebrew text, that these long strips were woven at Sinai?

All materials had to be available at Sinai either by bringing them or obtaining it in Sinai. Thread seems to have been an example where both cases were true. Some of the thread given as a gift appears to have been brought out of Egypt already spun (Exod 35:23) and some was spun at Sinai (Exod 25:25). Since linen thread was dyed after it was spun, and some linen was spun at Sinai, the women who did the work must have also brought dyes with them out of Egypt. Goats hair was also spun at Sinai (Exod 25:26). Since goats hair only appeared in the construction of the tent-sanctuary as a cloth layer made by sewing large strips together, at least the goats hair cloth layer was woven at Sinai and that would have required a large loom. As a result, if the goats hair strips were woven at Sinai, it is also conceivable that some linen was also woven at Sinai. In either case, some sort of loom was brought out Egypt (most likely the ground loom although it the presence of carts should not preclude the possibility of the much larger vertical loom since high quality, lengthy pieces of linen were made for the tabernacle). Also, since it was the Egyptian practice to not allow wool into any sacred space (see Chapter 6) and the Hebrews had the same law in regard to the garments of the priests (see Chapter 4), it seems likely that wool was not used for thread.

The carts may also have carried other large items out of Egypt. The text describes acacia wood as already being with the Hebrews when they were asked for the gift (Exod 35:24). This does seem to suggest that it was brought out of Egypt. While it is possible 
that Acacia nilotica grew in Sinai during the New Kingdom and the Hebrews simply had the tools necessary to cut and shape it (Exod 35:33), no evidence of this has been found. That species, being the only one known to have been in New Kingdom Egypt that grew high enough to produce the 10 cubit pillars and boards of similar length for the tabernacle, seems to suggest the possibility that this wood was also brought out of Egypt. It may be hard to imagine the effort, however, acacia wood was the most common wood used in construction during the New Kingdom (see Chapter 6). Since the Hebrews were actively building two cities (Exod 1:11; 5:1-19), there would have been plenty of wood available for the taking. It must be remembered that the text describes them as believing that they were heading directly to the land promised (in the southern Levant). A few months of inconvenience would pay off if they had wood to build their new homes with. After all, why cut what you already have cut? That said, this is only a suggestion based on modern evidence, which may or may not reflect the wood available at that time in Sinai.

When finally constructed, the tent-sanctuary appears to have been patterned to some degree after an Egyptian military camp. Naturally, this raises some questions. If the pattern was shown to Moses by God, why would God select an Egyptian military camp? Denis Fortin pointed out to me that years later, Balaam, when looking down at the arrangement of the Hebrews camp, recognized that God had set Himself up as king in their midst (Num 23:21-22). Was he able to discern this through observation or because he was told this directly in the oracle that God gave him? Certainly, this study shows that the former is possible. The Hebrew camp appears to have reflected a familiar style to those living in the Levant. The Egyptian military camp would have been well-known in 
the Levant because of the many Egyptian military campaigns. Regardless of when the Exodus event took place (either in the early $18^{\text {th }}$ or early $19^{\text {th }}$ dynasties) the Egyptian military had changed little. There had been some minor changes, however. Sometime shortly after Amenhotep II’s early reign, chariot wheels had increased by one spoke. Sometime after Tutankhamun's death, an extra military division was added. However, early rulers of the $19^{\text {th }}$ dynasty had been generals in the $18^{\text {th }}$ dynasty military so that it was relatively unchanged by the time of Ramesses II's military camp (as depicted in the battle of Kadesh). Thus, regardless of when the exodus event took place, the military camp would have looked relatively the same. So while the appearance of the camp was laid out like an Eygptian camp, certain items would not have been seen by anyone living in the Levant. One of these items was the ark, which closly resembles the barque of the gods of Eygpt. The barques of the gods never left Egypt (to our knowledge). As a result, it cannot be claimed that the Hebrew text was invented by someone living in the Levant. The author of the text would have had to have been in Egypt during the New Kingdom.

The similarity of the two camps (Egyptian and Hebrew) raises some interesting possibilities. The Egyptian military camp had shields lining its outer limits. The Hebrew text does not describe any similar device for marking their exterior limits of the Hebrew camp. That there was some sort of idea of where the edge of camp was seems clear since the mixed multitude appear to have lived beyond the outskirts of the camp of the Hebrews (Num 11:1-4). Also punishment sometimes included being sent out of the camp (Num 12:14-15). It is possible that the tents on the furthest edge simply marked the end of the camp. However, the Hebrew text does describe the Hebrews as having some semblance of military presence in the battle against the Amalekites (Exod 17:8-13) and 
so there may have been some attempt to have guards.

Organic materials, of which it appears were the majority of what were used in mobile structures in all three spheres of ancient Egyptian life (sacred, royal-domestic, and military), do not survive well over time, but break down on a molecular level, leaving little behind to study thousands of years later. Verbal descriptions and iconographic representations are often what is left. These representations are both interpretations (albeit from an ancient interpreter: artist or linguist) of physical reality. Without knowing the ancient interpreters’ biases, presuppositions, purposes, and standards for faithful representation, it is hard to completely trust (from a modern perspective and with modern standards) what has been left in these forms. However, the fact that they remain demands that they be studied. This has been attempted here.

The accidents of survival are in itself a skewing element in any statistical analysis that must be recognized. Because there is no way to know how much of the ancient world survived or, more importantly, how much there was to begin with, dogmatic statements of any study into the ancient world are foolish. It is possible to analyze what has been recovered to see the possibilities as long as the study is transparent and repeatable. The results should also lead to clear areas of further research that can be recommended for follow-up.

\section{Recommendations}

Phenomenological considerations (such as how a space was accessed and what could or couldn't be seen from a variety of locations) have not been possible until the results of this study were completed. To know better how the Hebrews might have experienced the tent-sanctuary requires that modern scholars better understand what the 
ancient Hebrews would have seen, heard, smelled, and felt. The most central part of the Hebrew tent-sanctuary was the tabernacle, only the outside of the top of which would have been easily seen by anyone who desired to view it from outside of the perimeter barrier of the courtyard. The same is seemingly true for any similar central structure inside a courtyard in Egypt. So what was the purpose of the symbols if only a few could ever experience them? A study on this and other phenomenological aspects should be conducted.

Perhaps one of the more useful aspects of a study such as this is the clarity that often arises regarding gaps in data. Sometimes this might be due to a lack of availability. Other times this might be due to a lack of vision. This study has revealed a number of gaps.

There is a gap in scholarship regarding the use of blue, purple, and scarlet thread in ancient Egypt. The combination of the colors together does present some interesting possibilities, but more needs to be done on the combination of these three as data becomes available.

There is a gap in scholarship regarding the use of goat hair and the tent-sanctuary. Very little scholarship has been done on this topic, perhaps because it is commonly known that in modern times, tents are made from goat hair. As data becomes available on goats in ancient Egypt, a study should consider how this was used.

It is also not clear exactly why Egyptians used poles. Educated theories can be suggested but this needs more study. Similarly, it is not known what was in the barques of the gods (if anything). A study seeking to determine if the barques of the gods had compartments (as the ark had) and what might have been in them would be useful. 
Some work has been done in comparing Assyrian military camp perimeter barriers to the Hebrew tent-sanctuary and those in Egypt. It is observationally noted that the Assyrian military camps, of approximately eight hundred years later, were round (rather than rectangular), made of apparently permanent materials (rather than shields or simple cloth hangings), and had towers (which were completely absent in either the Egyptian or Hebrew camps). However, statistical comparative analysis has not been conducted and should be. Also, other possible Near Eastern mobile courtyard barriers should be searched for and analysis should also be conducted.

In fact, this entire study should be repeated for Mesopotamian and Levantine cultures. It is one thing to say that the tent-sanctuary has clear Egyptian cultural influence. This cannot be ignored. However, what if the same is true for Mesopotamian, Levantine, or post-New Kingdom Egyptian cultures? Until a study is done, no one can be sure and no conclusions can be reached. Once it is done, a comparative study should be undertaken to examine relative quantitative and qualitative extents of cultural influences between Egypt, Mesopotamia, and the Levantine cultures. As more data emerges, it would be useful to update the data in the present study to keep it current.

A similar study could also be conducted concerning artistic design. The Hebrews used embroidery. It is not possible, at the moment to guess what patterns were used. However, Egyptians also used patterns. An interesting study might seek to determine Egyptian cultural influence in the earliest Hebrew designs. This might provide some hint at what the embroidery design may have been. Finally, it would be useful to have an artist's concept of what the tent-sanctuary may have looked like following the areas where Egyptian cultural influence has been identified. 


\section{APPENDIX A}

\section{FIGURES}

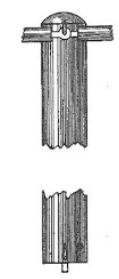

1. Round “pillar” sketch (Strong 1952: 15)

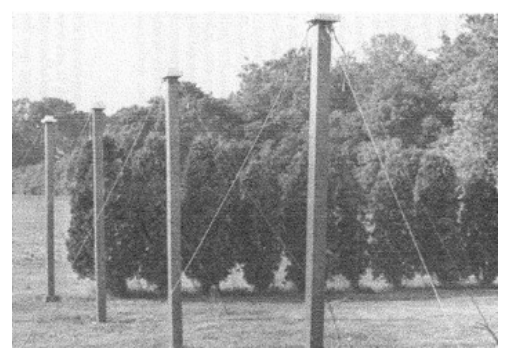

2. Squared pillars example (Zehr 1981: 33)

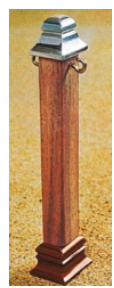

3. Squared pillar model (Kiene 1984: 41) 


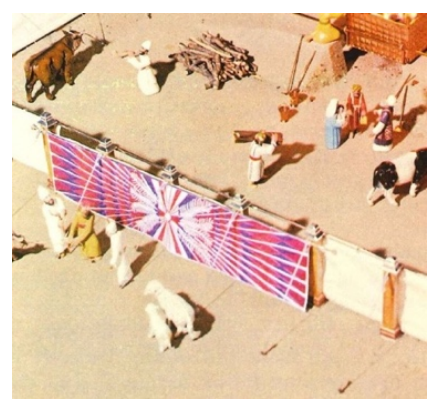

4. Courtyard gate model (Kiene 1984: 41)

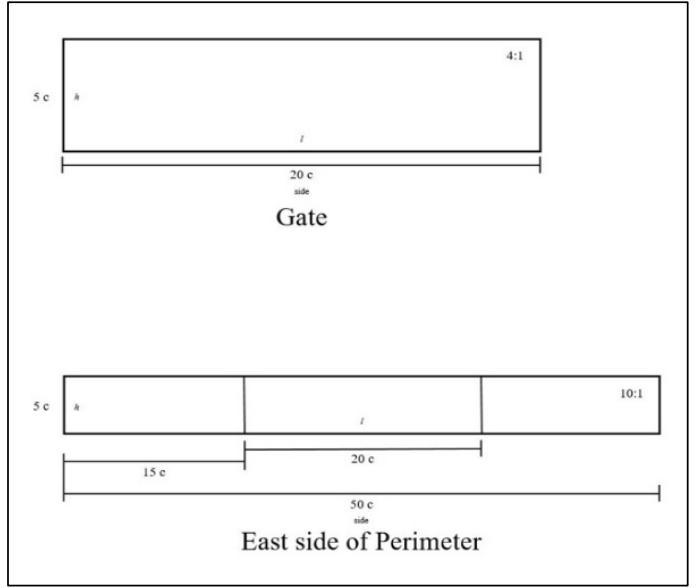

5. Gate and East side of Perimeter diagram
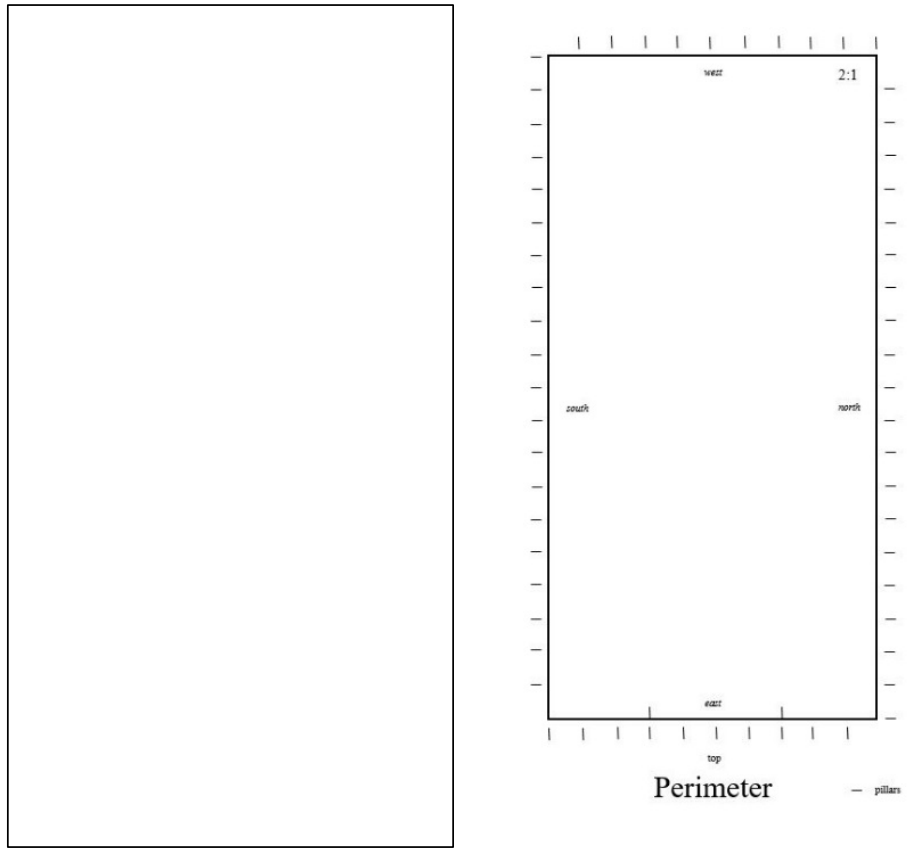

6. Perimeter diagram 


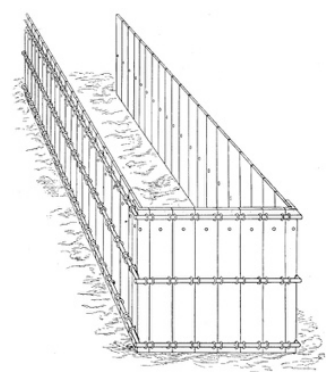

7. Frame of the tabernacle sketch (Strong 1952: 20)

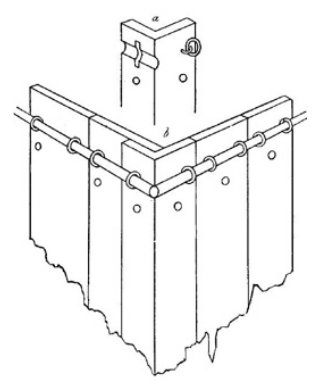

8. Corner boards of the frame sketch (Strong 1952: 22)

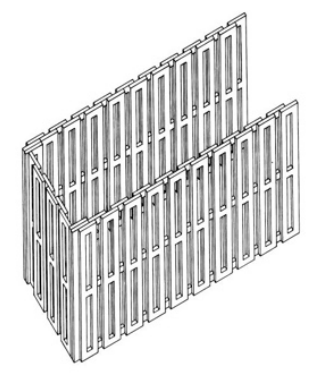

9. Frame shortened sketch (Friedman 1980: 243)

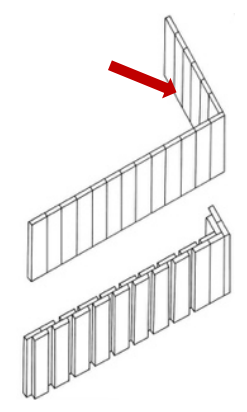

10. Frame corner options sketch (Friedman 1980: 242) 


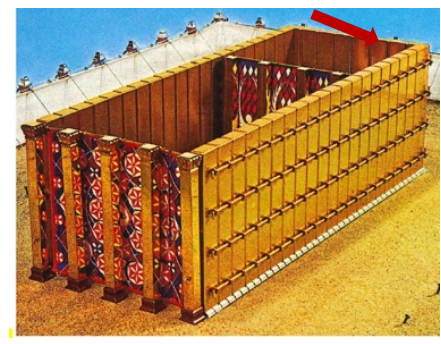

11. Frame corner option model (Kiene 1984: 92)

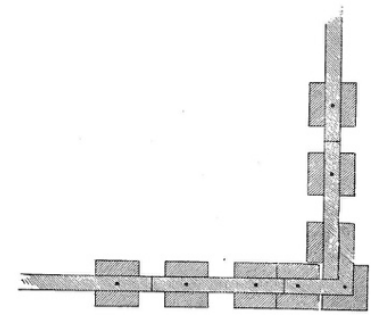

12. Frame sockets sketch (Strong 1952: 24)

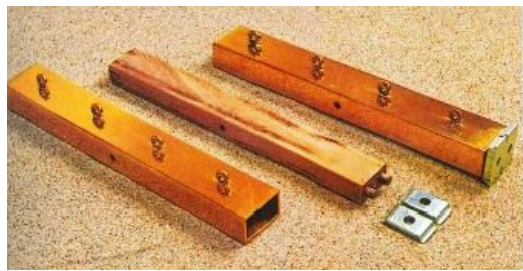

13. Frame sockets model (Kiene 1984: 95)

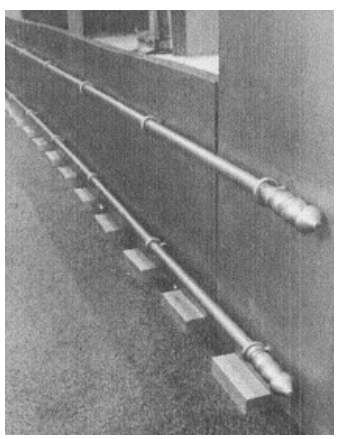

14. Frame bars example (Zehr 1981: 67) 


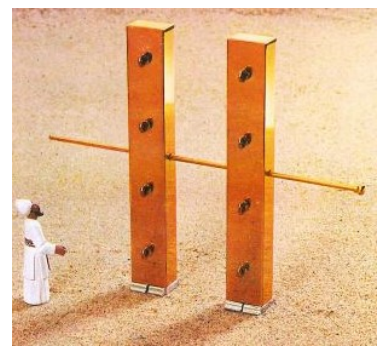

15. Frame bars model (Kiene 1984: 95)

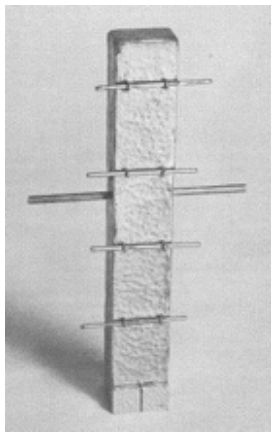

16. Frame bars model (Chambers 1958: 76)

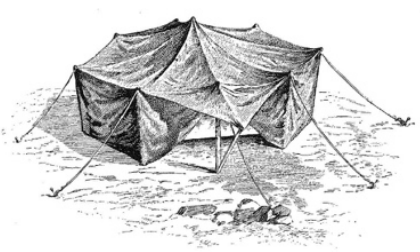

17. Bedouin tent sketch (Strong 1952: 33)

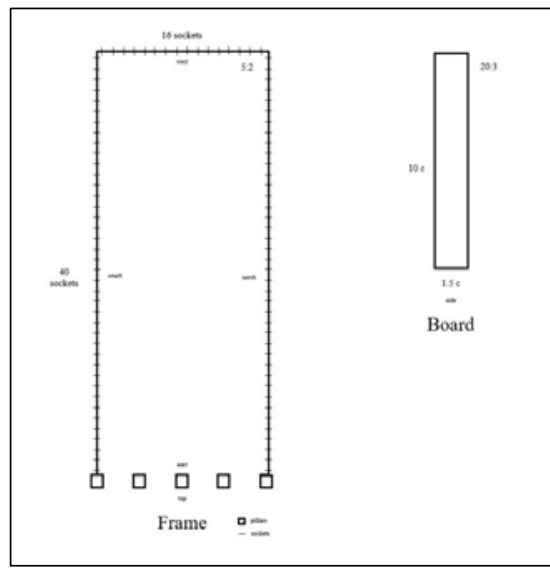

18. Frame and Board diagram 


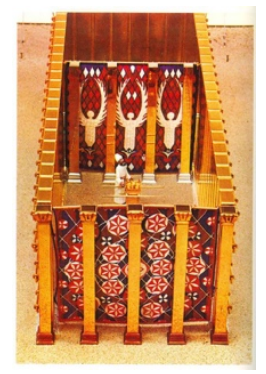

19. Screen model (Kiene 1984: 86)

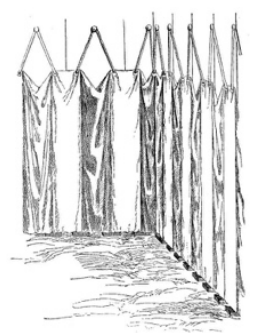

20. Linen layer as interior curtain sketch (Strong 1952: 39)

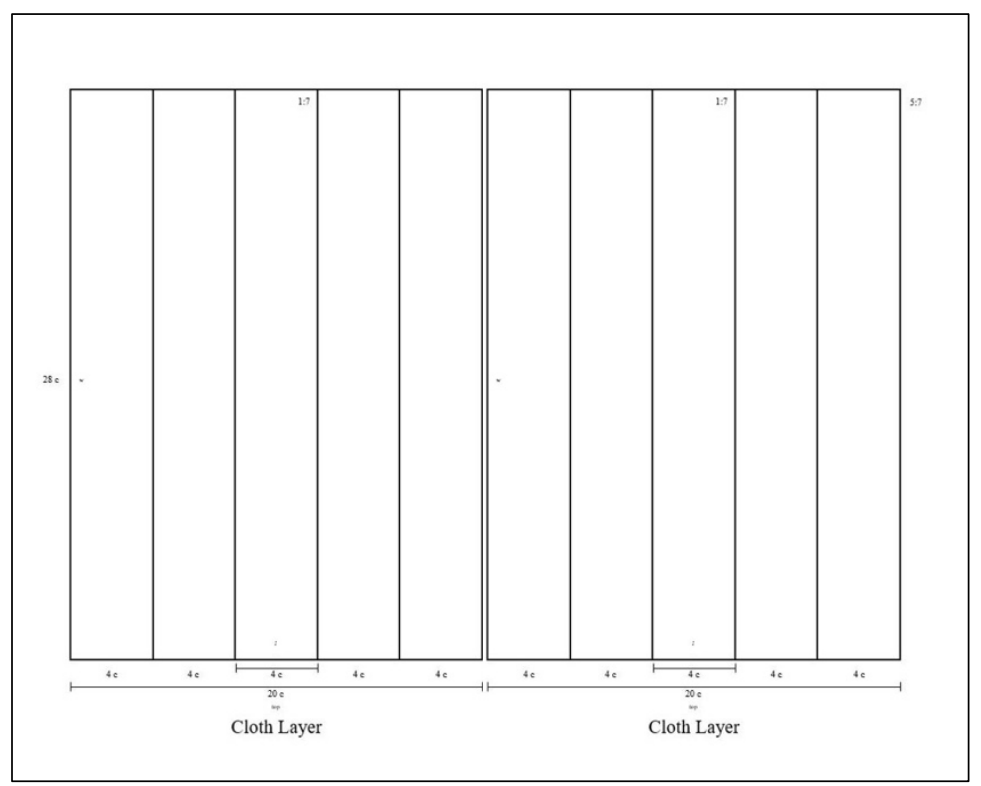

21. Linen Layer diagram 


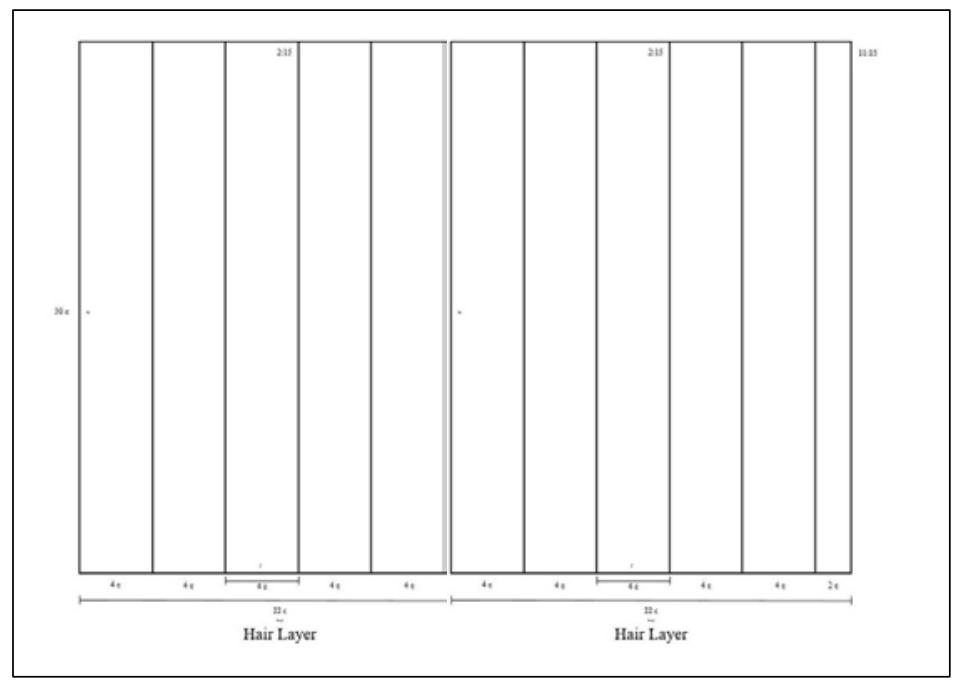

22. Hair Layer diagram

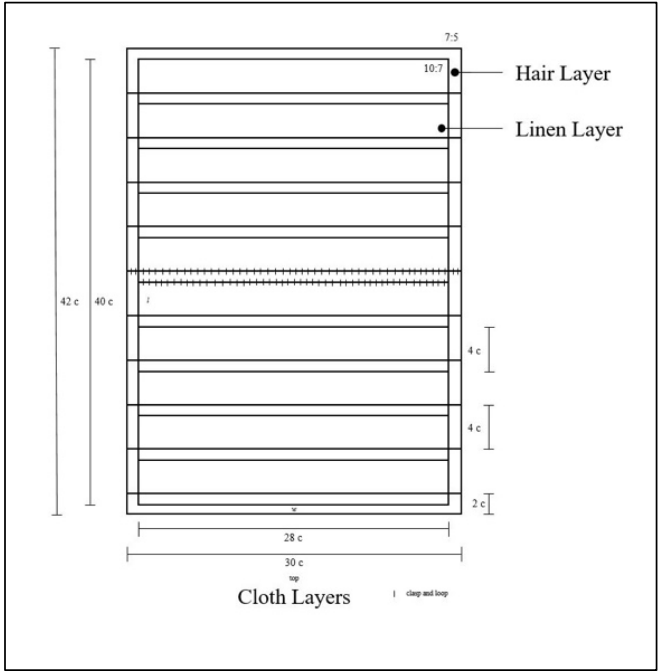

23. Cloth Layers diagram

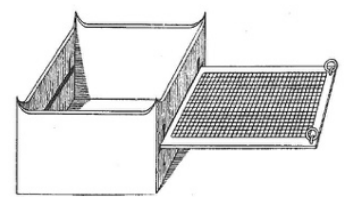

24. Bronze altar sketch (Strong 1952: 17) 


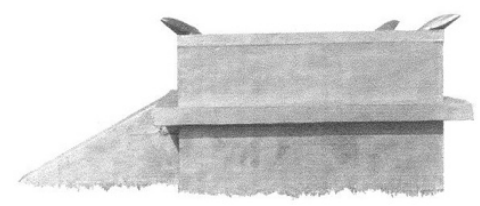

25. Bronze altar illustration (Zehr 1981: 37)

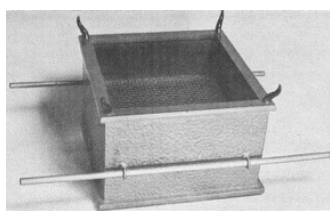

26. Bronze altar model (Chambers 1958: 90)

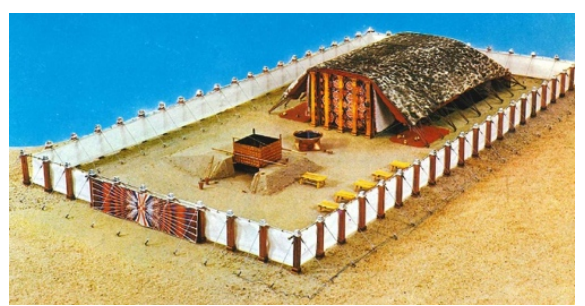

27. Tent-sanctuary model (Kiene 1984: 19)
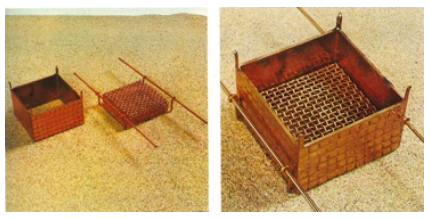

28. Bronze altar model (Kiene 1984: 59)

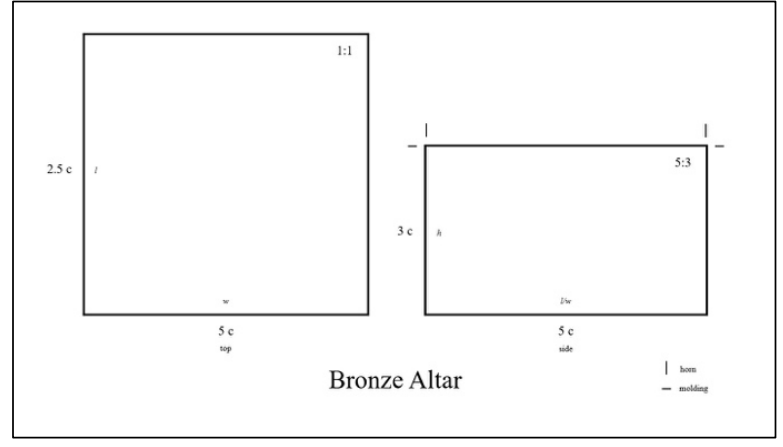

29. Bronze Altar diagram 


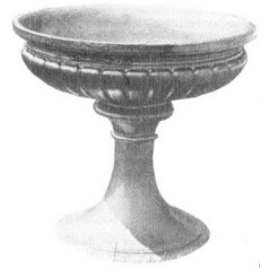

30. Laver illustration (Zehr 1981: 53)
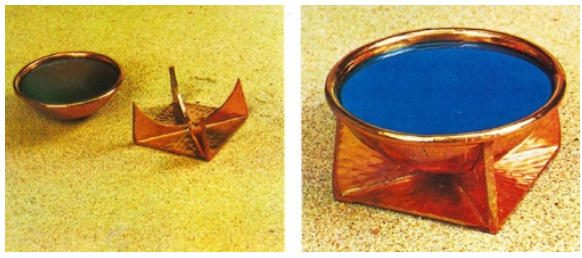

31. Laver model (Kiene 1984: 65)

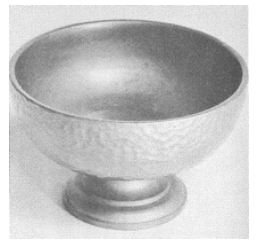

32. Laver model (Chambers 1958: 132)

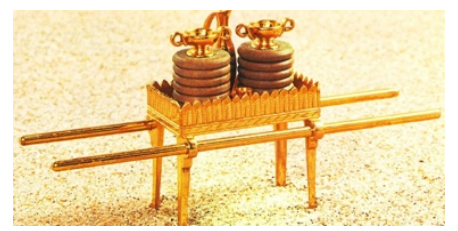

33. Table model (Kiene 1984: 107)

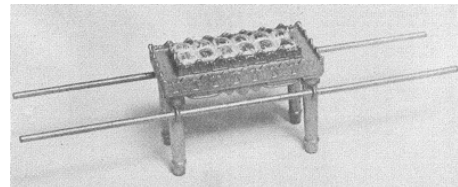

34. Table model (Chambers 1958: 44) 


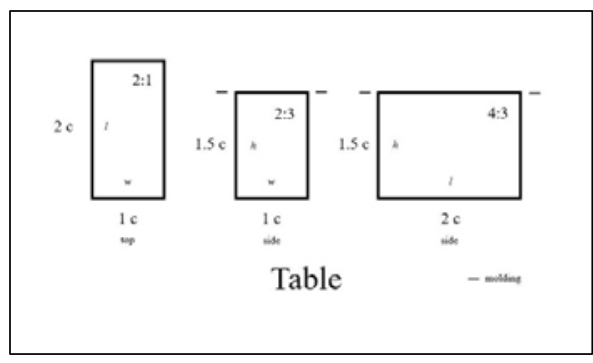

35. Table diagram

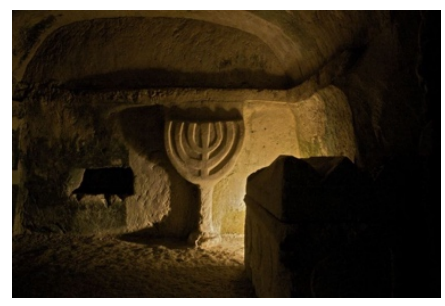

36. Menorah carving, Beit She’arim (Horowitz published July, 2015)

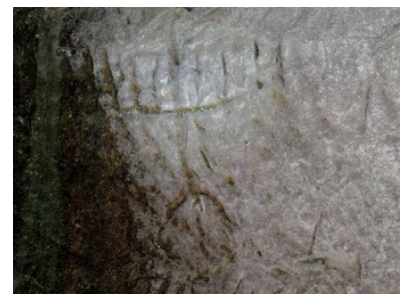

37. Menorah engraving, Judean Shephelah (Ganor published 2017)

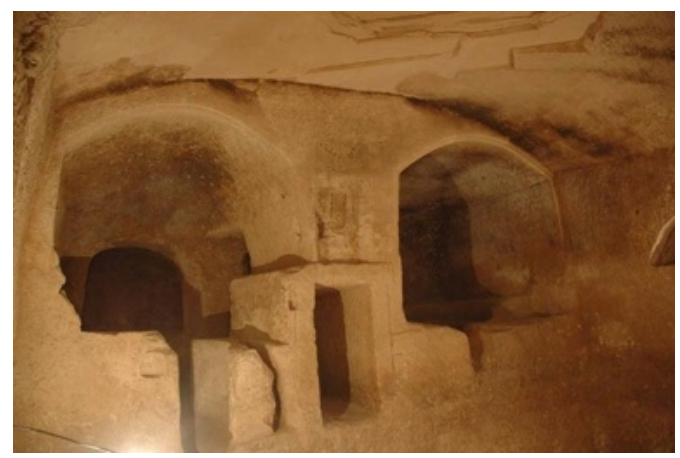

38. Menorah engraving Bet Loya (Gutfeld published March, 2009) 


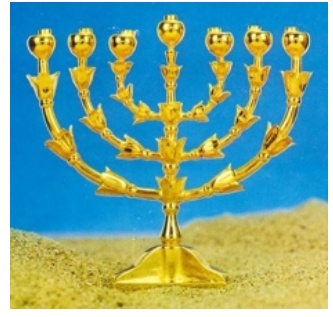

39. Lampstand model, uniform length (Kiene 1984: 115)

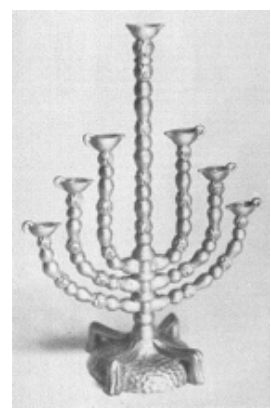

40. Lampstand model, various lengths (Chambers 1958: 52)

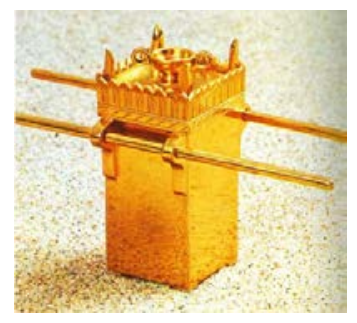

41. Gold Altar model, poles level (Kiene 1984: 120)

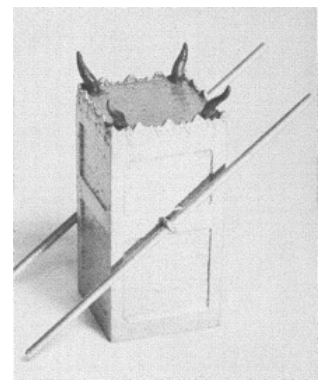

42. Gold Altar model, poles slanted (Chambers 1958: 128) 


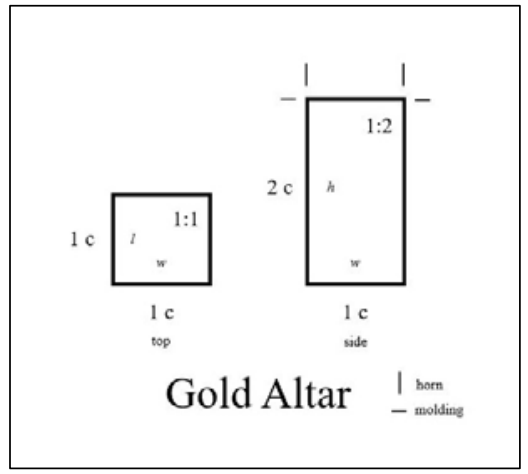

43. Gold Altar diagram

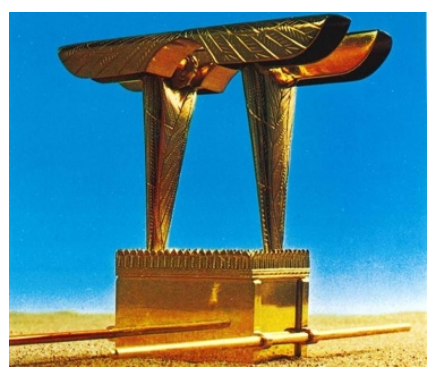

44. Ark model, poles on short side (Kiene 1984: 141)

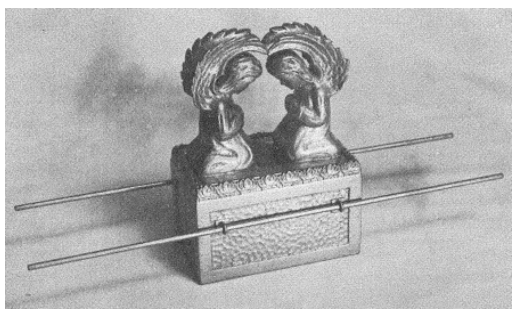

45. Ark model, poles on long side (Chambers 1958: 36)

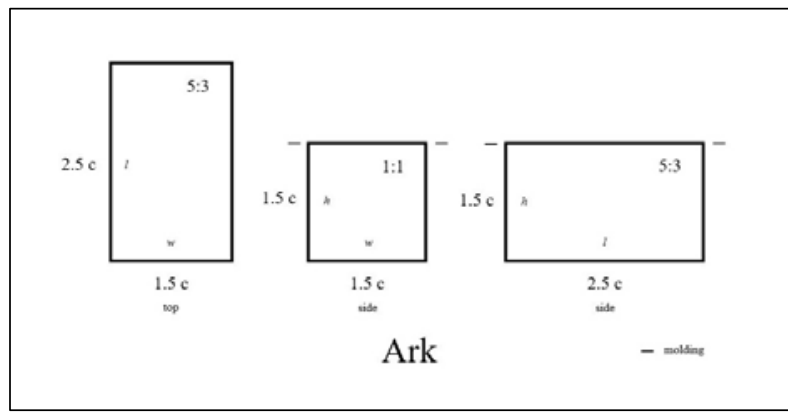

46. Ark diagram 


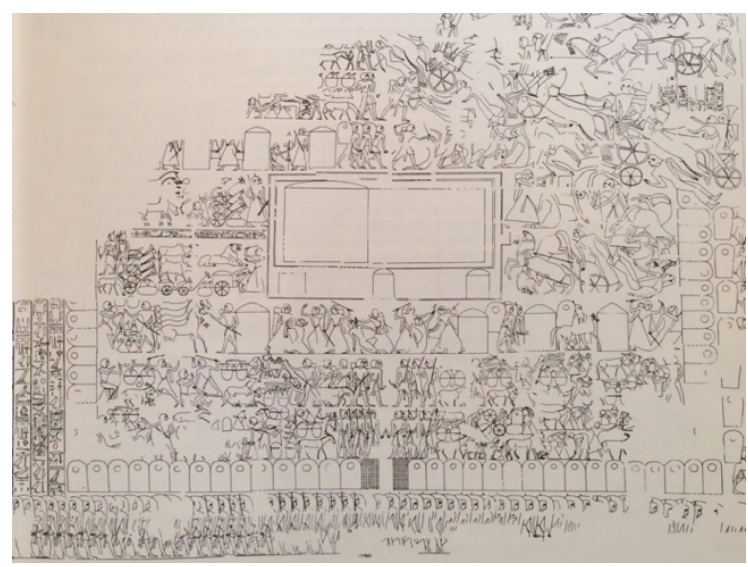

47. Mobile military camp, Luxor ( $\left.\mathrm{L}_{1}\right)$ (Yadin 1959: 109)

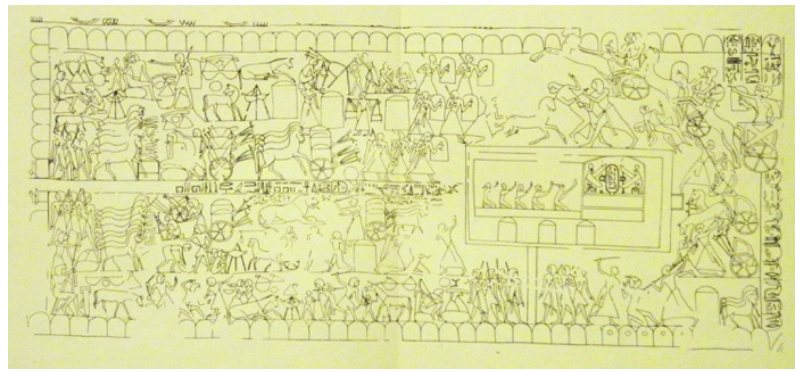

48. Mobile military camp, Abu Simbel (I) (Desroches-Nobelcourt, Donadoni, and Edel 1971: plate 1)

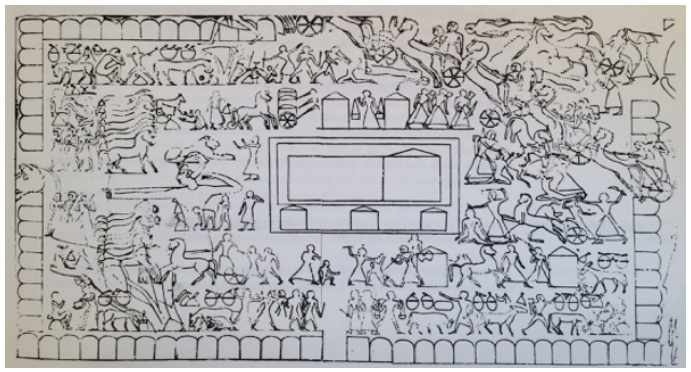

49. Mobile military camp, Ramesseum ( $\left.\mathrm{R}_{1}\right)$ (Yadin 1959: 107) 

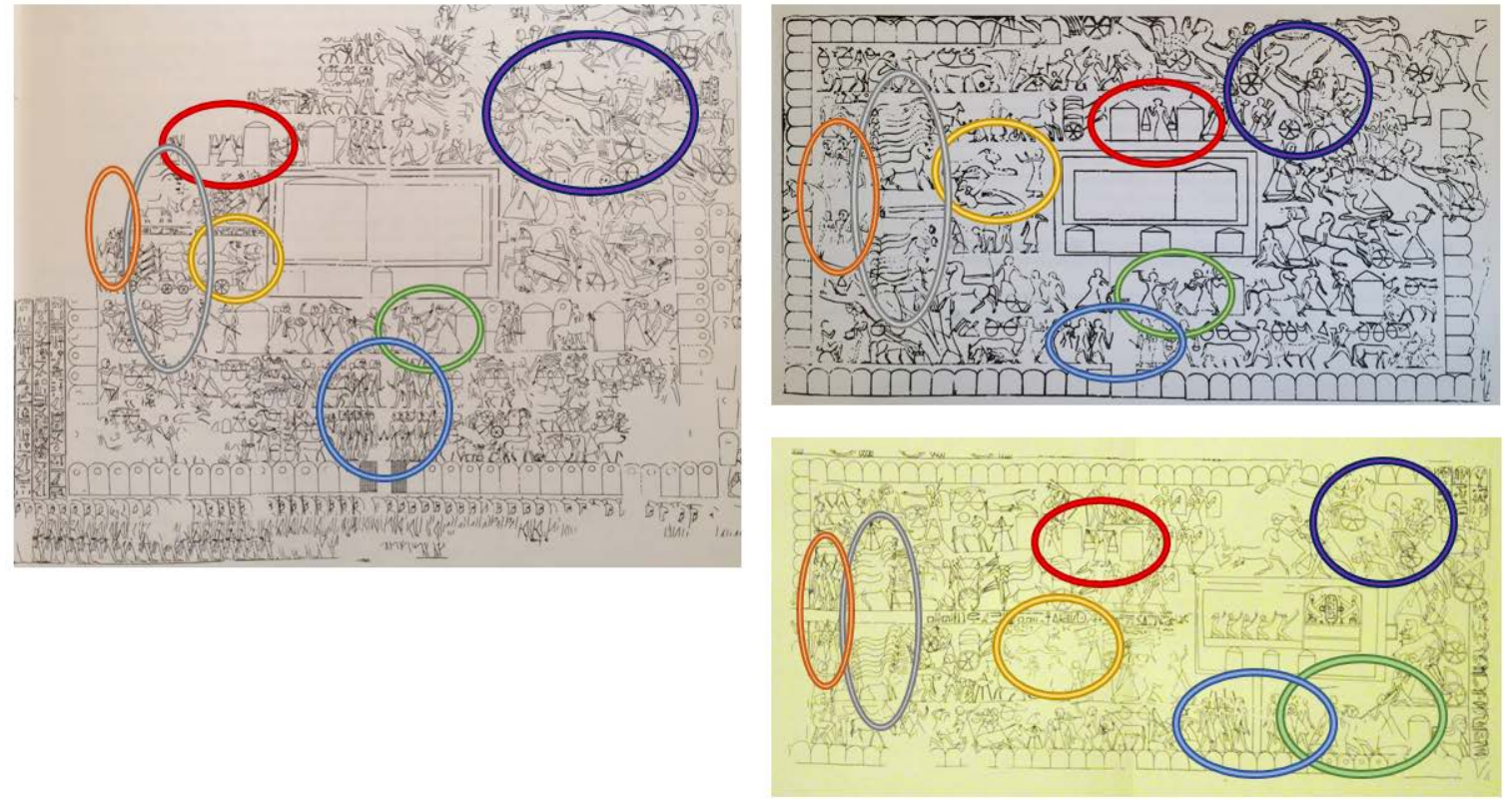

50. Mobile military camp collogue (Yadin 1959: 107, 109; Desroches-Nobelcourt, Donadoni, and Edel 1971: plate 1)

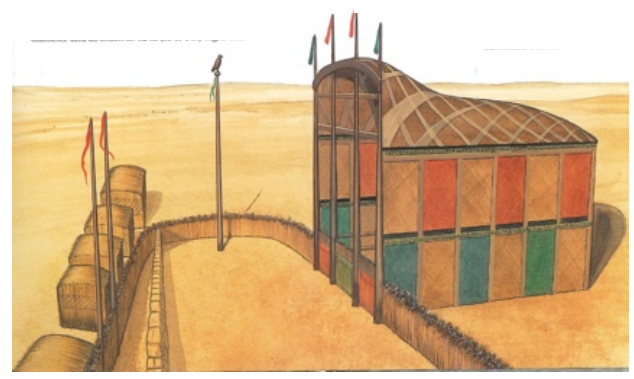

51. Early temple fronted by four wooden pillars (Wilkinson 2000: 17)

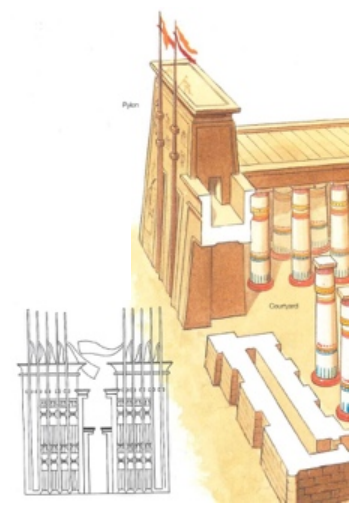

52. New Kingdom pylon with large flag poles (Wilkinson 2000: 24) 


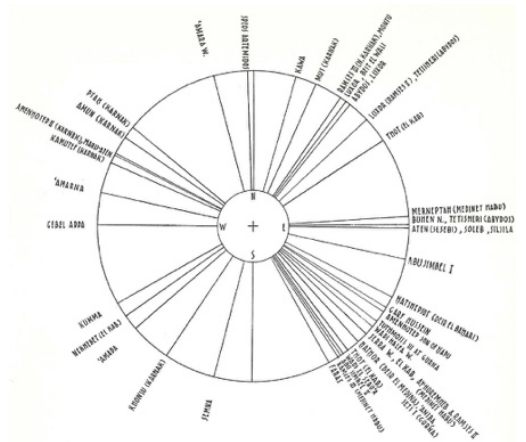

53. New Kingdom architectural orientation (Badawy 1968: 184)

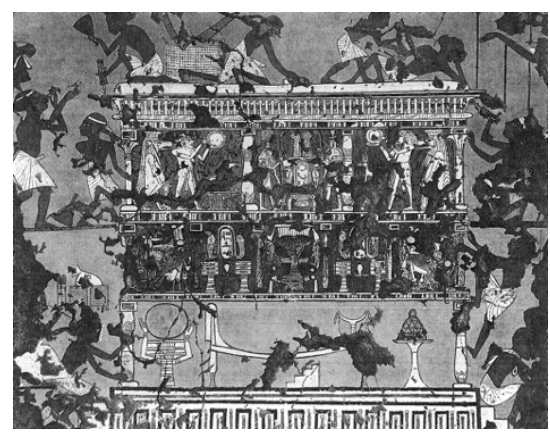

54. Tent shrine to Amenhotep I (Kitchen 2000: 21)

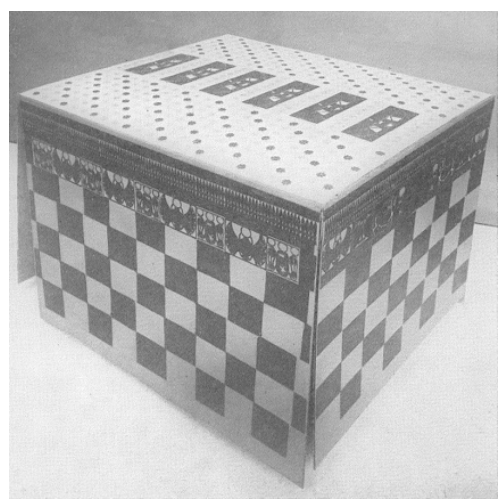

55. Tent of Isetemkheb (Forbes 1957: 43) 


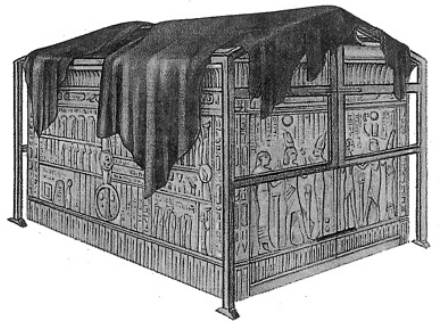

56. Gilded shrine of Tutankhamun (Kitchen 2000: 16)

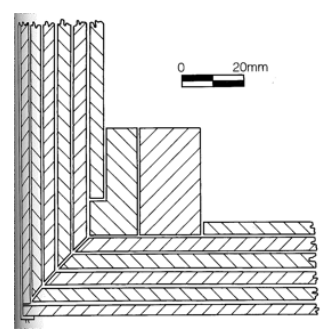

57. Plywood construction of $3^{\text {rd }}$ Dynasty coffin (Gale et al. 2000: 357)

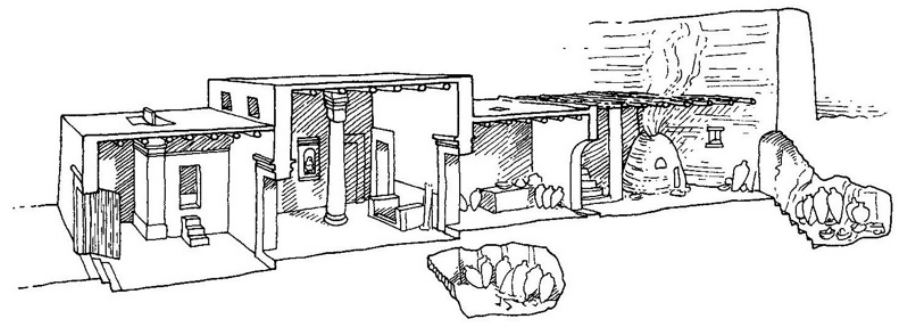

58. Typical row house design elements (McDowell 1999: 10)

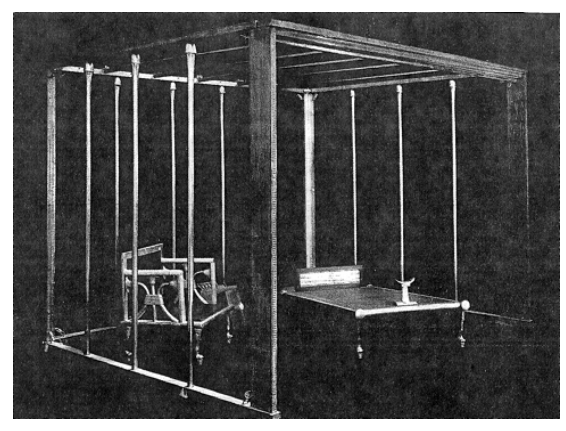

59. Hetepheres bed canopy (Kitchen 2000: 18) 


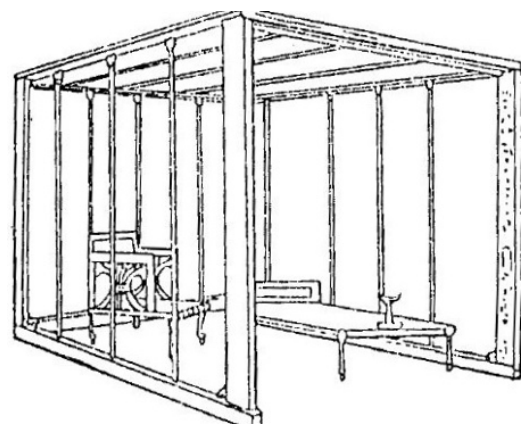

60. Hetepheres bed canopy line drawing (Kitchen 1993: 120*)

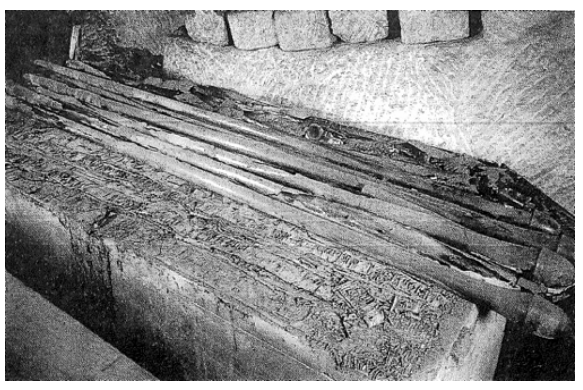

61. Hetepheres bed canopy stored (Kitchen 2000: 18)

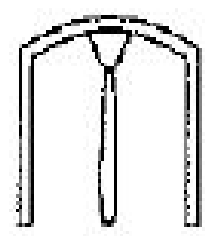

62. Hieroglyph O22 (Allen 2000: 438)
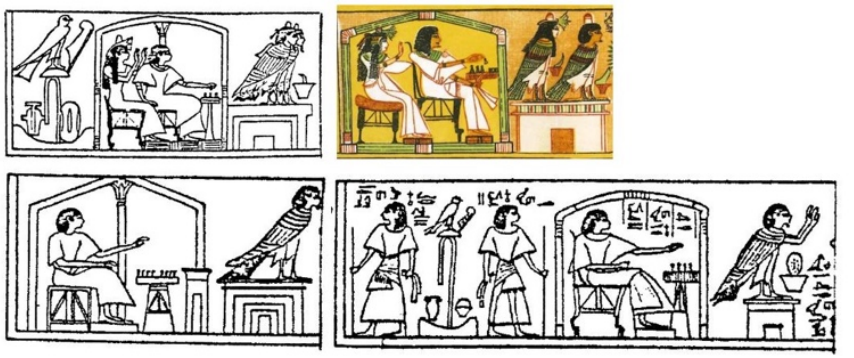

63. Tents with and without a center pole (Hoffmeier 1977: plate 4; Faulkner 2005: 42) 


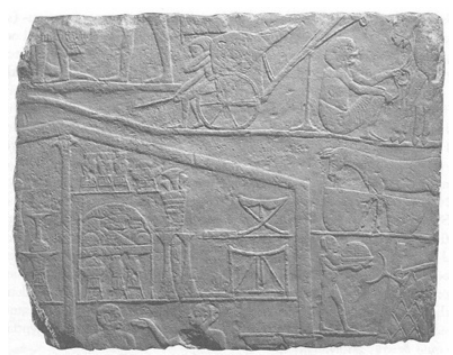

64. Tent from Horemheb’s tomb (Darnell and Manassa 2007: 88)

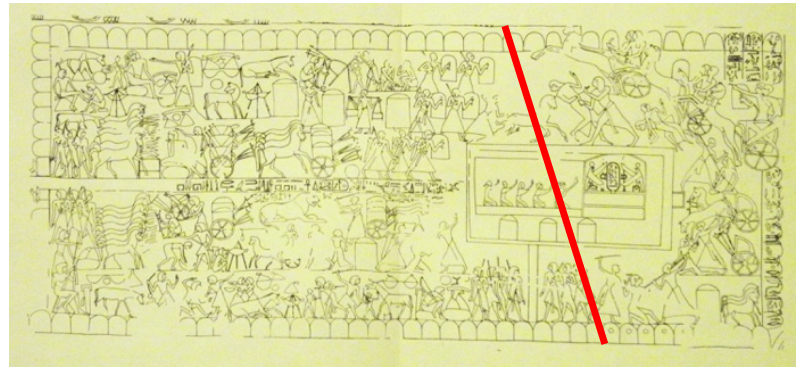

65. Tent of god-king between calm and chaos (Yadin 1959: 107, 109; DesrochesNobelcourt, Donadoni, and Edel 1971: plate 1)

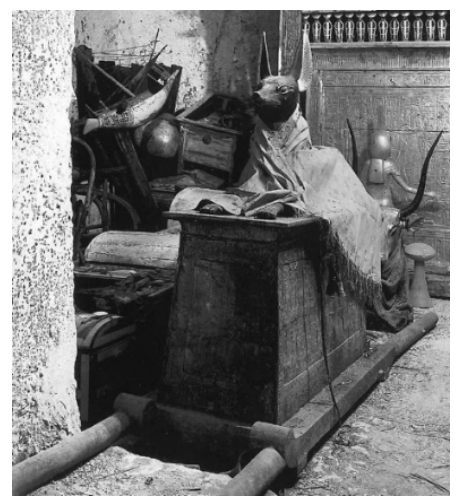

66. Simulacrum of Anubis (Reeves 1990: 87) 


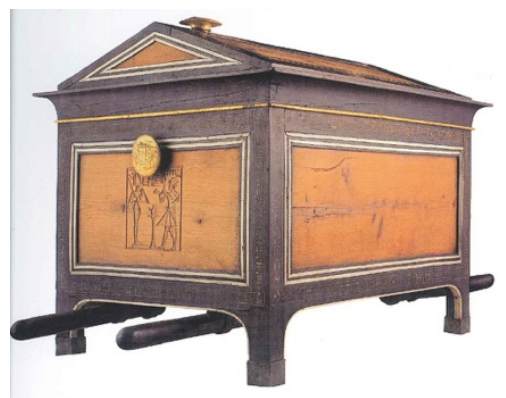

67. Carrying chest (Hawass and Vannini 2007: 28)
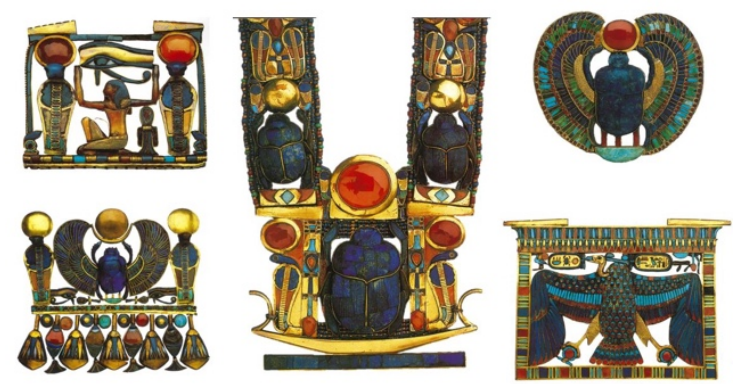

68. KV62 Jewelry examples (James 2009: 214, 31, 34-36)

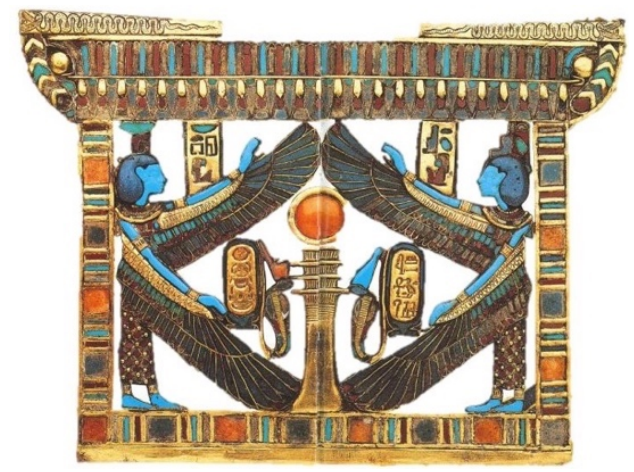

69. Winged protectresses on jewelry (James 2009: 222-23) 


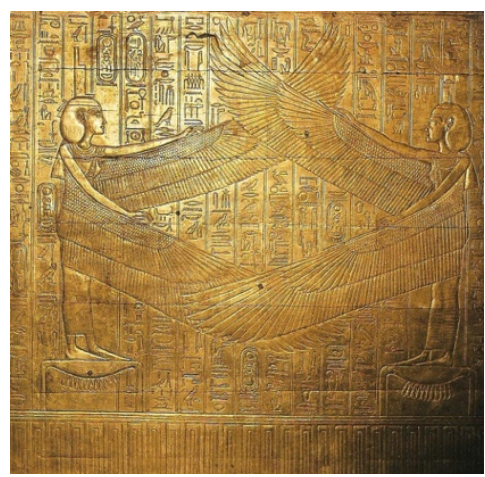

70. Winged protectresses on shrines (Reeves 1990: 102)

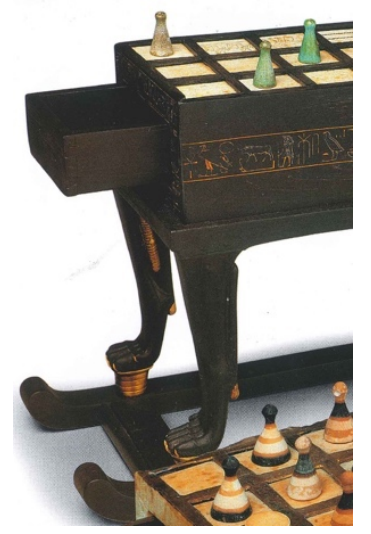

71. Ringed tenon feet (James 2009: 264)

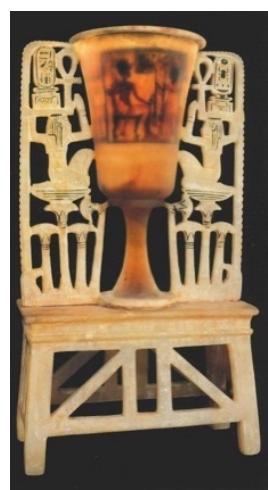

72. KV62 Lamp (Hawass and Vannini 2007: 75) 


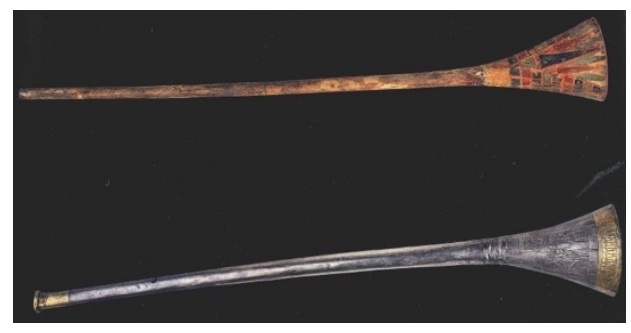

73. Trumpet (Hawass and Vannini 2007: 76)

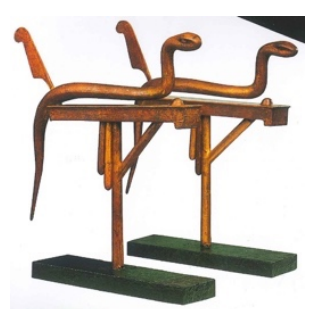

74. Standards (James 2009: 154)

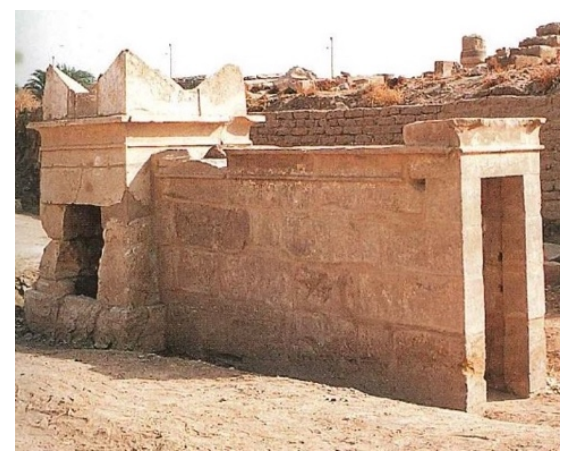

75. Stone altar (Wilkinson 2000: 69)

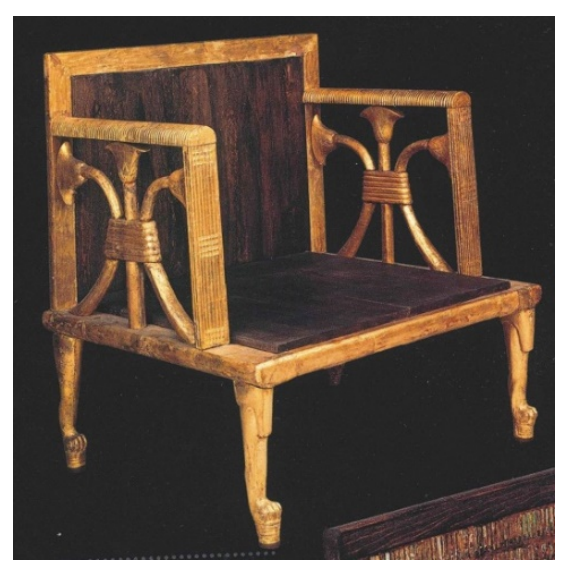

76. Hetepheres’s Sitting Chair (Amenta and De Luca 2005: 56) 


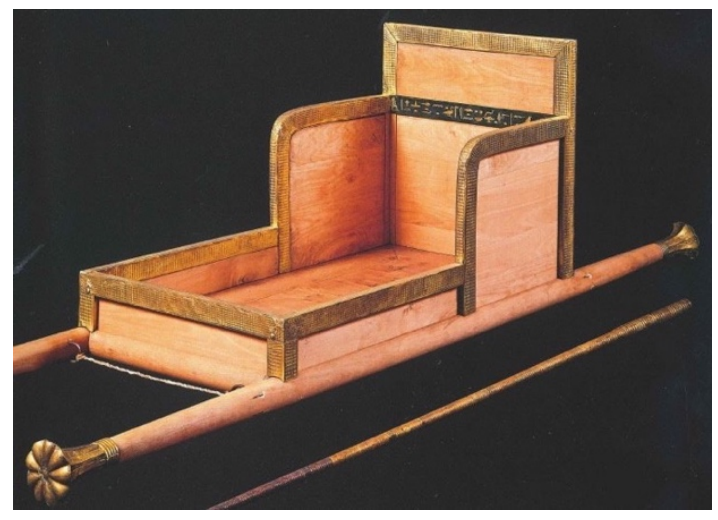

77. Hetepheres’s Sedan Chair (Amenta and De Luca 2005: 57)

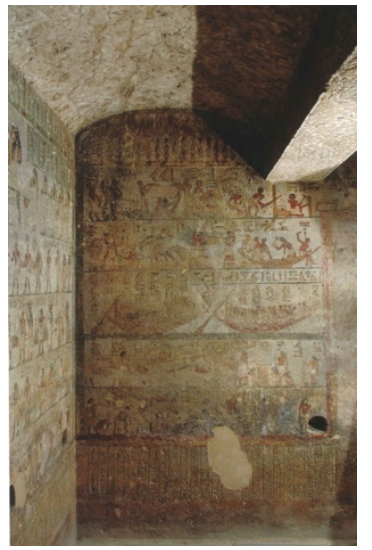

78. West wall, south of entrance, register 2 (Kanawati and Evans 2014: plate 24)

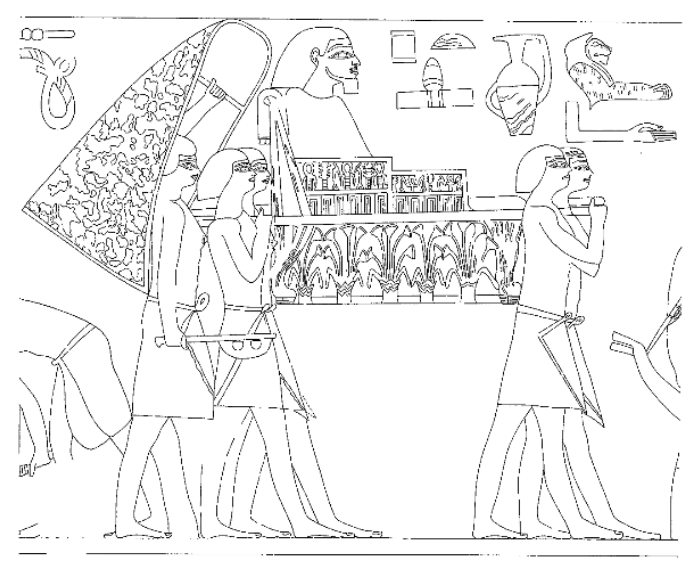

79. Carrying chair (palanquin) (Kanawati and Evans 2014: plate 122d) 


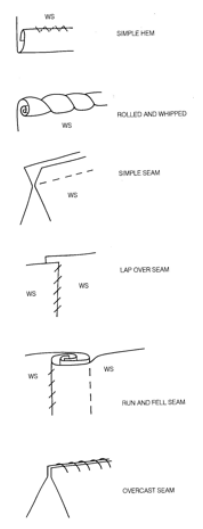

80. Seam and hem types (Vogelsang-Eastwood 2000: 283)
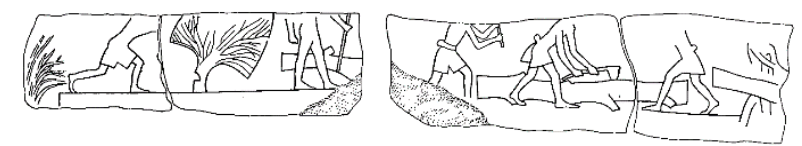

81. Tomb scene, felling a tree (Gale et al. 2000: 353)
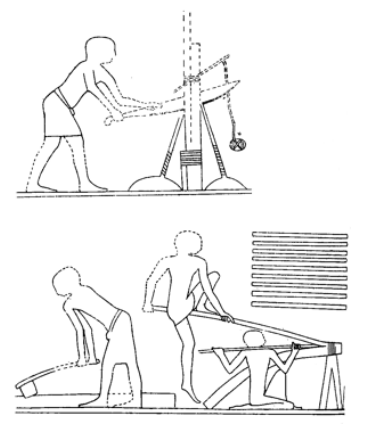

82. Tomb scene, cleaving a tree (Gale et al. 2000: 354)

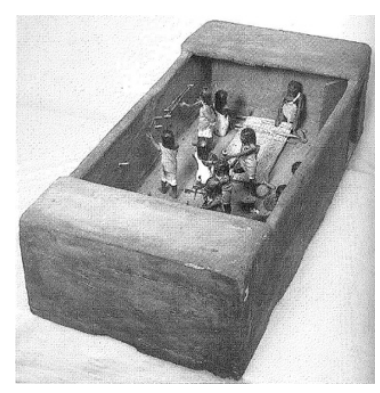

83. Model of spinning and weaving (Vogelsang-Eastwood 2000: 268) 


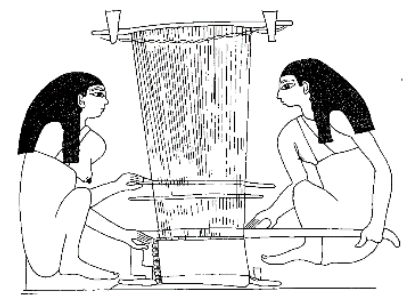

84. Ground loom (Vogelsang-Eastwood 2000: 277)

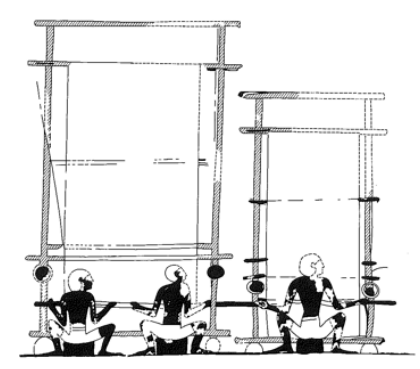

85. Vertical loom (Vogelsang-Eastwood 2000: 277)

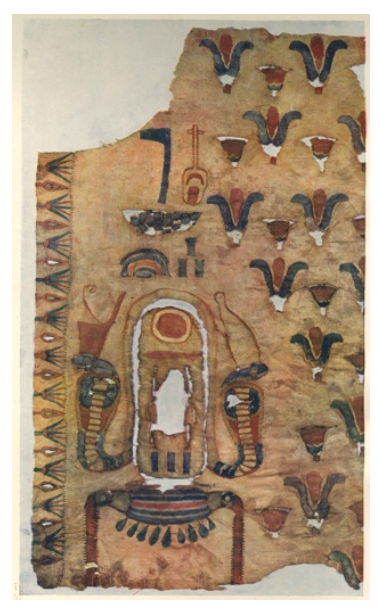

86. Woven tapestry of Amenhotep II (Carter and Newberry 1904: panel 1) 


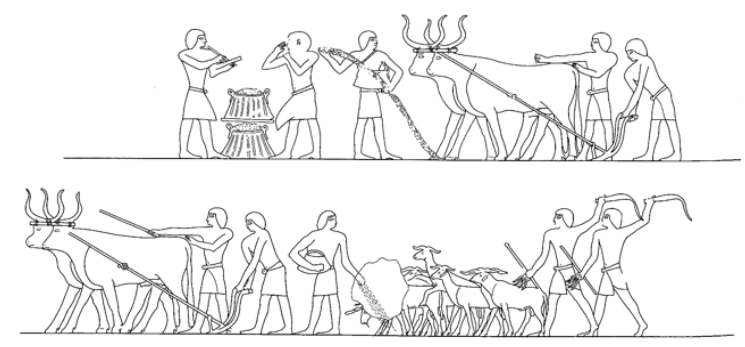

87. Sowing flax (Vogelsang-Eastwood 2000: 270)

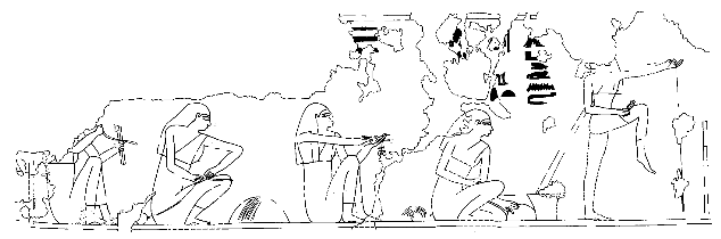

88. Spinning or splicing thread (Vogelsang-Eastwood 2000: 271)

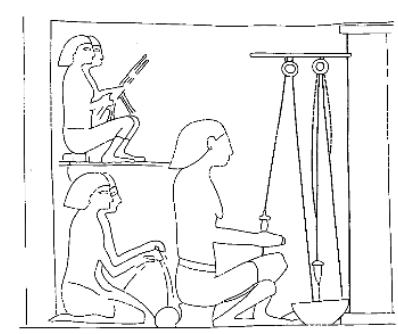

89. Dome-shaped whorl (Vogelsang-Eastwood 2000: 273)

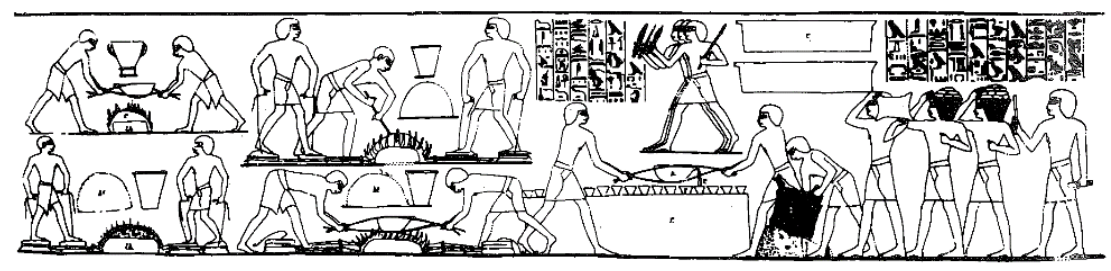

90. Metal work (Ogden 2000: 150) 


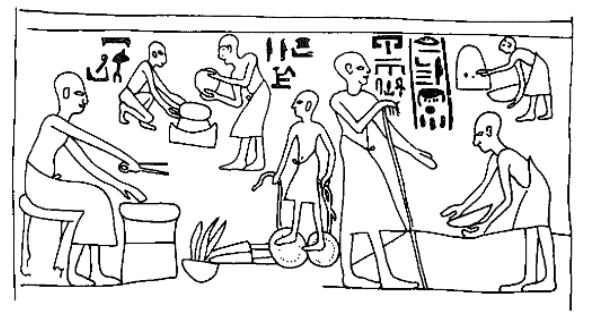

91. Gold processing (Ogden 2000: 162)
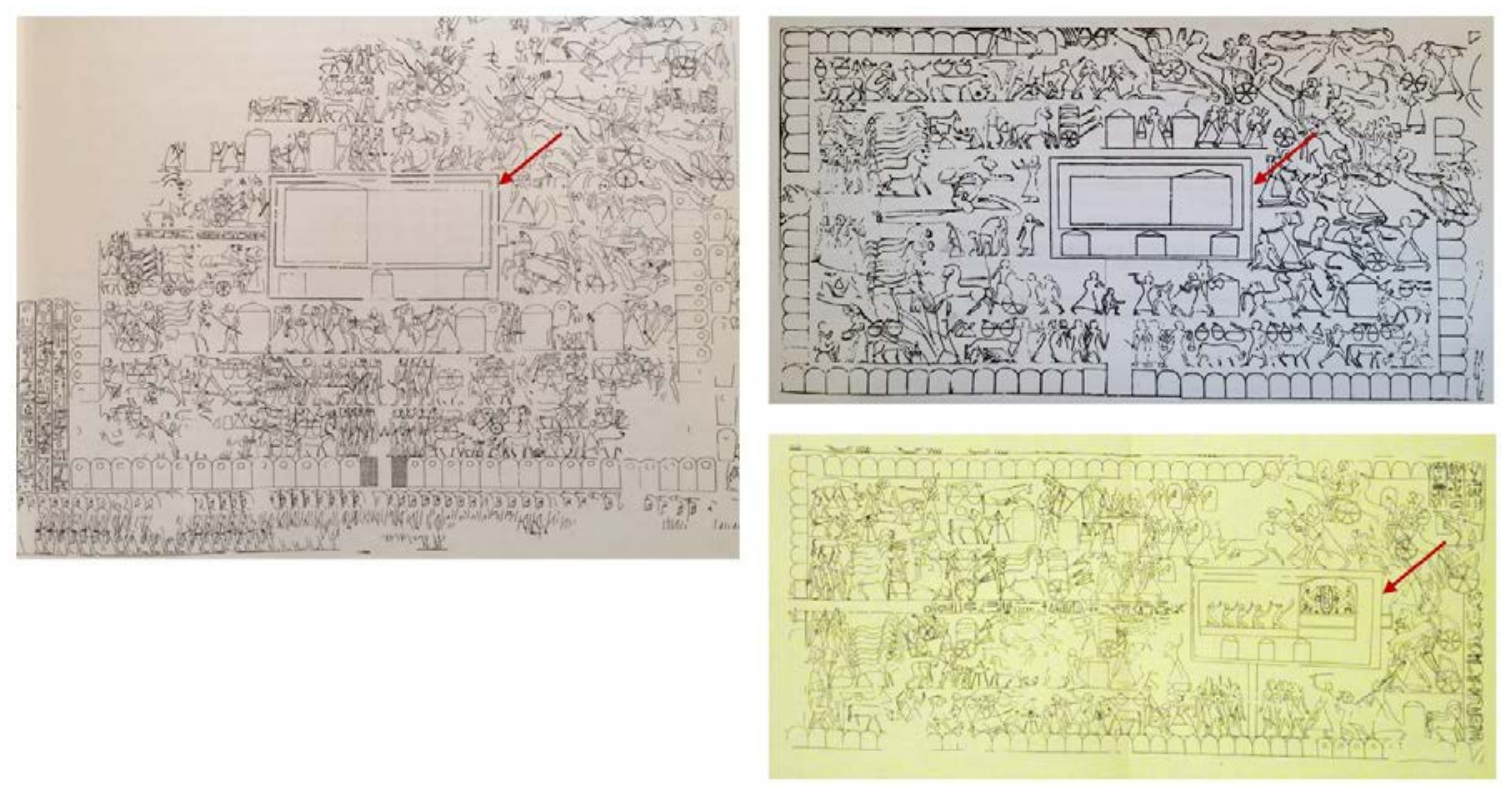

92. Mobile military camp collogue (Yadin 1959: 107, 109; Desroches-Nobelcourt, Donadoni, and Edel 1971: plate 1) 

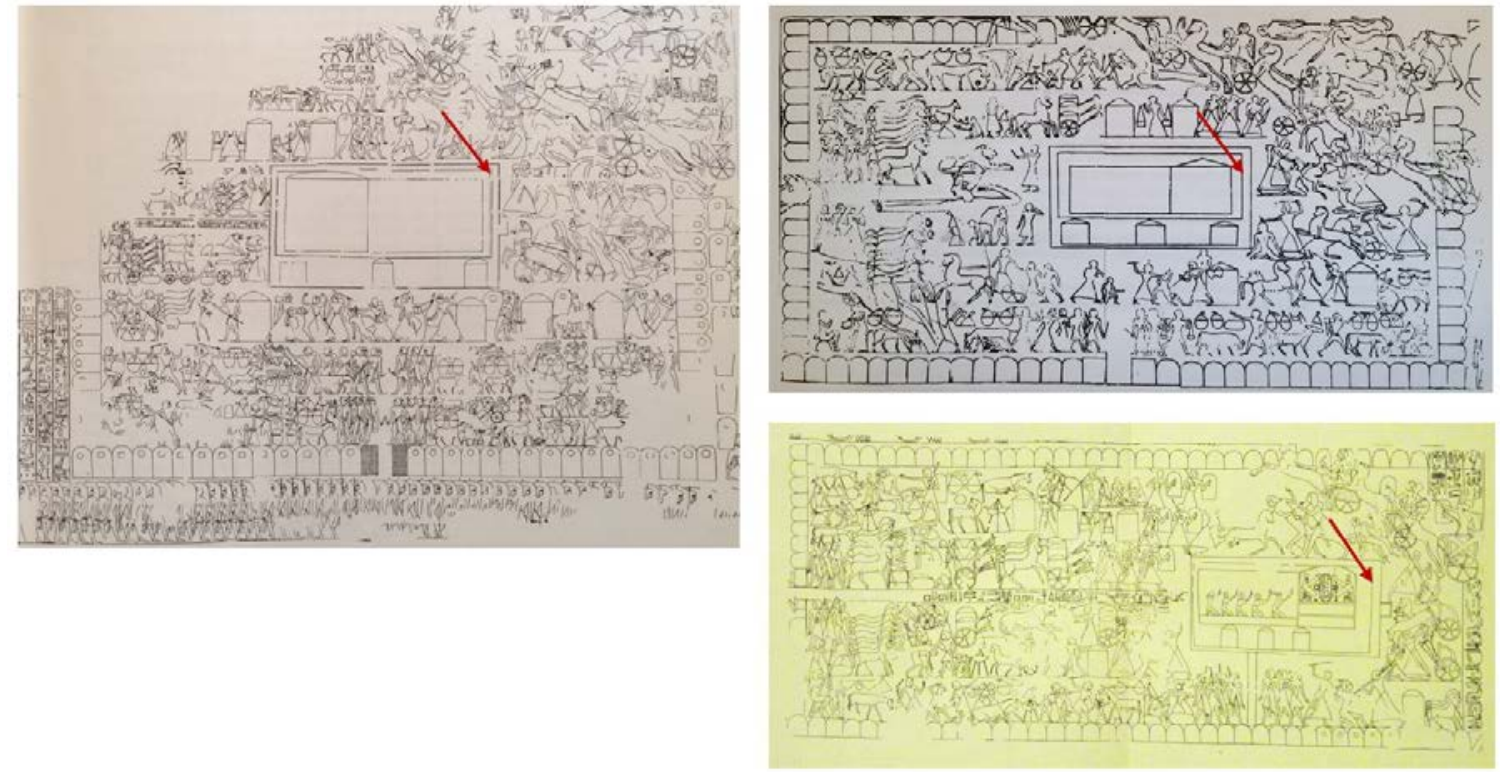

93. Mobile military camp collogue (Yadin 1959: 107, 109; Desroches-Nobelcourt, Donadoni, and Edel 1971: plate 1)

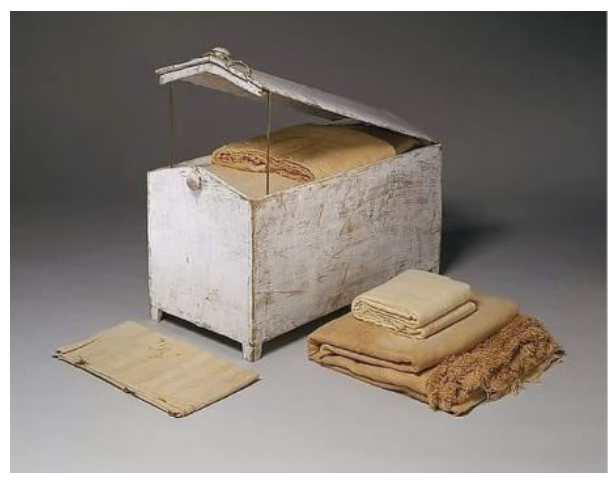

94. Linen chest from reign of Thutmose II (36.3.56 a, b) (Land_of_Gods [@the_holy_egypt] 2018)

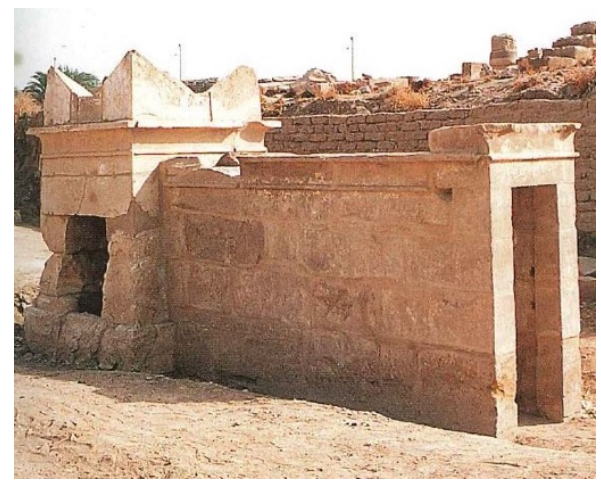

95. Stone altar (Wilkinson 2000: 69) 


\section{REFERENCE LIST}

Aharoni, Y.

1967 The Land of the Bible: A Historical Geography. Translated by A. F. Rainey. Philadelphia: Westminster Press.

Ahlström, G. W.

1991 The Origin of Israel in Palestine. Scandinavian Journal of the Old Testament. 5/2: 19-34.

Ahmad, Y.

2006 The Scope and Definitions of Heritage: From Tangible to Intangible.

International Journal of Heritage Studies, 12/3: 292-300.

Alexander, T. D.

2017 Appolos Old Testament Commentary: Exodus, eds. D. W. Baker and G. J. Wenham. Downers Grove, IL: InterVarsity Press.

Alexander, Jr., K. D.

2002 Ark of the Covenant: Simplified Information for Lay-Persons. Oxford: University of America.

Aling, C. F.

1979 The Sphinx Stele of Thutmose IV and the Date of the Exodus. Journal of the Evangelical Theological Society 22: 97-101.

Allen, J. P.

2000 Middle Egyptian: An Introduction to the Language and Culture of Hieroglyphs. Cambridge: Cambridge University Press.

2013 The Ancient Egyptian Language: An Historical Study. Cambridge: Cambridge University Press.

Allen, S. J.

2006 Tutankhamun's Tomb: The Thrill of Discovery. New York: The Metropolitan Museum of Art.

Altman, J.

1979 Gold in Ancient Palestine: Methods of Fabrication in Successive Cultures. Gold Bulletin 12/2: 75-82. 
Amenta, A., and De Luca, A.

2005 The Treasures of Tutankhamun and the Egyptian Museum of Cairo. Thailand: White Star Publishers.

Andreasen, N-E.

1981 The Heavenly Sanctuary in the Old Testament. Pp. 67-86 in The Sanctuary and the Atonement, eds. A. Wallenkampf and R. Lesher. Washington, DC: Biblical Research Institute.

Anstey, M.

1913 The Romance of Bible Chronology: An Exposition of the Meaning, and a Demonstration of the Truth, of every Chronological Statement Contained in the Hebrew Text of the Old Testament. London: Marshall Brothers, LTD.

Aptowitzer, V.

1931 The Celestrial Temple as Viewed in the Aggadah. Adapted by A. Rubinstein. Jerusalem: International Center for University Teaching of Jewish Civilization.

Archer, Jr., G. L.

1974 A Survey of Old Testament Introduction, rev. ed. Chicago: Moody Press.

Arnold, B. T., and Beyer, B. E.

1999 Encountering the Old Testament: A Christian Survey. Grand Rapids, MI: Baker Books.

Assmann, J.

2001 The Search for God in Ancient Egypt. Translated by D. Lorton. Ithaca, NY: Cornell University Press.

2002 Prayers, Hymns, Incantations, and Curses: Egypt. Pp. 350-53 in Religions of the Ancient World: A Guide, ed. by S. Johnston. Cambridge, MA: Belknap Press of Harvard University Press.

2014 From Akhenaten to Moses: Ancient Egypt and Religious Change. Cairo: The American University in Cairo Press.

Åström, P.

1987 High, Middle or Low? Acts of an International Colloquium on Absolute Chronology held at the University of Gothenburg 20-22 August 1987, Part 1 (of 2 Parts). Gothenburg: Paul Åströms Förlag.

1989 High, Middle or Low? Acts of an International Colloquium on Absolute Chronology held at the University of Gothenburg 20-22 August 1987, Part 3. Gothenburg: Paul Åströms Förlag. 
Auchincloss, W. S.

1908 Auchincloss' Chronology of the Holy Bible. New York: D. Van Nostrand Company.

Averbeck, R. E.

2003 Tabernacle. Pp. 807-27 in Dictionary of the Old Testament: Pentateuch, eds. T. D. Alexander and D. W. Baker. Downers Grove, IL: InterVarsity Press.

Badawi, A. Z.

1948 Memphis als zweite Landeshauptstadt im neuen Reich. Imprimerie de l’institute français d'archéologie orientale.

Badawy, A.

1968 A History of Egyptian Architecture: The Empire (the New Kingdom), from the Eighteenth Dynasty to the End of the Twentieth Dynasty 1580-1085 B.C. Berkeley: University of California Press.

Bähr, K. C. W. F.

1837 Symbolik des Mosaischen Cultus. Vol. 1.

Bárta, M.

2003 Sinuhe, the Bible, and the Patriarchs. Translation by R. Landgráfová. Roman Míšek: Set Out.

Becker, L., Pilosi, L., and Schorsch, D.

1994 An Egyptian Silver Statuette of the Saite Period - a Technical Study. Metropolitan Museum Journal 29: 37-56.

Beecher, D. D.

1907 The Dated Events of the Old Testament: Being a Presentation of Old Testament Chronology. Philadelphia: The Sunday School Times Company.

Bell, C.

1992 Ritual Theory, Ritual Practice. Oxford: Oxford University Press.

1997 Ritual: Perspectives and Dimensions. Oxford: Oxford University Press.

Bietak, M.

1975 Tell el-Dab'a II: Der Fundort im Rahmen einer ArchäologischGeographischen Untersuchung über das Ägyptische ostdelta. Vienna: Verlag der Österreichischen Akademie der Wissenschaften. 
2002 Relative and Absolute Chronology of the Middle Bronze Age: Comments on the Present State of Research. Pp. 29-42 in The Middle Bronze Age in the Levant, ed. M. Bietak. Wien: Österreichische Akademie der Wissenschaften.

2005a The Tuthmoside Stronghold Peru-nefer. Egyptian Archaeology 27/1: 1317.

2005b Neue Paläste aus der 18. Dynastie. Pp. 131-68 in Structure and Significance (Untersuchungen der Zweigstelle Kairo des Österreichischen Archäologischen Institutes vol. XXVII), ed. P. Jànosi. Vienna.

2007 Taureador Scenes in Tell el-Dab’a (Avaris) and Knossos (Untersuchungen der Zweigstelle Kairo des Österreichischen Archäologischen Institutes vol. XXVII). Vienna.

2009a Peru-nefer: An Update. Egyptian Archaeology 35: 16-17.

2009b Near Eastern Sanctuaries in the Eastern Nile Deltra. Baal, Hors-Série, vol. VI 209-228.

2010a From where came the Hyksos and where did they go. Pp. 139-81 in Current Research, Future Prospects (Proceedings of a Conference in the British Museum 2004) (Orientalia Lovanensia Analecta 192), ed. M. Marée. Leuven.

2010b Minoan Presence in the Pharaonic Naval Base of Peru-nefer. Pp. 11-24 in Cretan Offerings: Studies in Honour of Peter Warren (British School at Athens Studies 18), ed. O. Krzyszowska.

2017 Harbours and Coastal Military Bases in Egypt in the Second Millennium B.C.: Avaris, Peru-nefer, Pi-Ramesse. The Nile: Natural and Cultural Landscape in Egypt 36: 53-70.

Bietak, M. and Forstner-Müller, I.

2003 Ausgrabungen Im Palastbezirk von Avaris, Vorbericht Tell elDab’a/‘Ezbet Helmi Frühjahr 2003. Egypt and the Levant 13: 39-50.

2005 Ausgrabung eines Palastbezirkes der Tuthmosidenzeit bei 'Ezbet Helmi/Tell el-Dab’a, Vorbericht für Herbst 2004 und Frühjahr 2005. Egypt and the Levant 15: 65-100.

Bietak, M., Dorner, J., Jánosi, P., and Von der Driesch, A. 2001 Ausgrabungen in dem Palastbezirk von Avaris, Vorbericht Tell elDab’a/'Ezbet Helmi 1993-2000. Egypt and the Levant 11: 27-129. 
Bietenhard, H.

1951 Die himmlische Welt im Urchristentum und Spätjudentum.

Wissenschaftliche Untersuchungen zum Neuen Testament 2. Tübingen:

Mohr.

Bimson, J.J.

1981 Redating the Exodus and Conquest. Sheffield: The Almond Press.

Blackman, A. M., and Fairman, H. W.

1946 The Consecration of an Egyptian Temple according to the Use of Edfu. Journal of Egyptian Archaeology 32: 75-91.

Blake, J.

2000 On Defining the Cultural Heritage. The International and Comparative Law Quarterly, 49/1: 61-85.

Bliss, S.

1887 Analysis of Sacred Chronology with the Elements of Chronology; and the Numbers of the Hebrew Text Vindicated. Oxford: Oxford University Press.

Bonnet, $\mathrm{H}$.

1926 Die Waffen der Völker des alten Orients. Leipzig: J. C. Hinrichs.

Boreaux, C.

1932 Musee du Louvre: Department des antiquites egyptiennes. Guidecatalogue sommaire II. Paris: Musees Nationaux.

Borghouts, J. F.

1978 Ancient Egyptian Magical Texts. Nisaba: Religious Texts Translation Series 9. Leiden: Brill.

2000 Witchcraft, Magic, and Divination in Ancient Egypt. Pp. 1775-85 in Civilizations of the Ancient Near East, ed. by J. M. Sasson. Peabody, MA: Hendrickson.

Briggs, R. A.

1999 Jewish Temple Imagery in the Book of Revelation, ed. Hemchand Gossai. Studies in Biblical Literature 10. New York: Peter Lang.

Brinkman, J.

1992 The Perception of Space in the Old Testament: An Exploration of the Methodological Problems of its Investigation, Exemplified by a Study of Exodus 25 to 31. Kampen, Netherlands: Kok Pharos.

Brugsch, E.

1889 La Tente Funéraire de la Princesse Isimkheb. Le Caire 
Bruins, H. J.; van der Plicht, J.; and MacGillivray, J. A.

2009 The Minoan Santorini Eruption and Tsunami Deposits in Palaikastro (Crete): Dating by Geology, Archaeology, 14C, and Egyptian Chronology. Radiocarbon 51/2: 397-411.

Carter, $\mathrm{H}$.

1963 The Tomb of Tut·Ankh·Amen: Discovered by the Late Earl of Carnarvon and Howard Carter. 3 volumes. New York: Cooper Square Publishers, Inc.

Carter, H., and Newberry, P. E.

1904 Services des Antiquités de L'Égypte Catalogue Général des Antiquités Égyptiennes du Musée du Caire, Nos 46001-46529: The Tomb of Thoutmôsis, IV. Westminster: Archibald Constable and Co.

Casperson, L. W.

1988 The Lunar Date of Ramesses II. Journal of Near Eastern Studies, 47/3: $181-84$.

Černý, J.

1952 Ancient Egyptian Religion. London: Hutchinson’s University Library.

Chambers, L. T.

1958 Tabernacle Studies. Grand Rapids, MI: Zondervan.

Christophe, L. A.

1965 Abou-Simbel et L’Épopée de sa Découverte. Bruxelles: P. F. Merckx.

Cline, E. H.

2007 From Eden to Exile: Unraveling Mysteries of the Bible. Washington D.C.:

National Geographic.

Collombert, P. and Coulon, L.

2000 Les dieux contre la mer, le début du "papyrus d'Astarte” (Pbn 202).

Bulletin de l'Institut Français d'Archéologie Orientale 100: 193-242.

Comfort, P. W. and Elwell, W. A.

2001 Tyndale Bible Dictionary. Carol Stream, IL: Tyndale House Publishers.

Coulthard, M.

2004 Author identification, idiolect, and linguistic uniqueness. Applied Linguistics 25/4: 431-447.

Cross, Jr., F. M.

1947 The Tabernacle: A Study from an Archaeological and Historical Approach. Biblical Archaeologist 10/3: 45-68. 
1961 The Priestly Tabernacle. Pp. 201-28 in The Biblical Archaeologist Reader, eds. G. E. Wright and D. N. Freedman. New York: Anchor Books.

1984 The Priestly Tabernacle in the Light of Recent Research. Pp. 91-105 in The Temple in Antiquity Ancient Records and Modern Perspectives, ed. T. G. Madsen. Provo: Religious Studies Center, Brigham Young University.

2000 From Epic to Canon: History and Literature in Ancient Israel. Baltimore, MD: Johns Hopkins University Press.

Dalley, S.

2000 Hebrew Tahaš, Akkadian Duhšu, faience and beadwork. Journal of Semitic Studies 45: 1-19.

Daressy, G.

1928 Les branches du Nil sous la XVIIIe dynastie. Bulletin de la Société Royale de Géographie d'Égypte 16: 225-54, 293-329.

Darnell, J. C. and Manassa, C.

2007 Tutankhamun's Armies: Battle and Conquest During Ancient Egypt's Late Eighteenth Dynasty. Hoboken: John Wiley and Sons, Inc.

David, A. R.

1981 A Guide to Religious Ritural at Abydos. Warminster: Aris \& Philips.

Davidson, R. M.

1981 The Heavenly Sanctuary in the Old Testament. Adventist Heritage Center, Berrien Springs, MI.

Davies, N. de G.

1943 The Tomb of Rekh-Mi-Re at Thebes. Volume I, II. New York:

Metropolitan Museum of Art.

Davis, J. J.

1971 Moses and the Gods of Egypt. Grand Rapids: Baker Book House.

Dawson, W.

1926 Making a Mummy. Journal of Egyptian Archaeology 13/1/2: 40-49.

De Bruyn, P.

1955 A Graffito of the Scribe Dhuthotpe, Reckoner of Gold, in the Southeastern Desert. Journal of Egyptian Archaeology 41: 121-22. 
De Souza, E. B.

2005 The Heavenly Sanctuary/Temple Motif in the Hebrew Bible: Function and Relationship to the Earthly Counterparts. Adventist Theological Society Dissertation Series.

Der Manuelian, P.

1987 Studies in the Reign of Amenophis II. (Hildesheimer Ägyptologische Studien 26) Hildesheim.

Desroches-Noblecourt, C.

1951 Deux grandes obélisques précieux d'un sanctuaire à Karnak: Les Egyptiens ont-ils érigé des obélisques d'électrum? Revue d'Egyptologie 8: 47-61.

1969 Life and Death of a Pharaoh: Tutankhamun. London: The Connoisseur and Michael Joseph.

Desroches-Noblecourt, C.; Donadoni, S.; and Edel, E.

1971 Grand Temple D’Abou Simbel la Bataille de Qadech. Caire: Centre de Documentation et D'Etudes sur l'Ancienne Egypte.

Dever, W. G.

1991 Tell el-Dab’a and Levantine Middle Bronze Age Chronology: A Rejoinder to Manfred Bietak. Bulletin of the American Schools of Oriental Research, 281: 73-9.

2002 What Did the Biblical Writers Know \& When Did They Know It? Cambridge: William B. Eerdmans Publishing Company.

Dorner, J.

1999 Die Topographie von Piramesse. Egypt and the Levant 9: 77-83.

Drennan, R. D.

1996 Statistics for Archaeologists: A Commonsense Approach. New York: Plenum Press.

Drower, M., ed.

2004 Letters from the Desert: The Correspondence of Flinders and Hilda Petrie. Oxford: Aris and Phillips.

Dyer, C. H.

1983 The Date of the Exodus Reexamined. Biblio Sacra 140: 225-43. 
Edel, E.

1977 Die Stelen Amonophis’ II. aus Karnak und Memphis mit dem Bericht über die asiatischen Feldzüge des Königs. Zeitschrift des deutschen Palästina Vereins 69: 97-176.

Edwards, I. E. S.

1976 The Treasures of Tutankhamun. New York: The Viking Press.

EES

1882 Announcement. Academy April 1.

2017 Delta Survey. Egyptian Exploration Society. http://deltasurvey.ees.ac.uk/dshome.html.

Ego, B.

1989 Im Himmel wie auf Erden: Studien zum Verhältnis von himmlischer und irdischer Welt im rabbinischen Judentum. Tübingen: J.C.B. Mohr.

Eitan, I.

1925 An Egyptian Loan Word in Isaiah 19. Jewish Quarterly Review 15/3: 41920.

Enns, P.

2000 The Ark (25:10-22; 37:1-9). Pp. 510-12 in Exodus, The NIV Application Commentary: From biblical text...to contemporary life, eds. T. Muck, T. Longman III, J. H. Walton, R. Hubbard, A. Dearman. Grand Rapids, MI: Zondervan.

Epstein, E. M.

1911 The Construction of the Tabernacle. The Monist 21/4: 567-623.

Faulkner, R. O.

2005 Ancient Egptian Book of the Dead. New York: Barnes \& Nobel.

Finegan, J.

1964 Handbook of Biblical Chronology: Principles of Time Reckoning in the Ancient World and Problems of Chronology in the Bible. Princeton, NJ: Princeton University Press.

Finkelstein, I., and Silberman, N. A.

2001 The Bible Unearthed: Archaeology's New Vision of Ancient Israel and the Origins of Its Sacred Text. New York: The Free Press. 
Forbes, R. J.

1954 Extracting, Smelting, and Alloying. Pp. 572-99 in History of Technology, Volume I: From Early Times to Fall of Ancient Empires, eds C. Singer, E. J. Holymyard, A. R. Hall. New York: Oxford University Press.

1956 Studies in Ancient Technology, vol iv. Leiden: Brill.

1957 Studies in Ancient Technology, vol v. Leiden: Brill.

1963 Studies in Ancient Technology, vol vii. Leiden: Brill.

1964a Studies in Ancient Technology, vol viii. Leiden: Brill.

1964b Studies in Ancient Technology, vol ix. Leiden: Brill.

Forstner-Müller, I.

2009 Providing a Map of Avaris. Egyptian Archaeology 34: 10-13.

2014 Avaris, its harbours and the Perunefer problem. Egyptian Archaelogy 45: 32-35.

Forstner-Müller, I., Herbich, T., Müller, W., Schweitzer, C., and Weissl, M.

2007 Geophysical Survey 2007 at Tell el-Dab’a. Egypt and the Levant 17: 97106.

2010 Preliminary Report on the Geophysical Survey at Tell el-Dab'a/Qantir in Spring 2009 and 2010. Jahreshefte des ÖsterreichischenArchäologischen Institutes in Wien 79: 67-85.

Francisco, C. T.

1977 The Exodus in its Historical Setting. Southwestern Journal of Theology 20/Fall: 3-20.

Frandsen, P. J.

2000 On the Origin of the Notion of Evil in Ancient Egypt. Göttinger Miszellen 179: 9-34.

2004 Sin, Pollution, and Purity: Egypt. Pp. 497-99 in Religions of the Ancient World: A Guide, ed. by S. Johnston. Cambridge, MA: Belknap Press of Harvard University Press.

Frankfort, H.

1948 Kingship and the Gods: A Study of Ancient Near Eastern Religion as the Integration of Society \& Nature. Chicago: The University of Chicago Press. 
Friedman, F. D.

1994 Aspect of Domestic Life and Religion. Pp. 95-117 in Pharaoh's Workers: The Villageers of Deir el Medina, ed. L. H. Lesko. London: Cornell University Press.

Friedman, R. E.

1980 The Tabernacle in the Temple. The Biblical Archaeologist 43/4: 241-48.

1987 Who Wrote the Bible? Englewood Cliffs, NJ: Prentice Hall.

1992 Tabernacle. Pp. 292-300 in vol. 6 of The Anchor Bible Dictionary, eds. D. N. Freedman, G. A. Herion, D. F. Graf, J. D. Pleins. New York:

Doubleday.

Gale, R., Gasson, P., Hepper, N., and Killen G.

2000 Wood. Pp. 334-71 in Ancient Egyptian Materials and Technology, eds. P. T. Nicholson and I. Shaw. Cambridge: Cambridge University Press.

Gane, R. E.

1992 Ritual Dynamic Structure: Systems Theory and Ritual Syntax Applied to Selected Ancient Israelite, Babylonian, and Hittite Festival Days.

1999 Atlar Call. Fife, Scotland: Diadem.

2004 Leviticus 19. Pp. 333-58 in Leviticus, Numbers The NIV Application Commentary: From biblical text...to contemporary life, eds. T. Muck, T. Longman III, J. H. Walton, R. Hubbard, A. Dearman. Grand Rapids, MI: Zondervan.

2005 Cult and Character: Purification Offerings, Day of Atonement, and Theodicy. Winona Lake, IN: Eisenbrauns.

Ganor, S.

2017 Israel Antiquities Authority. via http://mfa.gov.il/mfa/israelexperience/ history/pages/engravings-of-a-seven-branched-menorah-and-a-crossdiscovered-by-hikers-3-january-2017.aspx\#

Gardiner, A. H.

1920 The Ancient Military Road between Egypt and Palestine. The Journal of Egyptian Archaeology 6/2: 99-116.

1924 The Geography of the Exodus: An Answer to Professor Naville and Others. The Journal of Egyptian Archaeology 10/1: 87-96.

1978 Egypt of the Pharaohs. Oxford: Oxford University Press. 
Garrett, D. A.

2014 A Commentary on Exodus. Grand Rapids, MI: Kregel Academic.

Garstang, J. and Garstang, J. B. E.

1948 The Story of Jericho, rev. ed. London: Marshall, Morgan, and Scott.

Geraty, L. T.

2013 Exodus Dates and Theories. Pp. 55-64 in Israel's Exodus in

Transdisciplinary Persepective, eds. T. E. Levy, T. Schneider, and W. H.

C. Propp. London: Springer International Publishing.

Glanville, S.

1931 Records of a Royal Dockyard of the Time of Thuthmosis III. Papyrus

British Museum 10056. Zeitschrift für ägyptische Sprache und

Altertumskunde 66: 105-21.

1932 Records of a Royal Dockyard of the Time of Thuthmosis III. Papyrus British Museum 10056. Zeitschrift für ägyptische Sprache und Altertumskunde 68: 7-41.

Glueck, N.

1940 The Other Side of the Jordan. New Haven, CT: American Schools of Oriental Research.

Goedicke, H., ed.

1985 Perspectives on The Battle of Kadesh. Baltimore: Halgo.

1987a Papyrus Anastasi IV 51-61. Studien zur Altägyptischen Kultur 14: 83-98.

1987b Ramesses II and the Wadi Tumilat. Varia Aegyptiaca 3/1: 13-24.

Goelet, O.

2016 Tomb Robberies in the Valley of the Kings. Pp. 448-467 in The Oxford Handbook of the Valley of the Kings, eds. R. H. Wilkinson and K. R. Weeks. Oxford: Oxford University Press.

Goodenow, S. B.

1896 Bible Chronology: Carefully Unfolded. New York: Fleming H. Revell Company.

Gray, G. B.

1908 The Heavenly Temple and the Heavenly Altar. The Expositor 5: 385-402. 
Greenberg, G.

2004 Manetho: A Study in Egyptian Chronology; How Ancient Scribes Garbled an Accurate Chronology of Dynastic Egypt. Warren Center, PA: Marco Polo Monographs.

Gutfeld, O.

2009 Excavation report. via http://www.hadashot-esi.org.il/ report_detail_eng.aspx?id=1065

Haas, H.; Devine, J.; Wenke, R.; Lehner, M.; Wolfli, W.; and Bonani, G.

1987 Radiocarbon Chronology and the Historical Calendar in Egypt. Pp. 585606 in Chronologies in the Near East: Relative Chronologies and Absolute Chronology 16,000-4,000 B.P.: C.N.R.S. International Symposium, Lyon (France), 24-28 November 1986, Vol. 2, ed. O. Aurenche. Oxford, England: B.A.R.

Habachi, L.

1974 Sethos Ist Devotion to Seth and Avaris. Zeitschrift für ägyptische Sprache und Altertumskunde 100: 95-102.

2001 Tell el-Dab’a I, Tell el-Dab'a and Qantir: The Site and its Connection with Avaris and Piramesse. Untersuchungen der Zweigstelle Kairo des Österreichischen Archäologischen Institutes vol. II, ed. E.-M. Engel, et al. Vienna.

Hamerton-Kelly, R. G.

1970 The Temple and the Origins of Jewish Apocaliptic. Vetus Testamentum 20: 1-15.

Hamza, M.

1930 Excavations of the Department of Antiquities at Qantîr (Faqûs District). Season, May $21^{\text {st }}-$ July $7^{\text {th }}$, 1928. Annales du Service des Antiquitiés de l'Égypte 30: 31-68.

Haran, M.

1962 Shiloh and Jerusalem: The Origin of the Priestly Tradition in the Pentateuch. Journal of Biblical Literature 81/1: 14-24.

Harris, J. R. 1961 Lexiographical Studies in Ancient Egyptian Metals. Berlin: AkademieVerlag. 
Hartenstein, F.

2001 Wolkendunkel und Himmelfeste: Zur Genese und Kosmologie der Vorstellung des himmlischen Heiligtums JHWHs. Pp. 125-79 in Das biblische Weltbild und seine altorientalischen Kontexte, eds. B. Janowski and B. Ego. Tübingen: Mohr Siebeck.

Hasel, M. G.

1994 Israel in the Merneptah Stele. Bulletin of the American Schools of Oriental Research 296: 45-61.

Hawass, Z., and Vannini, S.

2007 King Tutankhamun: The Treasures of the Tomb. London: Thames and Hudson.

Hayes, W. C.

1937 Glazed Tiles from a Palace of Ramesses II at Kantir. New York.

Helck, W.

1939 Der Einfluss der Militärführer in der 18. Ägyptischen Dynastie. Leipzig.

1971 Die Beziehungen Ägyptens zu Vorderasien im 3. und 2. Jahrtausend v. Chr. (Ägyptologische Abhandlungen 5), $2^{\text {nd }}$ ed. Wiesbaden.

Hendrix, R. E.

1989 An Analysis of MSKN and 'HL MW'D in the Masoretic Text of Exodus 25-40. M.A. thesis, Andrews University.

Hoffmeier, J. K.

1977 Tents in Egypt and the Ancient Near East. Journal (The) of the Society for the Study of Egyptian Antiquities Newsletter 7/3: 13-28.

1985 "Sacred" in the Vocabulary of Ancient Egypt: The Term D $\underline{S} R$, with Special Reference to Dynasties I-XX. Oribis Biblicus et Orientalis 59. Fribourg: Universitätsverlag.

1996 Israel in Egypt: The Evidence for the Authenticity of the Exodus Tradition. Oxford: Oxford University Press.

2005 Ancient Israel in Sinai. Oxford: Oxford University Press.

2015 Akhenaten and the Origins of Monotheism. Oxford: Oxford University Press. 
Holbrook, F. B., ed.

1989a The Doctrine of the Sanctuary: A Historical Survey (1845-1863). Daniel and Revelation Committee Series, vol. 5. Silver Spring, MD: Biblical Research Institute of the General Conference of Seventh-day Adventists.

1989b The Sanctuary and the Atonement: Biblical, Theological, and Historical Studies. Abridged. Silver Spring, MD: Biblical Research Institute of the General Conference of Seventh-day Adventists.

Holladay, Jr., J. S.

1982 Cities of the Delta, Part III: Tell el-Maskhuta: Preliminary Report on the Wadi Tumilat Project 1978-1979. Malibu: Undena Publications.

Homan, M. M.

2000 The Divine Warrior in His Tent: A Military Model for Yahweh’s Tabernacle. Bible Review 16/6: 22-33, 55.

2002 To Your Tents, O Israel! The Terminology, Function, Form, and Symbolism of Tents in the Hebrew Bible and the Ancient Near East. Leiden: Brill.

Hornung, E.

1982 Tal der Könige: Die Ruhestätte der Pharaonen. Zürich.

1983 Conceptions of God in Ancient Egypt: The One and the Many. Translated by J. Baines. London: Routledge \& Kegan Paul.

Hornung, E. Krauss, R., and Warburton, D. A., eds.

2006 Ancient Egyptian Chronology. Boston: Brill.

Horowitz, D.

2015 News article. via http://www.timesofisrael.com/ancient-jewish-necropolisnamed-world-heritage-site/

Hundley, M. B.

2011 Keeping Heaven on Earth: Safeguarding the Divine Presence in the Priestly Tabernacle. Tübingen, Germany: Mohr Siebeck.

2013 Gods in Dwellings: Temples and Divine Presence in the Ancient Near East. Atlanta: Society of Biblical Literature.

Hurowitz, V. A.

1985 The Priestly Account of Building the Tabernacle. Journal of the American Oriental Society 105/1: 21-30. 
Hurvitz, A.

1967 The Usage of \#\# and Cwb in the Bible and its implication to the Date of P. Harvard Theological Review 60/1: 117-21.

Izuchi, Y., Takashima, T, and Hatano, N.

2016 Rapid and Accurate Identification of Animal Species in Natural Leather Goods by Liquid Chromatography/Mass Spectrometry. Mass Spectrom (Tokyo) 5/1. https://www.ncbi.nlm.nih.gov/pmc/articles/MPC4894823

Jacob, B.

1992 The Second Book of the Bible, Exodus. Translated by W. Jacob. Hoboken, NJ: KTAV.

James, T. G. H.

1972 Gold Technology in Ancient Egypt: Mastery of Metal Working Methods.

Gold Bulletin 5.2: 38-42.

1982 Excavating in Egypt: The Egyptian Exploration Society 1882-1982.

Chicago: The University of Chicago Press.

2009 Tutankhamun: The Eternal Splendor of the Boy Pharaoh. New York: Fall River Press.

Jeffreys, D. G. and Smith, H. S.

1988 Memphis and the Nile in the New Kingdom. Pp. 55-66 in Memphis et ses nécropoles au Nouvel Empire, ed. A.-P. Zivie. Paris.

Jones, F. N.

2004 The Chronology of the Old Testament. Green Forest, AR: Master Books.

Kamish, M.

1985 Foreigners at Memphis in the Middle of the $18^{\text {th }}$ Dynasty. Wepwawet 1: 12-13.

1986 Problems of Toponymy with Special Reference to Memphis and Prw-nfr. Wepwawet 2: 32-36.

Kanawati, N. and Evans, L.

2014 Beni Hassan. Volume I: The Tomb of Khnumhotep II. Oxford: Aris and Philips.

Kemp, B.

2012 The City of Akhenaten and Nefertiti: Amarna and Its People. London: Thames and Hudson. 
Kenyon, K. M.

1951 Some Notes on the History of Jericho in the Second Millennium B.C. Palestinian Exploration Quarterly. 83/2: 101-38.

Kiene, P. F.

1984 The Tabernacle of God in the Wilderness. Grand Rapids: Zondervan Publishing House.

Killen, G.

1980 Ancient Egyptian Furniture: vol 1 4000-1300 B.C. Warminster, England: Aris and Phillips Ltd.

Kim, S.

2002 The Heavenly Sanctuary/Temple in the Hebrew Bible. Unpublished Ph. D. Dissertation, University of Sheffield.

Kitchen, K. A.

1960 Some Egyptian Backgrounds to the Old Testament. Tyndale Bulletin 5: 713.

1966 Ancient Orient and Old Testament. Downers Grove, IL: InterVarsity Press.

1977 The Bible in its World: The Bible and Archaeology Today. Downers Grove, IL: InterVarsity Press.

1991 The Chronology of Ancient Egypt. World Archaeology 23: 201-08.

1993 The Tabernacle-A Bronze Age Artifact. Eretz-Israel 24 (Avaham Malamat Volume): 119*-29*. (The * indicates the English side of the volume.)

2000 The Desert Tabernacle: Pure Fiction or Plausible Account? Bible Review 16/6: 14-21.

2003 On the Reliability of the Old Testament. Grand Rapids: Eerdmans.

Kitchen, K. A. and Mitchell, T. C.

1980 Chronology (OT). The Illustrated Bible Dictionary, eds. H. Hillyer and J. D. Douglas. Leicester: Inter-Varsity Press.

Knobel, A.

1857 Exodus. Pp. 272-73 in Kurzgef. exeg. Handbuch d. A. T. Leipsic. 
Krauss, R.

1986 Zum archäologischen Befund im thebanischen Königsgrab Nr. 62.

Mitteilungen der Deutschen Orientgesellschaft 118: 165-81.

Kuniholm, P.; Kromer, B.; Manning, S. W.; Newton, M.; Latini, C. E.; and Bruce, M. J. 1996 Anatolian Tree Rings and the Absolute Chronology of the Eastern Mediterranean, 2220-718 BC. Nature 381: 780-83.

Kurin, R.

2004 Safeguarding Intangible Cultural Heritage in the 2003 UNESCO

Convention: a critical appraisal. Museum International 56/221-22: 66-77.

LaBianca, Ø.S.

2007 Thinking Globally and also Locally: Anthropology, History, and Archaeology in the Study of Jordan's Past. Pp. 1-9 in Crossing Jordan: North American Contributions to the Archaeology of Jordan, eds. T. E. Levy, P. M. M. Daviau, R. W. Younker, and M. Shaer. London: Equinox Publishing Ltd.

Lambdin, T. O.

1962 Pithom. P. 821 in vol. 3 of Interpreters Dictionary of the Bible, ed. G. A. Buttrick. New York: Abingdon Press.

Land_of_Gods [@the_holy_egypt]

2018 [A towels linen storage box dating back to the reign of King Tuthmosis II of Egypt around the year 1492-1473 BC]. Retrieved from https://www .instagram.com/p/Bq-piBbBzTa/

Leclant, J.

1969 Espace et temps: Ordre et chaos dans l'Egypte pharaonique. Revue de Synthese 90/55-56: 217-39.

Lee, $\mathrm{P}$.

2001 The New Jerusalem in the Book of Revelation: A Study of Revelation 2122 in the Light of Its Background in Jewish Tradition. Wissenschaftliche Untersuchungen zum Neuen Testament 2/129. Tübingen: Mohr Siebeck.

Levine, B. A.

1965 The Descriptive Tabernacle Texts of the Pentateuch. Journal of the American Oriental Society 85/3: 307-18.

1993 Lpny YHWH - Phenomenology of the Open-Air-Altar in Biblical Israel. Pp. 196-205 in Biblical Archaeology Today, 1990: Proceedings of the Second International Congress on Biblical Archaeology, eds. A. Biran and J. Aviram. Jerusalem: Israel Exploration Society. 
Levy, T. E., and Higham, T. F. G., eds.

2005 The Bible and Radiocarbon Dating: Archaeology, Text and Science. London: Equinox.

Lichtheim, M.

1976 Ancient Egyptian Literature: A Book of Readings. Volume 2: The New Kingdom. Berkeley: University of California Press.

Lorton, D.

1999 The Theology of Cult Statues in Ancient Egypt. Pp. 123-210 in Born in Heaven, Made on Earth: The Making of the Cult Image in the Ancient Near East, ed. by M. B. Dick. Winona Lake, IN: Eisenbrauns.

Lucas, A.

1962 Ancient Egyptian Materials and Industries. London: Edward Arnold.

Lucas, A. and Harris, J. R.

1999 Ancient Egyptian Materials and Industries. Mineola, NY: Dover Publications.

MacQuitty, W.

1965 Abu Simbel. New York: G.P. Putnam’s Sons.

Mauro, P.

1922 The Chronology of the Bible. New York: George H. Doran Company.

May, H. G., ed.

1962 Oxford Bible Atlas. London: Oxford University Press.

McDowell, A. G.

1999 Village Life in Ancient Egypt: Laundry Lists and Love Songs. Oxford: Oxford University Press.

McNicol, A. J.

1974 The Relationship of the Image of the Highest Angel to the High Priest Concept in Hebrews. Unpublished Ph. D. Dissertation, Vanderbilt University.

1987 The Heavenly Sanctuary in Judaism: A Model for Tracing the Origin of an Apocalypse. Journal of Religious Studies 13/2: 66-94.

Meeks, D.

1975 Pureté et purification en Égypte. Supplément au Dictionnaire de la Bible 9, ed. by H. Cazelles and A. Feuillet. 430-52. 
1999 The Daily Life of the Egyptian Gods. Translated by G. M. Goshgarian. London: Pimlico.

Mercer, S. A. B.

1949 The Religion of Ancient Egypt. London: Luzac \& Co.

Merkel, J. F.

1995 Egyptian New Kingdom Copper Smelting - Smelting Experiments. Pp. 22 in Abstracts of the International Conference on Ancient Egytian Mining and Metallurgy and Conservation of Metallic Artifacts (April 10-12, 1995). Cairo: Ministry of Culture, Supreme Council of Antiquities.

Merrill, E. H.

1966 An Historical Survey of the Old Testament. Grand Rapids: Baker Book House.

Meskell, L.

2002 Private Life in New Kingdom Egypt. Princeton: Princeton University Press.

Metzger, M.

1970 Himmliche und Irdische Wohnstatt Jahwes. Ugarit-Forschungen 2: 13958.

Meyer, M.

2012 Placing and tracing absence: A material culture of the immaterial. Journal of Material Culture, 17/1: 103-110.

Meyers, C. L.

1976 The Tabernacle Menorah: A Synthetic Study of a Symbol from the Biblical Cult. Edited by D. N. Freedman. Missoula, MO: Scholars Press for The American Schools of Oriental Research.

1982 The Elusive Temple. Biblical Archaeologist 45/1: 37.

Milgrom, J.

1990 Numbers: The Traditional Hebrew Text with the New JPS Translation. Philadelphia: Jewish Publications Society.

1996 Law and Narrative and the Exegesis of Leviticus XIX 19. Vetus Testamentum 46/4: 544-48.

Moles, A. A., and Jacobus, D. W. 1988 Design and Immateriality: What of It in a Post Industrial Society? Design Issues, 40/1/2: 25-32. 
Moorey, P. R. S.

1991 A Century of Biblical Archaeology. Louisville, KY: Westminster/John Knox Press.

Morkot, R. G.

2005 The Egyptians: An Introduction. London: Routledge.

Morgenstein, M. E. and Redmount, C. A.

1998 Mudbrick Typology, Sources, and Sedimentological Composition: A Case

Study from Tell el-Muqdam, Egyptian Delta. Journal of the American

Research Center in Egypt 35: 129-46.

Muchiki, Y.

1999 Egyptian Proper Names and Loanwords in North-west Semitic. Atlanta:

Society of Biblical Literature.

Naville, E.

1887 The Shrine of Saft el Henneh and the Land of Goshen (1885). London:

Egypt Exploration Fund.

1903 The Store-City of Pithom and the Route of the Exodus. London: Egypt Exploration Fund.

Newberry, P.

1894 El-Bersheh, vol. 1. London: Egypt Exploration Fund.

Newman, R. and Serpico M.

2000 Adhesives and Binders. Pp. 475-94 in Ancient Egyptian Materials and

Technology, eds. P. T. Nicholson and I. Shaw. Cambridge: Cambridge

University Press.

Newsom, C.

1985 Songs of the Sabbath Sacrifice: A Critical Edition. Harvard Semitic

Studies 27. Atlanta, GA: Scholars Press.

Nibbi, A.

1975 The Sea Peoples and Egypt. Park Ridge, New Jersey: Noyes Press.

Nicholson, P. T. and Shaw, I.

2000 Introduction. Pp. 1-2 in Ancient Egyptian Materials and Technology, eds. P. T. Nicholson and I. Shaw. Cambridge: Cambridge University Press. 
Nixon, H. A.

1984 Typology of the Mosaic Tabernacle: and its Articles as Interpreted by Authors of the Nineteenth and twentieth centuries. Unpublished Ph.D. Dissertation, Drew University.

Noonan, B. J.

2012 Hide or Hue? Defining Hebrew th\#. Biblica 93/4: 580-89.

2016 Egyptian Loanwords as Evidence for the Authenticity of the Exodus and Wilderness Traditions. Pp. 49-67 in Did I Not Bring Israel Out of Egypt? Biblical, Archaeological, and Egyptological Perspectives on the Exodus Narratives, eds. J. K. Hoffmeier, A. R. Millard, and G. A. Rendsburg. Winona Lake, IN: Eisenbrauns.

Noth, M.

1960 The History of Israel. London: Adam and Charles Black.

Oblath, M. D.

2004 The Exodus Itinerary Sites: Their Locations from the Perspective of the Biblical Sources. New York: Peter Lang.

O’Conner, D., and Quirke, S.

2003 Introduction: Mapping the Unknown in Ancient Egypt. Pp. 1-21 in Mysterious Lands, eds. D. O’Conner and S. Quirke. London: Institute of Archaeology, University College London Press.

Ogden, J.

1983 Surface Changes in Buried Gold Items. Pp. 24-6 in Preprints of the Second International Symposium 'Historische Technologie, der Edelmatalle’ 25-28 April, Meersburg.

1993 Aesthetic and Technical Considerations Regarding the Colour and Texture of Ancient Goldwork. Pp. 39-49 in Metal Plating and Patination: Cultural, Technical, and Historical Developments, eds. S. La Niece and P. T. Craddock. London: Butterworth-Heinemann.

2000 Metals. Pp. 148-76 in Ancient Egyptian Materials and Technology, eds. P. T. Nicholson and I. Shaw. Cambridge: Cambridge University Press.

Oren, E. D.

1981 How Not to Create a History of the Exodus - A Critique of Professor Goedicke’s Theories. Biblical Archaeology Review 7/Nov-Dec: 46-53. 
Oswalt, J. N.

1979 Chronology of the Old Testament. International Standard Bible

Encyclopedia. 1:677.

Paine, T. O.

1885 The Holy Houses. Boston: Houghton, Mifflin \& Co.

Papaioannou, K., and Giantzaklidis, I., eds.

2017 Earthly Shadows Heavenly Realities: Temple/Sanctuary Cosmology in Ancient Near Eastern, Biblical, and Early Jewish Literature. Berrien Springs: Andrews University Press.

Parcak, S. H.

2008 Site Survey in Egyptology. Pp. 57-76 in Egyptology Today, ed. R. H. Wilkinson. Cambridge: Cambridge University Press.

Partington, J. R.

1921 A Text-book of Inorganic Chemistry: For University Students. London: Macmillan and Company.

Peet, T.E.

1923 Egypt and the Old Testament. London: Hodder and Stroughton Ltd.

Pelzl, B.

1975 Das Zelt Heiligtum von Ex. 25ff. die frage nach der Möglichkeit seinen Errichtung. Ugarit-Forschungen 7: 370-88.

1976 These zur Entstehung des Zeltsbaurichtes von Ex. 25ff. UgaritForschungen 8: 323-27.

Petrie, W. M. F.

1906 Hyksos and Israelite Cities. London: British School of Archaeology in Egypt and Egyptian Research Account, Publications: 12.

Petrovich, D.

2006 Amenhotep II and the Historicity of the Exodus-Pharaoh. Theological Master's Seminary Journal 17/1: 81-110.

2013 Toward Pinpointing the Timing of the Egyptian Abandonment of Avaris during the Middle of the $18^{\text {th }}$ Dynasty. Journal of Ancient Egyptian Interconnections 5/2: 9-28.

Pfeiffer, C. F.

1963 Tell El Amarna and the Bible. Grand Rapids: Baker Book House. 
Pokrifka, H. J.

2018 Exodus: A Commentary in the Wesleyan Tradition. Kansas City: Beacon Hill Press.

Price, C.

2016 Other Tomb Goods. Pp. 274-89 in The Oxford Handbook of the Valley of the Kings, eds. R. H. Wilkinson and K. R. Weeks. Oxford: Oxford University Press.

Pritchard, J. B., ed.

1969 Ancient Near Eastern Texts Relating to the Old Testament. Third edition. Princeton: Princeton University Press.

Pumpenmeier, F.

1998 Eine Gunstgabe von Seiten des Königs. Ein extrasepulcrales Schabtidepot Qen-Amuns in Abydos (Studien zur Archäologie und Geschichte Altägyptens, 19). Heidelberg.

Quirke, S.

1992 Ancient Egyptian Religion. New York: Dover.

Rabe, V. W.

1966 The Identity of the Priestly Tabernacle. Journal of Near Eastern Studies 25/2: 132-34.

Ray, P. J., Jr.

1997 Problems of Middle and Late Bronze Age Chronology: Toward a Solution. Near East Archaeological Society Bulletin 42: 1-13.

Redmount, C. A.

1989 On an Egyptian/Asiatic frontier: An archaeological history of the Wadi Tumilat Unpublished PhD Dissertation, University of Chicago.

Reeves, N.

1990 The Complete Tutankhamun: The King. The Tomb. The Royal Treasure.

London: Thames and Hudson.

2015 The Burial of Nefertiti? Valley of the Kings: Occasional Paper No. 1. Tucson, AZ: Amarna Royal Tombs Project.

Reeves, N. and Wilkinson, R. H.

1996 The Complete Valley of the Kings: Tombs and Treasures of Egypt's

Greatest Pharaohs. London: Thames and Hudson. 
Reisner, G. A. and Smith, W. S.

1955 A History of the Giza Necropolis II: The Tomb of Hetep-heres the Mother of Cheops. Cambridge, MA: Harvard University Press.

Ritner, R. K.

1993 The Mechanics of Ancient Egyptian Magical Practice. Studies in Ancient Oriental Civilization. Chicago: Oriental Institute of the University of Chicago.

2002a Magic. Pp. 191-98 in The Ancient Gods Speak: A Guide to Egyptian Religion, ed. by D. Redford. Oxford: Oxford University Press.

2002b Magic in Medicine. Pp. 198-204 in The Ancient Gods Speak: A Guide to Egyptian Religion, ed. by D. Redford. Oxford: Oxford University Press.

2002c Magic in Daily Life. Pp. 204-09 in The Ancient Gods Speak: A Guide to Egyptian Religion, ed. by D. Redford. Oxford: Oxford University Press.

Robbins, G.

2005 Cult Statues in Ancient Egypt. Pp. 1-12 in Cult Image and Divine Representation in the Ancient Near East, ed. by N. H. Walls. Boston, MA: American Schools of Oriental Research.

Robins, G.

1984 The Proportions of Figures in the Decoration of the Tombs of Tutankhamun (KV 62) and Ay (KV 23). Göttinger Miszellen 72: 27-32.

2007 The Decorative Program in the Tomb of Tutankhamun. Pp. 321-42 in The Archaeology and Art of Ancient Egypt: Essays in Honor of David B. O’Connor 2, edited by Z. H. Hawass and J. E. Richards. Cairo: Conseil Suprême des Antiquitiés de l’Egypte.

Robinson, E.

1841 Biblical Researches in Palestine and the Adjacent Regions. Boston:

Croker and Brewster.

Röhrig, C. H.

1990 The Eighteenth Dynasty Titles Royal Nurse (mn'.t-nswt), Royal tutor (mn'nswt) and Foster Brother/Sister of the Lord of the Two Lands (sn/snt mn'n $n b$ tzwy). Dissertation Berkeley. Ann Arbor, MI.

Romer

1981 Valley of the Kings. New York: William Morrow. 
Roth, A. M.

2006 The Representation of the Divine in Ancient Egypt. Pp. 24-37 in Text Artifact, and Image: Revealing Ancient Israelite Religion, ed. by G. M. Beckman and T. J. Lewis. Brown Judaic Studies 346. Providence, RI: Brown Judaic Studies.

Ryken, L. and Wilhoit, J. C., eds.

1998 Dictionary of Biblical Imagery. Leicester: InterVarsity Press.

Sarna, N. M.

1991 Exodus: The Traditional Hebrew Text with the New JPS Translation. Philadelphia: Jewish Publications Society.

Sauneron, S.

1966 Le monde du magician égyptien. Pp. 27-65 in Le monde du sorcier: Égypte, Babylone, Hittites, Israël, Islam, Asie centrale, Inde, Nepal, Cambodge, Vietnam, Japon. Ed. S. Sauneron. Paris: Éditions du Seuil.

2000 The Priests of Ancient Egypt. Ithaca: Cornell University.

Säve-Söderbergh, T.

1946 The Navy of the Eighteenth Egyptian Dynasty, Uppsala/Leipzig.

Schaedel, H. D.

1935 Die Listen des grossen Papyrus Harris. Glückstadt, Hamburg: Augustin.

Schiller, R.

1983 The Biblical Exodus: Fact or Fiction. Reader's Digest April: 133-38.

Schwantes, S. J.

1965 A Short History of the Ancient New East. Grand Rapids: Baker Book House.

Schwarz, S.

2000 Altägyptisches Lederhandswerk. Frankfurt: Peter Lang.

Shanks, $\mathrm{H}$.

1981 The Exodus and the Crossing of the Red Sea According to Hans

Goedicke. Biblical Archaeology Review 7/Sept-Oct: 42-50.

Sharkey, S. A.

1986 The Background of the Imagery of the Heavenly Jerusalem in the New Testament. Unpublished Ph. D. Dissertation, Catholic University of America. 
Shaw, I.

2000 Introduction: Chronologies and Cultural Change in Egypt. Pp. 1-16 in The Oxford History of Ancient Egypt, ed. I. Shaw. Oxford: Oxford University Press.

Shea, W. H.

1982 Exodus, Date of the. Pp. 230-38 in vol. 2 of The International Standard Bible Encyclopedia, ed. G. W. Bromiley. Grand Rapids, MI: William B. Eerdmans Publishing Company.

1987 New Light on the Exodus and on Construction of the Tabernacle: Gerster's Protosinaitic Inscription No. 1. Andrews University Seminary Studies 25/1: 73-96.

1992 Sabbath Hymns for the Heavenly Sanctuary. Pp. 391-407 in Symposium on Revelation-Book 1, ed. F. B. Holbrook. Daniel and Revelation Committee Series 7. Silver Spring, MD: Biblical Research Institute.

Smoláriková, K.

2008 Saite Forts in Egypt: Political-Military History of the Saite Dynasty.

Prague: Charles University in Prague.

Snape, S.

2014 The Complete Cities of Ancient Egypt. London: Thames and Hudson.

Spalinger, A. J.

1985 Notes on the Reliefs of the Battle of Kadesh. Pp. 1-42 in Perspectives on The Battle of Kadesh, ed. H. Goedicke. Baltimore: Halgo.

1998 The Limitations of Formal Ancient Egyptian Religion. Journal of Near Eastern Studies 57: 241-60.

2005 War in Ancient Egypt: The New Kingdom. Oxford: Blackwell Publishing. Spiegelberg, W.

1927 La ville de Prw-nfr dans le Delta. Revue de l'Égypte ancienne 1: 215-17.

Stadelmann, R.

1967 Syrisch-palästinensische Gottheiten in Ägypten. Leiden.

Strong, J.

1952 The Tabernacle of Israel in the Desert: With Detailed Plans, Drawings, and Descriptions. Grand Rapids, MI: Baker Book House.

Stuart, V.

1882 The Funeral Tent of an Egyptian Queen. London: John Murray. 
Thompson, J. A.

1982 The Bible and Archaeology, $3^{\text {rd }}$ edition. Grand Rapids: Wm. B. Eerdmans Publishing Co.

Tronchère, $\mathrm{H}$.

2010 Approche paléoenvironnementale de deux sites archéologiques dans le delta du Nil. Avaris et la branche Pélusiaque, Taposiris et le lac Mariout, Thèse présentée à l’Université Lyon 2 le 3 septembre 2010 en vue d’obtenir le grade de Docteur en Géographie, Lyon. Lyon.

Tronchère, H., Salomon, F., Callot, Y., Goiran, J., Schmitt, L., Forstner-Müller, I., and Bietak, M.

2008 Geoarchaeology of Avaris: First Results. Egypt and the Levant 18: 33952.

Thiele, E. R.

1951 The Mysterious Numbers of the Hebrew Kings: A Reconstruction of the Chronology of the Kingdoms of Israel and Judah. Chicago: University of Chicago Press.

Thompson, S. E.

2002 Cults. Pp. 61-71 in The Ancient Gods Speak: A Guide to Egyptian Religion, ed. by D. Redford. Oxford: Oxford University Press.

Tobin, V. A.

2002a Amun and Amun-Re. Pp. 18-20 in The Ancient Gods Speak: A Guide to Egyptian Religion, ed. by D. Redford. Oxford: Oxford University Press.

2002b Myths. Pp. 239-46 in The Ancient Gods Speak: A Guide to Egyptian Religion, ed. by D. Redford. Oxford: Oxford University Press.

2002c Creation Myths. Pp. 246-51 in The Ancient Gods Speak: A Guide to Egyptian Religion, ed. by D. Redford. Oxford: Oxford University Press.

Tylecote, R.

1981 From Pot Bello to Tuyéres. Levant 13: 107-18.

Unger, M. F.

1954 Archaeology and the Old Testament. Grand Rapids: Zondervan Publishing House.

Ussher, J.

1722 Annales Veteris et Novi Testamenti, a prima mundi origine deducti. Genevae: Gabrielem de Tournes et filios. 
Valentine, J.

1987 Theological Aspects of the Temple Motif in the Old Testament and Revelation. Unpublished Ph. D. Dissertation, Boston University.

Van der Veen, $\mathrm{P}$.

2001 Israel in Canaan (Long) Before Pharaoh Merenptah?: A Fresh Look at Berlin Statue Pedestal Relief 21687. Journal of Ancient Egyptian Interconnections, 2/4: 15-25.

Van Driel-Murray, C.

2000 Leatherwork and Skin Products. Pp. 299-319 in Ancient Egyptian Materials and Technology, eds. P. T. Nicholson and I. Shaw. Cambridge: Cambridge University Press.

Van Seters, J.

1966 The Hyksos: A New Investigation. New Haven: Yale University Press.

Velazquez, E.

2008 An Archaeological Reading of Malachi. Ph. D. dissertation, Andrews University.

Veldmeijer, A. J.

2008 Leatherwork. UCLA Encyclopedia of Egyptology. http://escholarship.org/ uc/item/13g5n8th

2009a Studies of Ancient Egyptian Footwear. Technological Aspects Part XV. Leather Curled-Toe Ankle Shoes. PalArch's Journal of Archaeology of Egypt/Egyptology 6/4: 1-21.

2009b Studies of Ancient Egyptian Footwear. Technological Aspects Part VI. Sewn Sandals. Pp. 554-80 in Beyond the Horizon: Studies in Egyptian Art, Archaeology, and History in Honour of Barry J. Kemp, eds. S. Ikram and A. Dodson. Cario: SCA.

2011 Amarna's Leatherwork. Part 1. Preliminary Analysis and Catalogue. Leiden: Sidestone Press.

Veldmeijer, A. J. and Laidler, J.

2008 Leather Work in Ancient Egypt. Pp. 1215-20 in Encyclopedia of the History of Science, Technology, and Medicine. Heidelberg: Springer Verlag.

Vogelsang-Eastwood, G.

2000 Textiles. Pp. 268-98 in Ancient Egyptian Materials and Technology, eds. P. T. Nicholson and I. Shaw. Cambridge: Cambridge University Press. 
Waltke, B. K.

1972 Palestinian Artifactual Evidence Supporting the Early Date of the Exodus. Bibliotheca Sacra 129/513: 33-47.

Weeks, K. R.

2005 Atlas of the Valley of the Kings: Study Edition. Cairo: The American University in Cairo Press.

Weeks, K. R. and De Luca, A.

2001 The Treasures of the Valley of the Kings: Tombs and Temples of the Theban West Bank in Luxor. Cairo: The American University in Cairo Press.

Wellhausen, J.

1957 Prolegomena to the History of Ancient Israel. Reprint of the 1885 edition. Atlanta: Georgia: Scholars Press.

Wells, B.

2009 Materials for the Tabernacle (25:1-27:21). Pp. 247-53 in vol. 1 of Zondervan Illustrated Bible Backgrounds Commentary, ed. J. H. Walton. Grand Rapids, MI: Zondervan.

Wilkinson, R. H.

2000 The Complete Temples of Ancient Egypt. London: Thames and Hudson.

2003 The Complete Gods and Goddess of Ancient Egypt. London: Thames and Hudson.

Wilkinson, R. H. and Weeks, K. R., eds.

2016 The Oxford Handbook of the Valley of the Kings. Oxford: Oxford University Press.

Willems, $\mathrm{H}$.

2004 Sacrifices, Offerings, and Votives: Egypt. Pp. 326-30 in Religions of the Ancient World: A Guide, ed. by S. Johnston. Cambridge, MA: Belknap Press of Harvard University Press.

Wiseman, D.

1978 The Lived in Tents. Pp. 195-200 in Biblical and Near Eastern Studies:

Essays in Honor of William Sanford Lasor, ed. G. Tuttle. Grand Rapids, MI: Eerdmans.

Wright, G. E.

1962 Biblical Archaeology. Philadelphia: Westminster. 
1983 What Archaeology Can and Cannot Do. Pp. 65-72 in The Biblical Archaeologist Reader I, eds. by E. R. Campbell Jr. and D. N. Freedman. Sheffield: The Almond Press.

Wright, T. F.

1899 Was the Tabernacle Oriental? Journal of Biblical Literature, 18/1-2: 19598.

Yadin, Y.

1959 The Fourth Season of Excavation at Hazor. The Biblical Archaeologist 22: $1-20$.

Yarden, L.

1971 The Tree of Light: A Study of the Menorah, the Seven-branched Lampstand. Ithaca, NY: Cornell University Press.

Young, E.

1959 Note on a Hitherto Unknown Technique in Egyptian Bronze Working. The Journal of Egyptian Archaeology 45: 104-06.

Young, R. C.

2003 When Did Solomon Die? Journal of the Evangelical Theological Society 46/4: 589-604.

Younker, R. W.

2000 The Bible and Archaeology. Pp. 458-77 in Symposium on the Bible and Adventist Scholarship, Juan Dolio, Dominican Republic March 19-26. Silver Spring, MD: Institute for Christian Teaching.

Zehr, P. M.

1981 God Dwells with His People: A Study of Israel's Ancient Tabernacle. Scottdale, Penn: Herald Press.

Zevit, Z.

1992 Timber for the Tabernacle: Text, Tradition, and Realia. Eretz-Israel: Archaeological, Historical, and Geographical Studies, 23: 136-43.

Zivie, A.-P., ed.

1988 Aper-El et ses voisins: considerations sur les tombes rupestres de la XVIIIe dynastie à Saqqarah. Pp. 103-12 in Memphis et ses nécropoles au Nouvel Empire: nouvelles données, nouvelles questions Actes du colloque international CNRS, Paris 9 au 11 octobre 1986, ed. A.-P. Zivie. Paris. 


\section{CURRICULUM VITA}

Name: Leslie Scott Baker, Jr.

Born: January 13, 1973

Family: wife: Arnie; children: Einra and Lora

\section{Education:}

2011

2009

2003

2003
PhD in Ancient Near Eastern Archaeology, Andrews University, Berrien Springs, MI

MA in Egyptian Archaeology, University College London, London, England

MDiv (Archaeology Emphasis), Andrews University, Berrien Springs, MI

BA in Theology (Biblical Studies), Adventist University of the Philippines, Philippines

BA in History and Philosophy of Religion (Biblical Studies), Adventist University of the Philippines, Philippines

\section{Relevant Work Experience:}

2018-Present Co-Host, Inside the Bible, Hope Channel

2017-Present Substitute Teacher/Guest Lecturer, Andrews University, Berrien Springs, MI

2015-Present Editorial and Marketing Coordinator, Andrews University Press, Berrien Springs, MI

2014-2015 Exhibit Manager, Siegfried H. Horn Archaeology Museum Institute of Archaeology, Andrews University, Berrien Springs, MI

\section{Archaeological Experience:}

2019

2019

2018

2015

2014

2013

2009

2008

2007
Epigraphic Survey, Karnak, Egypt

Square Supervisor (Field D, Squares 4 \& 5), Khirbet Safra, Jordan Square Supervisor (Field D, Square 2), Khirbet Safra, Jordan Square Supervisor (Field W, Square 7), Tal Jalul, Jordan Technical Supervisor, Tal Jalul, Jordan Square Supervisor (Field E, Square B4 \& B5), Tel Gezer, Israel Square Supervisor (Field D, Square1), Tal Jalul, Jordan Square Supervisor (Field D, Square1), Tal Jalul, Jordan Square Supervisor (Field D, Square1), Tal Jalul, Jordan 